\title{
Understanding Radioactive Waste
}

Raymond L. Murray

North Carolina State University

Raleigh, North Carolina

December 1981

Prepared for the U.S. Department of Energy under Contract DE-AC06-76RLO 1830

Pacific Northwest Laboratory Operated for the U.S. Department of Energy by Battelle Memorial Institute 


\title{
NOTICE
}

This report was prepared as an account of work sponsored by the United States Government. Neither the United States nor the Department of Energy, nor any of their employees, nor any of their contractors, subcontractors, or their employees, makes any warranty, express or implied, or assumes any legal liability or responsibility for the accuracy, completeness or usefulness of any information, apparatus, product or process disclosed, or represents that its use would not infringe on privately owned rights.

The views, opinions and conclusions contained in this report are those of the author and do not necessarily represent those of the United States Government or the United States Department of Energy or of the contractor; nor do they constitute policy of the U.S. Government or the DOE.

\author{
PACIFIC NORTHWEST LABORATORY \\ operated by \\ BATTELLE \\ for the \\ UNITED STATES DEPARTMENT OF ENERGY \\ Under Contract DE-AC06-76RLO 1830
}

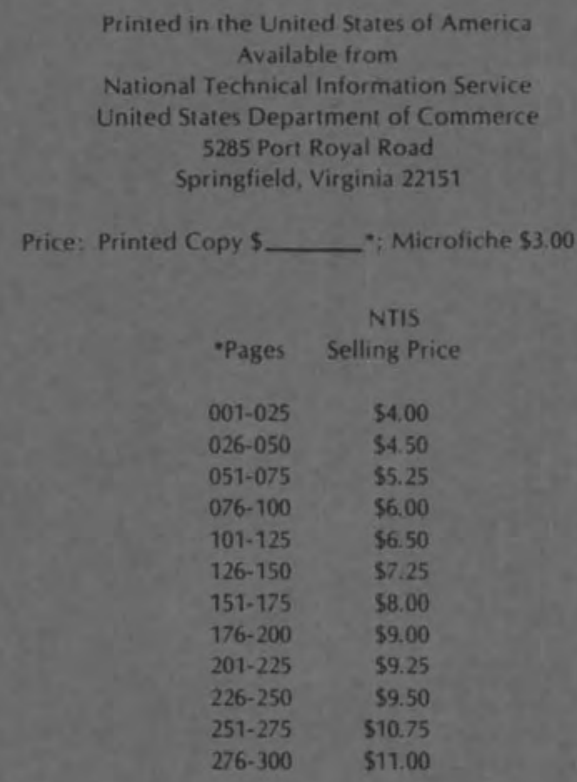




\title{
Understanding Radioactive Waste
}

\author{
Raymond L. Murray, Professor Emeritus \\ Nuclear Engineering Department \\ North Carolina State University \\ Raleigh, North Carolina
}

December 1981

Prepared for Pacific Northwest Laboratory under Special Agreement B-A5507-A-V for the U.S. Department of Energy under Contract DE-AC06-76RLO 1830

Pacific Northwest Laboratory

Richland, Washington 99352 


\section{ACKNOWLEDGMENTS}

This document was prepared for Pacific Northwest Laboratory (PNL) as information on all aspects of radioactive wastes. The author has sought to present facts about radioactive wastes in a simple, clear, and unbiased manner and thus make the information readily accessible to any interested and concerned members of the public. To accomplish this goal, assistance and advice from many people was needed.

The writer wishes to express appreciation to John V. Robinson of PNL for his suggestions, assistance, and encouragement throughout the preparation of the material and to North Carolina State University graduate students Rashid Sultan and Ayad Rubaii for their fine efforts to select useful material in the literature.

The author is grateful to those who made extensive suggestions for improvement-his wife, Elizabeth Reid Murray; M. Ray Seitz of Columbia Basin College, Pasco, Washington; Edwin L. Fankhauser of Columbia High School, Richland, Washington; Margaret N. Maxey of the South Carolina Research Institute, Columbia, South Carolina; David W. Levy, environmentalist, of Tucker, Georgia; Frank K. Pittman, nuclear consultant, of Fort Worth, Texas; and Eugene A. Eschbach of PNL. Particularly, thanks go to Donald Fankhauser, Scott Nealey, and Douglas Robinson, who reviewed the manuscript from the viewpoint of high school students.

Thanks are extended to others who contributed-LawrenceJ.Smith of Rockwell International, Rocky Flats, Colorado; Stanley M. Nealey and Thomas Overcast of Battelle Human Affairs Research Centers, Seattle; John T. Suchy of the Office of Nuclear Waste Isolation, Columbus, Ohio; Harry Babad of Rockwell Hanford Operations; Kenneth J. Schneider, Orville F. Hill, Harold H. Hollis, and Dennis K. Kreid of PNL. The author, however, takkes full responsibility for the statements made herein.

Appreciation is extended to Judith A. Powell of PNL for ideas on format and style of the final document and for careful review of it. Thanks are also due to Dianne Hain and Tina Blackburn for expeditious typing and draft material. Some of the illustrations were done by Vann Webb and by Ann Kennedy.

Raymond L. Murray 



\section{CONTENTS}

Acknowledgments $\ldots \ldots \ldots \ldots \ldots \ldots \ldots \ldots \ldots \ldots \ldots \ldots \ldots \ldots \ldots \ldots \ldots \ldots \ldots$ iii

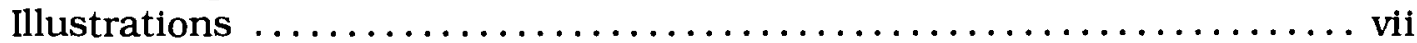

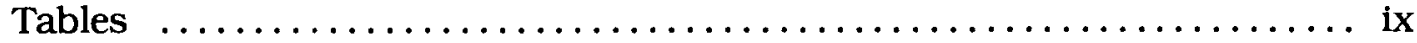

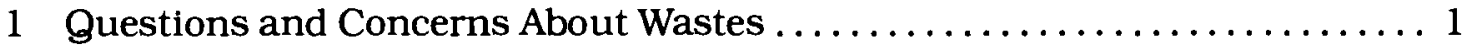

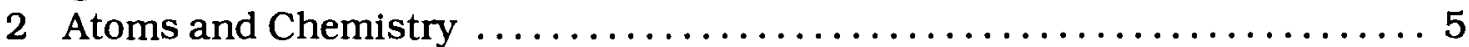

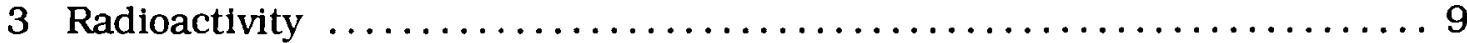

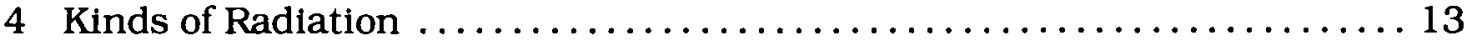

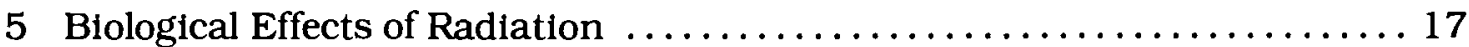

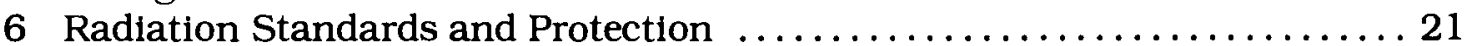

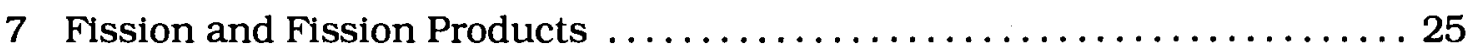

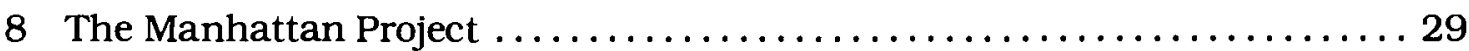

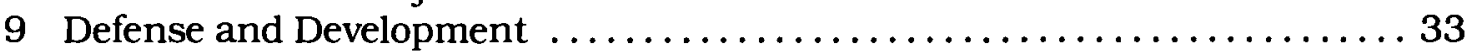

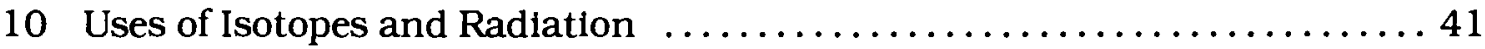

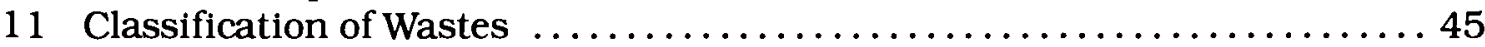

12 Spent Fuel from Nuclear Reactors $\ldots \ldots \ldots \ldots \ldots \ldots \ldots \ldots \ldots \ldots \ldots \ldots$

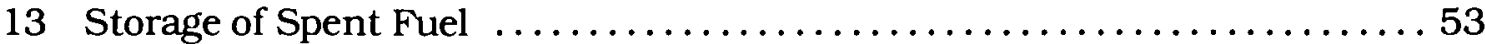

14 Reprocessing, Recycling, and Resources $\ldots \ldots \ldots \ldots \ldots \ldots \ldots \ldots \ldots \ldots$

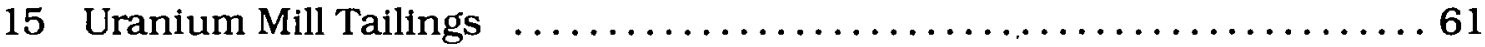

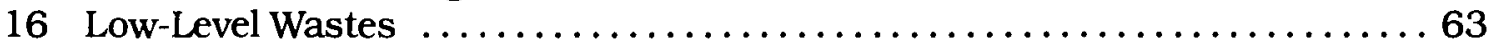

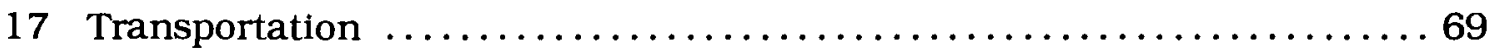

18 Methods of Handling High-Level Nuclear Wastes $\ldots \ldots \ldots \ldots \ldots \ldots \ldots \ldots$

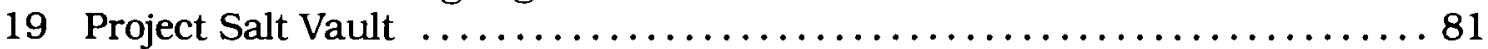

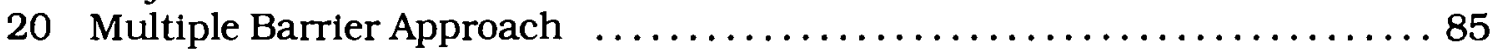

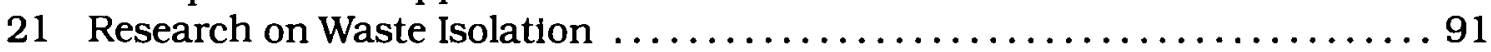

22 Legal Requirements ............................... 97

23 The National Radioactive Waste Management Program ............. 103

24 Societal Aspects of Radioactive Wastes $\ldots \ldots \ldots \ldots \ldots \ldots \ldots \ldots \ldots \ldots \ldots$

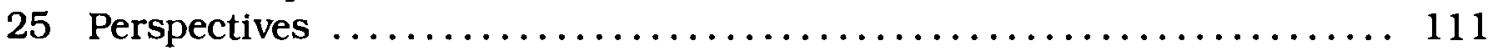

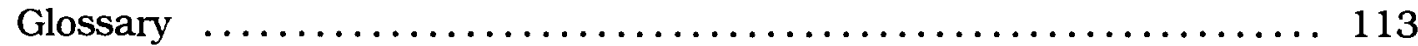

Appendix A Scientific American Articles $\ldots \ldots \ldots \ldots \ldots \ldots \ldots \ldots \ldots \ldots 117$

Appendix B Reference Material on Wastes $\ldots \ldots \ldots \ldots \ldots \ldots \ldots \ldots \ldots$ 


\section{ILLUSTRATIONS}

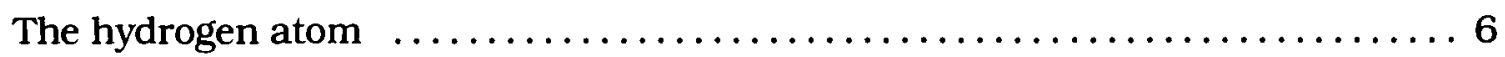

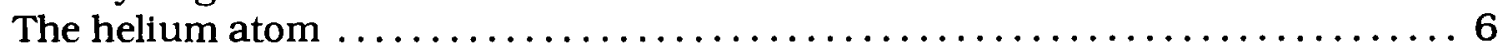

The uranium atom with its 92 electrons in orbits around the nucleus $\ldots \ldots \ldots \ldots 7$

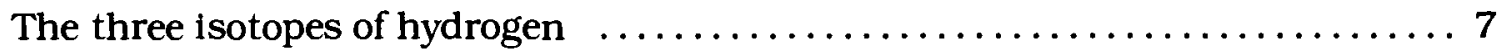

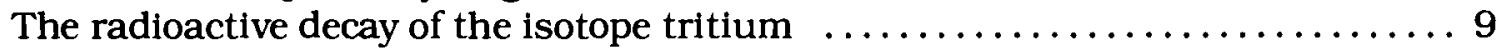

Graph of radioactive decay of tritium with time, starting with 1000 atoms ....9

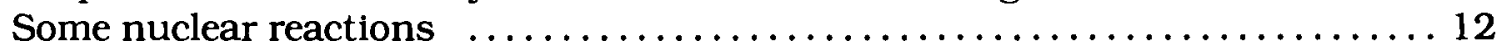

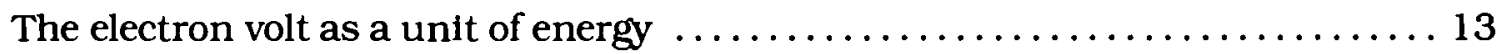

The electromagnetic spectrum, showing that radio-TV, visible light,

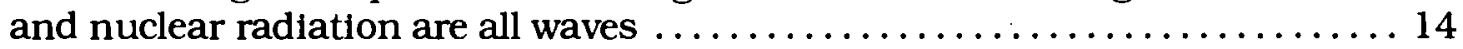

Comparison of the spreading of two forms of radiation-visible light and

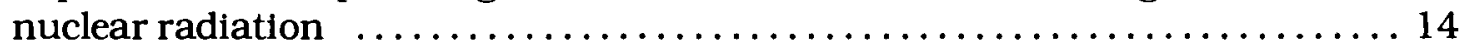

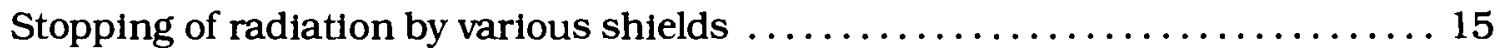

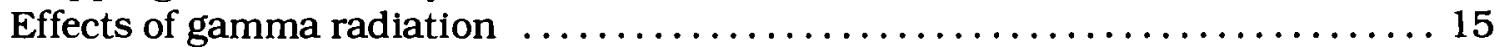

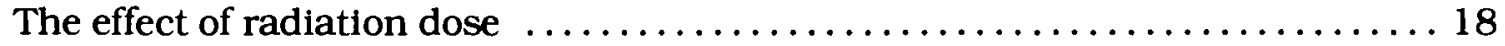

Radiation worker with protective clothing, dosimeter, and portable detector . . 24

Examples of methods of protection against radiation $\ldots \ldots \ldots \ldots \ldots \ldots \ldots \ldots 24$

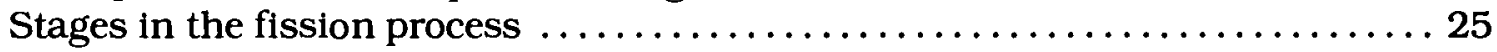

Yield of fission products according to mass number $\ldots \ldots \ldots \ldots \ldots \ldots \ldots \ldots \ldots 25$

Two fission product decay chains leading to the important waste isotopes strontium-90 and cesium-137 ............................ 26

Heat generated by fission product isotopes as it depends on time after removal from a nuclear reactor $\ldots \ldots \ldots \ldots \ldots \ldots \ldots \ldots \ldots \ldots \ldots \ldots, 27$

Composition of different enrichments of uranium $\ldots \ldots \ldots \ldots \ldots \ldots \ldots \ldots 29$

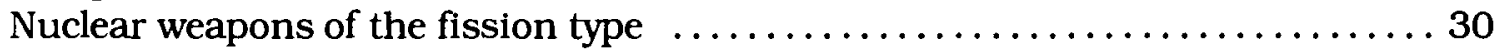

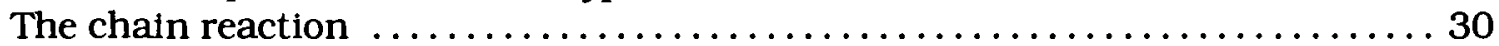

Separation of uranium isotopes by gaseous diffusion $\ldots \ldots \ldots \ldots \ldots \ldots \ldots \ldots 30$

Artist's sketch of Fermi's chain-reacting pile at the University of Chicago, 1942 ........................................ 31

The gaseous diffusion plant for separating uranium isotopes at

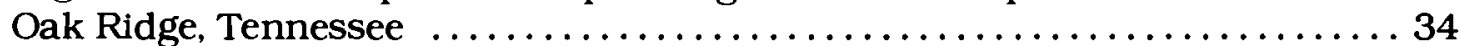

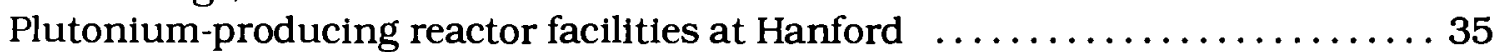

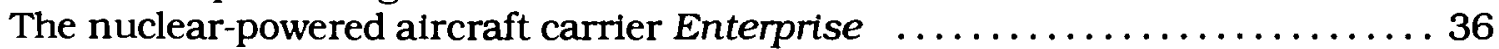

The Experimental Breeder Reactor (EBR-I) at Arco, Idaho ............... 37

The H. B. Robinson nuclear plant at Hartsville, South Carolina $\ldots \ldots \ldots \ldots . .38$

Flow of fluids in the pressurized water reactor (PWR) $\ldots \ldots \ldots \ldots \ldots \ldots \ldots . \ldots . \ldots 39$

Two uses of radioactive tracers $\ldots \ldots \ldots \ldots \ldots \ldots \ldots \ldots \ldots \ldots \ldots \ldots . \ldots \ldots 1$

Locating a brain tumor by imaging-Injecting a radioactive chemical $\ldots \ldots \ldots \ldots 2$

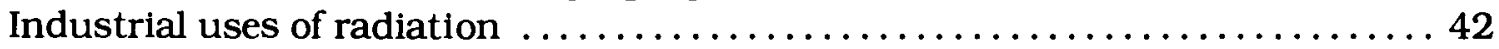

Plutonium-238 heart pacemaker $\ldots \ldots \ldots \ldots \ldots \ldots \ldots \ldots \ldots \ldots \ldots . \ldots \ldots 4$

High-level defense waste storage at the Hanford Site in Washington State $\ldots .48$

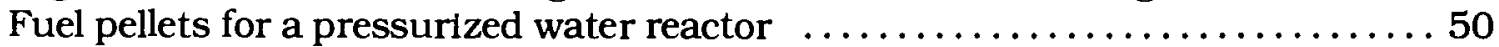

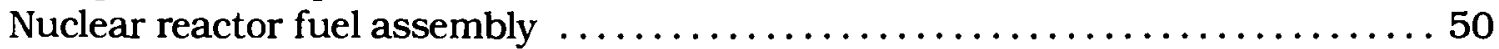

Reactor vessel of a pressurized water reactor $\ldots \ldots \ldots \ldots \ldots \ldots \ldots \ldots \ldots \ldots, 50$

Compositions of fresh fuel and spent fuel $\ldots \ldots \ldots \ldots \ldots \ldots \ldots \ldots \ldots \ldots, \ldots 1$ 
Spent fuel storage rack to hold 54 fuel assemblies $\ldots \ldots \ldots \ldots \ldots \ldots \ldots \ldots \ldots 3$

Water pool for storage of spent fuel at the Morris, Mlinois, facility . . . . . . . 54

Comparison of the volume of fission products with the volume of spent fuel $\ldots 55$

The nuclear fuel cycle, carrying uranium from the mine to spent fuel storage

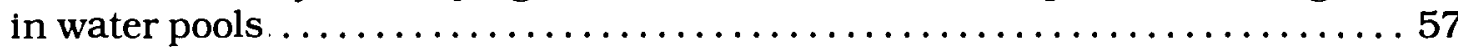

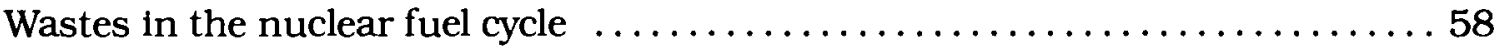

Significant uranium mining areas of the U.S. ...................... 61

A mill tailings pile, resulting from the first processing of uranium ore $\ldots \ldots \ldots 61$

Burial of 55-gallon drums containing low-level wastes in a trench at a

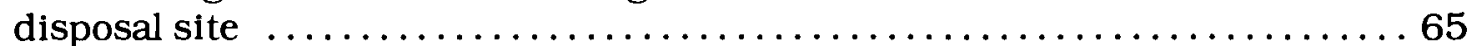

Generating, storage, and disposal sites for solid low-level radioactive waste $\ldots 65$

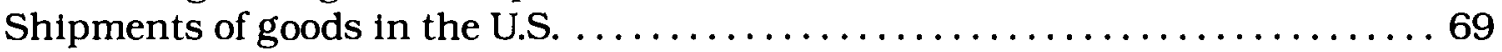

Diagram of a representative type A shipping container $\ldots \ldots \ldots \ldots \ldots \ldots \ldots 70$

Type B transport cask used by Chem-Nuclear Systems, Inc. . . . . . . . . 71

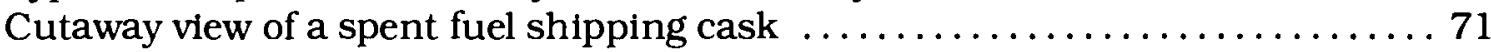

Spent fuel cask in normal arrangement for shipment by railroad $\ldots \ldots \ldots \ldots 71$

Photograph taken a fraction of a second after collision of a tractor-trailer

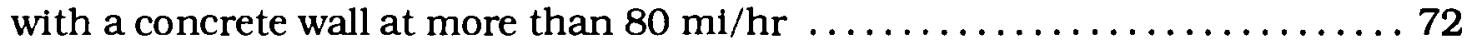

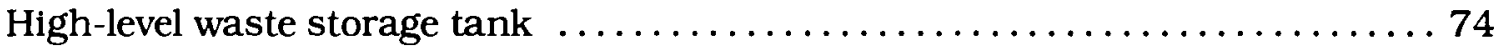

Air-cooled vault for the surface storage of solidified wastes $\ldots \ldots \ldots \ldots \ldots \ldots 75$

Cutaway view of an above-ground storage facility for solidified wastes $\ldots \ldots \ldots 75$

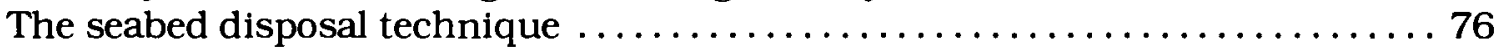

Ice-sheet disposal of solidified radioactive wastes $\ldots \ldots \ldots \ldots \ldots \ldots \ldots \ldots$

Extraterrestrial disposal of wastes by use of rockets $\ldots \ldots \ldots \ldots \ldots \ldots \ldots 79$

Rock-melting technique for waste disposal $\ldots \ldots \ldots \ldots \ldots \ldots \ldots \ldots \ldots \ldots$

Emplacement of waste canisters in a mined cavity $\ldots \ldots \ldots \ldots \ldots \ldots \ldots \ldots$

Underground transporter for waste containers $\ldots \ldots \ldots \ldots \ldots \ldots \ldots \ldots \ldots . \ldots 3$

Artist's sketch of placement of canisters of waste in holes in the

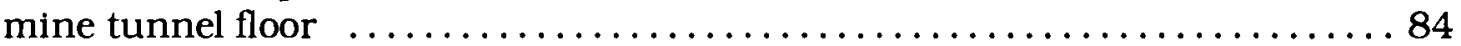

Major pathways by which environmentally dispersed radionuclides can affect

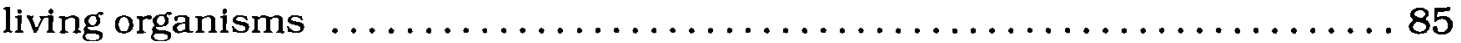

The use of multiple barriers to prevent the escape of radioactivity from a

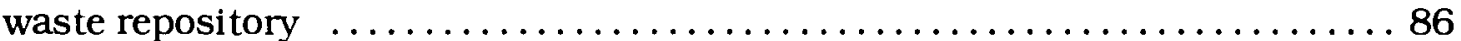

Vitrification of waste-glass mixture by the spray calciner, in-can

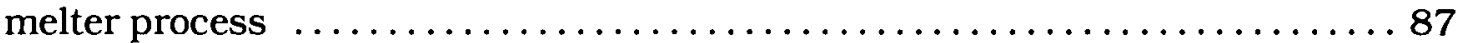

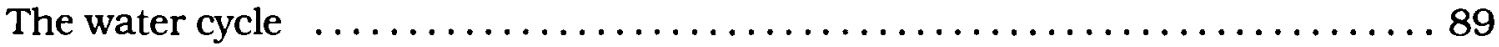

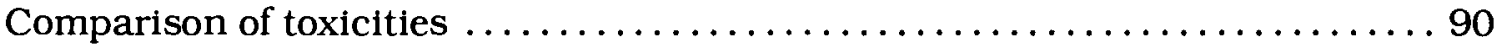

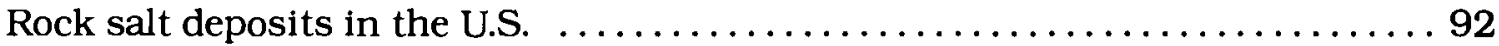

Deposits of crystalline rock (basalt, granite, tuff) in the U.S. ............ 93

Deposits of argillaceous material (clay and shale) in the U.S. . . . . . . . . 93

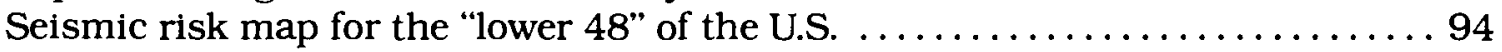

Relationship of three main governmental agencies in the commercial

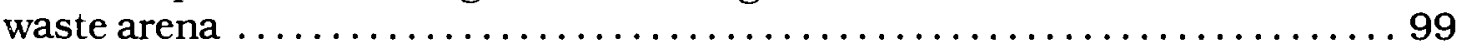

Artist's conception of a high-level radioactive waste repository $\ldots \ldots \ldots \ldots .105$ 


\section{TABLES}

The Chain of Natural Radioactivity Starting with Uranium

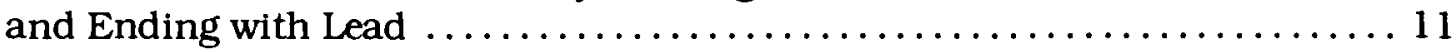

Major Causes of Death in the U.S. for $1978 \ldots \ldots \ldots \ldots \ldots \ldots \ldots \ldots \ldots$

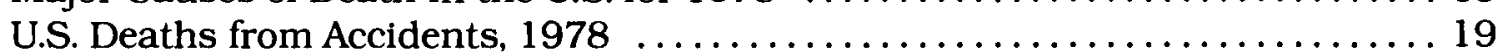

Maximum Permissible Concentrations, $\mathrm{Ci} / \mathrm{ml}$, Above Natural

Background for Selected Radioisotopes ........................ 23

The Manhattan Project: Research, Development and Production .......... 29

Total Energy Consumption in the U.S. by Primary Energy Type, $1979 \ldots \ldots . .39$

Electrical Energy Produced in the U.S., $1979 \ldots \ldots \ldots \ldots \ldots \ldots \ldots \ldots \ldots \ldots . \ldots . \ldots . \ldots$

Existing Department of Energy Defense and Research High-Level

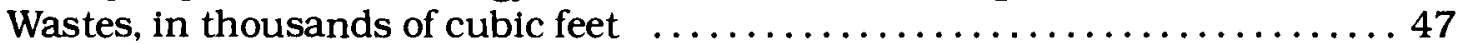

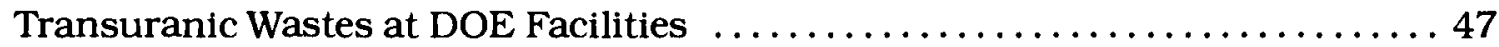

World List of Nuclear Power Plants Operable, Under Construction, or on Order (30 MWe and Over) as of January $1,1981 \ldots \ldots \ldots \ldots \ldots \ldots 49$

Isotopes in Non-Fuel-Cycle Low-Level Waste Sent to Commercial

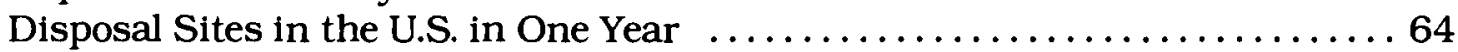

Volumes of Low-Level Wastes at Commercial Burial Sites . . . . . . . . . . . 65

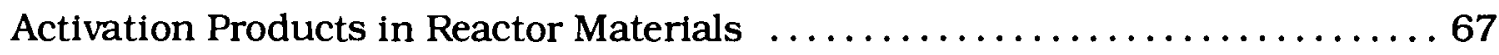

Annual Shipments of Nuclear Materials in the U.S. ................ 70

Five-year Total of Hazardous Materials Incident Reports in the U.S.

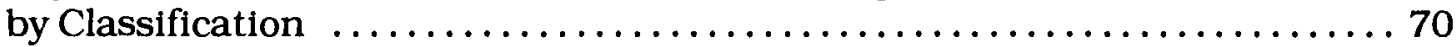




\section{QUESTIONS AND CONCERNS ABOUT WASTES}

\section{Energy and the Environment}

The world today faces two major problems that are related to energy and the environment: pollution and potential scarcity.

The environmental movement of the 1960's brought to people's attention that there was a growing problem of pollution from our industrial civilization. Concerns developed around the world about the release of chemicals to the land, air, and waters. Still more recently, in the 1970's, the problem of solid chemical wastes has become prominent. It is now clear that large amounts of hazardous chemicals have been stored or discarded with inadequate precautions to protect the public. People have become aware also of radioactive wastes, those that emit radiation as they break up or "decay."

The Arab oil boycott of 1973 focused attention on the energy problem. Sources of oil are in the hands of unstable or vulnerable countries. Costs of petroleum have increased dramatically, contributing to economic difficulties, in both advanced and emerging countries. The national energy policy of the United States is to give each alternative energy type an opportunity to compete in the market, and to encourage informed choices by the American people, with a minimum of governmental restraints. * Nuclear power is viewed as one of the choices of energy to meet national needs, along with natural gas, coal, and solar energy.

\section{Questions About Nuclear Energy}

Although people recognize the need for alternative energy sources, they often raise the question about nuclear energy, "What is

\footnotetext{
*As described in Securing America's Energy Future, The National Energy Policy Plan. U.S. Department of Energy, July 1981 .
}

being done with radioactive wastes?" The Federal government and the nuclear industry have stated that such wastes were known to be dangerous ever since they first were generated in large quantities in World War II, and that special care has been taken to protect the public over the years. Observers note, however, that decisions as to the final disposal of wastes have not had a high priority in the overall nuclear development. Examples of poor strategy, of uncertainty, and of hesitancy in the waste management program have been cited. As a consequence many people believe that industry and government do not know what to do with radioactive wastes.

The question "Is nuclear power safe?" is also raised frequently. People are aware of the fearful effects of the atom bomb. They know that a nuclear weapon is not the same as a nuclear reactor, but they tend to associate the two and are uneasy because both involve fission and radioactivity. Many people think of all radiation as mysterious and

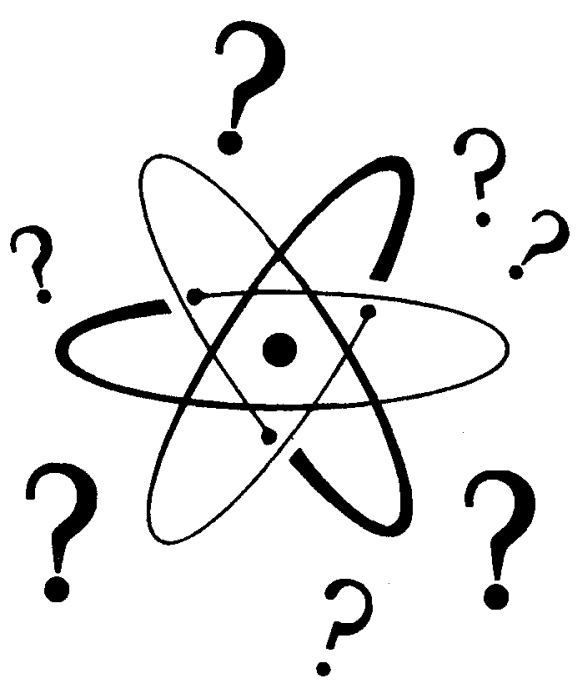


lethal. When these ideas are combined with Murphy's law, "If anything can go wrong, it will," it is easy to see why many people are uncomfortable, worried about, or frightened by continued or expanded use of nuclear energy. Most people are aware that there are few if any fatalities due to the use of the nucleus to produce electricity, and that one's chances of being harmed in other ways are far greater. Nonetheless, since they feel they have no personal control over the nuclear hazard, it is less acceptable than other, more familiar, risks such as riding in automobiles.

\section{The Need for Information}

Approval for new nuclear electric plants and continued use of existing plants may depend on the satisfactory demonstration of safe waste disposal. In making decisions about power plants it is important that citizens and lawmakers alike know the nature of the waste problem and be able to separate myth, feelings, and opinions from the facts.

Unfortunately, public information on the subject of radioactive wastes is not very useful. Much of what is said or written is rhetoric intended either to frighten or to soothe. Debaters exaggerate in order to convince rather than to inform. The polarization is now so great that neither the strong opponents nor the strong advocates of nuclear power are credible to the average person.

The public is often confused by conflictIng statements about nuclear energy and the waste problem. Scientists of presumed equal qualifications, for example, Nobel Prize winners, are seen taking opposite stands. There is a wealth of technical literature, but it is written for use by scientists and engineers familiar with the technical terms and background. Reports on plans and progress are in formal governmental language, which is sometimes hard to translate into ordinary English.

The writer hopes to accomplish several things: (a) to explain the origin and nature of nuclear by-products in a way that is under- standable, (b) to provide facts and figures about nuclear wastes and the actions being planned on a national basis, (c) to provide perspective on the safety of waste isolation systems, and (d) to distinguish knowledge from opinion whenever possible, in an unbiased and candid manner. The author rejects exaggerated statements about the waste problem at both poles of the debateassertions by proponents that it is merely a matter of politics, by opponents that a technical solution is impossible.

\section{Understanding and Decisions}

The most important premise behind this document is that an informed public will make the best decisions. We intend to help the reader understand such nuclear topics as uranium, radioactivity, radiation, and fission, along with the role of materials, chemical processes, and geology in the treatment and long-term handling of wastes. We will touch on people's knowledge and attitudes about the subject of radioactive wastes.

It is likely that the nuclear debate is characteristic of our times. Some would say, "The government bureaucracy tries to go ahead without any interference by the public, but fortunately there are public interest groups to help the people speak out." Others would say instead "We have dedicated leaders who are seeking to serve the public most effectively and economically, versus a small number of activists who would like to see power decentralized and the present system dismantled." Perhaps there is some truth in both views. The author believes that all thinking citizens have some interest in and concern about the waste problem and that a thorough explanation will be useful.

Some of the questions we hope to answer to the reader's satisfaction are:

1. What are radioactive wastes?

2. How are radioactivity and radiation related? 
3. What are the effects of radiation on living beings?

4. How can we be protected from harm by radiation?

5. In what ways can radiation be beneficial?

6. Where do radioactive wastes come from? How much do we now have?

7. How are nuclear wastes similar to or different from those released from chemical plants or from electrical power plants fueled by coal or oil?

8. How do the effects of radioactive materials compare with the effects of other substances that we call poisons?

9. What methods of handling radioactive wastes have been used in the past? Are these methods still suitable?

10. Why would we store used fuel from nuclear reactors instead of processing it to separate radioactive wastes?

11. Where should materials be stored? When it is impossible to store them on site, where must they be taken?

12. How are used nuclear reactor fuel and processed nuclear wastes transported? What precautions are taken to prevent accidents and to protect the public?

13. Should the public be informed that radioactive wastes are being transported through their states via public highways and railways? Are the vehicles marked adequately?

14. What are the advantages and disadvantages of a policy of long-term storage of wastes for possible retrieval compared with early permanent disposal?

15. What is regarded as the most promisingdisposal method? Why? What needs yet to be known?

16. How much space (volume, land area) is needed for the near future to store the wastes of defense programs and nuclear power plants? How much additional surrounding area should have restricted access?

17. What kind of terrain (geographic, geologic, and biologic) should be selected for the storage of wastes? What do the sub- jects of earth sciences say about such storage?

18. Is it necessary to achieve "perpetual care" of buried wastes?

19. What organization would be responsible for managing wastes?

20. What are the economic costs of disposal?

\section{The Sciences Help Explain}

What one shouId learn in order to understand both the questions and the answers depends on the person's attitude. No information is needed if one says either "I am satisfied that those in government and industry will make good decisions" or "I am convinced that nuclear power is unsafe and must be abandoned at once." At another extreme, if one says, "I must have the same background as scientists and engineers who are advising on wastes," years of specialized college training would be required.

We take a middle ground and assume that the reader wishes to learn enough technical information to be able to think about the subject clearly and discuss it rationally. We believe it is helpful to know some atomic and nuclear science, to have been exposed to a little of the history of nuclear energy development, and to have some appreciation of what a nuclear reactor is and does, as a basis for learning about radioactive wastes and their handling.

Some basic science background is needed, because many subjects bear on nuclear wastes-general science, chemistry, physics, biology, and earth science. Let us see how these sciences come into play:

- Wastes consist of many chemicals, composed of about half the 106 elements in the periodic table. Chemistry tells us how well we can remove certain hazardous substances, what form the wastes are in, what they will mix well with, how easily they are dissolved, and how fast they move through air, water, and earth.

- Physics describes properties of the nucleus of the atom, including how many types of 
radioactive atoms there are, how long they last, and what radiation they emit.

- Biology explains how radioactive materials may be brought to man through food chains involving plants and animals, which organs of the human body have an affinity for certain materials, and what is the nature of the damage by radiation to cells and tissues.

- Earth science describes the features of rocks and soil in which wastes may be placed, explains how water is transferred through the ground, and identifies the types of medium and best locations for long-term waste storage.

In the next several chapters we review our knowledge of the atom, the periodic table of elements, simple chemical reactions, the nature of isotopes, radioactivity, and radiation. Special attention is given to effects of radiation and ways to protect human beings. We need such background for an understanding of radioactive waste. 


\section{ATOMS AND CHEMISTRY}

\section{Some Distinctions: Atomic and Nuclear}

The scientific basis of radioactive waste management involves two levels: atomic and nuclear. These words are often confusedthey refer, however, to quite different realms of matter. Atomic (or molecular) refers to chemical processes, in which the electrons of the atoms participate; nuclear refers to the very energetic processes involving the inner core of the atoms. The subject of chemistry deals with interactions of atoms or molecules.

Thus chemistry reveals what treatment or processing of used (spent) fuel from nuclear reactors will separate the useful from the useless. It tells what wastes might combine well with and resist attack by acids and what metals would make good containers. It also indicates how to prevent waste-particle migration in the ground.

On the other hand, the subject of nuclear physics explains the processes of radioactivity, the behavior and effects of radiation, and the production of new species of material by neutron bombardment in a reactor.

To fully understand the radioactive waste problem, we need both atomic and nuclear concepts. Let's review, very briefly, the important facts as discovered in the last hundred years or so.

\section{Our World of Atomic Chemistry}

Recall from basic science courses that all matter is made up of a small number of different kinds of atoms, the chemical elements. The first and lightest of these is hydrogen, and the 92nd and heaviest natural element is uranium. There are 14 manmade elements that are heavier than uranium.
Chemical elements combine to form new substances called compounds. Some familiar processes, expressed as equations, are these.

burning of hydrogen: hydrogen + oxygen $\rightarrow$ water

preparation of table salt: sodium + chlorine $\rightarrow$ sodium chloride rusting of iron: iron + oxygen $\rightarrow$ Iron oxide

burning of natural gas: methane + oxygen $\rightarrow$ carbon dioxide + water

neutralization of an acid by an alkali (lye): nitric acid + sodium hydroxide $\rightarrow$ sodium nitrate + water

More complicated still are the reactions in living organisms, such as photosynthesis in plants and digestion in animals. The regularity with which chemical reactions take place led to the discovery of the atomic theory-that matter is composed of individual particles called atoms, which combine to form molecules. Atoms are extremely small. It would take a row of 10 million hydrogen atoms to span the head of a pin. One teaspoon of water contains an enormous number of molecules-around $200,000,000,000,000,000,000,000$ lor $2 \times 10^{23}$ ).

As many readers know, the periodic table of chemistry lists the elements according to their chemical similarity. Each element is assigned a symbol and an "atomic number," $Z$. On this scale hydrogen $(H)$, for example, is 1 , helium (He) is 2 , oxygen $(\mathrm{O})$ is 8 , iron ( $\mathrm{Fe}$ ) is 28 , gold ( $\mathrm{Au}$ ) is 79 , and uranium (U) is 92 . Thus we say, "The atomic number for iron is 28 ," or more simply "For $\mathrm{Fe}, \mathrm{Z}$ is 28." 


\section{Inside the Atom}

Until the twentieth century the internal composition of atoms was not known. Only after an experiment by Rutherford in 1911 was it realized that the electrically neutral atom had a central core (nucleus) of positive charge and an outer region of negative charge. Then studies by Bohr in 1913 revealed the relationship between light and atomic structure. He assumed a motion of the electron about the nucleus similar to that of a planet around the sun.

We shall use that analogy to explain features of the atom. Picture the atom as a miniature solar system. In place of the sun there is the heavy positively-charged central core of the atom, called the nucleus (plural: nuclei). This core is composed in general of still more basic particles-protons and neutrons. In place of the planets, there are electrons, the small negatively-charged particles that give us electricity.

The sketch representing an atom of hydrogen shows its single electron in orbit

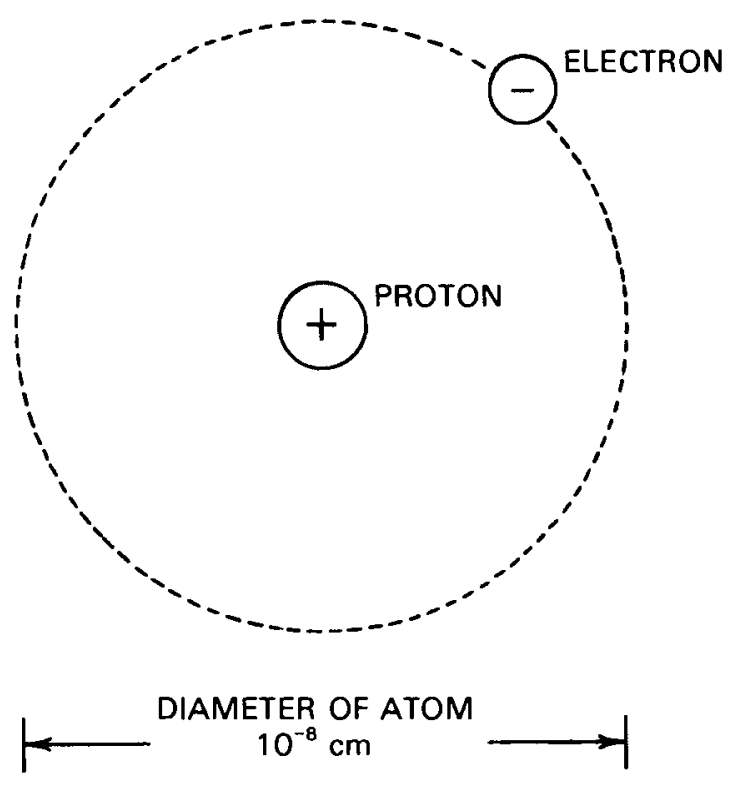

The hydrogen atom. One electron is in orbit about the nucleus (proton). The atom is a hundred millionth of a centimeter across. If the proton were the size of a golf ball, the electron would be $2000 \mathrm{ft}$ away. about the nucleus, which in this case is the proton. The proton has a weight about 1800 times that of the electron. In place of gravity. the force of electrical attraction holds the particles together.

How atoms produce and absorb light also comes from Bohr's theory. Electrons have the ability to suddenly "jump" to an orbit of smaller radius, accompanied by the emission of energy in the form of light. Similarly, an electron goes to a larger orbit when light is absorbed. If enough energy is supplied to the atom, the electron can be removed completely, leaving the positivelycharged nucleus, the proton (which is also the ion $\mathrm{H}^{+}$).

The next most complicated chemical element is helium, used as a gas in dirigibles like the Goodyear "blimp." It has two electrons in orbit and a nucleus with two protons and two neutrons. The neutron is an electrically neutral particle weighing almost the same as the proton. Diagrams here illustrate the arrangement of particles in the helium atom, and that of the much more complex uranium atom.

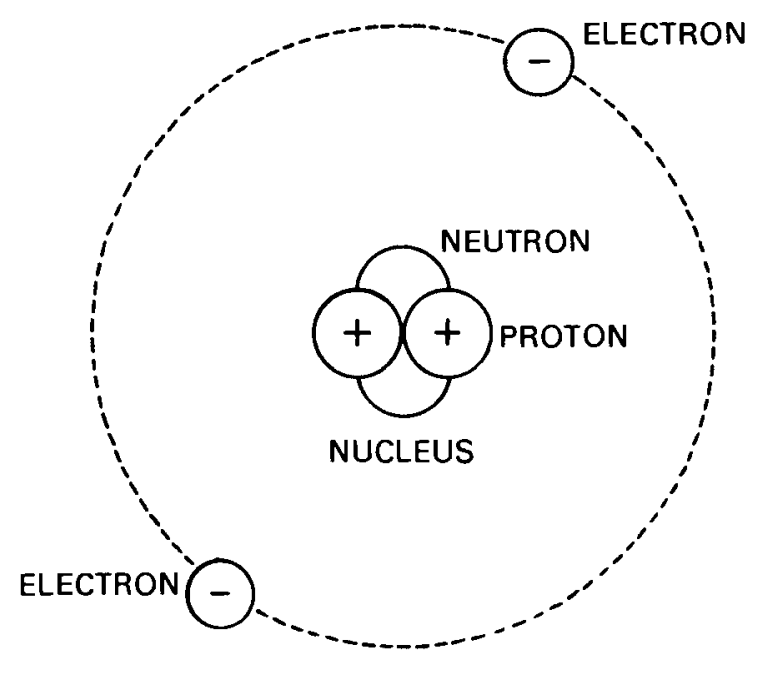

The helium atom. There are two electrons in orbit about the nucleus, which consists of two protons and two neutrons. The nucleus of helium is the same as the alpha particle. 


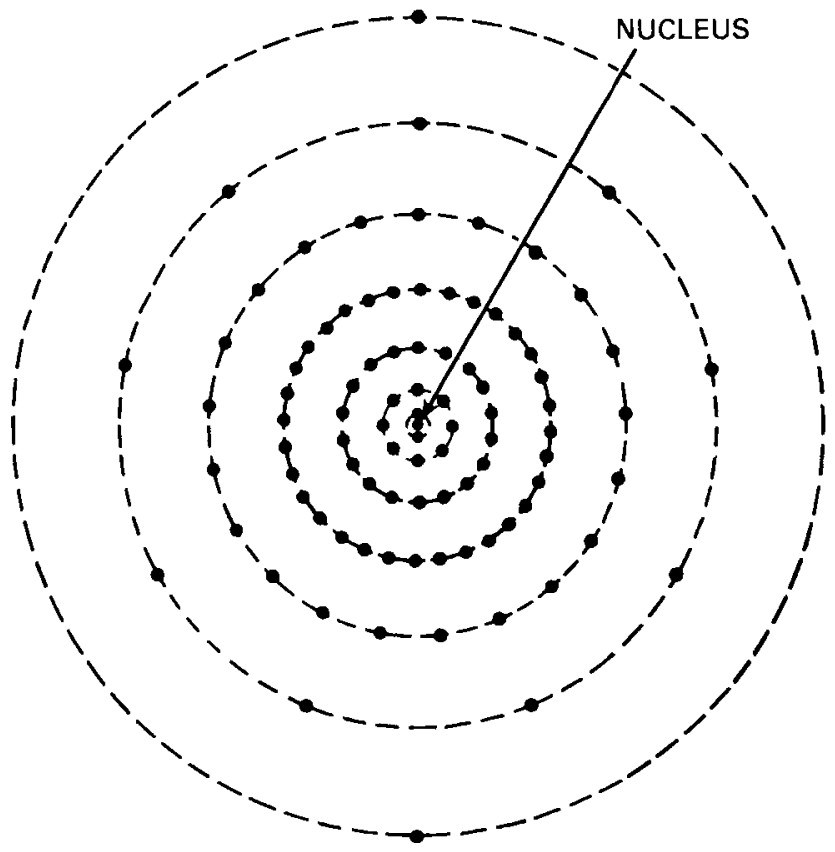

The uranium atom with its 92 electrons in orbits around the nucleus. (Courtesy of Raymond L. Murray and Grover C. Cobb, Physics: Concepts and Consequences, Prentice-Hall, Englewood Cliffs, New Jersey. 1970).

\section{Radiation and Isotopes}

It is important to note here that the electron is the same as the beta ( $B$ ) particle, one form of radiation. If the two electrons are removed from the helium atom, what remains is the positively charged Ion $\mathrm{He}^{+}$, which is also the helium nucleus, and the alpha $(\alpha)$ particle, another form of radiation. The third main type of radiation is light, which takes several forms. We see by means of ordinary visible light, which comes from atoms and molecules. The $x$-rays used for medical examination are more energetic than ordinary light. They can come from atoms or an $\mathbf{x}$-ray machine. Gamma rays have still more energy and arise in the nucleus of the atom.

Each chemical element is made up of several types of atoms called isotopes. The difference between Isotopes lies in the weight of their nuclei, which is determined by the number of protons plus neutrons.

For example, hydrogen is made up of the three species, as illustrated here: ordinary hydrogen with the proton as nucleus, deute-

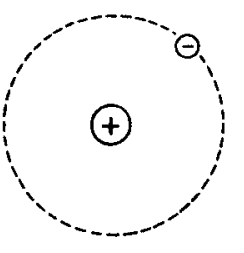

HYDROGEN

${ }_{1}^{1} \mathrm{H}$

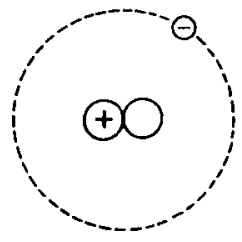

DEUTERIUM

${ }_{1}^{2} \mathrm{H}$

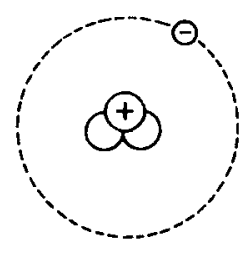

TRITIUM

${ }_{1}^{3} \mathrm{H}$
The three isotopes of hydrogen. Each has one proton in the nucleus; the difference between them is only in the number of neutrons in their nuclei-none, one, and two

rium with a proton plus neutron as nucleus, and tritium with a proton plus two neutrons as nucleus. We let A, called "mass number," represent the number of nucleons (protons plus neutrons) in the nucleus. Thus $A=1,2$, and 3 for the isotopes of hydrogen. Recalling that $Z=1$ for hydrogen, we can write symbols to uniquely specify them: ${ }_{1}^{1} \mathrm{H}$ is ordinary hydrogen, ${ }_{1}^{2} \mathrm{H}$ is deuterium or heavy hydrogen, and ${ }_{1}^{3} \mathrm{H}$ is tritium. The superscripts are mass numbers A (nucleons); the subscripts are atomic numbers $Z$ (protons).

The chemical hydrogen is familiar to us as one component of water $\mathrm{H}_{2} \mathrm{O}$. Deuterium is rare in nature, there being only one atom for every 6000 atoms of ordinary hydrogen. Tritium is a manmade isotope. These heavier species of hydrogen are the ingredients in the fusion process being developed for practical energy.

At the other end of the periodic table of natural elements is uranium, atomic number 92. It is composed of two main isotopes, of mass numbers 235 and 238, with symbols ${ }_{92}^{235} \mathrm{U}$ and ${ }_{92}^{238} \mathrm{U}$. Only $0.7 \%$ is the lighter isotope, $99.3 \%$ the heavier. Each of these two isotopes plays a role in the fission nuclear reactor, as we shall take up later.

We have presented the abbreviated notation for isotopes because it is found in the technical literature. For most purposes, however, it is sufficient to use only the name and mass number, for example, "uranium235," or sometimes "235U." 


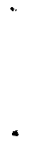




\section{RADIOACTIVITY}

\section{The Process of Decay}

Many of the isotopes of nature are stable, meaning that they never change. Other isotopes, both natural and manmade, are radioactive, meaning that they are unstable and can change into another form.

Radioactivity is a process in which a nucleus spontaneously disintegrates or "decays." For the simplest example, see the diagram depicting the decay of hydrogen-3 or tritium. One of the two neutrons in its nucleus changes into a proton and an electron. The new nucleus, composed of two protons and a neutron, is the same as that of an isotope of helium (helium-3). The electron emitted is called a high-speed beta particle. Radioactivity can be described by a reaction equation. That for the decay of tritium is

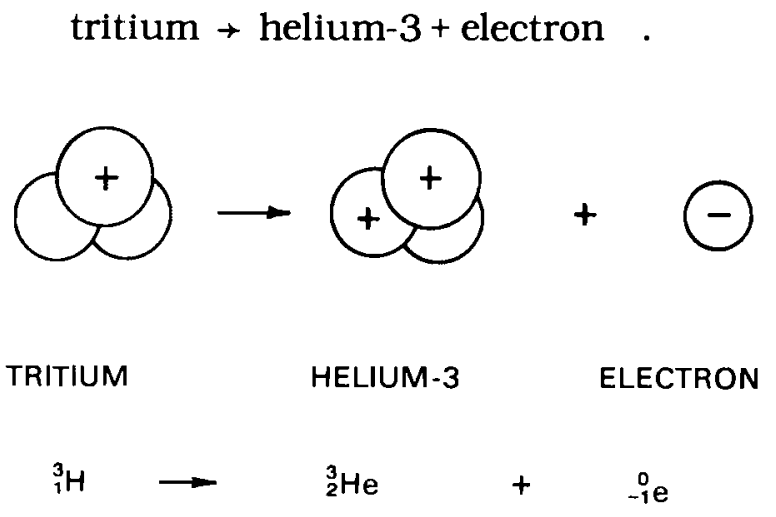

The radioactive decay of the isotope tritium, shown as a diagram and by a word equation.

A few other important nuclear reactions that involve radioactive decay are:

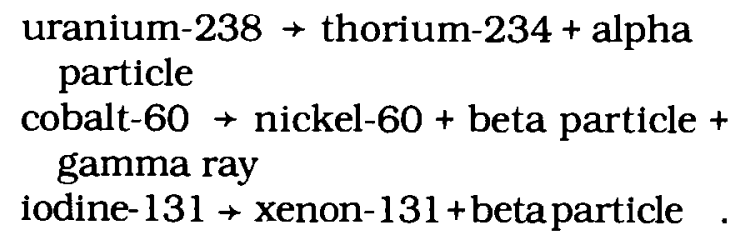

\section{Half-Life and Activity}

One cannot predict when a particular nucleus will decay. If we could watch a group of radioactive atoms, some would decay at once, others later, still others much later. The number that decay in any second of time depends on only two things-how many there are and the nuclear species. Each isotope has its own "half-life" $\left(t_{H}\right)$, which is the time it takes for half of any sample to decay. For instance, $t_{H}$ for tritium is 12.3 years. Thus if we started now with 1000 atoms of tritium, after 12.3 years we would have 500 atoms, after 24.6years, 250 atoms, and so on. The graph shows the trend with time of the number of atoms. ${ }^{*}$

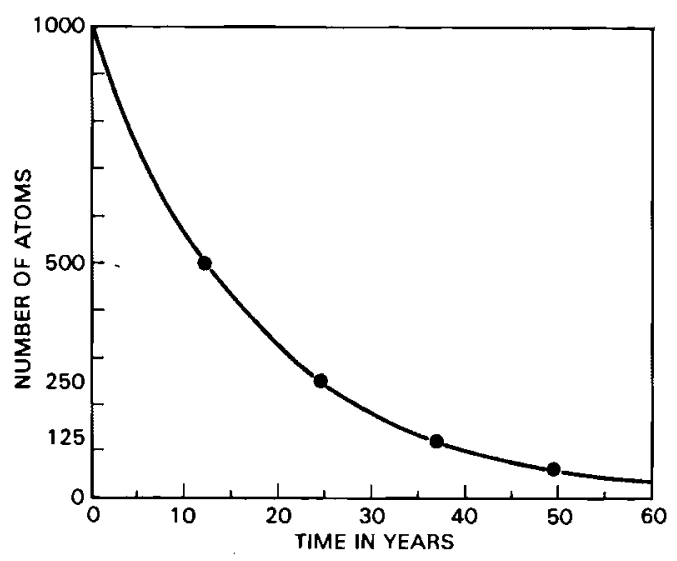

Graph of radioactive decay of tritium with time, starting with 1000 atoms. The half-life of tritium is 12.3 years.

"It is easy to calculate the fraction $f$ of particles that remain at any time, $t$. Let $p$ stand for the number of half-lives elapsed, which is the ratio $t / t_{\mathrm{H}}$. Then

$$
f=\left(\frac{1}{2}\right)^{p} \text {. }
$$

If the power $p$ is an integer, we can do the calculation in our heads. For example, if the time is three half-lives, $t=3 t_{H}$, then

$$
p=3 \text { and } f \text { is } \frac{1}{8} \text {. }
$$

If $p$ is not an integer, we need to use a pocket calculator. For example, if $t_{H}=12.3$ years as for tritlum and $t$ is 100 years, then 


\section{Disintegrations of Nuclei}

The rate of decay is called the activity, being the number of disintegrations per second $(\mathrm{d} / \mathrm{s})$. The activity decreases with time in the same way that the number of atoms present decreases. Thus the hazard due to the radioactive emissions decreases with time. In summary, the smaller the amount of material we have and the longer its half-life, the smaller is the activity and the safer is the sample. One rough rule of thumb is that it takes 10 half-lives to eliminate a radioisotope. Since $(1 / 2)^{10}$ is only about $1 / 1000$, this rule is too crude to be of value when factors of $1 / 1,000,000$ or better are needed.

\section{Natural Radioactivity}

Several of the heavier isotopes in nature are unstable and decay with the emission of an alpha particle. A good example is radium, which becomes the gaseous element radon when it decays, according to

radium-226 $\rightarrow$ radon-222 + alpha particle.

The half-life of radium is 1600 years, and the number of disintegrations per second $(d / s)$ is around $3.7 \times 10^{10}$. This value of $d / s$ is called the curie (abbreviation $\mathrm{Cl}$ ) after Madame Curie, who first studied the radioactivity of uranium. Thus when we say that a cobalt -60 radiation source has an activity or "strength" of $1000 \mathrm{Ci}$, it means that the decay rate is $(1000)\left(3.7 \times 10^{10}\right)=3.7 \times 10^{13} \mathrm{~d} / \mathrm{s}$.

\section{Natural Decay Chains}

The radium-radon step is but one in a long chain of radioactive processes starting with uranium-238, as shown in the following table. This radioactivity is important since it occurs in the residues called "tailings" from the mining and milling of uranium ore. The final isotope is seen to be stable lead-206. Other natural chains start with uranium-235 and thorium-232. Some isotopes decay with the release of an alpha particle only; others yield beta particles only; but many give both betas and gamma rays, which are similar to visible light except that their energy is much higher and they are better able to penetrate matter.

Uranium as a mineral found in nature is only mildly radioactive, since the half-lives of both its isotopes are very long: for $238 \mathrm{U}, 4.47$ billion years; for 235U, 704 million years. + However, uranium is found in many types of rock, and since several of its descendants are more radioactive than $238 \mathrm{U}$, many building materials give us a significant level of radiation. The lightest naturally occurring radioactive element is potassium. Accompanying stable potassium-39 is weakly radioactive potassium-40 (0.012 atom\%) with a half-life of 1.43 billion years.

Among the hundreds of radioactive isotopes (also called radioisotopes) are found half-lives ranging from a small fraction of a second to billions of years, as we saw in the table. A stable substance has a half-life of infinity, of course. Each isotope has its own half-life, which is unaffected by any treatment.

We have emphasized the "natural" radioisotopes, i.e., those found in nature. "Artificial" or manmade radioisotopes can be produced by irradiating (bombarding) stable nuclei by various particles such as protons, neutrons, alpha particles, and deuterons. Radioisotopes also are by-products of nuclear fission, as will be seen later. The figure below, showing some nuclear reactions, provides information on neutron absorption and radioactivity, for use in later sections.

\footnotetext{
*Fractions of a curle are the millicurie $\left(10^{-3}\right)$, microcurie $\left(10^{6}\right)$, nanocurie $\left(10^{-9}\right)$, and plcocurie $\left(10^{12}\right)$. For example, one nanocurie is $37 \mathrm{~d} / \mathrm{s}$.
}

\footnotetext{
tFrom a gram of pure ${ }^{238} \mathrm{U}$, the number of disintegrations per second is 124,000 , corresponding to about 3 microcuries.
} 
RADIOACTIVITY

The Chain of Natural Radioactivity Starting with Uranium and Ending with Lead. (Data from Table of /sotopes, 7th Ed. by C. M. Lederer and V. S. Shirley, New York, John Wiley \& Sons, 1978.)

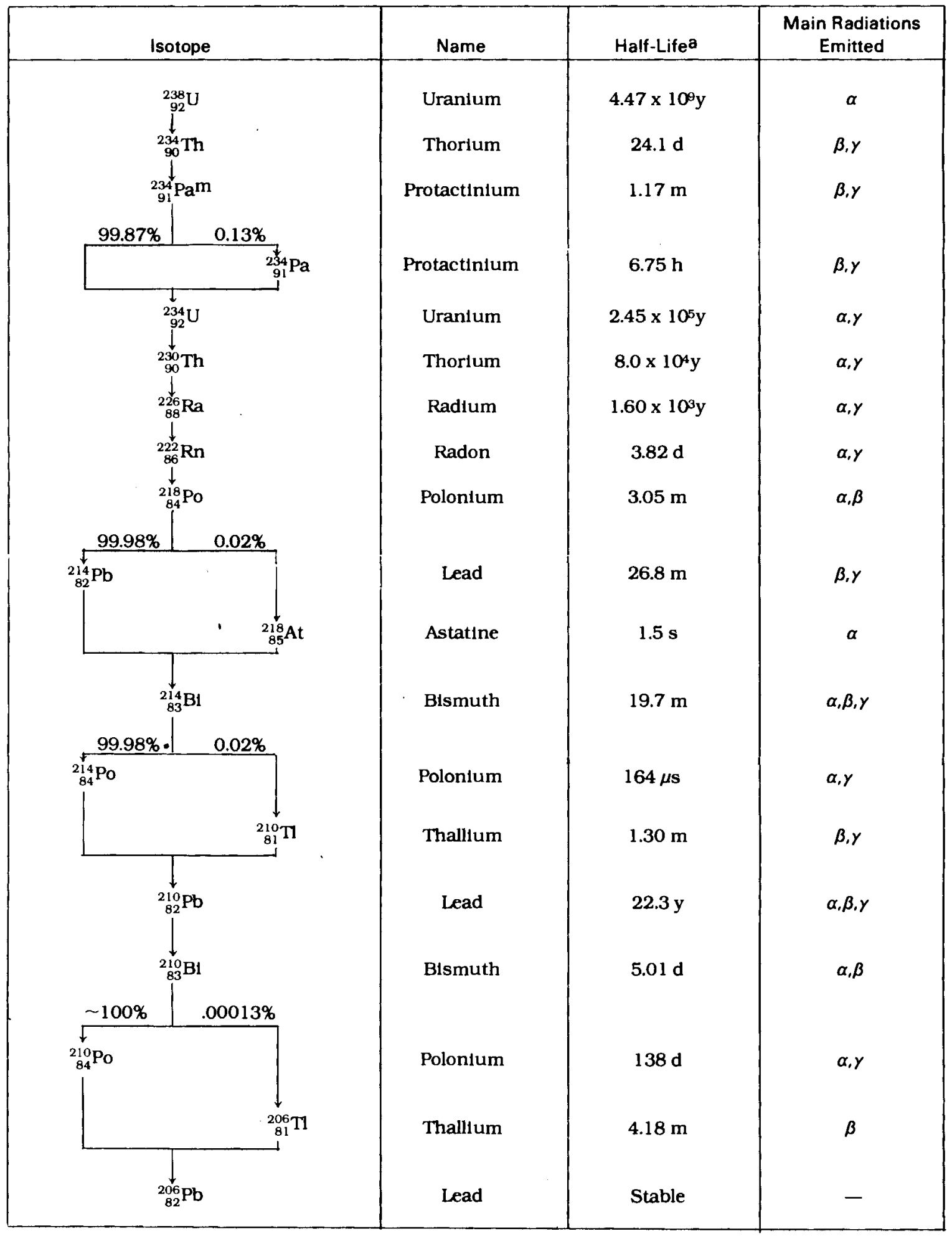

a Note that numbers are rounded off to three digits. $(y=$ year, $d=$ day, $h=$ hour, $m=$ minute, $s=$ second). 


\section{NEUTRON ABSORPTION}

(n) + (H) D $\rightarrow$ D NEUTRON HYDROGEN DEUTERIUM GAMMARAY<smiles></smiles>
NEUTRON URANIUM-238 PLUTONIUM-239 TWO BETA PARTICLES

RADIOACTIVE DECAY PROCESS

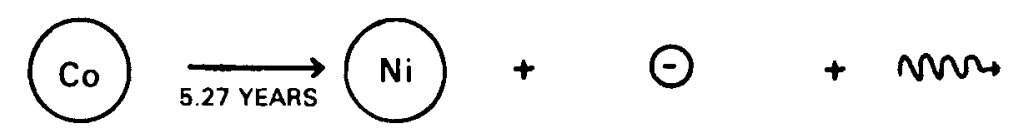
COBALT-60 NICKEL-60 BETAPARTICLE GAMMARAY

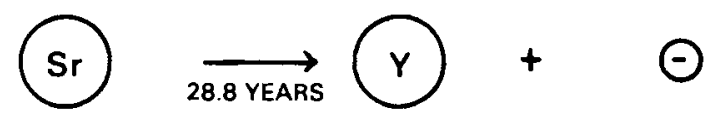

STRONTIUM-90 YTTRIUM-90 BETA PARTICLE

$$
\begin{aligned}
& \text { (Ra) } \underset{1600 \mathrm{YEARS}}{\longrightarrow} \mathrm{Rn}+\oplus \\
& \text { RADIUM-226 RADON-222 ALPHA PARTICLE }
\end{aligned}
$$

Some nuclear reactions. The symbol $D$ is often used for deuterium (heavy hydrogen ${ }^{2} H$ ); the wavy line with arrow is intended to suggest that the gamma ray is an electromagnetic wave; half-lives of the decay processes are listed. 


\section{KINDS OF RADIATION}

\section{Particle Energy}

We introduced each of the main types of radiation $(\alpha, \beta$ and $\gamma)$ in the preceding section. Recall that the beta particle is the same as the electron, which is a negatively charged particle with very small mass, found in atoms. The beta particle is emitted from the nucleus in radioactive decay also. An example is the reaction

strontium-90 $\rightarrow$ yttrium-90+electron .

Strontium is an important nuclear waste because of its relatively long half-life of 28.8 years.

The energy of a beta particle depends on the process from which the particle comes. Also, its energy determines its ability to penetrate matter and cause radiation damage.

The typical unit in which particle energies are expressed is the "electron volt." We can understand the unit by doing an experiment. Picture a one-volt battery connected to two plates of opposite polarity. If an electron is carried across the gap, the energy given to the electron is said to be one electron volt, abbreviated $\mathrm{eV}$. Now, suppose that one electrically accelerates a beta particle to the maximum energy it has on emission from strontium. This time the energy is much larger $-546,000 \mathrm{eV}$ or $0.546 \mathrm{MeV}$ (million electron volts). These strontium- 90 beta particles are still less energetic than some, e.g, those of about $4 \mathrm{MeV}$ from gallium- 66 and silver-112.

Remember that the alpha particle is the helium nucleus. It is emitted by reactions such as the decay of uranium-238 into thorium-234. The alpha particles have an energy of $4.2 \mathrm{MeV}$, typical for alphas emitted by heavy natural radioactive isotopes. The neutron is produced by certain reactions involving the bombardment of a nucleus of

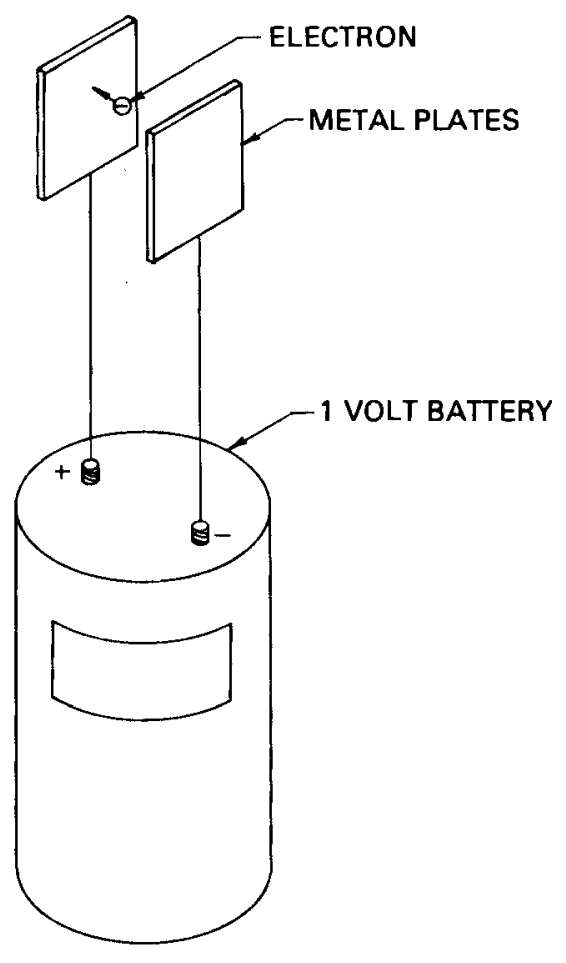

The electron volt as a unit of energy. One kilowatt-hour of energy, the amount used by a 1000 -watt appliance in an hour, is equal to $2.25 \times 10^{25}$ electron volts.

an element such as beryllium by alpha particles from radium decay. The final nuclear reaction is

beryllium $-9+$ helium $-4+$ carbon- $14+$ neutron .

Such processes gave rise to the neutrons that were used in the discovery of fission. However, the neutron is not involved in the radioactivity of nuclear wastes since practically no nuclei decay with neutron emission.

On the other hand, neutrons from outer space continuously produce radioactive carbon by the reaction

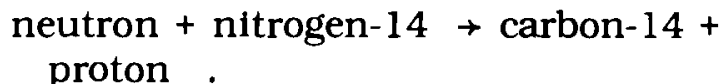


The radioactive carbon- 14 is used to find the age of archeological items, as noted in Chapter 10. Neutrons can also produce new elements. Neutrons absorbed in uranium-238 give rise to the artificial (manmade) isotope plutonium-239. Plutonium-239 is an alpha particle emitter that can serve both as a nuclear reactor fuel or as a weapon, as we shall see later.

\section{Gamma Rays}

The gamma ray can be imagined to be a burst of energy, a particle, or a wave. Each view is correct in some sense. Gamma rays are at the high-energy end of what is called the electromagnetic spectrum. As shown in the chart here, it includes radio, microwaves, infrared, visible light, ultraviolet, $x$-rays, and gamma rays, in increasing order of energy.

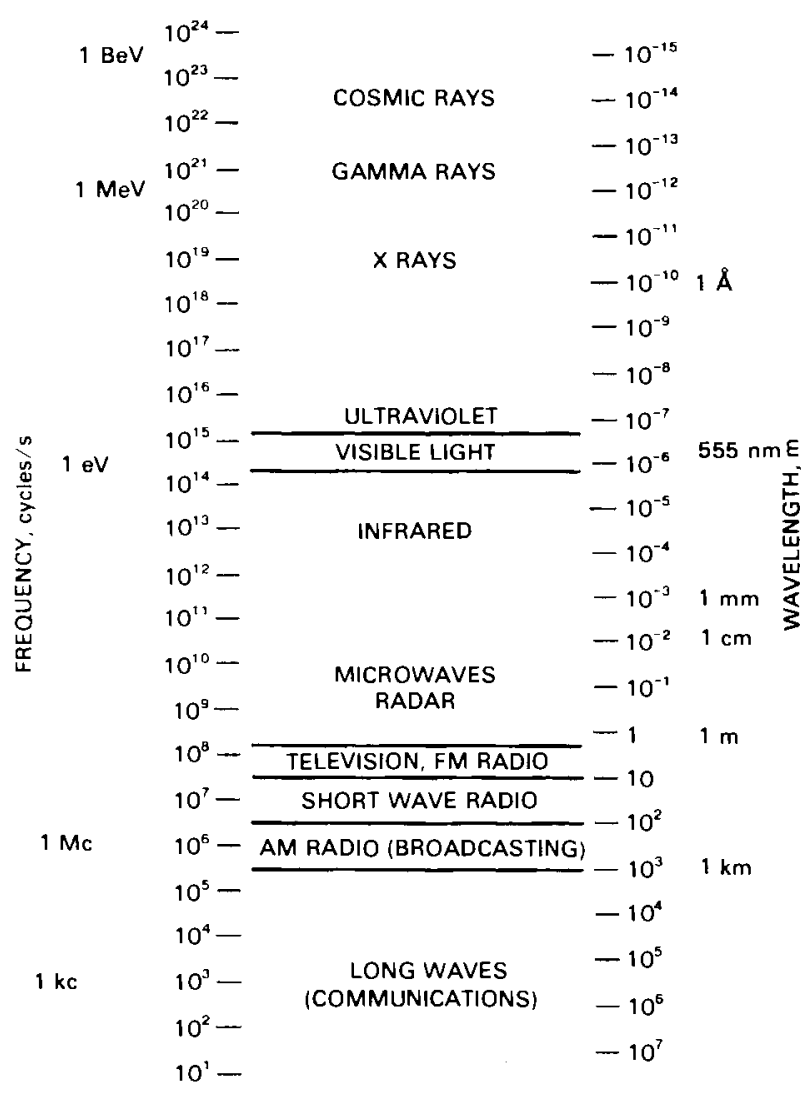

The electromagnetic spectrum, showing that radio-TV, visible light, and nuclear radiation are all waves. (Courtesy of R. L. Murray and G. C. Cobb, Physics: Concepts and Consequences, Prentice-Hall, 1970).
For nuclear purposes, though, it is often better to think of a gamma ray as a particle of light or a bundle of energy called a photon. Many radioisotopes are gamma emitters, For example, cobalt- 60 gives two gamma rays of energy around $1.25 \mathrm{MeV}$ that can be used in medicine in either diagnosis or cancer therapy, as an alternative to $\mathrm{x}$-rays. Gamma rays are emitted at the same time as beta particles from many of the fission by-products, which are part of the radioactive wastes for disposal.

\section{Radiation Spreading and Stopping}

Let us now study the behavior of these various particles in air or in a vacuum. If we were in a laboratory with a small piece of radioactive material, say strontium or cobalt, the particles would come out in all directions. As seen in the sketch, radiation from such a source is similar to that from a light bulb. First, the rays become less intense with distance because of "inverse square spreading." * Prolonged exposure to radiation of either kind can be harmful. The ultraviolet light component can harm eyes, while infrared light can burn the skin; alpha particles, beta particles or gamma rays can damage body tissue as well.

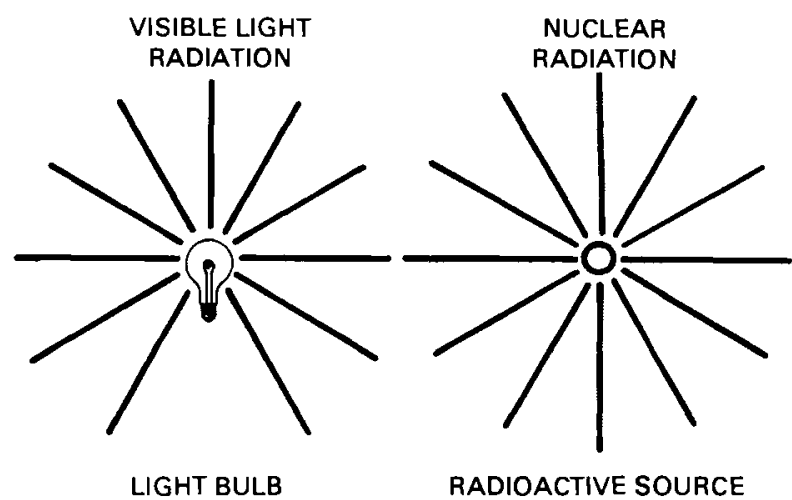

Comparison of the spreading of two forms of radiation-visible light and nuclear radiation. If the distance from the source is doubled, the intensity is divided by four.

\footnotetext{
*The intensity varies inversely as the square of the distance because all radiation goes through spheres of area $4 \pi \mathrm{r}^{2}$.
} 
We can protect ourselves by backing away from the sources. Or, as shown in the sketch, we can interpose some solid material between us and the source of radiation. Each of the particles is slowed down or stopped by collisions with the atoms of the substancein some cases by interactions with the electrons, and in others with the nuclei. A sheet of paper would be enough to stop alphas, but it would take a sheet of aluminum metal $1 / 25$ in. thick to stop betas, such as those from strontium-90. These particles are thus said to have a certain "range," which increases with particle energy, of course. The intensity of gamma rays is merely reduced by passage through matter, just as light intensity is reduced by fog. A half thickness " $t_{H}$ " can be defined, reminiscent of half-life. It is the distance it takes to cut the intensity of gamma radiation in half. For the cobalt gammas, the element lead has a $\mathrm{t}_{\mathrm{H}}$ of close to one centimeter $(\mathrm{cm})$, making it a useful shield for medical radiation diagnosis or treatment.

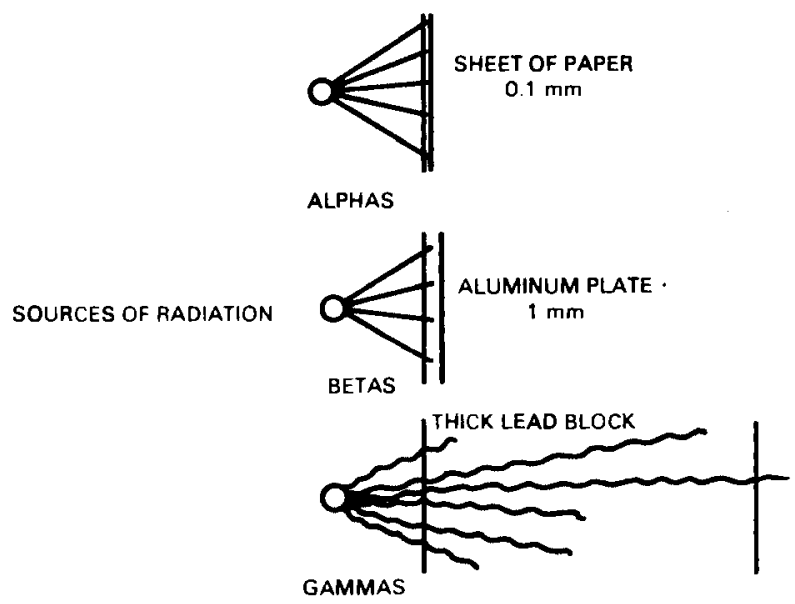

Stopping of radiation by various shields.
How radiation interacts with matter on a submicroscopic level is well understood. We can visualize, for example, the effects of a collision between a gamma ray and a simple atom, as sketched here. There are three possible events: (a) scattering, in which the gamma ray bounces off the electron; (b) ionization, in which the energy of the gamma ray goes into removing the electron from the atom, leaving an ion; and (c) pair production, in which the gamma ray energy is converted into the mass of two particles-an electron and a positron (positively charged electron). This process, pair production, illustrates Einstein's theory that energy and mass are two forms of the same thing.

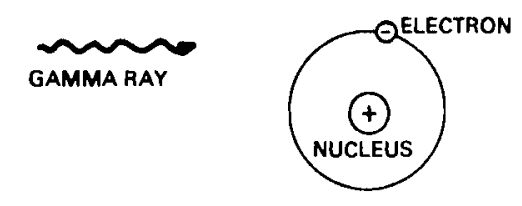

BEFORE COLLISION

(A) SCATTERING
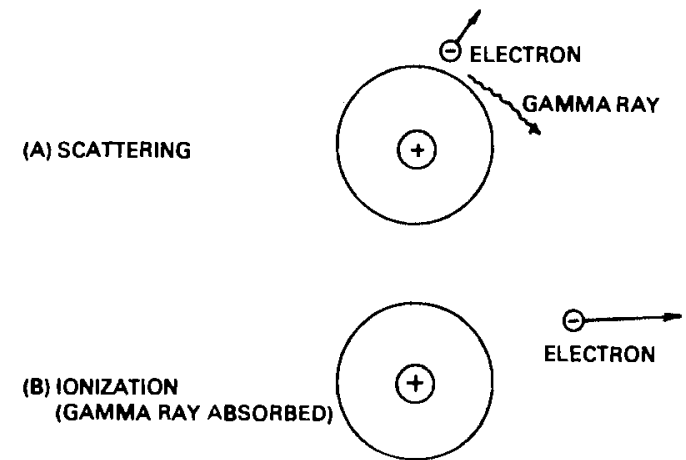

(C) PAR PRODUCTION
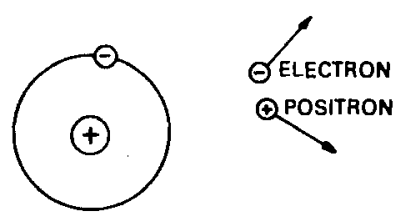

AFTER COLLISION

Effects of gamma radiation. There are three possibilitiesscattering, ionization, and electron-positron pair production. 



\section{BIOLOGICAL EFFECTS OF RADIATION}

\section{Radiation Takes Many Forms}

Modern people are already familiar with quite a few forms of radiation. They make use of visible light, both natural and artificial, in all their activities. They enjoy microwave ovens, radio, and television, which operate on low-frequency electromagnetic waves. They have experienced the well-known form of radiation exposure - sunburn.

Less familiar but real is the unfelt but continued bombardment by radiation from space and the earth. Also little understood are the radiations from manmade devices and products. In this chapter we shall study the effects of rays and particles from radioactive materials, with special attention to low-level radiation.

\section{Radiation and Living Cells}

When high-speed particles such as alphas, betas, gammas, or neutrons strike living tissue, they slow down and stop just as if they had hit paper or aluminum or lead. The energy of motion of the individual particles is imparted to the biological cells as localized heat. Molecules of the cells are broken into atoms, or atoms are changed into ions, or the atomic nuclei are displaced from their positions.

The disruptive action caused by absorbed energy impairs human body cell functions. If the amount of radiation received is extremely small, there may be no significant damage. If the amount is very large, radiation sickness, genetic effects, or death may result. The words "large" and "small" are, of course, relative, so we need to express the amounts of radiation received in terms of numbers.

The blological effect of radiation, which we call dose or dosage, depends on the amount of energy absorbed and also on the type of radiation. Each radiation has a different effect on tissue. For example, neutrons are five times as damaging as $\mathrm{x}$-rays, gamma rays, or low-energy beta particles. Alpha particles are ten times as damaging. These factors that represent biological effectiveness are taken into account when the dosage is expressed in rems. ${ }^{*}$ The rem is a unit of dosage just as the inch is a unit of length. For low radiation levels encountered regularly by human beings we use the millirem (mrem) as 1/1000 rem.

We can cite some typical doses. First is the dose due to natural radiation from the ground and from cosmic rays, which come from outside the earth and bombard our atmosphere and all beings on the earth's surface. At sea level a person receives from these two sources a total of 59 mrems per year. As one goes to higher elevation, the dose increases roughly $1 \mathrm{mrem} / 100 \mathrm{ft}$. Thus at mile-high Denver the background dose is around 112 mrems. Radiation from minerals in houses contributes each year around 40 mrems, food eaten 25 mrems, and a chest $\mathrm{x}$-ray 10 mrems. A small amount of exposure is due to the radioactive potassium-40 naturally in our bodies. The average annual dose to a person in the U.S., including both natural and manmade causes, is around 200 mrems.

\section{Hazards to the Body}

Questions often asked when there is extra radiation present are "How much danger is there?" and "What effect will the radiation have?"

\footnotetext{
*The actual energy absorption is measured in rads, with $1 \mathrm{rad}$ as 0.01 watt-second energy absorbed per kilogram of tissue weight. The factors of biological effectiveness are applied to convert the number of rads into the number of rems.
} 
There are two general classes of radiation effects-somatic, meaning damage to body tissue, and genetic, referring to hereditary characteristics. The main somatic effect is cancer, for example, leukemia. Genetic effects include impaired fertility and transmitted birth defects.

Each tissue and organ of the body has a different degree of sensitivity to radiation effects. The blood-forming tissue, the gastrointestinal tract, and the gonads are some of the more readily affected. The body's external layer of skin provides some protection from bombardment byalpha particles because the particles penetrate only a short distance. However, radioactive material that emits alpha particles can be very hazardous if taken into the body.

Evidence of these physiological effects of massive radiation dosage comes from many sources: laboratory experiments on lower animals such as mice; observation of side effects of radiation treatment of certain diseases; data from the past on radium poisoning of people who painted luminous watch dials; the incidence of lung cancers among uranium miners who worked with inadequate ventilation of radioactive radon gas: and, finally, studies on the survivors of the atomic bombing of Hiroshima and Nagasaki. The conclusion from these data is that a single radiation dose of around 400 rems will be fatal to half of those who receive it, while half will survive, perhaps with some impairment of function. Since such large doses are rare, we are more interested in the effects of small doses.

\section{Low-Level Radiation and the Linear Model}

The subject of low-level radiation is subtle and complex. Let us start with some facts. First, there are no directly observable effects on human beings of a radiation dose smaller than 10 rems. Second, people are exposed continuously to a radiation background from cosmic rays and the ground of about
100 mrems per year in the U.S. and many times larger in some countries such as India or Brazil, where there are large natural deposits of radioactive minerals. Third, it is logical to assume that there is some level of dosage below which there is no permanent effect because of the body's ability to recover; however, one can argue equally well that any amount of radiation is harmful.

We are faced with a large gap in information between the extremes of zero radiation (and zero effect) and very high radiation doses. The simplest assumption is that radiation effect is directly proportional to radiation dose. Thus, as shown in the drawing, one starts with the available data on effects of high radiation doses and draws a straight-line graph down to zero. This solid line expresses an important statement, often called the "linear model" or "linear hypothesis." The other two dashed curves are possible alternatives. The lower one involves a threshold dose, below which nothing happens. It is safer to use the straight-line graph since it predicts a larger effect for a certain dose. The linear graph is thus said to be "conservative." On the other hand, few

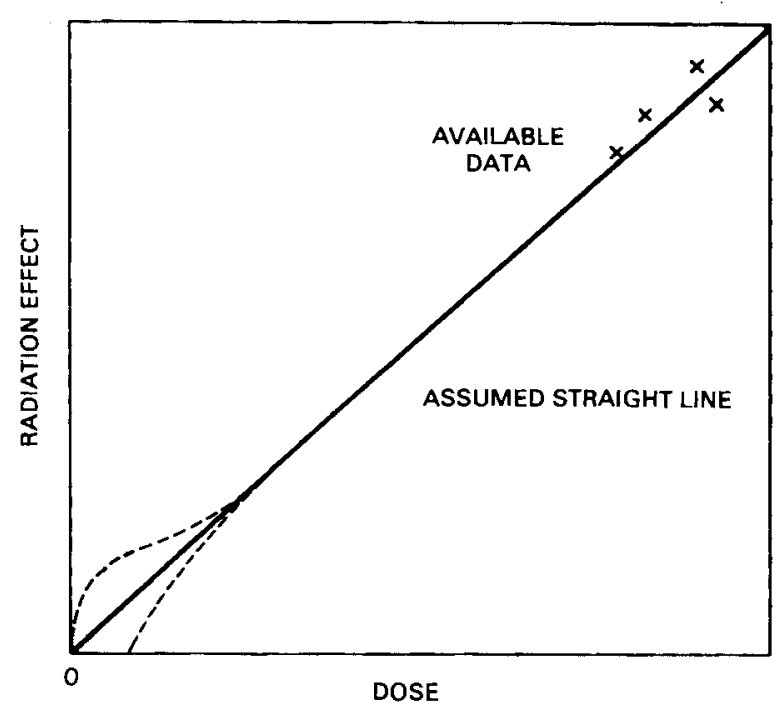

The effect of radiation dose. The solid line is assumed as an extension of data on fatalities from high radiation doses. The lower dashed curve is more likely to be correct than the upper dashed curve. 
believe that the upper dashed curve is correct.

Very recently there has been a move to represent hazard versus dose by a formula that predicts the effect to vary directly with dose for very low values and varying as the square of the dose for larger values. This "linear-quadratic" model is reasonable if damage to sensitive tissues at low doses is by single radiation "hits" while that at high doses is by two or more "hits."

\section{How Sure Can We Be?}

Since we cannot observe the effect of low-level radiation on an individual, we must view the effect statistically. Thus if a large number of people all receive the same small dosage, it is presumed that there will be a few fatalities over the course of years. A unit of total population dose is called the personrem. For instance, if each in a group of 100 people received 5 mrems $(0.005 \mathrm{rem})$, the population dose would be $100 \times 0.005=0.5$ person-rem. The linear model yields a prediction of one additional cancer death for each 5000 person-rems.

We can apply this to the Three Mile Island reactor accident of March 1979 near Harrisburg, Pennsylvania. It was estimated that the 2 million people living within a 50 mile radius received a total of 3300 personrems. The predicted additional cancer deaths (over and above those from other causes) would thus be $3300 / 5000=0.66$. Assuming that there would be an equal number of radiation-caused genetic deaths, the total comes out fewer than two additional fatalities attributable to the accident. Looked at in another way, each of the two million people in the Harrisburg area could say that his or her increased chance of dying as a consequence of the incident was about one in a million.

\section{What Is Risk?}

To put such a number into perspective in comparison with other risks, we need to examine data on fatalities from other causes, including diseases and accidents. The following tables give U.S. figures for the year 1978. From these let's find the chance of death each year from some common causes. The number of fatalities from heart

Major Causes of Death in the U.S. for 1978. The total population was approximately $218,228,000$, and total live births during the year 3,333,200. (From Monthly Vital Statistics

Report, September 17, 1980, U.S. Department of Health and Human Services.)

\begin{tabular}{|c|c|}
\hline Heart disease & 729,510 \\
\hline Cancer & 396,992 \\
\hline Stroke & 175.629 \\
\hline Accidents, total & 105,561 \\
\hline Motor vehicle 52,411 & \\
\hline Others & \\
\hline Influenza, pneumonla & 58.319 \\
\hline Dlabetes & 33,841 \\
\hline Llver disease & 30,066 \\
\hline Hardening of arteries & 28,940 \\
\hline Sulcide & 27,294 \\
\hline Infant mortallty & 22,033 \\
\hline Lung disease & 21,875 \\
\hline Homiclde & 20,432 \\
\hline Kidney disease & 8,86 \\
\hline Blood poisoning & 7,800 \\
\hline All other causes & 260,628 \\
\hline Tota & , \\
\hline
\end{tabular}

U.S. Deaths from Accidents, 1978 (From Vital Statistics of the United States, Vol. 2, Pt. A, "Mortality 1978" [in press])

Motor vehicle

52,411

Falls

13,690

FIres

6,163

Drowning

Industrial

Poisoning

5,784

4,772

Medical procedures $\quad 3,076$

Inhalation, Ingestion of objects $\quad 3,063$

Alr and space transport $\quad 1,880$

Firearms $\quad 1,806$

Water transport $\quad 1,467$

Rallway $\quad 602$

All other

5,679

Total

105.561 
disease was 729,510 out of a total population of $218,228,000$. The chance of dying of heart disease each year is then 1 in 299: $(729,510 / 218,229,000=1 / 299)$ From the figure on automobile accidents, 52,411 , we deduce the chance to be 1 in 4164 .

Clearly, one's chances of being killed on the highway greatly exceed those of being killed by radiation; but most people feel that they have control of their fate when they drive but do not if a nuclear reactor is operated by someone else. Also, automobile accidents are common, easily understood, and only a few people are affected in each accident, while reactor accidents are rare and mysterious, and it is possible that a large number of people could be affected.

The question is often asked "Why do we not know the effect of low-level radiation more precisely?" The basic reason is that there are too many competing causes of injury. Radiation can cause cancer, but so can exposure to many kinds of foods, drugs, chemicals, and other pollutants. To demonstrate this statistical situation, suppose that we made a very careful study of 10,000 atomic workers over their lifetimes and found that 560 of them died of cancer. The table indicates that the number of such fatalities in an average group of 10,000 persons in the population would be 536 . Thus there appears to be an excess of 24 deaths that might have been radiation-induced. Statistical variations of at least that number, however, are to be expected among samplings of people. It is not possible to conclude that radiation caused any of, all of, or even more than the 24 fatalities. Although continued studies should and will be made, there is not likely to be a major improvement in accuracy of the estimated effect of lowlevel radiation.

\section{Comparison with Chemical Wastes}

Radioactive wastes from various nuclear processes, one source of harmful radiation, should be viewed in perspective. Certainly the hazard seems very ominous because some of the isotopes last for thousands or even millions of years. Some chemical poisons, however, such as arsenic, lead, and mercury last forever. In a sense, radioactive materials are degradable, while the poisons are not.

As pointed out by Cohen," the "potential" hazard is greater for several toxic chemicals than for radioactive wastes. He states that the lethal doses produced per year in the U.S. of chlorine, phosgene, ammonia, cyanide, and barium all exceed those of nuclear waste. He also notes that the chemicals are more accessible than are radioactive wastes.

\footnotetext{
"Bernard L. Cohen, "High Level Radioactive Waste From Light-Water Reactors," Reviews of Modem Physics, January 1977.
} 


\section{RADIATION STANDARDS AND PROTECTION}

When high-energy atomic and nuclear radiation was first discovered early in this century, many experimenters received excessive doses of radiation. The discovery of $\mathrm{x}$-rays led to widespread use of this radiation for medical diagnosis. Scientists and doctors were not aware of the biological damage that such radiation could produce and of the need for great caution in administering $\mathrm{x}$-rays. As a result there were a number of radiation burns and fatalities. In painting the naturally radioactive element radium on watch dials to make them luminous in the dark, workers who pointed their brushes with their lips received excessive radiation and many died of leukemia.

\section{Standards for Protection}

Over the years, however, more information became available and greater safety measures were developed. Certain official organizations were established and standards for maximum allowed exposure were set. The limits on dosage have generally come down. New sciences appeared: radiology, health physics, and radiation protection. In the early days, the test of radiation dose was reddening of the skin. Such primitive methods have been replaced by detection using sensitive electronic instruments and photographic film. There are well known rules for ensuring the safety of patients who receivex-rays. We now have detalled tables of standard values of maximum permissible concentration (MPC) of radioactive isotopes in air or water and information on the allowed dose to specific tissues and organs of the body. Organizations responsible for recommending new standards are the International Commission on Radiological Protection (ICRP), formed in 1928, followed the next year by the United States counterpart, the National Council on Radiation Protection (NCRP).* The NCRP has specified dose limits for nuclear plant workers.

\section{What Determines Radiation Dosage?}

The radiation dose that we could receive depends in part on the amount of radioactivity in the air that we breathe or the water that we drink. The maximum permissible concentrations (MPC) of radioisotope are obtained by use of the science of health physics. Several questions are considered:

- First, what is the affinity of the isotope for an organ of the body? It may be an element that deposits in the bone, such as strontium-90. It may deposit mainly In the thyroid gland, such as iodine-131 or lodine-129. It may be a gas that affects the lungs, such as radon-222 or krypton-85.

- Second, what radiations does it emit? If it gives off only soft (low-energy) betas, as carbon- 14 does, the hazard is less. But if it emits alphas, as plutonium does, or hard (high-energy) gammas, as cobalt does, the hazard is greater.

- Third, what is its half-life? If it is extremely short, the isotope may be practically gone before the body takes it in. If it is very long, the activity is low and thus little radiation is received.

- Finally, how does the body react when the isotope is ingested? Certain heavyelement oxides, if taken orally, would not

\footnotetext{
- The NCRP consists of 75 council members from univer sities, hospitals, national laboratories, and government agen cles. The body is not an official government agency, however.
} 
remain in the body, but would soon be eliminated. If breathed as large particles, however, they might lodge in the lungs and stay for a long time. An isotope of ordinary body chemical such as hydrogen, carbon, oxygen, nitrogen, sodium, or chlorine, would become a part of the body, but would also be eliminated rather soon because of normal body processes. Thus hydrogen- 3 (tritium) and carbon14 are readily eliminated in water and carbon dioxide.

The radiation effect of a radioisotope that has entered the body thus depends on how rapidly the substance is removed by a combination of radioactive decay and biological elimination. Each process has a half-life. A formula involving the half-lives of the two processes is used to find the "effective" halflife of the substance. * For example, the ordinary half-life for tritium is 12.3 years and its biological half-life is 12 days, but its effective half-life is only 11.97 days.

\section{Radiation Protection Practices}

A special document known as the BEIR reportt provides some general guidance on radiation protection standards. The principles in simplified form are as follows:

1. Allow no exposure unless there is an important benefit.

2. Protect the public but do not waste large amounts of money on small improvements.

3. Radiation risks should be small compared with normally accepted risks.

"If $t_{H}$ is the radioactive half-life and $t_{B}$ is the biological half-life, the effective half-life $t_{E}$ is found from the formula

$$
1 / t_{\mathrm{E}}=1 / \mathrm{t}_{\mathrm{H}}+1 / \mathrm{t}_{\mathrm{B}} \text {. }
$$

Values of $t_{B}$ are cerlum 70 days, soluble plutonium 1 year, insoluble plutonlum 2 years, strontium 50 years.

+The Effects on Population of Exposure to Low Levels of Ionizing Radiation, Report of the Advisory Committee on the Blological Effects of Ionizing Radiation. National Academy of Sclences, National Research Council, November 1972. This document is called BEIR I. Later are BEIR II (1977). BEIR III (1980).
4. The average dose to many persons should be much less than that for an individual.

5. Medical radiation exposure can and should be reduced by avoiding mass $\mathrm{x}$-rays, by inspection and licensing, and proper training and certification.

6. Cost-benefit analysis should be applied to the nuclear industry.

7. Extraordinary efforts should be made to minimize the risk of a serious reactor accident.

8. Occupational and emergency exposure limits should be set.

9. Studies should be made on the relationship of radiation and ecology.

10. Good estimates and predictions should be sought.

\section{Regulation of Radiation}

Specifications on maximum permissible concentrations (MPC) of radioisotopes in air and water appear in the publication, Code of Federal Regulations 10 Energy, $\neq$ Part 20, Standards for Protection Against Radiation, abbreviated 10CFR20. The table lists typical numbers in microcuries per milliliter (cubic centimeter) of air or water, for materials to which the general public might be exposed. Figures are given in the publication 10CFR20 for soluble and insoluble materials, for exposure of people in restricted areas, and for many more isotopes.

When there are several isotopes in a mixture of air or water, the fractions of an MPC of the materials present must total less than 1. For example, suppose we had a mixture of plutonium-239 and water containing tritium. If the activity of $239 \mathrm{Pu}$ is $4 \times 10^{-6}$ (0.8 MPC) and that of $3 \mathrm{H}$ is $1 \times 10^{-3}$ (0.33 MPC), the total would be $1.13 \mathrm{MPC}$,

\footnotetext{
\#This book, reissued yearly by the Superintendent of Documents, includes regulations of the Nuclear Regulatory Commission (NRC), based on specifications by the Federal Radiation Councll (FRC), whose actions require presidential approval.
} 
Maximum Permissible Concentrations, $\mathrm{uCi} / \mathrm{ml}$, Above Natural Background for Selected Radioisotopes*

\begin{tabular}{lll}
\hline \multicolumn{1}{c}{ Isotope } & \multicolumn{1}{c}{ Air } & Water \\
\hline Cesium-137 & $2 \times 10^{-9}$ & $2 \times 10^{-5}$ \\
Cerlum-144 & $3 \times 10^{-10}$ & $1 \times 10^{-5}$ \\
Hydrogen-3 & $2 \times 10^{-7}$ & $\mathbf{3} \times 10^{-3}$ \\
Iodine-129 & $2 \times 10^{-11}$ & $\mathbf{6 \times 1 0 ^ { - 8 }}$ \\
lodine-131 & $1 \times 10^{-10}$ & $\mathbf{3} \times 10^{-7}$ \\
Krypton-85 & $3 \times 10^{-7}$ & - \\
Neptunium-237 & $1 \times 10^{-13}$ & $\mathbf{3} \times 10^{-6}$ \\
Plutonium-238 & $3 \times 10^{-8}$ & $1 \times 10^{-4}$ \\
Plutonium-239 & $6 \times 10^{-14}$ & $5 \times 10^{-6}$ \\
Radium-226 & $3 \times 10^{-12}$ & $\mathbf{3} \times 10^{-8}$ \\
Radon-222 & $3 \times 10^{-9}$ & - \\
Strontium-90 & $3 \times 10^{-11}$ & $\mathbf{3 \times 1 0 ^ { - 7 }}$ \\
Uranium-235 & $2 \times 10^{-11}$ & $\mathbf{3 \times 1 0 ^ { - 5 }}$ \\
Uranium-238 & $3 \times 10^{-12}$ & $4 \times 10^{-5}$
\end{tabular}

*From Code of Federal Regulations 10 Energy, January 1,1981 . Superintendent of Documents, Washington, DC. The allowed concentrations are extremely small-for example. that for cesium in air is two microcurles per billion milliliters.

exceeding the limit of 1 . We see from the table that allowed air activity values of the gases krypton and radon are much higher than those of neptunium and the two plutonium isotopes. It turns out, however, that chemical toxicity of natural uranium rather than the radioactive hazard is the limiting factor.

The Nuclear Regulatory Commission also specifies in 10CFR20 the maximum allowed dosage for occupational workers. In each calendar quarter, the dose an individual receives from radioactive material and radiation must not exceed the following values:

1. Whole body, head and trunk, active blood-forming organs, lens of eyes, or gonads- 1.25 rems

2. Hands and forearms, feet and ankles18.75 rems

3. Skin of whole body -7.5 rems

The value in item 1 above can be as large as 3 rems under certain conditions: if the cumulative dose in rems is not more than five times the person's age beyond 18 and if a full exposure history is available. Minors are not allowed more than $1 / 10$ of the above values.

The allowed dose limit for the general public is also lower by a factor of ten than that of occupational workers. The reason for the difference is that the latter voluntarily accept employment where radiation may be found. They also have protection through control and monitoring practices. For individual members of the general public the standard is 0.5 rem per year ( $1 / 10$ that of a nuclear power plant worker), and for the average public group it is 0.17 rem per year.

\section{"As Low As Is Reasonably Achievable"}

The NRC's General Provisions 10CFR20.1 states that persons or organizations holding NRC licenses "should make every reasonable effort to maintain radiation exposures, and releases of radioactive materials in effluents to unrestricted areas, as low as is reasonably achievable." This principle, called ALARA, is to be applied "taking into account the state of technology, and the economics of improvements in relation to benefits to the public health and safety, and other societal and socioeconomic considerations, and in relation to the utilization of atomic energy in the public interest." The application of this principle led NRC (in 10CFR50 Appendix I) to limit annual dose to any individual outside a nuclear power plant to 3 millirems via liquid and 5 millirems via air. The annual total release of radioactive material (excluding tritium and dissolved gases) should be no more than 5 curies.

Nuclear plants meet the standards set by the Nuclear Regulatory Commission by using a combination of sensitive radiationdetection equipment and certain procedures. The photograph shows a plant worker using a portable radiation instrument. Radiation levels are measured by radiation detectors and dosimeters, while radioactive contamination is determined by samplers that take in water or air which might contain radioactive isotopes. For improved 


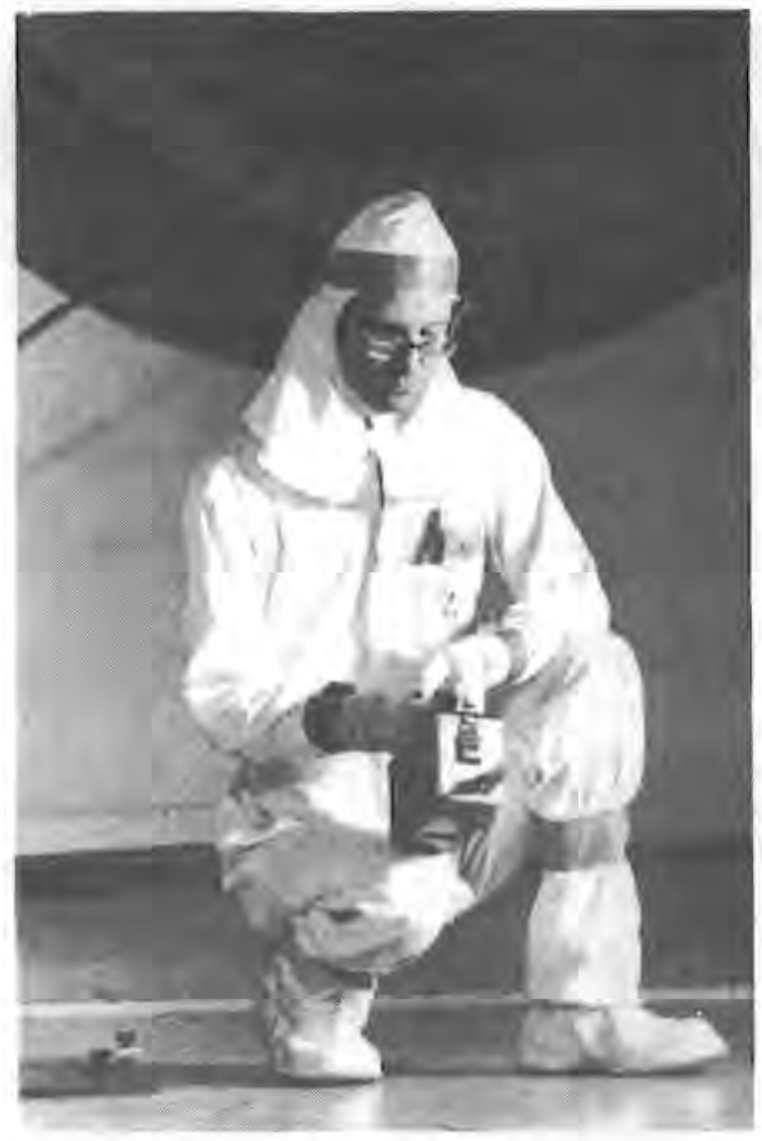

Radiation worker with protective clothing, dosimeter, and portable detector. (Adapted from Ralph Lapp and George Russ, Radiation Risks for Nuclear Workers, Atomic Industrial Forum. Inc., 1979)

accuracy of measurement, large water samples can be evaporated to increase the radioactive concentration, and large air samples can be passed through filters that collect the contained radioisotopes.

The values of MPC are extremely small, but the very fact that the isotopes are radioactive and emit radiation makes it possible for them to be detected. Even though radiation cannot be seen, felt, heard, smelled, or tasted, its presence can be sensed by radiation detectors and the amount of hazard can be measured.

\section{How To Protect Against Harm}

Radioactive particles are said to enter the body by ingestion-by eating, drinking or breathing. To protect against radiation hazard, it is necessary to isolate the source of radioactivity or to render it harmless. Storing the material in a safe place until it decays solves the problem if the half-life is short, for example, iodine-131 with its halflife of 8 days. Releasing the material into very large volumes of air or water can dilute the activity to below the MPC values shown in the preceding table. Mixture with dirt in the ground is possible in some applications.

To provide protection against radiation that is external to the body, three factors can be used-distance, time, and shielding. A person is safer the farther from the source of radiation, the shorter the time of exposure, and the thicker the shielding. This sketch shows some ways dosage is minimized. The radiation warning symbol is used universally: rope barriers remind workers of a potential hazard. Limits on people's exposure to radiation from radioactive wastes are the same as those described above for air and water. We shall discuss later how these limits are to be achieved. *

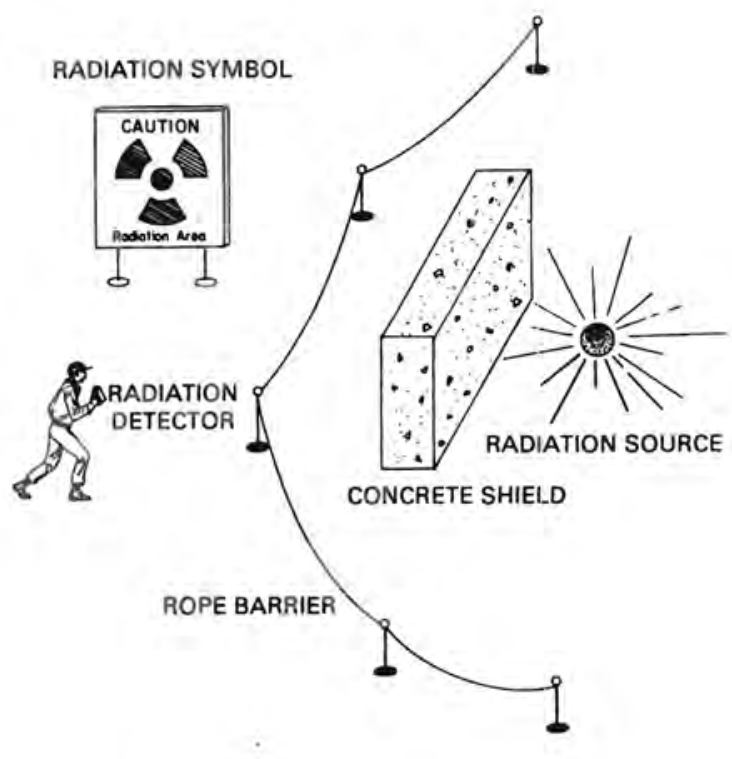

Examples of methods of protection against radiation.

-Practical health physics material appears in Earnest F. Gloyna and Joe O. Ledbetter, Principles of Radiological Health. Marcel Dekker, 1969. 


\section{FISSION AND FISSION PRODUCTS}

\section{The Splitting of the Nucleus}

The radioactive wastes that are byproducts of nuclear power generation arise mainly from the fission process. Fission is the splitting of a nucleus into two parts, triggered by absorption of a neutron."

Using the sketch, picture the stages, beginning with a neutron approaching the nucleus of uranium-235. The neutron is absorbed and forms uranium-236, a compound nucleus. This particle is unstable, with some forces trying to hold it together, others trying to disrupt it. Imagine internal vibrations being set up that cause the shape of the nucleus to be distorted. Electric repul-

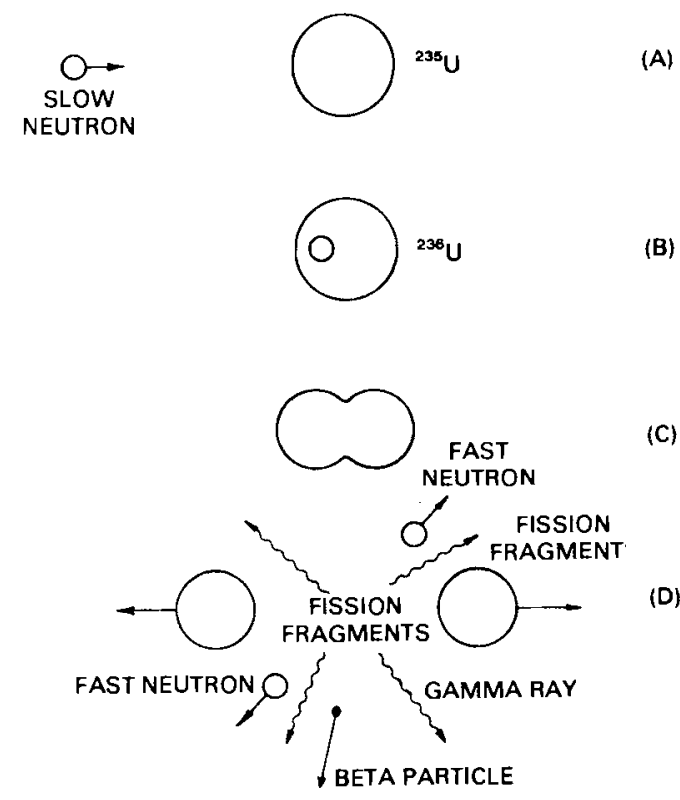

Stages in the fission process. A slow neutron approaches the uranium-235 nucleus in step (A), is absorbed to form uranium236 , as in (B). The nucleus becomes distorted as in (C), and the two fragments fly apart at high speed and various radiations are emitted, including neutrons, as in (D). (Adapted from Raymond L. Murray, Nuclear Energy, Pergamon Press, 1980.)

"Fission happens spontaneously (1.e., the isotope does not need to absorb a neutron) only in a few isotopes such as callfornium-252. sion forces then cause the nucleus to separate into two fragments that fly apart at high speed. These fission fragments are the radioactive "fission products." Their energy of motion will eventually be converted into useful heat. As shown, several neutrons, gamma rays and beta particles are released during this violent separation.

Nuclei of uranium-236 may split in many different ways. If three neutrons were released, the most likely atomic weights would be around 140 and 93. The graph shows which fission product masses are most likely. It tells us, for example, that isotopes with $A=134$ are produced in about $7 \%$ of the fissions. We deduce that strontium-90 and cesium-137 are abundant in the fission products.

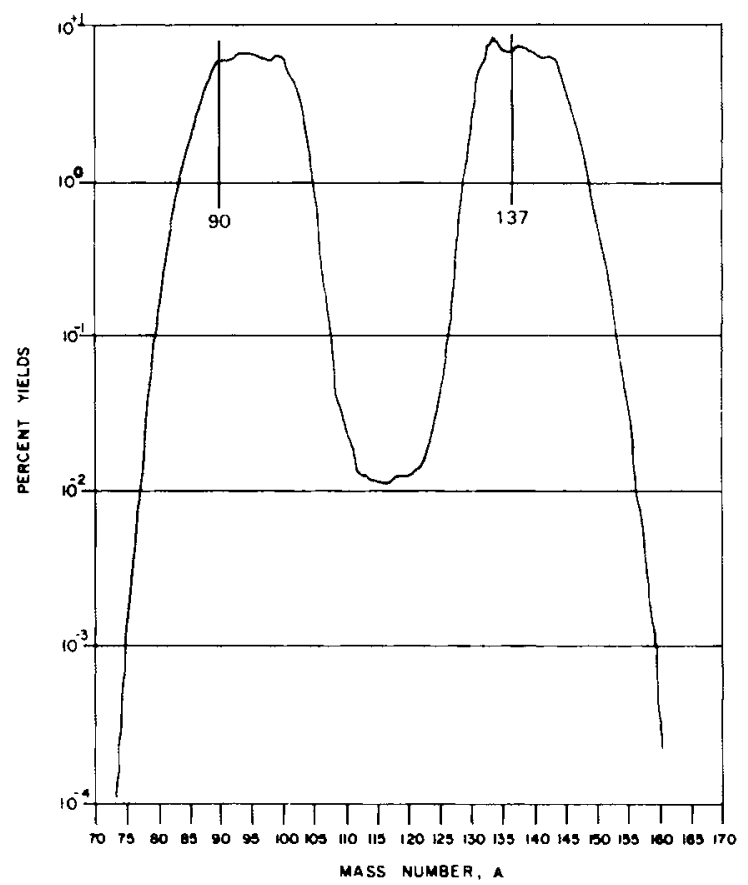

Yield of fission products according to mass number. Many elements and isotopes are present, both stable and radioactive. 
Typical nuclear reactions are:

uranium-235 + neutron $\rightarrow$ uranium-236 uranium-236 $\rightarrow$ krypton-90 + barium$144+2$ neutrons.

The uranium-236 splits into fission fragments in about $85 \%$ of the cases but merely releases a gamma ray in $15 \%$. Note that although we talk about " 235 U fission" it is really the ${ }^{236} \mathrm{U}$ that divides.

The terms "fissionable" and "fissile" are often used to describe types of nuclei. All nuclei can be made to undergo fission if the bombarding neutron has high enough energy. In other words, all nuclei are fissionable, but only a few, the fissile isotopes, can be fissioned with slow (thermal) neutrons. These are uranium-235, uranium-233, plutonium-239, and plutonium-241. Another technical term, "fertile," refers to an isotope that can be converted into a fissile one by absorbing a neutron. Examples are uranium238, thorium-232, and plutonium-240.

Several neutrons come from the fission process. Thus a chain reaction is possible, in which neutrons cause fissions that release neutrons that produce more fissions and so on. When conditions are right, we have a steadily operating source of energy, a "critical" nuclear reactor. The only ingredients that are absolutely essential are uranium and neutrons; but many other components are needed in a reactor to ensure a favorable neutron energy for fission, to take away heat, to provide structural strength, and to permit control and safety. Uranium, through its fissile isotope uranium235 , is the fuel for a nuclear reactor; it is "burned" in the sense that the absorption of a neutron causes energy to be released.

\section{Radioactive Fission Products}

The fission fragments are individual nuclei. Collectively they are fission products, about 800 different isotopic species. They are highly unstable and are thus radioactive, emitting a series of beta particles and gamma rays, with half-lives that generally start out short and become longer in later stages of the chain.

Two important chains are depicted here, with the half-lives for each decay shown. Note that as beta particles are released, the atomic number of the isotope increases. These chains lead to the nuclear waste isotopes strontium-90, half-life 28.8 years, and cesium-137, half-life 30.2 years. Some other important fission products and their halflives are: iodine-131, 8 days; krypton-85, 10.7 years; cesium-134, 2.1 years; cerium-144. 285 days; iodine-129, 15.7 million years. Other isotopes produced are hydrogen-3 (tritium), 12.3 years, and carbon-14, 5700 years. A few of the fission product isotopes are valuable for use in research, medicine, and industry. Amounts available are greater than the demand, however, and additional research and development is being done on new applications.

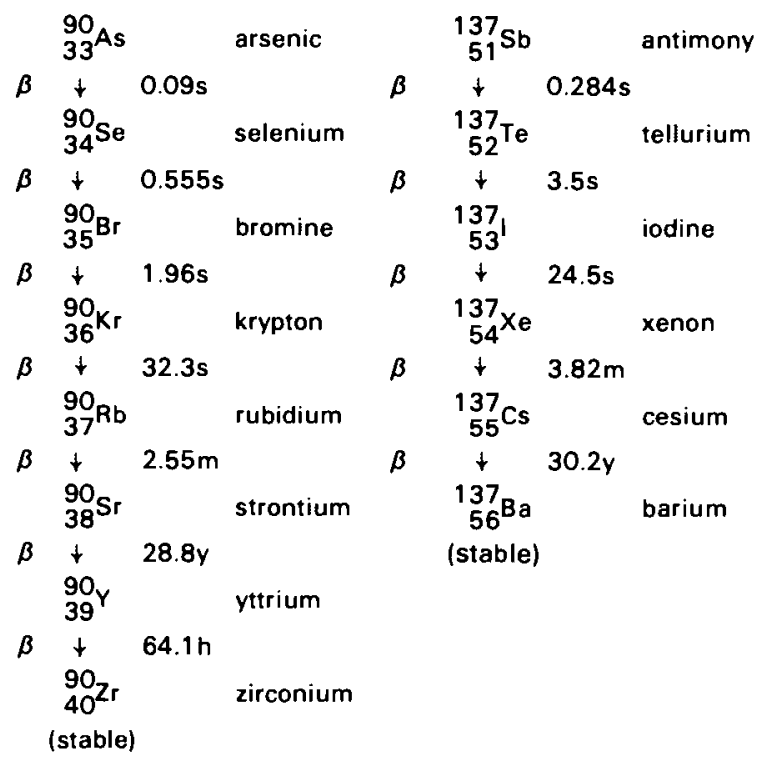

Two fission product decay chains leading to the important waste isotopes strontium- 90 and cesium-137. These isotopes dominate the radioactivity in the waste for several hundred years. See also the following graph. (Data mainly from Table of Isotopes, 7th Ed. by C.M. Lederer and V.S. Shirley, New York, John Wiley \& Sons, 1978.)

When fuel is first installed in a nuclear reactor, it has a rather low radioactivity, mainly from uranium-235 and uranium238. Upon irradiation by neutrons, fission 
products are produced and decay, but they build up to a rather constant inventory. The decay with emission of betas and gammas contributes to the useful heat energy of the reactor, but also lasts for years after fuel is removed from the reactor. The graph shows the slow decline in rate of heat generation.

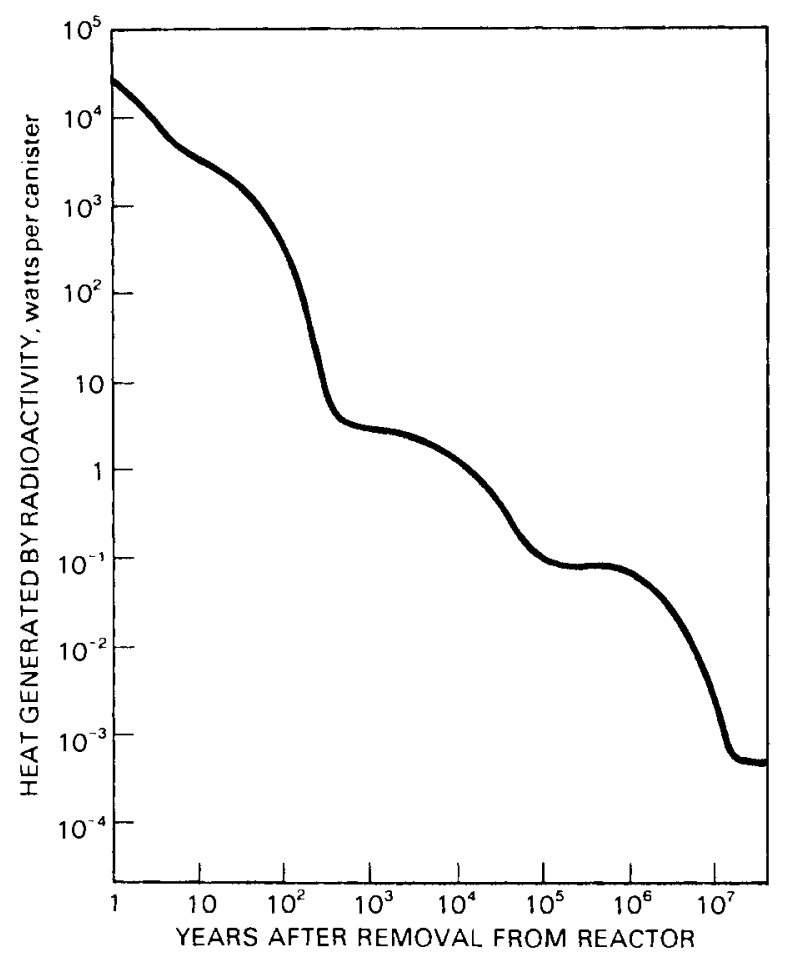

Heat generated by fission product isotopes as it depends on time after removal from a nuclear reactor. (After Bernard L. Cohen, Scientific American, June 1977.)

\section{Energy from Fission}

Each fission reaction releases a very large amount of energy, about $200 \mathrm{MeV}$, i.e., $200,000,000 \mathrm{eV}$. The fission fragments carry about $166 \mathrm{MeV}$ of this total, and the neutrons $5 \mathrm{MeV}$, and about $20 \mathrm{MeV}$ goes to other radiations. The $200 \mathrm{MeV}$ figure is to be contrasted with the low energy obtained by burning a chemical fuel. When hydrogen atoms react with an oxygen atom to produce a molecule of water, the energy yield is only $3 \mathrm{eV}$. Per pound of fuel burned, the energy from nuclear fission is millions of times that from burning a chemical fuel such as coal or oil. As a consequence, the weight of nuclear wastes per kilowatt-hour of energy produced is correspondingly small. One gram of waste results from one megawatt-day of reactor heat energy production.* In contrast, there is a weight of some 2.5 tons of waste solids and gases from burning of a fossil fuel such as coal to produce the same amount of heat.

The fission process is sometimes confused with another important nuclear process, fusion. The latter process consists of bringing together two light isotopes such as deuterium and tritium to "fuse" or combine and release large amounts of energy. The fusion process, which is the source of the sun's energy, is being investigated as a potential source of energy. If successful technically, the fusion process would produce relatively few radioactive wastes. Few predict, however, that fusion will contribute to the world's energy in the twentieth century.

-Recall that 1000 watts is a kilowatt and a million watts is a megawatt. 


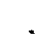




\section{THE MANHATTAN PROJECT}

\section{Wartime Wastes}

Large volumes of nuclear wastes were produced in World War II in the effort to collect the plutonium needed for atomic bombs. This work was a part of the Manhattan Project, a code name for the whole defense enterprise. A review of its history* will reveal how the present waste situation arose.

We recall that direct involvement of the United States in the war began in December 1941 following the attack on Pearl Harbor by the Japanese. The Allies-consisting mainly of the United States, Great Britain, Russia, Canada, and France-were opposed by the Axis powers-Germany, Japan, and Italy.

\section{The Atom Bomb}

The Allies were particularly worried about the possibility that Germany might develop and use a fission weapon. The Germans, with their high level of scientific and technical skill, had discovered the fission process.

As the result of urging by Albert Einstein and others, President Franklin D. Roosevelt launched a research and development program known as the Manhattan Project, briefly outlined here. The ultimate objective of the whole enterprise was to harness the fission process to form an explosive, i.e., a bomb. The first material sought was highly enriched uranium, around $90 \%{ }^{235} \mathrm{U}$, starting with natural uranium, $0.7 \% 235 \mathrm{U}$ (see the illustration). The second material was plutonium, the result of neutron bombardment of ${ }^{238} \mathrm{U}$.

Two types of weapons in which the materials were to be used were devised at Los

*The administrative and technical history of the World War Il period is in H. D. Smythe's book, Atomic Energy for Military Purposes. Princeton University Press, 1945.

\section{The Manhattan Project: Research, Development and Production}

Location
Columbia University,
New York City
University of Chicago
"Metallurgical Labora-
tory"
University of California,
Berkeley

Oak Ridge, Tennessee
Hanford Works, Richland, Washington

Los Alamos, New Mexico Weapons research Iowa State College

Activities studies reactor research reactors

Reactor materials
Gaseous diffusion uranium isotope separation

First nuclear reactor; materials and chemical

Uranium enrichment facilitles: isotope separation; chemistry of plutonium

Production facilities; chemical process and

Plutonium production

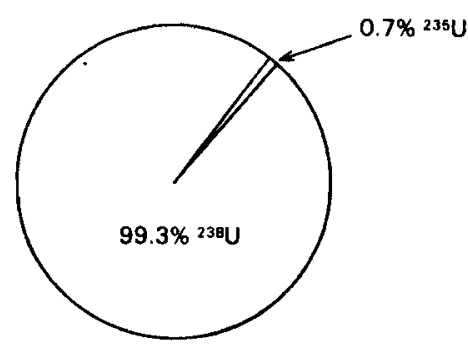

NATURAL URANIUM

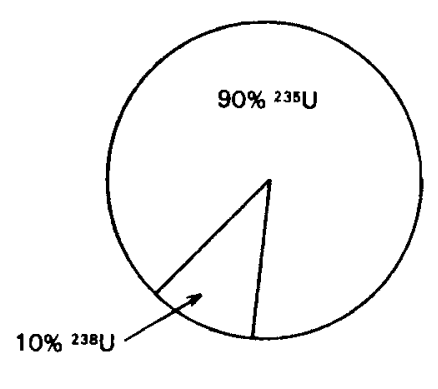

WEAPONS GRADE URANIUM

Composition of different enrichments of uranium. 
Alamos in New Mexico. In the "gun" type, sketched here, halves of the assembly were brought together in a supercritical ${ }^{*}$ condition in a tube very quickly by the use of conventional chemical explosives. In the "implosion" type, also illustrated, a chemical explosive compressed the material to the supercritical state. In either case, a tremendous amount of energy was released almost instantly, with a great deal of radiation and heat. In the nuclear weapon, the chain reaction is used to cause rapid neutron multiplication through the consumption of fissile nuclei, as shown in the sketch.

The separation of $238 \mathrm{U}$ from ${ }^{235} \mathrm{U}$ was needed to provide a readily fissionable material. Techniques tested were thermal diffusion, centrifuge, electromagnetic, and gaseous diffusion. The diagram here shows the principle of gaseous diffusion. Although the electromagnetic isotope separation process produced enough highly enriched uranium (about $90 \% 235 \mathrm{U}$ ) for one of the first bombs, it was gaseous diffusion that proved to be the more economical. It now provides the slightly enriched uranium (about 3\%

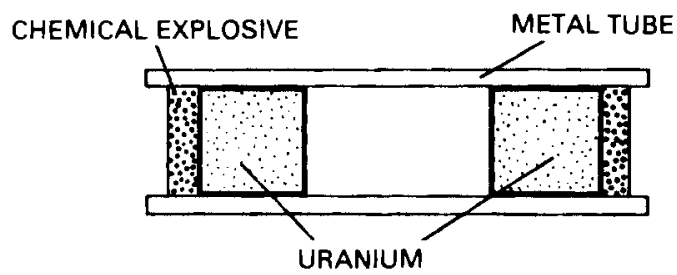

THE "GUN" TYPE DEVICE

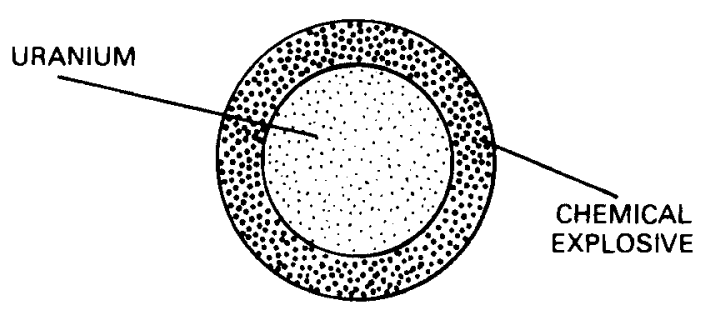

THE "IMPLOSION" TYPE WEAPON

Nuclear weapons of the fission type

"The terms "subcritical," "critical," and "supercritical" indicate whether a neutron in the chain reaction on the average produces neutrons in number less than one. one. or more than one.

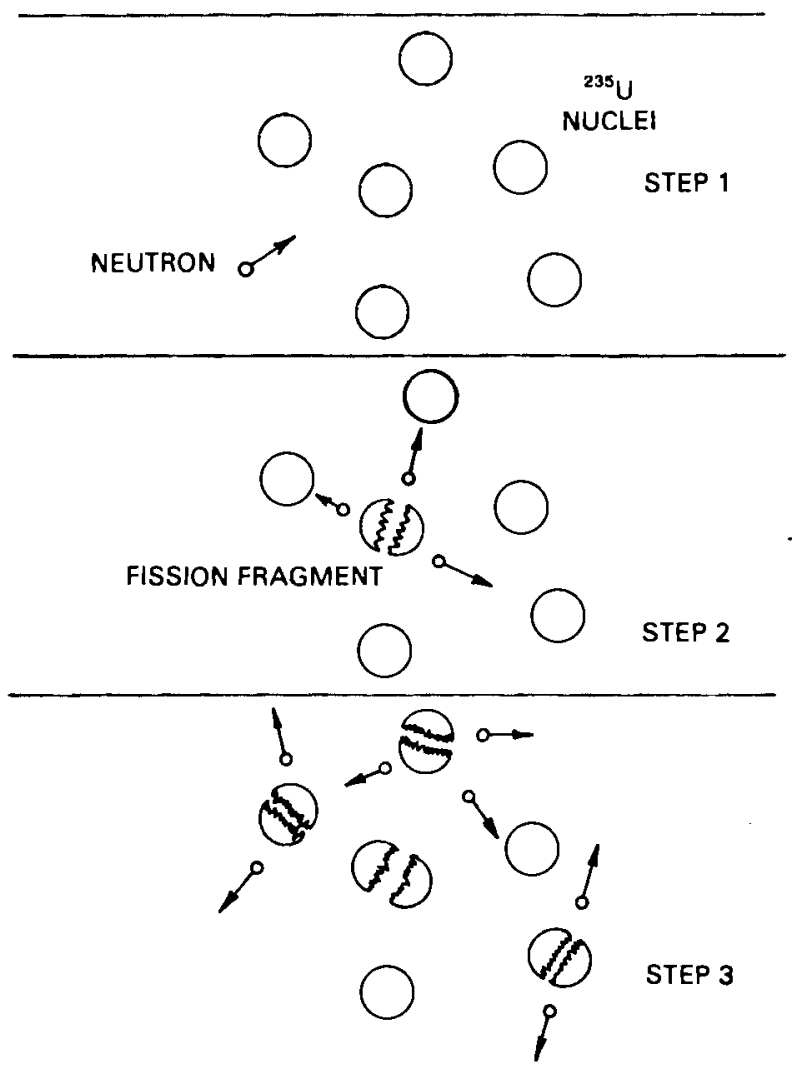

The chain reaction. In just three steps one neutron is "multi plied" to form seven neutrons. Four uranium nuclei are fissioned in this example, each giving rise to energy.

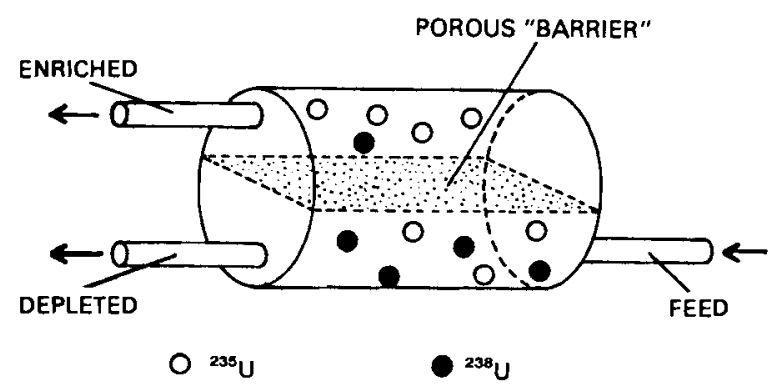

Separation of uranium isotopes by gaseous diffusion. The uranium-235 atoms pass through the "barrier" more readily than do the uranum-238 atoms. Thousands of such units are connected.

$235 \mathrm{U})$ used in present nuclear power reactors. Because of their construction and type of fuel, reactors cannot explode as does a bomb.

\section{The World's First Nuclear Reactor}

The first nuclear reactor was built at the University of Chicago in 1942, under the leadership of Enrico Fermi. The questions to 
be answered were, first, whether a controlled chain reaction involving neutrons and uranium could be achieved and, second, whether irradiation of uranium by neutrons could produce enough plutonium to build a bomb.

The reactor shown in the artist's sketch was constructed of chunks of natural uranium as metal and oxide embedded in graphite blocks. The graphite (carbon) served to slow the neutrons to low energy; that is, it served as "moderator." This first uncooled "pile" went critical on December 2, 1942, and reached a power of 200 watts. The success of the Chicago reactor led to the construction of several large plutonium production reactors at the Hanford Works, located near the present city of Richland, Washington. These reactors also used graphite and natural uranium, with the uranium metal canned in aluminum to protect it from the effects of water coolant. The pieces of uranium, "slugs," were pushed through the reactor after they were irradiated.

A chemical operation called "reprocessing" was then applied to recover the plutonium that had been produced by neutron irradiation of ${ }^{238} \mathrm{U}$. The aluminum coating was removed by sodium hydroxide, and the uranium was dissolved by nitric acid. The chemical bismuth phosphate was then added to precipitate the plutonium, leaving uranium and fission products in solution. A separate process was required to remove the uranium. One disadvantage of the process was that rather large volumes of solids were mixed with the fission products. At the time, of course, the object was to get plutonium. and the waste problem was given a much lower priority. As the result of reprocessing spent fuel, large volumes of the waste were accumulated during and since the war, as the nation stockpiled nuclear weapons for the "cold war" with the USSR. These defense wastes exist and must be dealt with, regardless of the rate of production of wastes from commercial nuclear power.

A series of three articles in The New Yorker of December 3,10, and 17, 1979, is recommended. In the section "Profiles," written by Jeremy Bernstein, the articles are about Dr. Hans Bethe, a Nobel Prize winning nuclear scientist. In a very readable way, they cover the physics research before, during, and after the second world war.

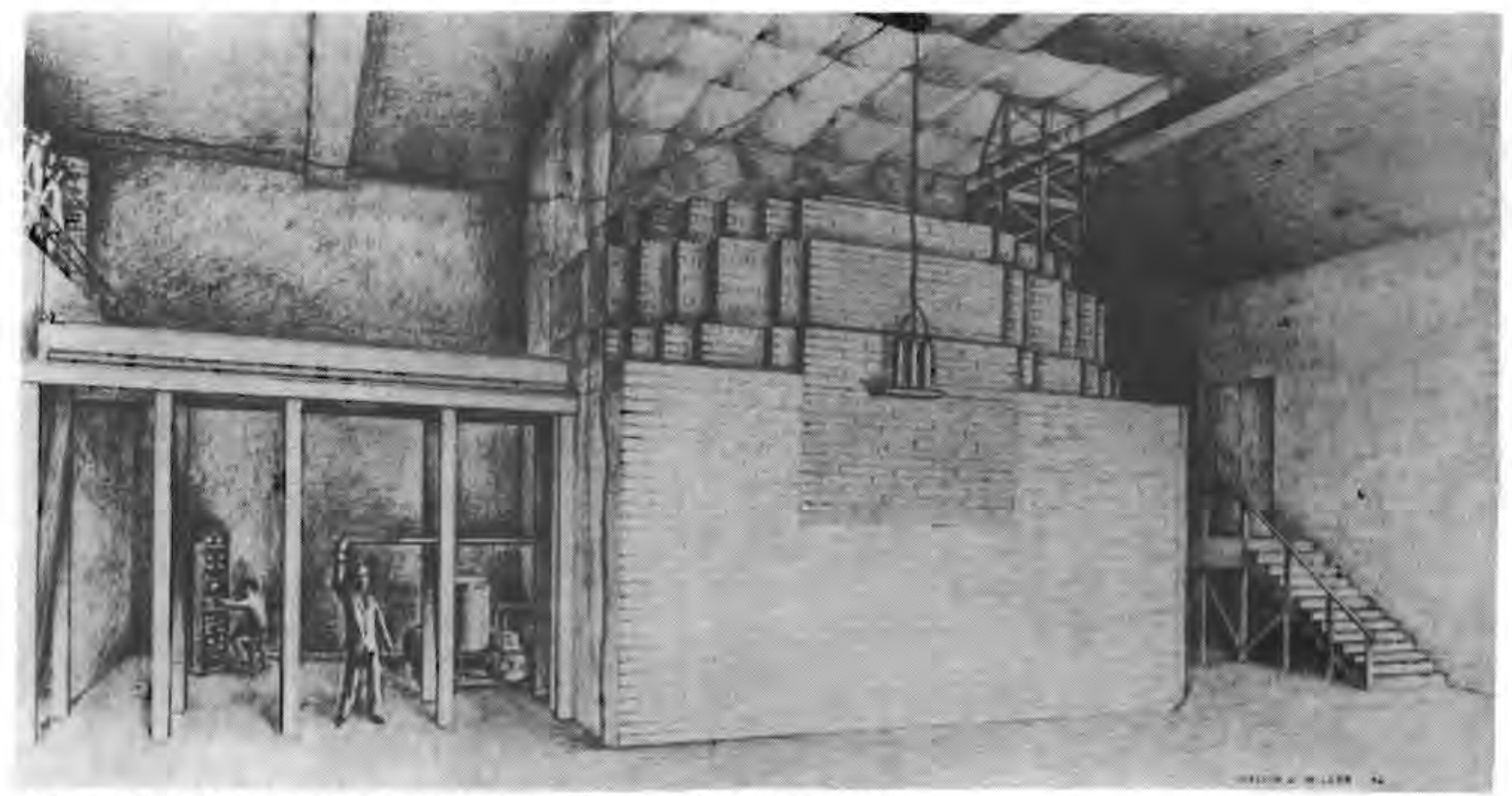

Artist's sketch of Fermi's chain-reacting pile at the University of Chicago, 1942. 


\section{DEFENSE AND DEVELOPMENT}

After the end of World War II in 1945, the United States investigated ways to use nuclear energy for peaceful purposes and, at the same time, sought to maintain and extend the nation's weapons capability. Pollcies made and actions taken in the period since 1945 have shaped the present state of development of nuclear energy, with its accomplishments, opportunities, and problems.

\section{National Laboratories for Research}

When the war with Japan ended, many of the workers of the Manhattan Project were laid off, and most of the scientists who had led the program returned to universities. The U.S. Atomic Energy Commission (AEC) was created in 1946. In that year the Atomic Energy Act charged the AEC to provide materials for defense purposes and to carry out weapons tests, to further the successful application of fission for nuclear power, and to find ways to use the new radioactive materials for beneficial purposes.

Several "national laboratories" were designated to carry out related research and development. The first of these were Oak Ridge National Laboratory in Tennessee, Argonne National Laboratory near Chicago, Brookhaven National Laboratory on Long Island, and Los Alamos National Laboratory in New Mexico. Additional centers in later years include Lawrence Livermore National Laboratory and Lawrence Berkeley Laboratory near San Francisco, Sandia National Laboratories in New Mexico, Bettis Laboratory near Pittsburgh, Idaho Nuclear Engineering Laboratory near Idaho Falls, the Pacific Northwest Laboratory near Richland, Washington, and others.

\section{Defense Projects}

The national nuclear defense of the United States was supported by several weapons production facilities, administered by the Atomic Energy Commission. These included isotope separation plants using gaseous diffusion at Oak Ridge (pictured), in Kentucky, and in Ohio. For the continued production of plutonium, the Hanford reactors (also pictured) were operated for several additional years.

The plutonium generated in the AEC reactors is called "weapons grade" plutonium, containing a rather small concentration of the isotope plutonium-240. This isotope is undesirable because some of its nuclei undergo spontaneous fission, yielding neutrons, which tend to cause premature detonation and inefficient explosion in a weapon. In contrast, "reactor grade" plutonium, produced by long irradiation, has a large plutonium-240 content and is not useful for constructing a weapon.

For the generation of tritium, used as an ingredient of the thermonuclear weapon (hydrogen bomb or $\mathrm{H}$-bomb), reactors were built at the Savannah River Plant near Aiken, South Carolina. The exact nature of nuclear weapons and the stockpile of material is not publicly known, but the weapons capability currently includes some 2000 strategic delivery systems. Chemical treatment (reprocessing) of the spent fuel from the "production reactors" led to an accumulation of what are called defense wastes.

\section{The Nuclear Navy}

The original production reactors were composed of graphite, with cylindrical natu- 


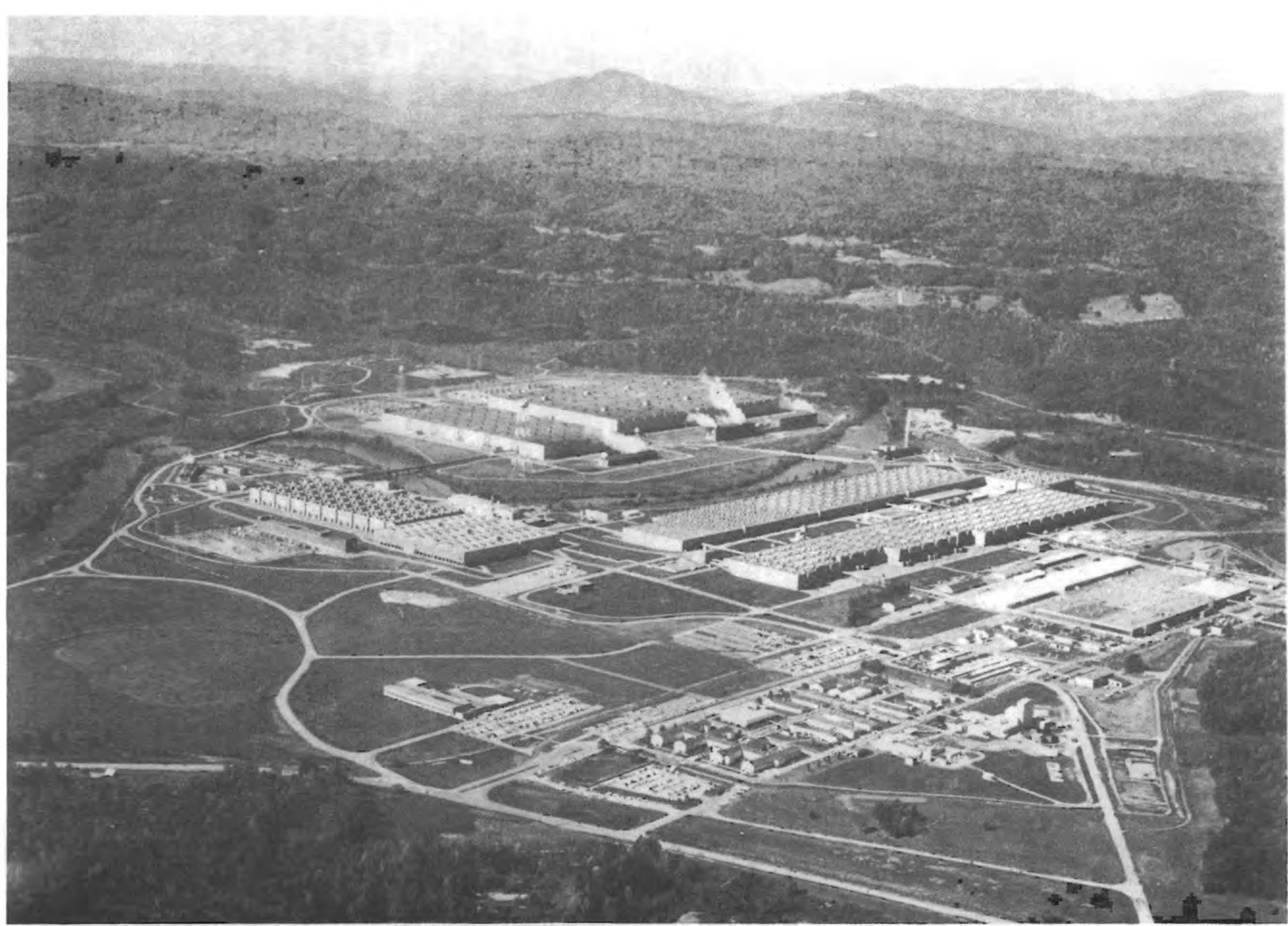

The gaseous diffusion plant for separating uranium isotopes at Oak Ridge, Tennessee. (Courtesy of the Department of Energy.) 


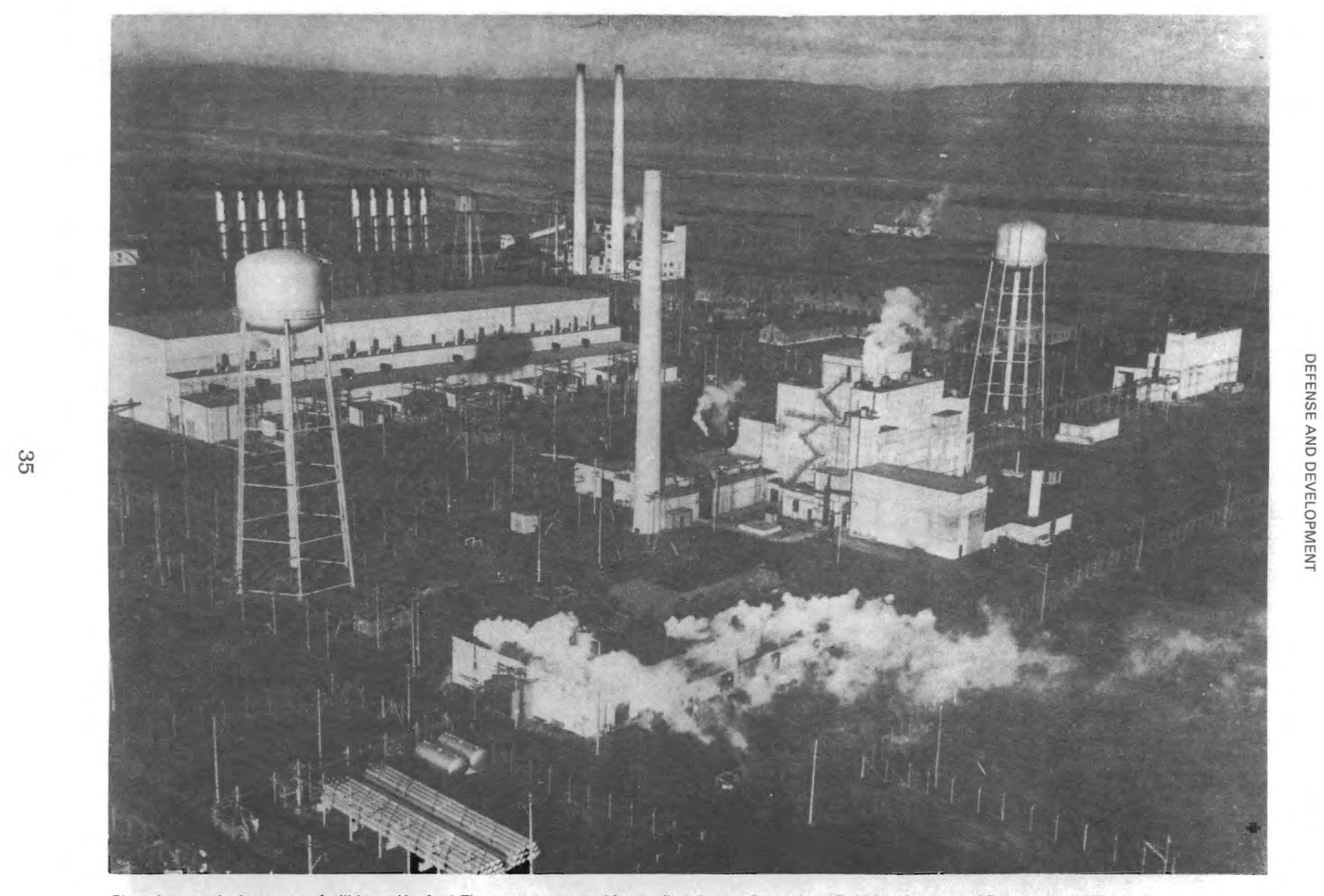

Plutonium-producing reactor facilities at Hanford. These were operated for the first time on December 17, 1944. (Courtesy of Department of Energy.) 
ral uranium fuel rods. The availability of uranium enriched in 235U made possible a new type of reactor, consisting of metal alloy fuel plates, with water as both cooling agent (coolant) and moderator. This reactor was investigated at Oak Ridge, Tennessee, as a possible power source for naval vessels, especially submarines. Between 1948 and 1953 a submarine reactor was built and tested at Idaho Falls, Idaho, by Argonne National Laboratory and Westinghouse Electric Corporation, under the leadership of Admiral H. G. Rickover.

The submarine Nautilus went to sea in 1955 powered by this nuclear reactor using enriched uranium fuel. Because the weight of fuel used was so small, the submarine was able to stay under water for months and to go under the ice at the North Pole. With its first core loading it went 62,000 miles.
All of the Polaris missile-carrying submarines in the U.S. fleet use nuclear engines. The current nuclear fleet includes 120 warships. Of these, 41 are ballistic missile submarines, 69 are attack submarines, seven are cruisers, and three are aircraft carriers. The photograph shows the nuclear-powered carrier Enterprise. The spent fuel from the navy reactors is sent to Idaho Falls for reprocessing.

\section{Electrical Generation}

The Atomic Energy Act of 1954 called for encouragement of nuclear reactor development for commercial electric power. Industrial organizations cooperated with the Atomic Energy Commission in programs designed to find out what reactor types were suitable for economical production of electricity. The homogeneous reactor consisted

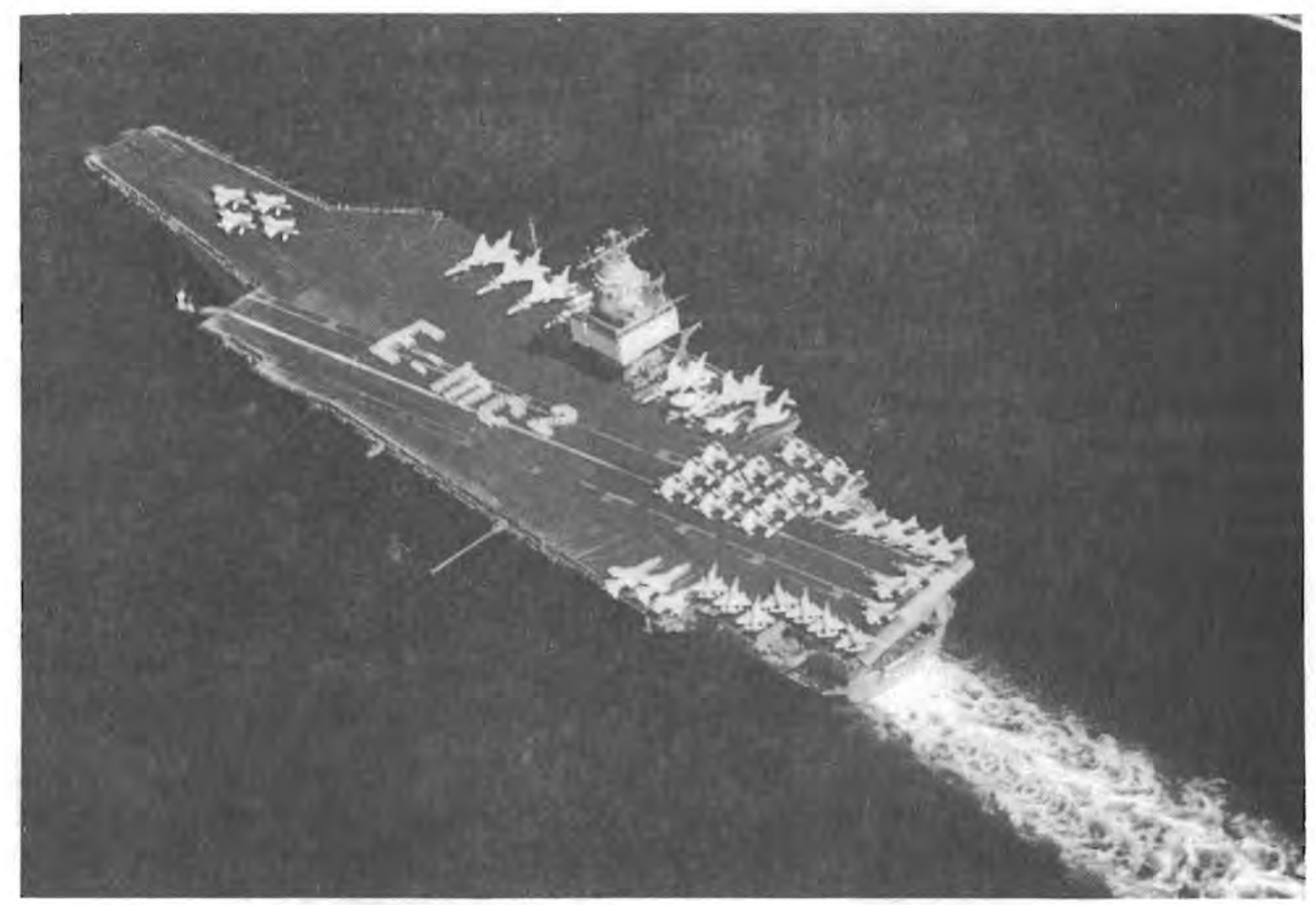

The nuclear-powered aircraft carrier Enterprise. Einstein's formula relating mass and energy is spelled out by crew members. (Courtesy of the Office of Information, Department of the Navy.) 
of a water solution of a uranium salt, with both fuel and moderator circulated through heat removal equipment. Corrosion problems led to the abandonment of this concept. A graphite-moderated reactor similar to the production types but cooled with liquid sodium was tested and found impractical. A reactor was tried that was cooled with a petroleum-derived liquid with boiling point much higher than that of water. The cooling agent turned out to be affected adversely by radiation.

Successful, however, was the Experimental Breeder Reactor, at Arco, Idaho (pictured). In 1951 it produced the first commercial nuclear electric power. It was of the fast-reactor type, without moderator. and cooled by liquid metal.

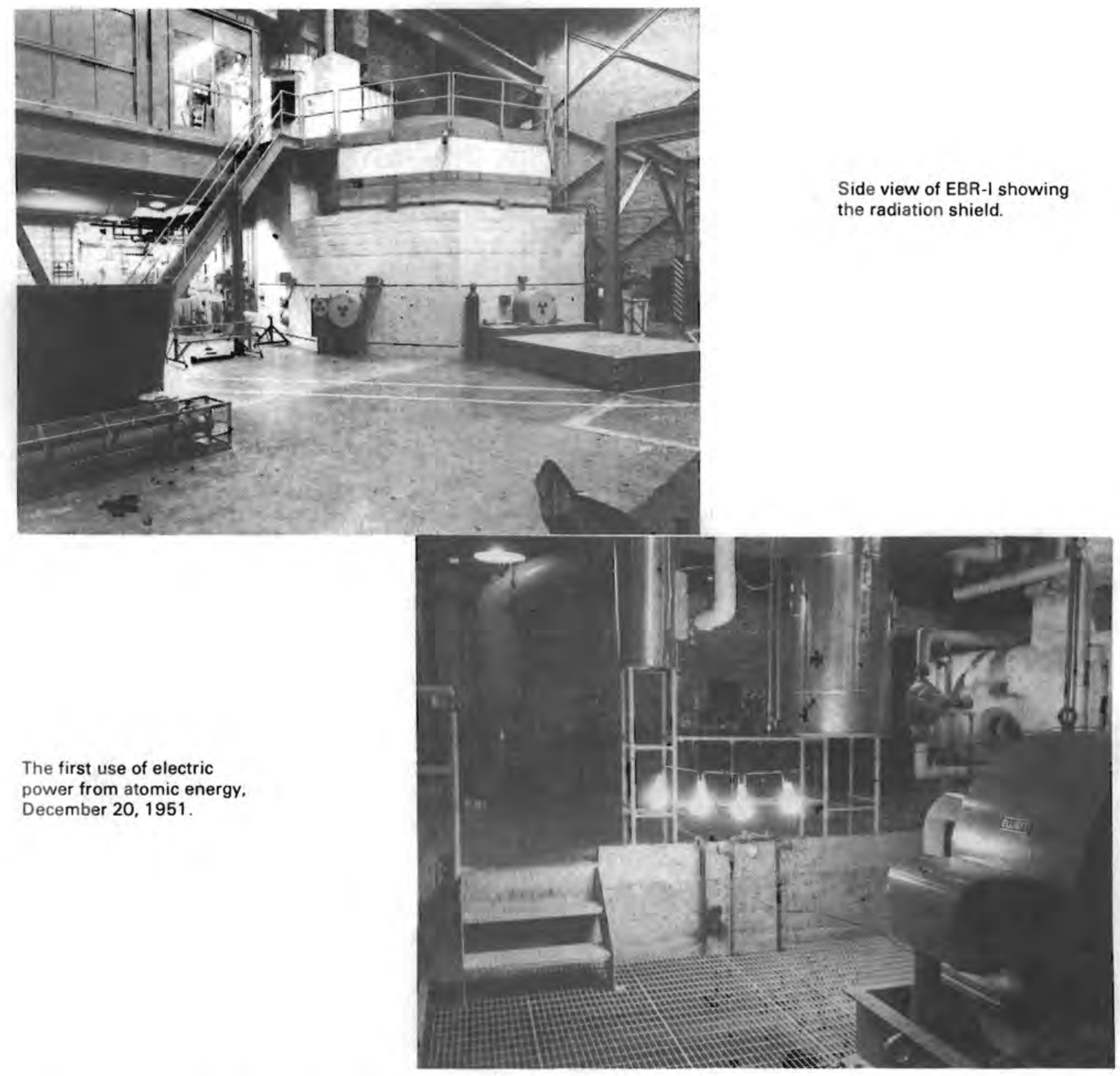

The Experimental Breeder Reactor (EBR-I) at Arco, Idaho. (Courtesy of Idaho Operations Office, Department of Energy.) 
A breeder is a reactor that takes advantage of the number of neutrons, an average of about three, emitted in fission caused by fast neutrons in the element plutonium. Although one neutron must be used to continue the chain reaction, another is available to be absorbed by the fertile isotope uranium-238 to produce additional plutonium. More fuel can be produced than is burned to obtain power.

The advantage of the breeder is that it can use the abundant uranium-238 (converted into plutonium-239) as fuel while other reactors use mainly the scarce uranium235. The total uranium resources of the earth are available if the breeder is adopted. The investigation of the commercial breeder is continuing in the U.S. and abroad.

By the mid-1960's two commercial versions of what is called the light water reactor had been developed. One is the pressurized water reactor, developed by Westinghouse Electric Corporation as a spinoff of the submarine program. The other is the boiling water reactor, first tested at Argonne National Laboratory and perfected by the General Electric Company. In the period 1965-1970, large numbers of reactors were ordered by U.S. utilities, and a major construction program was begun. By 1981 more than 70 power reactors were in operation in the U.S. and twice that number abroad. The photo shows the exterior of a typical nuclear power plant, and the schematic drawing shows the basic system. One other major type of reactor, CANDU, with heavy water, containing deuterium as the moderator, is in operation in Canada, India, and Pakistan. Gas-cooled reactors have been used extensively in the United Kingdom.

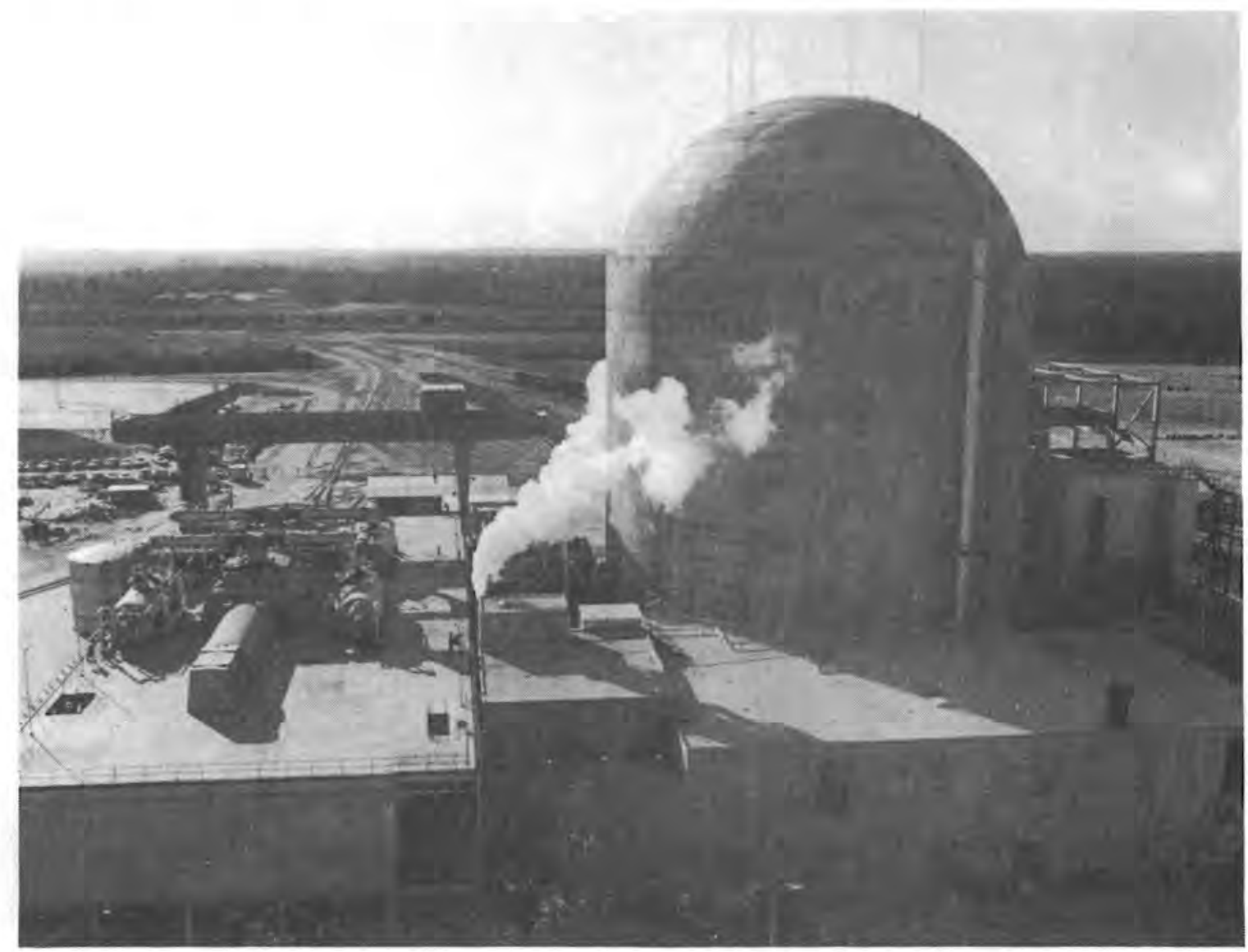

The H. B. Robinson nuclear plant at Hartsville, South Carolina, operated by the Carolina Power and Light Company. On the right is the reactor containment building; on the left is the turbine-generator. (Courtesy of George Zellars.) 


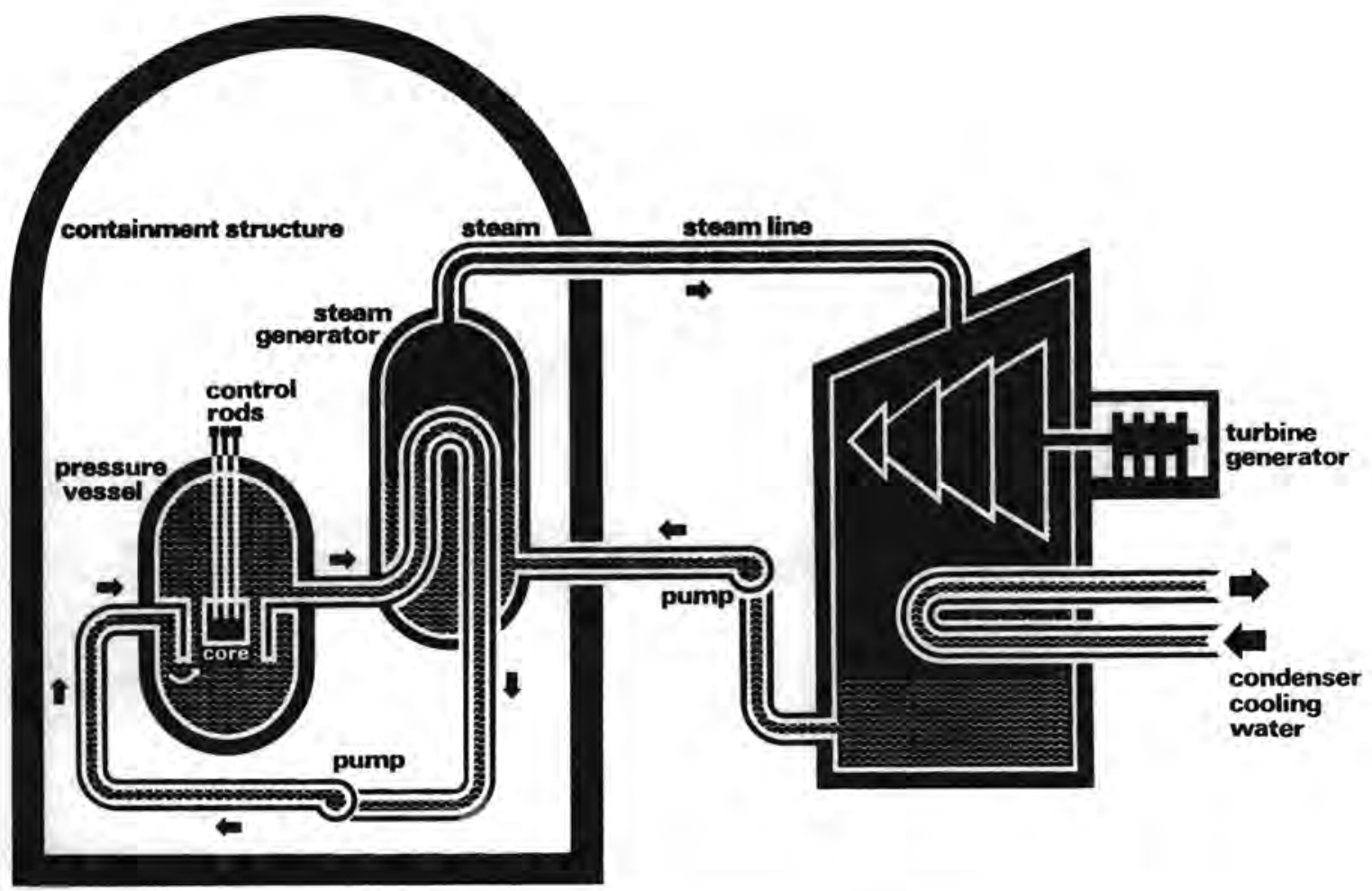

Flow of fluids in the pressurized water reactor (PWR). (Courtesy of Atomic Industrial Forum, Inc.)

A perspective of the present role of nuclear power in the U.S. can be gained from some statistics. First is the energy consumed from different basic fuels, shown in the following table. This consumption in-

\section{Total Energy Consumption in the U.S. by Primary Energy Type, 1979. (From Energy Data Report,}

U.S. Department of Energy, May 14, 1980.)

\begin{tabular}{lrrr} 
Energy Type & & $\begin{array}{c}\text { Consumption, } \\
10^{16} \text { Btu }^{*}\end{array}$ & Percent \\
\cline { 1 - 1 } Coal & 15.21 & 19.5 \\
Natural Gas & & 19.83 & 25.4 \\
Petroleum & & 37.06 & 47.4 \\
Hydroelectric & & 3.16 & 4.0 \\
Nuclear & 2.77 & 3.5 \\
Other & 0.15 & 0.2 \\
Total & 78.18 &
\end{tabular}

"British thermal units. One Btu is the amount of heat energy it takes to raise the temperature of $1 \mathrm{lb}$ of water one Fahrenheit degree. cludes transportation, building heating, process heat, and electricity. As we see in the other table, showing the amount of electricity produced in 1979, the electrical production by commercial nuclear power plants is comparable to that of plants using oil, natural gas, and hydroelectric.

\section{Electrical Energy Produced in the U.S., 1979.}

(From Monthly Energy Review, February 1980, Department of Energy.)

\begin{tabular}{lccc} 
Type of Plant & & $\begin{array}{c}\text { Energy, } \\
\text { billion kWh }\end{array}$ & Percent \\
\cline { 3 - 4 } Coal & & 1.076 & 47.8 \\
Natural Gas & & 0.330 & 14.7 \\
Oil & 0.303 & 13.5 \\
Hydroelectric & & 0.280 & 12.4 \\
Nuclear & & 0.255 & 11.4 \\
Other & 0.004 & & 0.2 \\
Total & 2.248 & & 100.0
\end{tabular}


. 


\section{USES OF ISOTOPES AND RADIATION}

In the period following World War II the Federal government through the AEC encouraged the development of new applications of radioisotopes and radiation. The objective was to find beneficial uses that would provide direct economic return, advance scientific knowledge, and more generally Improve human life. Areas in which uses were found included agricultural research, medical diagnosis, medical treatment, and Industrial applications.

A review of just a few applications of nuclear technology will provide historical background and set the stage for consideration of the management of low-level wastes, which are by-products of the use of isotopes as well as the operation of nuclear power plants.

\section{Tracers}

Complicated physical, chemical, and biological processes can be studied by the use of isotopes that "trace" the material of interest. For example, the radioisotope sodium-24, formed by neutron absorption in ordinary sodium-23, has a half-life of $15 \mathrm{hr}$. If a salt solution containing a small amount of sodium-24 is injected into a person's vein, the speed of blood flow through the body can be measured by the radioactive emanations.

The flow of oil or other fluid in a long pipeline is measured by injecting a small amount of radioisotope at one end and detecting its passage at the other end, as shown in the sketch.

The isotope phosphorus-32, half-life 14.3 days, can be mixed with the fertilizer applied to the roots of plants, as sketched here. The radioactive substance is then taken up by the plant, and its presence in the stem and leaves reveals where the fertilizer

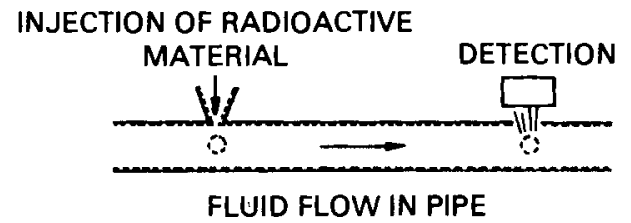

THE SPEED OF FLOW OF LIQUID IN A PIPE CAN BE FOUND BY TIMING THE ARRIVAL OF RADIOACTIVITY.

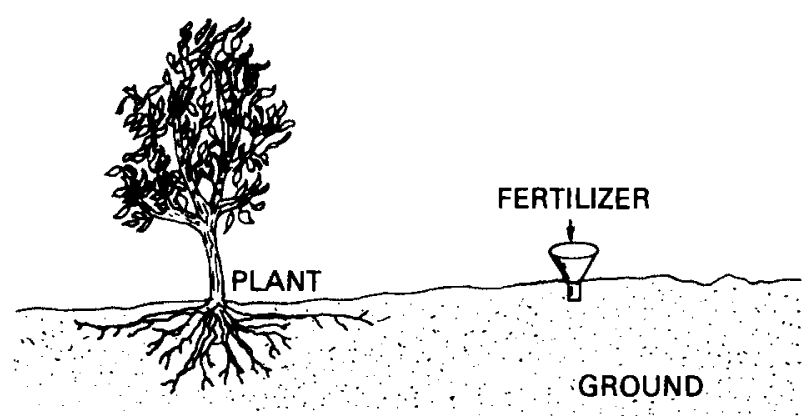

THE BEST WAY TO APPLY FERTILIZER CAN BE FOUND BY MEASURING THE ACTIVITY OF PHOSPHORUS-32 IN PLANT LEAVES

Two uses of radioactive tracers.

goes. Effects of placement, timing, and amounts of fertilizer can be deduced using this method.

If a radioactive species of an element is used in a chemical compound, the substance is said to be "labeled," i.e., given a special identification. Tritium (hydrogen-3), as an isotope of hydrogen with a half-life of $12.3 \mathrm{yr}$, and radiocarbon (carbon-14), halflife $5700 \mathrm{yr}$, are excellent isotopes for labeling organic compounds (which contain carbon, hydrogen, oxygen, and nitrogen) in a great variety of biological research studies. Many molecules have carbon atoms in different places, so that several differently labeled compounds can be formed. 


\section{Imaging}

Radioactive substances help physicians diagnose diseases in certain organs of the body through the method of imaging. The patient is given a solution containing a small concentration of a radioisotope that has a special affinity for tissue where a difficulty is suspected. The radiation pattern reveals information about size, shape, and condition of the organ. The table and the sketch indicate how this technique works.

\section{Radioisotopes Used in Imaging of Organs of the Body}

Iodine-125. 13I Thyrold, liver, kidney, heart, lung, brain Chromium-51 Spleen

Technetlum-99m Brain. liver. spleen, kidney, lung, bone Selenium-75 Pancreas

Strontium-85 Bone

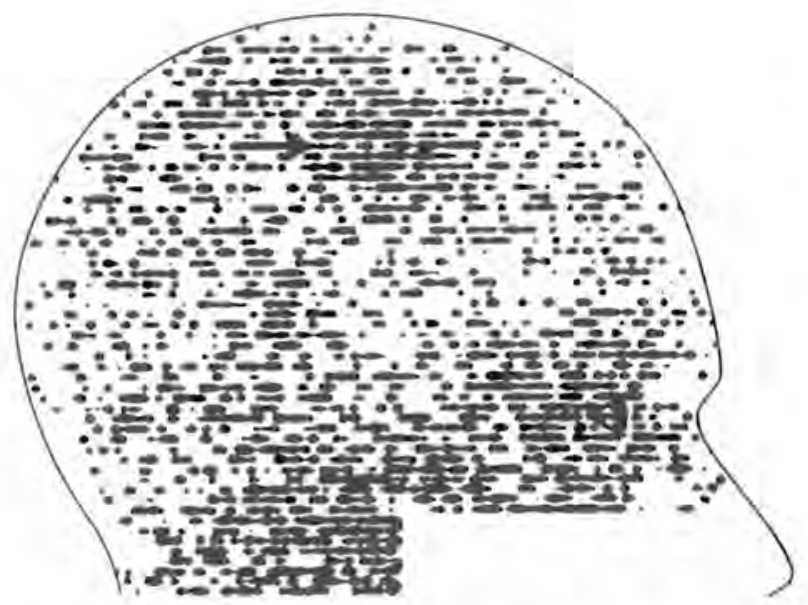

Locating a brain tumor by imaging-injecting a radioactive chemical. The arrow near the top of the head points to the malignancy. (Courtesy of Robert T. Morrison, M.D., Vancouver. British Columbia, General Hospital.)

\section{Therapy}

The treatment of disease by the use of radiation from radioisotopes is a common practice. Some of the diagnostic isotopes can be used with higher activity levels to irradiate organs, For example, radiation from phosphorus is applied in leukemia therapy. and that from iodine can treat hyperthyroid- ism or brain tumors. Several iodine isotopes are available: iodine-125, half-life 60 days, comes from the cyclotron, a particle accelerator: iodine-131, half-life 8-days, is a fission product.

The radiation from cobalt- 60 , half-life $5.3 \mathrm{yr}$, consists of two gamma rays with an average energy of $1.25 \mathrm{MeV}$. These rays are widely used for the treatment of cancer. The radiation may be applied from outside the body or inside the body by the use of radioactive needles.

\section{Radiography}

$\mathrm{X}$-rays are used routinely in medical diagnosis. However, in the inspection of metal parts in industry to find internal flaws as shown in the sketch, cobalt-60 gamma rays are preferable. Advantages are (1) the high energy for good penetration of metal, and (2) portability, achieved without the need for an electrical supply, as an x-ray machine requires.

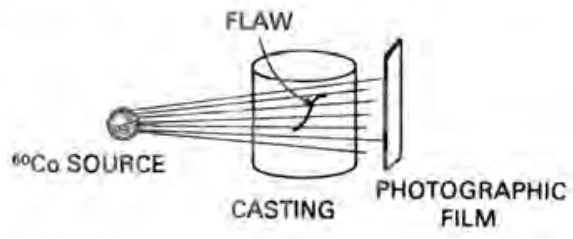

FLAW IN A LARGE METAL CASTING BEING DETECTED BY COBALT GAMMA RAYS

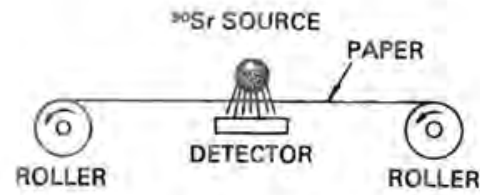

THICKNESS OF PAPER BEING MEASURED DURING MANUFACTURE.

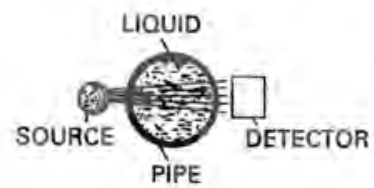

DENSITY OF A LIQUID FLOWING IN A PIPE BEING FOUND BY OBSERVING GAMMA RAY INTENSITY,

Industrial uses of radiation. 


\section{Gaging}

The rays from radioisotopes are useful for making a variety of measurements. One example is the continuous testing of the thickness of paper during its manufacture, as sketched here, by the use of beta particles from strontium-90. Variations are detected in the number of particles that get through the paper. In solls the moisture content is measured by the migration of neutrons coming from the reaction of alpha particles on beryllium. Also, as pictured here, the density of a fluid moving in a pipe can be foundwithout taking a sample-by detecting the gamma rays that get through the pipe.

\section{Dating}

The age of archeological and historical objects is found by the carbon-dating technique. There has always been a certain amount of carbon-14 in the atmosphere. Plants such as trees use $\mathrm{CO}_{2}$, and traces of this 5700-yr half-life isotope are deposited in their tissues. At any later time, measurement of the carbon- 14 content tells us the age of any artifact made from the plant.

The age of mineral deposits can be found by examining the ratio of uranium and lead isotopes, $238 \mathrm{U}$ and $206 \mathrm{~Pb}$. (Recall the uranium radioactive decay chain given on p. 11.) A recently deposited mineral would have little lead; an ancient one would have a great deal. The age of the earth has been estimated by this method.

\section{Neutron Activation Analysis}

The absorption of neutrons by many stable isotopes renders them radioactive, and detection of the resulting radiation indicates the amount and type of the original substance. Extremely minute amounts can be measured by this process called "neutron activation analysis." Examples are: industrial mercury pollution in water that is taken up by animals and deposited in their tissues; crime investigation, in which the composition of stolen goods is compared with the original stock; authentication of old paintings by testing the paint for agreement with that available in earlier times; measuring an alloy for minute traces of undesirable elements.

\section{Elimination of Pathogens}

Radiation is used to kill pathogens (disease-causing agents such as bacteria, fungi, and viruses). Similarly, foods can be kept from spolling by the use of gamma rays from cesium-137 or cobalt-60, without the use of chemicals that may be carcinogenic (that is, cancer-causing). The gamma rays from the long-lived ( $30.2 \mathrm{yr}$ ) fission product cesium-137 are used to sterilize medical supplies and pharmaceuticals. Also its rays, in doses around a million rads, destroy most of the pathogens in sewage sludge. The resulting product may be used safely as a fertilizer and soil conditioner. Recently, radiation has been found effective in killing the organisms that attack works of art.

\section{Elimination of Insect Pests}

Certain insect pests can be controlled by using a special radiation technique. An example is the screwworm fly, whose larvae can kill cattle; it was recently eradicated in the southern part of the U.S. Large numbers of males of that species were sterilized by gamma irradiation and then released. Since their mating resulted in no offspring, the screwworm population dropped rapidly.

\section{Remote Power Sources}

The heat produced by the beta-decay of strontium-90 is useful for thermoelectric generators, which produce small but steady, reliable amounts of electric power for remote locations. One navigational beacon powered by strontium- 90 has been in operation since 1965.

The isotope plutonlum-238, half-life $86 \mathrm{yr}$, is produced by neutron irradiation in a nuclear reactor. The isotope is an alpha emitter $(5.5 \mathrm{MeV})$ that is used in thermoelectric powergenerators for space missions. Equipment for the exploration of the moon 
by Apollo and of other planets by Pioneer, Viking, and Voyager has been powered by such radioisotope devices.

Some heart pacemakers, which provide regular stimuli to defective hearts, are also powered by small plutonium radioisotope generators, as pictured here. Another heavy artificial radioisotope americium-241, halflife $432 \mathrm{yr}$, is used in smoke detectors for use in fire alarms.

\section{Resultant Wastes}

Each application of isotopes involves a certain amount of radioactive waste. Some arises in producing the isotopes and in fabricating the devices; some remains after completing an experiment, or a medical test, or at the end of the useful life of a piece of equipment. The degree of hazard resulting from the radioactivity depends on many factors - the amount of material, the rate at which it decays, the energy and type of radiation. whether the substance can enter the human body, and how long it remains in the body. Obviously, an isotope of half-life $15 \mathrm{hr}$.

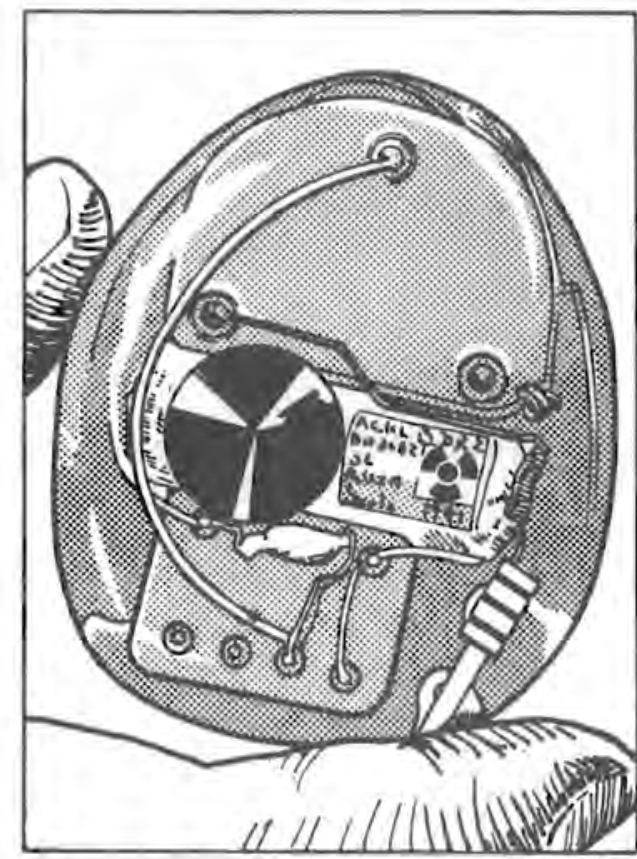

IMPLANTABLE PACEMAKER WITH NUCLEAR BATTERY. such as sodium-24, will be essentially gone after a week's storage, at which time the material can be discarded. Others such as 5.3 yr cobalt- 60 require precautions over a much longer time span.*

The foregoing account reveals the ironic fact that the very radiation that can harm human beings can also benefit health and general welfare.

People often ask why we do not use all the radioactive wastes for beneficial purposes and thus reduce the need for storage and disposal. The answer is that the amounts of radioactive material far exceed the demand for research or medical purposes. It is logical to use the wastes as a source of heat, but the cost of preparing suitable devices and providing the necessary protection is prohibitive except for a few applications. In summary, we produce more radioactive waste than can be economically used.

*A good discussion of both the uses of radiation and its effects is found in Eric J. Hall. Radiation and Life, Pergamon Press, 1976.

Plutonium-238 heart pacemaker. A thermoelectric cell provides the impulses: 


\section{CLASSIFICATION OF WASTES}

Radioactive materials fall into several categories according to their origin, the type of material present, and their level of radioactivity. The first and broadest distinction is:

Defense

Commercial.

\section{Defense Wastes}

Defense wastes were generated over the period during and since World War II, at three main Department of Energy (DOE) installations-the Hanford Site near Richland, Washington, Idaho Nuclear Engineering Laboratory, near Idaho Falls, Idaho, and the Savannah River Plant near Alken, South Carolina. Plutonium and other isotopes were separated from production reactor spent fuel at Hanford and at Savannah River, while naval propulsion reactor spent fuel was processed at Idaho Falls. In each case the chemIcal process left a residue of fission product waste. Other plutonium-contaminated wastes evolved from weapons fabrication at Rocky Flats, Colorado, and several other sites.

\section{Commercial Wastes}

Commercial wastes are those produced by reactors used for electrical power, by facilities used to process reactor fuels, and by a variety of institutions and industries. There is only a small volume of power reactor wastes since little reprocessing has been done to date. The level of radioactivity is higher, however, than that in defense wastes because the radioisotopes were produced more recently. The only reprocessing of commercial wastes done was by Nuclear Fuel Services, Incorporated, at West Valley, New York, in the period 1966 to 1972 . This plant was shut down because it was uneconomical to operate. Since 1972 spent fuel has been accumulating at nuclear power plants. This unreprocessed material is highly radioactive, and the total activity present now exceeds that of the earlier by-products of reprocessing. The volume of spent fuel from reactors is continuing to grow rapidly. Institutional and industrial wastes are generally of lower radioactivity level since most of them do not contain fission products.

Certain comparisons and contrasts between defense wastes and commercial reactor wastes should be noted. Both types stemmed from the operation of fission reactors, but, on the average, the defense material is less radioactive because of its age. On the other hand, its volume is great because less efficient methods of chemical separations were used during the war. Technically speaking, there are practically no separated commercial wastes; but there is a large amount of spent fuel from reactors that contains highly radioactive materials. Thus there is one waste disposal challenge with two distinct parts.

\section{Three Important Types of Wastes}

Another distinction among radioactive wastes is:

High-level

Transuranic

Low-level.

High-level wastes (HLW) are those resulting from the reprocessing of spent fuel from a reactor, either defense or commercial. Since most of the uranium and plutonium has been removed from the spent fuel, the residue consists mainly of fission products. However, there will be a small amount of plutonium and other isotopes heavier than uranium not separated by reprocessing. The 
HLW are the main candidates for disposal by burial deep in the ground. We shall discuss such geologic disposal in a later section.

Transuranic wastes (TRU) are those containing isotopes above uranium in the periodic table of chemical elements. They are the by-products of fuel assembly and weapons fabrication and of reprocessing operations. Their radioactivity level generally is low, but since they contain several long-lived isotopes, they must be managed separately. This classification has a transuranic content greater than 10 nanocuries * per gram of waste material. Isotopes include: plutonium, with the main isotope plutonium-239, halflife 24.131 yr; americium-241, $432 \mathrm{yr}$; americium-243,7370yr; curium-244, 18.1 yr; and curium-245, $8537 \mathrm{yr}$. A very long-lived isotope is also present-neptunium-237, 2.14 million yr. Transuranic wastes give off very little heat, and most of them can be handled by ordinary methods not requiring remote control. For many years they were buried in shallow trenches, but since 1970 they have been placed in retrievable storage. Some plutonium-contaminated soil at Rocky Flats in Colorado, resulting from fires and leaks, is being cleaned up.

Low-level wastes (LLW) often have relatively little radioactivity and contain practically no transuranic elements. Most of them require little or no shielding, may be handled by direct contact, and may be buried in nearsurface facilities. Part of the LLW, however, have high enough radioactivity that they must be given special treatment and disposal. Low-level wastes come from certain reactor operations and from many institutions such as hospitals, research organizations, and from industry. We will devote a later chapter to low-level wastes.

Tailings from the milling of uranium ore comprise another type of waste with a low level of radioactivity content, but they are not usually classified with low-level waste. We

"Recall that one nanocurie is 37 disintegrations per second. will discuss this special residue in a later chapter.

There is no standard accepted scheme forlisting types of wastes. Other waste classifications are found. For example, in the Department of Energy's environmental impact statement on commercial wastes, one finds these categories, each applied to the word "wastes": primary, secondary, nuclear power plant, spent fuel basin storage, fuel reprocessing plant, mixed-oxide fuel fabrication, decommissioning. In an official tabulation of waste inventories prepared by Oak Ridge National Laboratory for DOE, one finds these major classes: spent fuel, low-level waste, high-level waste, transuranic waste, mill tailings, remedial action waste. The last item refers to material from decontamination and decommissioning activities at several DOE sites.

\section{How Wastes Are Being Stored}

A large volume of wastes classified as high-level defense waste is now stored in underground tanks at three main government sites-Hanford, Idaho Falls, and Savannah River. Estimated amounts according to physical form are shown in the next table. In addition, there is a large volume of transuranic wastes (TRU) at DOE facilities, also listed in a table here. About an eighth of the TRU could be retrieved, at considerable expense. Not included in the table is a large volume of soil that is slightly contaminated with plutonium.

It is difficult for us to visualize very large quantities such as a million barrels of oil, a billion dollars, and a million cubic feet. To appreciate the total volume figure of 10,279 thousand cubic feet cited in the table, merely note that this is the same as a cube about $217 \mathrm{ft}$ on a side, i.e, sitting on and covering about one acre of land.

The Hanford project site was selected immediately after Fermi's successful test of the first nuclear reactor. The semi-arid area in southeastern Washington State (see the two maps) was selected because of its remoteness and the availability of water 
Existing Department of Energy Defense and Research High-Level Wastes, ${ }^{*}$ in thousands of cubic feet. (Reference Spent Fuel and Radioactive Waste Inventories and Projections as of December 31, 1980. DOE/NE-0017 [September 1981].)

\begin{tabular}{|c|c|c|c|c|c|c|}
\hline & Liquid & Salt Cake & Sludge & Calcine & $\begin{array}{l}\text { Cesium and } \\
\text { Strontium } \\
\text { Capsules }\end{array}$ & Total \\
\hline Hanford & 1377 & 3354 & 1730 & - & 0.060 & 6461 \\
\hline Idaho Falls & 330 & - & - & 73 & - & 403 \\
\hline Savannah River & 2112 & 932 & 371 & - & - & 3415 \\
\hline Subtotals & 3819 & 4286 & 2101 & 73 & 0.060 & 10,279 \\
\hline
\end{tabular}

"Liquid" is the acidic by-product of reprocessing; "sludge" results from the neutralization of the acidic solution; "salt cake" comes from evaporation of liquid; and "calcine" is the result of evaporation and high-temperature treatment. "Capsules" are special containers for separated radioisotopes.

Transuranic Wastes at DOE Facilities. (Reference Spent Fuel and Radioactive Waste Inventories and Projections as of December 31, 1980 , DOE/NE-0017 [September 1981].)
Location

Hanford Site

Idaho National Engineering Laboratory

Los Alamos National Laboratory Oak Ridge National Laboratory Savannah River Plant Nevada Test Site
Millions of cubic feet 5.90

2.02

0.41

0.22

1.09

less than 0.01 from the Columbia River. During World War II and afterward, the Federal government constructed there a total of nine plutonium production reactors, five chemical processing plants, and 149 underground storage tanks.

Leaks of radioactive liquid from the metal tanks at Hanford occurred, apparently because of deterioration of the metal with age plus inadequate attention. Fortunately, the site for the tanks was chosen in part for the impervious nature of the soll, and thus the radioactive material did not migrate very far. Since then, liquid wastes have been put in tanks with double walls to prevent further leaks. In a study published in 1978 by the
National Research Council, "Radioactive Wastes at the Hanford Reservation," it was noted that there had been no hazard to the public there, but that the wastes stored in underground tanks should be isolated.

The present program, started in 1968 , involves the chemical separation of the two 30-year half-life fission products cesium137 and strontium-90. They are transferred in liquid form to a nearby encapsulation facility, where they are solidified and placed in metal containers about $3 \mathrm{in}$. in diameter and $21 \mathrm{in}$. long. These capsules are stored under $13 \mathrm{ft}$ of water. A total of about 3000 capsules will have been filled by some time in the 1980's.

Within a year or so of removal of spent fuel from a reactor, most of the short-lived isotopes have decayed away. The cesium and strontium that remain provide most of the heat. Thus when these isotopes are removed and encapsulated, what one has is a very small volume of high-intensity solid wastesand a very large volume of much lower level wastes as salt cake. The residue is pumped back into the underground storage tanks as sludge awaiting final solidification for permanent disposal.*

\footnotetext{
"Reference: J. H. Roecker Radtoactlve Waste Management at Hanford, Rockwell International, 1979.
} 


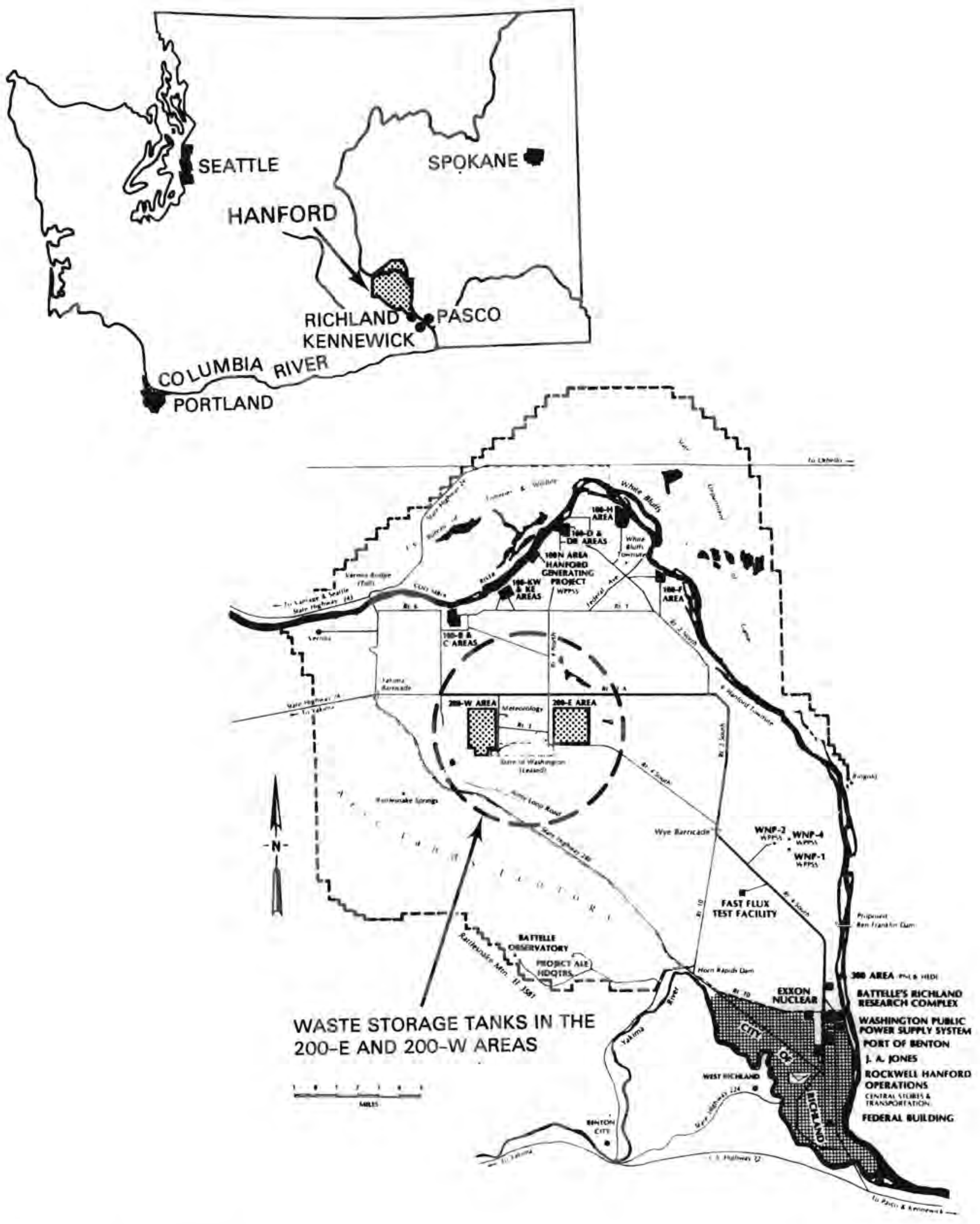

High-level defense waste storage at the Hanford Site in Washington State. 


\section{SPENT FUEL FROM NUCLEAR REACTORS}

The main reactor type in use in the U.S. and throughout the world is the light water reactor (LWR). It is so named because it uses ordinary water formed from hydrogen (not deuterium, as in a heavy water reactor). The water serves as a "moderator," the substance composed of light elements with which neutrons collide and slow down. The water also serves as a "coolant," the medium that removes the fission heat. Two types of LWRs are in use: the pressurized water reactor (PWR), in which the water is at high pressure and temperature but does not boil, and the boiling water reactor (BWR), in which steam is produced directly in the reactor bylimited boiling at relatively low pressure. Refer again to the coolant flow diagram for the PWR on p. 39.

\section{Reactors in the U.S. and Abroad}

Of the commercial light water nuclear reactors in the U.S., 75\% are PWR's, 25\% are BWR's, and there is one high-temperature, gas-cooled reactor. As of mid-1981, 76 reactors were in operation and 98 were under construction or on order. Some sites have more than one reactor; for example, Duke Power Company operates three reactorsOconee-1, -2, and -3 near Seneca, South Carolina.

The total power capacity of the 174 U.S. reactors is over 160,000 megawatts (160 gigawatts). If all were in full operation, they would provide about $25 \%$ of the nation's electricity production. The use of nuclear power is growing in countries outside the U.S. The following table shows the status of nuclear power worldwide. A total of 22 countries have operable nuclear power plants, and 14 more have reactors under construction.
World List of Nuclear Power Plants Operable, Under Construction, or on Order (30 MWe and Over) as of January $1,1981^{*}$

\begin{tabular}{|c|c|c|c|c|}
\hline \multirow[t]{2}{*}{ Country } & \multicolumn{2}{|c|}{ Net MWe } & \multicolumn{2}{|c|}{$\begin{array}{l}\text { Number of } \\
\text { Reactors }\end{array}$} \\
\hline & Total & Operable & Total & Operable \\
\hline 1. Argentina & 1,627 & 335 & 3 & 1 \\
\hline 2. Austria & 692 & & 1 & \\
\hline 3. Belg1um & 5,450 & 1.650 & 7 & 3 \\
\hline 4. Brazll & 3,116 & & 3 & \\
\hline 5. Bulgaria & 1,760 & 880 & 4 & 2 \\
\hline 6. Canada & 15,356 & 5,476 & 24 & 10 \\
\hline 7. Czechoslovakua & 4,510 & 990 & 11 & 3 \\
\hline 8. Egypt & 622 & & 1 & \\
\hline 9. Finland & 2.160 & 1.500 & 4 & 3 \\
\hline 10. France & 56.168 & 12,818 & 61 & 21 \\
\hline 11. Germany DR & 2,710 & 1.390 & 7 & 4 \\
\hline 12. Germany FR & 27,758 & 8,576 & 28 & 11 \\
\hline 13. Hungary & 1,760 & & 4 & \\
\hline 14. Indla & 1,684 & 602 & 8 & 3 \\
\hline 15. Iraq & 900 & & 1 & \\
\hline 16. Italy & 5,295 & 1,387 & 9 & 4 \\
\hline 17. Japan & 24,334 & 14,552 & 34 & 22 \\
\hline 18. S. Korea & 7,398 & 564 & 9 & 1 \\
\hline 19. Libya & 300 & & 1 & \\
\hline 20. Luxembourg & 1,250 & & 1 & \\
\hline 21. Mexico & 1,308 & & 2 & \\
\hline 22. Netherlands & 495 & 495 & 2 & 2 \\
\hline 23. Pakistan & 125 & 125 & 1 & 1 \\
\hline 24. Philippines & 620 & & 1 & \\
\hline 25. Poland & 880 & & 2 & \\
\hline 26. Rumania & 1,040 & & 2 & \\
\hline 27. S. Africa & 1,844 & & 2 & \\
\hline 28. Spain & 14,397 & 1,073 & 17 & 3 \\
\hline 29. Sweden & 9,410 & 5,500 & 12 & 8 \\
\hline 30. Switzerland & 4,947 & 1.940 & 7 & 4 \\
\hline 31. Tatwan & 4,924 & 1,208 & 6 & 2 \\
\hline 32. Turkey & 440 & & 1 & \\
\hline 33. United Kingdom & 14,420 & 8,080 & 43 & 33 \\
\hline 34. United States & 163,549 & 52,456 & 172 & 72 \\
\hline 35. U.S.S.R & 24,795 & 15,075 & 41 & 29 \\
\hline 36. Yugoslavia & 615 & & 1 & \\
\hline World Total & 408,659 & 136.672 & 533 & 242 \\
\hline
\end{tabular}

* Similar to a table in Prospects and Problems in the Transfer of Nuclear Technology by Massoud Simnad. GA-A15797, General Atomic Company, March 1980. 


\section{Nuclear Fuel Irradiation}

Modern reactors use uranium that has a higher percentage of ${ }^{235} \mathrm{U}(3 \%)$ than is found in nature $(0.7 \%)$. The fuel is in the form of uranium dioxide $\mathrm{UO}_{2}$ as small pellets about $3 / 16 \mathrm{in}$. in diameter and 3/8 in. long, as pictured here. These are inserted into 14 -ftlong, thin-walled (0.025 in.) tubes composed of an alloy of the element zirconium. Since the metal tube surrounds the fuel, it is often called "cladding"-a coating that prevents radioactive fission products from getting into the cooling water. The tube also provides support for the fuel. After the pellets have been introduced, the ends of the tubes are sealed to prevent water from getting in and gaseous fission products from getting out. Bundles of about 200 of the resulting fuel rods are formed, and the necessary space is maintained between rods as shown in the diagram. These fuel assemblies are about $8 \mathrm{in}$. on a side, are $14 \mathrm{ft}$ long and weigh about $1200 \mathrm{lb}$, but are readily handled with suitable hoists and cranes.

About 180 of the assemblies are closely packed vertically into what is called the reactor core, located in the lower part of the reactor vessel, pictured in the diagram. This vessel has a thick steel wall to withstand the

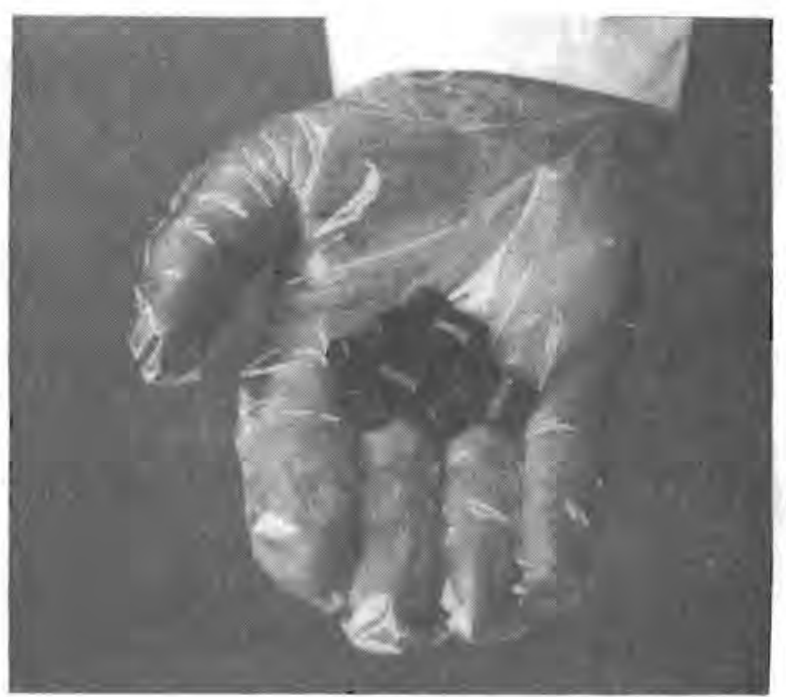

Fuel pellets for a pressurized water reactor. The uranium oxide contains ${ }^{235} \mathrm{U}$ at $3 \%$ enrichment. (Courtesy of AgipNucleare.)

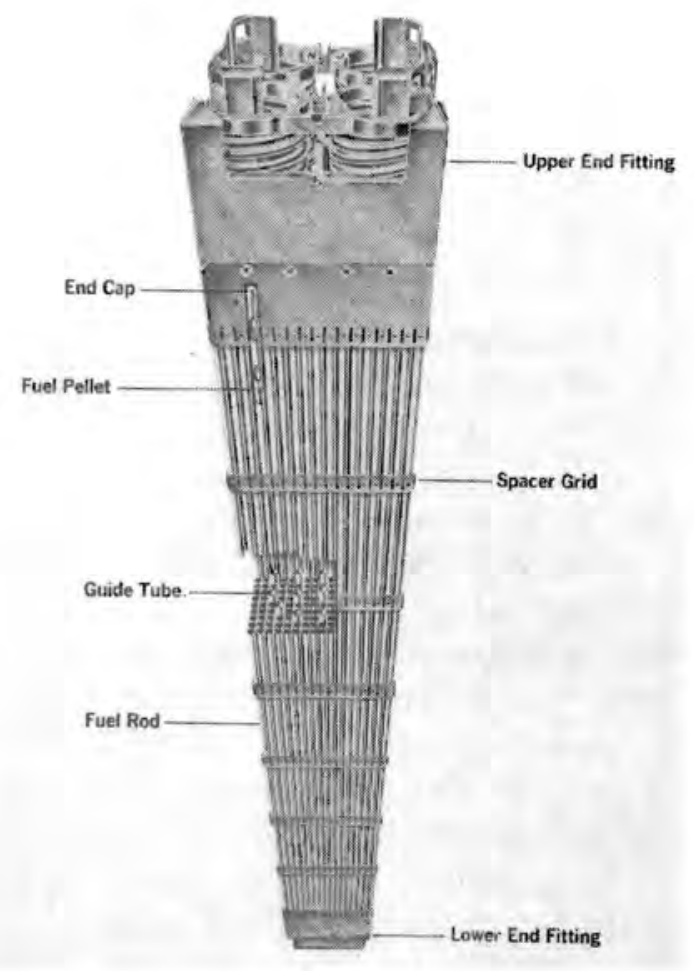

Nuclear reactor fuel assembly. Bundles of 200 fuel rods, $14 \mathrm{ft}$ in length, $8 \mathrm{in}$. on a side, are formed into an assembly. (Courtesy of Babcock and Wilcox Company)

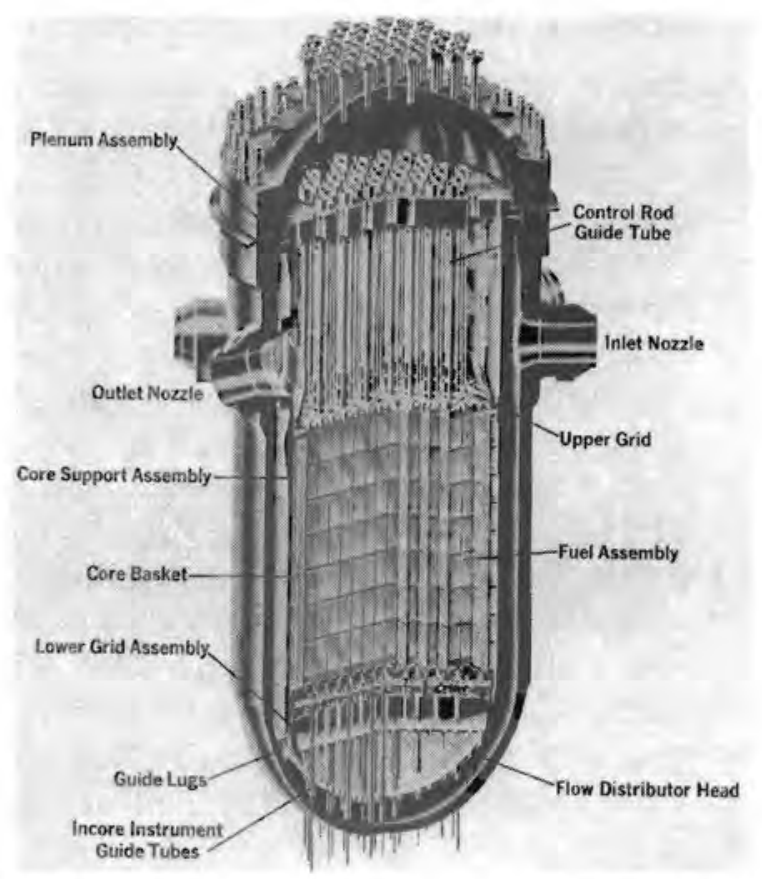

Reactor vessel of a pressurized water reactor. Cooling water enters the side, goes down the inside wall of the vessel, then comes up through the core containing uranium. (Courtesy of Babcock and Wilcox Company) 
high pressure, $2200 \mathrm{lb}$ per square inch, resulting from operation with water at $600^{\circ} \mathrm{F}$. Cooling water enters the vessel through large pipes welded to the side, comes down around the outside of the core, and is forced up past the fuel tubes, removing the heat of fission and keeping the rods at a reasonable temperature. As fuel is consumed, the reactor is held at a steady power level by adjusting the concentration of the neutron-absorbing boric acid in the cooling water. To change the power of the reactor or to shut the reactor down, the position of special metal control rods is adjusted.

Each typical operating period of a reactor is $1 \mathrm{yr}$. At the end of that period, the operators take the top of the reactor vessel off and remove about one-third (60) of the assemblies. This highly neutron-irradiated fuel is called "spent fuel" since it cannot sustain a chain reaction. However, it still contains some of the original 235U and most of the 238U. The remaining two-thirds are rearranged to give the best power, and a fresh one-third is inserted. The vessel is then closed and operation begins again.

\section{New Isotopes in Used Fuel}

During the 3 years that the fuel has been in the reactor, the irradiation of assemblies by neutrons has consumed some of the uranium and produced some new material. The content of uranium-235 as the main fissile material has been reduced from about $3 \%$ to about $1 \%$, while the uranium-238 has gone down from $97 \%$ to $94 \%$. The main new isotope is plutonlum-239, formed by the reaction

$$
\begin{aligned}
& \text { neutron }+ \text { uranium-238 } \rightarrow \text { plu- } \\
& \text { tonium-239 }
\end{aligned}
$$

There are actually three steps in the process. First, uranium-238 captures a neutron to become uranium-239, which is unstable, decaying with half-life $23.5 \mathrm{~min}$ into nep- tunium-239, which decays with half-life 2.35 days into plutonium-239. This isotope of plutonium is fissile, and complements the uranium-235 as fuel. It has a half-life of $24,131 \mathrm{yr}$, emitting an alpha particle of $5.1 \mathrm{MeV}$ energy. Other isotopes of elements above uranium in the periodic table (transuranic elements) are also produced. By successive neutron absorption 239Pu becomes $240 \mathrm{Pu}$, fissile $241 \mathrm{Pu}, 242 \mathrm{Pu}$, and short-lived 243Pu. The following chart shows the "before" and "after" compositions of spent fuel.

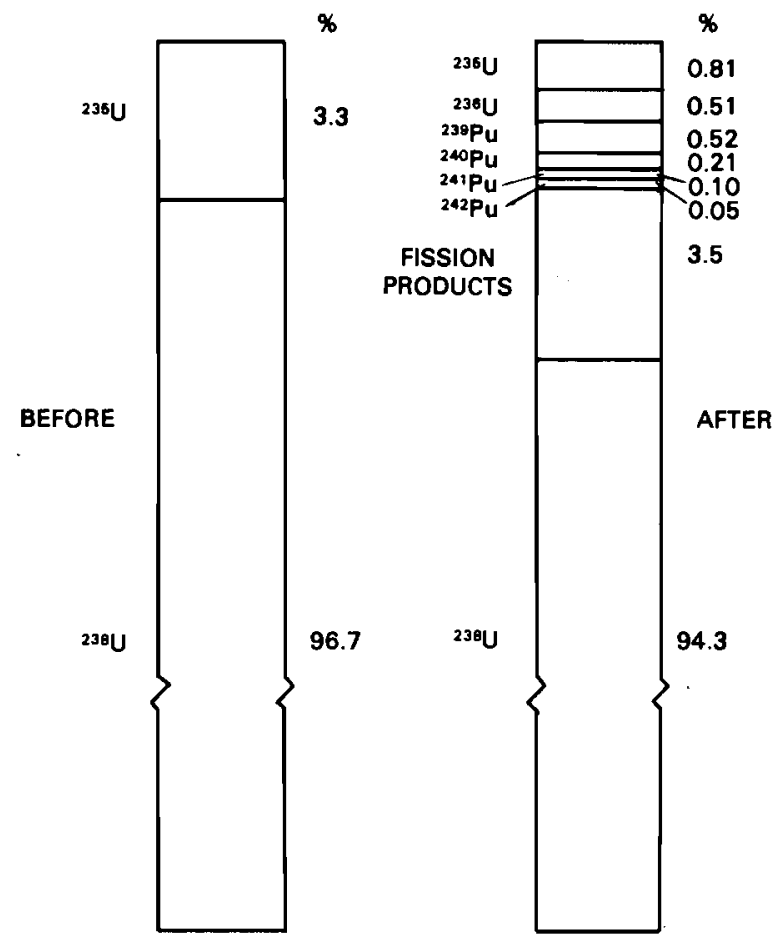

Compositions (in percent) of fresh fuel and spent fuel. Uranium235 is burned to form fission products and ${ }^{236} \mathrm{U} ;{ }^{238} \mathrm{U}$ is converted into plutonium

The spent fuel still has most of its original 238U and a fairly high fissile fuel content. The total of $235 \mathrm{U}, 239 \mathrm{Pu}$, and $241 \mathrm{Pu}$ is $1.43 \%$. The fuel removed is not really as "spent" as it might seem. The light-water reactors are called "converters" because they transform some of the ${ }^{238} \mathrm{U}$ into plutonium isotopes. 


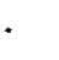


STORAGE OF SPENT FUEL

\section{Radiation and Heat from Spent Fuel}

The spent fuel taken from the reactor after it has operated for a year is highly radioactive. The potential radiation dosage at contact with the surface of the fuel assemblies then is millions of rems per hour. Recalling that the lethal dose is around 400 rems, we can see that the fuel must be handled with great care. Moreover, it would be difficult to steal spent fuel without experiencing serious personal risk.

The spent fuel continues to be a source of heat and radiation after removal from the reactor, and thus is stored under water in a deep pool at the reactor site. The water keeps the fuel assemblies cool, and it acts as a shielding material to protect workers from gamma radiation. The water is kept free of minerals that would corrode the fuel tubes.

\section{Fuel Storage Methods}

The fuel is no longer suitable for operation in a reactor, but precautions must still be taken to avoid accidental criticality. The assemblies are kept separated in the pool by metal racks that leave about $1 \mathrm{ft}$ between centers. This grid structure is composed of metal containing boron, which absorbs neutrons and prevents their multiplication. The diagrams depict these fuel storage racks, and the photograph shows a spent fuel pool.

Electric utilities that built reactors in the 1960's and early 1970's expected to send their spent fuel to a reprocessing plant within a few months after its removal from the reactor. Indeed, the Barnwell Nuclear Fuels Plant was constructed at Barnwell, South Carolina, for this purpose. There uranium and plutonium were to be extracted and recycled, with the fission product wastes stored for "cooling" and ultimate disposal.

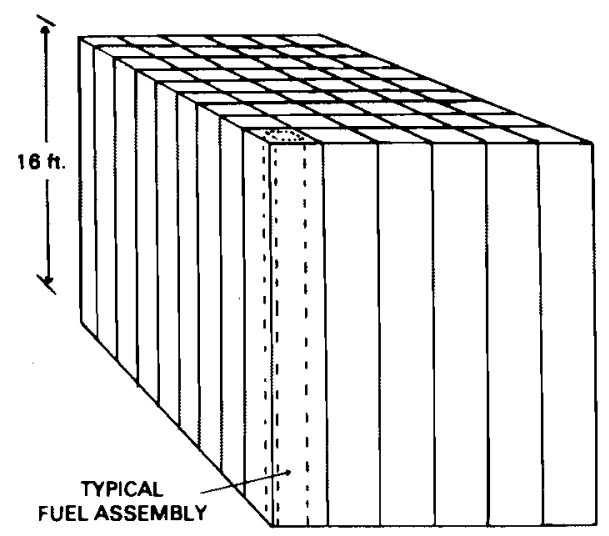

PERSPECTIVE VIEW OF METAL RACK, LOCATED IN A WATER POOL.

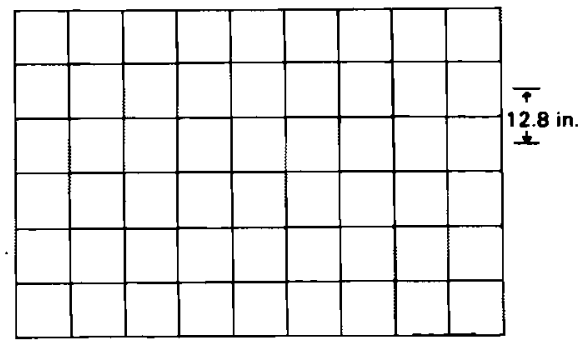

TOP VIEW OF THE 6 WY 9 ARRAY OF OPENINGS FOR SPENT FUEL.

Spent fuel storage rack to hold 54 fuel assemblies.

However, a 1977 Federal moratorium on reprocessing was instituted, requiring the utilities to keep the spent fuel at the reactor site. The requirement to store more fuel than anticipated was met by building closerpacked racks, reducing the spacing between fuel assemblies from 20 in. to 12 in. Storage in existing pools is only a temporary measure because the spent fuel keeps comingabout 60 assemblies a year for each operating reactor. Some companies have sought to transfer fuel from an operating plant to the pool of a plant still under construction. A limited amount of storage is available at the reprocessing plants at Barnwell and at Morris, Illinois; but these will fill up in time, and additional storage will be required. 


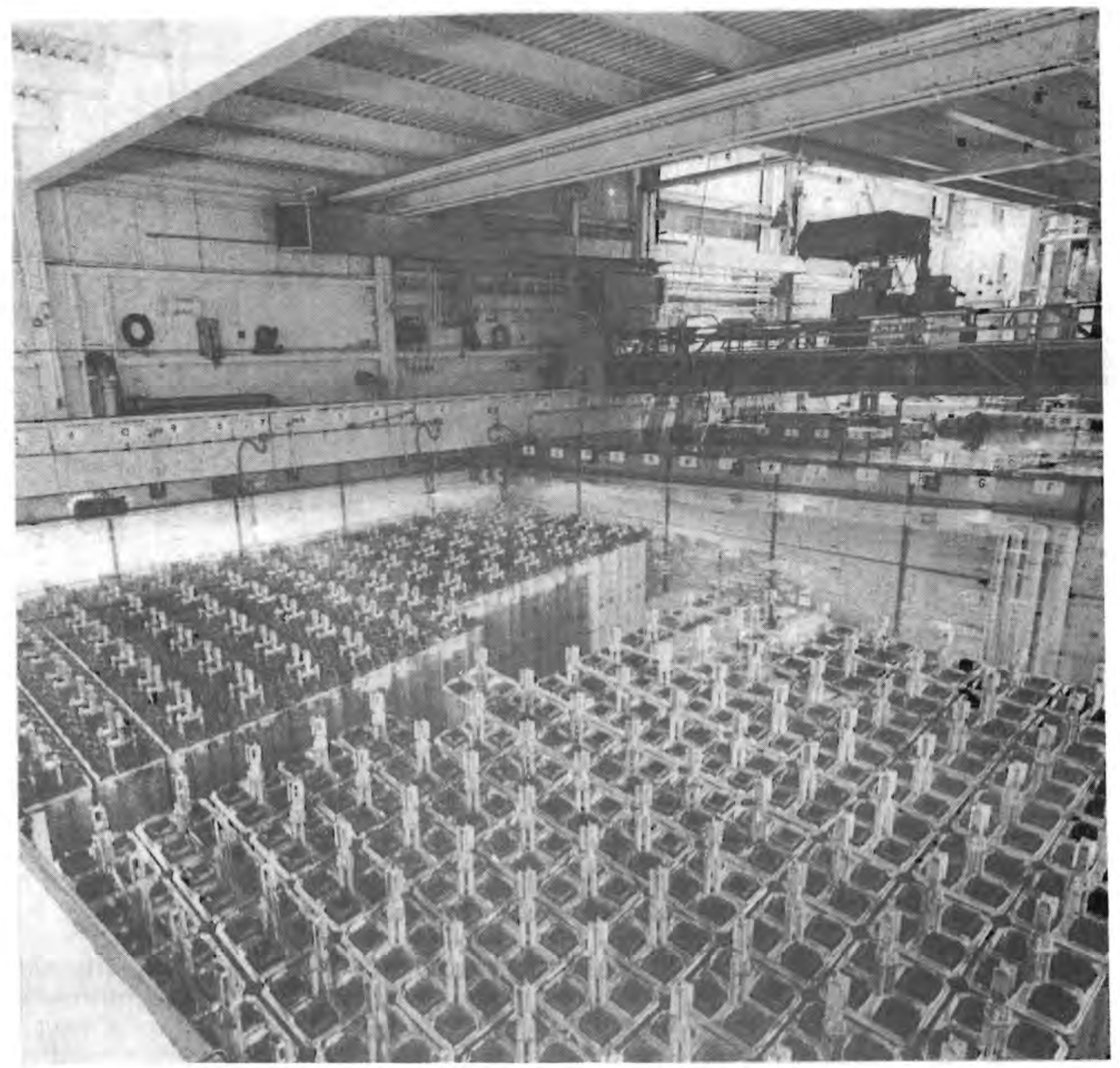

Water pool for storage of spent fuel at the Morris, Illinois, facility. (Courtesy of General Electric Company.)

This necessary storage for spent fuel may take the form of a central facility at some location other than the reactor plants. There, the spent fuel may be stored in water basins or may be stored dry in suitable containers. Several techniques for dry storage have been studied: (a) an air-cooled, heavily-shielded concrete vault, (b) a caisson, consisting of a metal-lined hole in the ground with a concrete plug, and (c) an above-ground concrete cask with natural convection air cooling.

\section{Weights and Volumes}

Eventually a choice has to be made among reprocessing the spent fuel, storing it indefinitely in the form as removed from the reactor, or disposing of it by burial or other techniques. Let us consider how much material is involved. The spent fuel assembly has a uranium weight of around $1000 \mathrm{lb}$; other metals add some $200 \mathrm{lb}$. The volume of one assembly is $6.7 \mathrm{ft}^{3}$, so the 60 assemblies 
removed per year from each reactor give a total of around $400 \mathrm{ft}^{3}$ of spent fuel.

The amounts of actual radioactive material in the spent fuel are comparatively small. From the previous chapter we saw that fission products have a weight of $3.5 \%$ of the spent fuel. If the fuel were reprocessed, these would be extracted, as would most of the plutonium isotopes. The uranium would be cleaned up in preparation for reuse. For each $1200-1 b$ assembly there would be only around $35 \mathrm{lb}$ of fission product waste. For 60 assemblies discharged per year this is $2100 \mathrm{lb}$, or about one ton. Assuming that the weight of these fission product elements on the average is ten times that of water (which weighs $62.4 \mathrm{lb}$ per cubic foot), their actual volume would be only $3.4 \mathrm{ft}^{3}$, which is $18 \mathrm{in}$. on a side. The material, however, would not be stored or disposed of in such a concentrated form because its radioactivity would produce intense heat. The wastes would be diluted by some solid before being discarded. This simple sketch compares volumes of fission products and spent fuel produced by one reactor in a year.

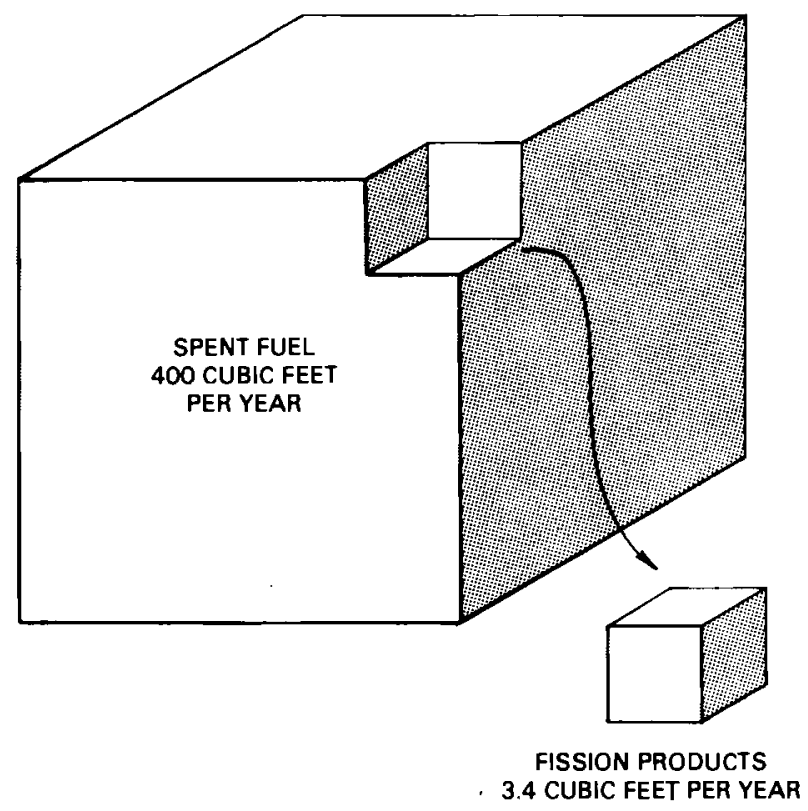

Comparison of the volume of fission products with the volume of spent fuel. The numbers refer to the production by one reactor in a year.

In the next chapter we consider the processes that yield nuclear fuel and the choices of what to do with used fuel. 



\section{REPROCESSING, RECYCLING, AND RESOURCES}

Between the mining of uranium and the final disposal of waste products are many processes; these comprise the nuclear fuel cycle. The term "front end" of the cycle refers to preparation of uranium for use in power reactors; the term "back end" refers to operations performed on spent fuel.

\section{The "Once-Through" Cycle}

The sketch outlines the steps in the "once-through" cycle for nuclear reactors as it has been operating in the nuclear industry. First, exploration for new uranium deposits is done. Then uranium is mined in several western states of the U.S.-mainly Colorado, Utah, and Wyoming. Natural uranium $(0.7 \% 235 \mathrm{U}, 99.3 \% 238 \mathrm{U})$ is extracted from the low-grade ores by a milling process, leaving a large waste residue called mill "tailings."

A complex uranium compound called "yellow cake" is the useful product purified by chemical refining. The compound is then converted to uranium hexafluoride, $\mathrm{UF}_{6}$, a gas at ordinary temperatures and pressures. $\mathrm{UF}_{6}$ is shipped to the isotope separation plant, where a process of gaseous diffusion separates an enriched or product stream of $235 \mathrm{U}$ content greater than that of natural uranium from a "tails" stream of depleted uranium. The slightly enriched uranium (about 3\% 235U), still as gaseous $\mathrm{UF}_{6}$, goes to the fuel fabrication plant, where it is converted to the form of solid pellets of uranium dioxide, $\mathrm{UO}_{2}$. The pellets are inserted into tubes to form fuel rods, which are sealed, tested, and assembled into bundles for shipment to the reactor site. Each fuel assembly remains in the converter reactor for about three years, after which it is removed and placed in a storage pool for radioactive "cooling."

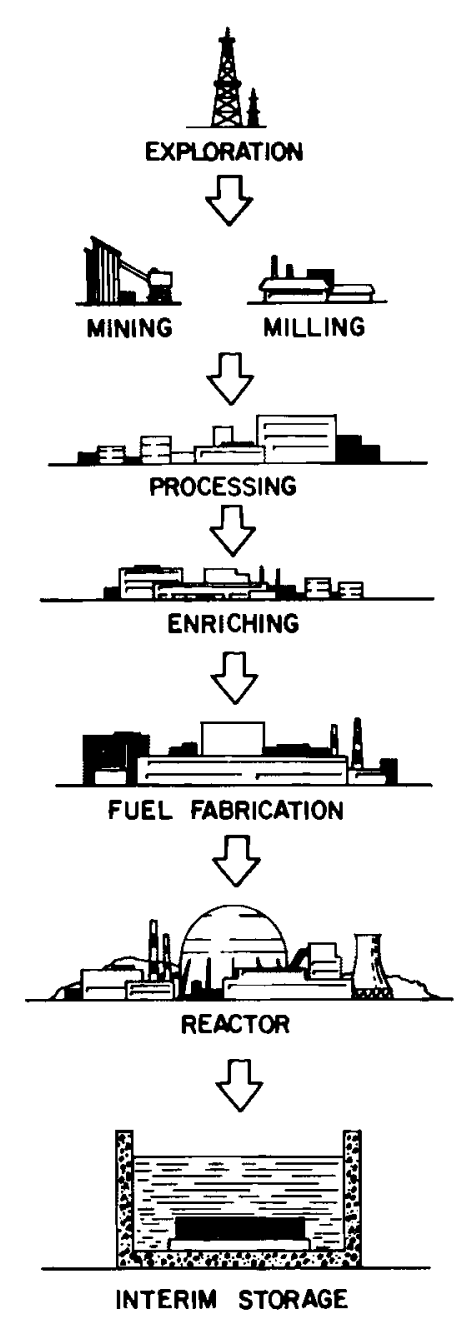

The nuclear fuel cycle, carrying uranium from the mine to spent fuel storage in water pools.

There are now two choices of what to do with the spent fuel. The first is to continue interim storage in water-filled pools in a "once-through" cycle. The fuel assemblies would then be stored or disposed of intact or in bundles of fuel rods in a waste repository. The flow of materials and the wastes that arise in such a cycle are shown in the diagram by dashed lines. 


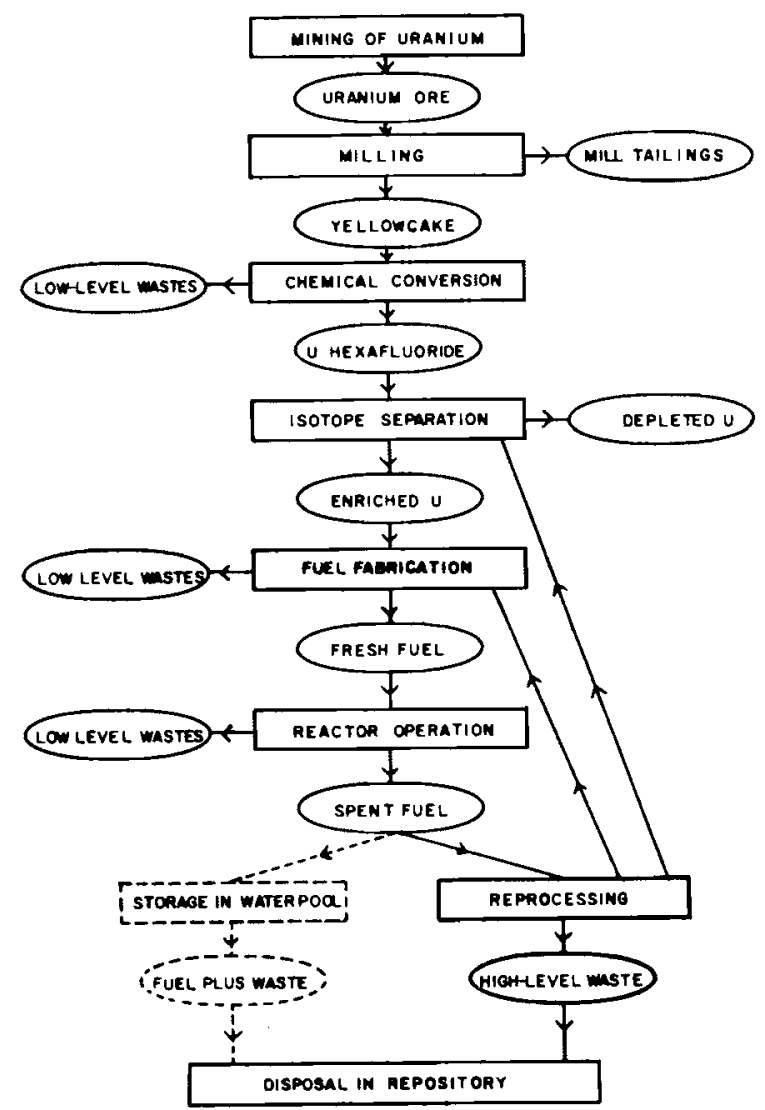

Wastes in the nuclear fuel cycle. Two alternatives are shownthe once-through cycle and a recycle of uranium and plutonium.

\section{Reprocessing of Spent Fuel}

The long-range expectation by the nuclear industry was to perform "reprocessing," a material recovery operation that has been successfully done for many years.* Thus spent fuel would be sent to a plant such as the one at Barnwell, South Carolina, for reprocessing to separate useful fuels from waste materials. There fuel assemblies can be cut in pieces, the contents of the fuel tubes dissolved with nitric acid, and a solvent extraction (Purex) process applied to separate the three main groups of spent fuel materials-uranium, plutonium, and fission products. The flow of materials in the more general recycle, along with wastes, is shown also in the diagram. The uranium in

*For an excellent discussion of reprocessing, we recommend the article by William P. Bebbington. "The Reprocessing of Nuclear Fuels," Scienttfic American, December 1976, p. 30. spent fuel is still above natural uranium in $235 \mathrm{U}$ content. It can be returned to the isotope separation plant for re-enrichment and reuse.

There are several advantages of reprocessing, in contrast to a "once-through" use of nuclear materials. The valuable energy resources contained in fissile plutonium-239 and plutonium-241 are made available. By recycling uranium and plutonium the amount of mining and milling of new uranium ore is reduced and the uranium reserves are conserved. The waste volumes to dispose of are smaller for the fission products separated in reprocessing than for spent fuel. There is also some indication that rare strategic metals could be extracted from the fission products. Disadvantages include the extra cost of the reprocessing facility and its operation, the radiation exposure to workers at the facility, and the increased accessibility of plutonium, which concelvably could be diverted and used by terrorists. The plutonium can also be recycled to the light water reactors. It would be blended with slightly enriched uranium to form a fuel called "mixed oxide" (MOX), which is a combination of $\mathrm{UO}_{2}$ and $\mathrm{PuO}_{2}$.

Reprocessing was banned as a U.S. national policy by President Carter in 1977 because it makes plutonium more readily accessible. It was hoped that countries not yet having nuclear weapons would thus be discouraged from developing reprocessing facilities to obtain plutonium.

\section{The Breeder Reactor}

The fissile content of spent fuel is equivalent to uranium enriched to $1.43 \%$ in $235 \mathrm{U}$, which is twice the fissile content of natural uranium. More than half the atoms are plutonlum, which can be used as starting fuel for "breeder" reactors. The breeder is a reactor that does not have a neutron moderator, and thus fission is initiated by fast neutrons. When fueled by plutonium with the core surrounded by $238 \mathrm{U}$ as a "blanket." the breeder produces more fissile material than it burns. Over a period of 10 to $20 \mathrm{yr}$ it can 
create a new core of plutonium. The great virtue of the breeder is that it makes use of the more abundant isotope of $238 \mathrm{U}$ rather than depending on the less abundant 235U as in the converter reactor. In the oncethrough mode, the latter uses only half of the 235U in natural uranium. The available uranium supply would last around 50 times longer if the breeder cycle were adopted.

Decisions about the breeder affect the management of nuclear wastes. Some believe that the breeder is undesirable because of the production of plutonium, which is both toxic and usable for nuclear weapons. Others, however, note that the safest place to put plutonium is in a reactor, which is itself a very strong source of radiation. As breeder reactors are built and go into operation, they may be fueled initially with fissile plutonium from light water reactors. As the fertile material they can use the large stockpile of depleted uranium from uranium isotope separation over many years. This has less 235U (about 0.2\%) than natural uranium $(0.7 \%)$, but only the $238 \mathrm{U}$ is needed to produce new plutonium in the breeder.

We now have a picture of the present nuclear fuel cycle and possible variations on it involving recycling of uranium or plutonium. As was seen in the diagram, some radioactive wastes are produced in every stage. The disposal of these in an environmentally sound way will be discussed in subsequent chapters. 



\section{URANIUM MILL TAILINGS}

The amount of uranium in ore is quite small, about $0.2 \%$ by weight in the U.S. Thus there is a large residue called "tailings" from the chemical processing of ore, called milling. Each 1000 megawatt electric nuclear reactor requires about 150 tons per year of natural uranium. The total ore required is 500 times this figure. The map shown locates the main areas of uranium mining in the United States.

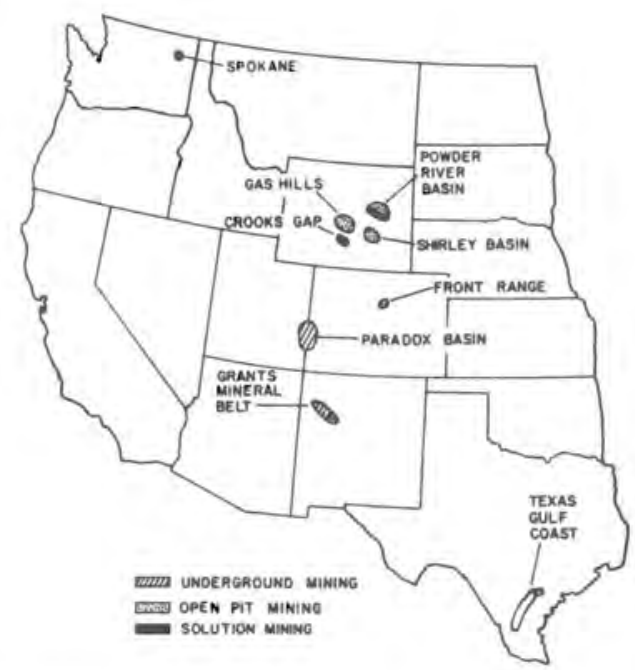

Significant uranium mining areas of the U.S. (From report GJO-108(77) of the Grand Junction Office of Department of Energy.)

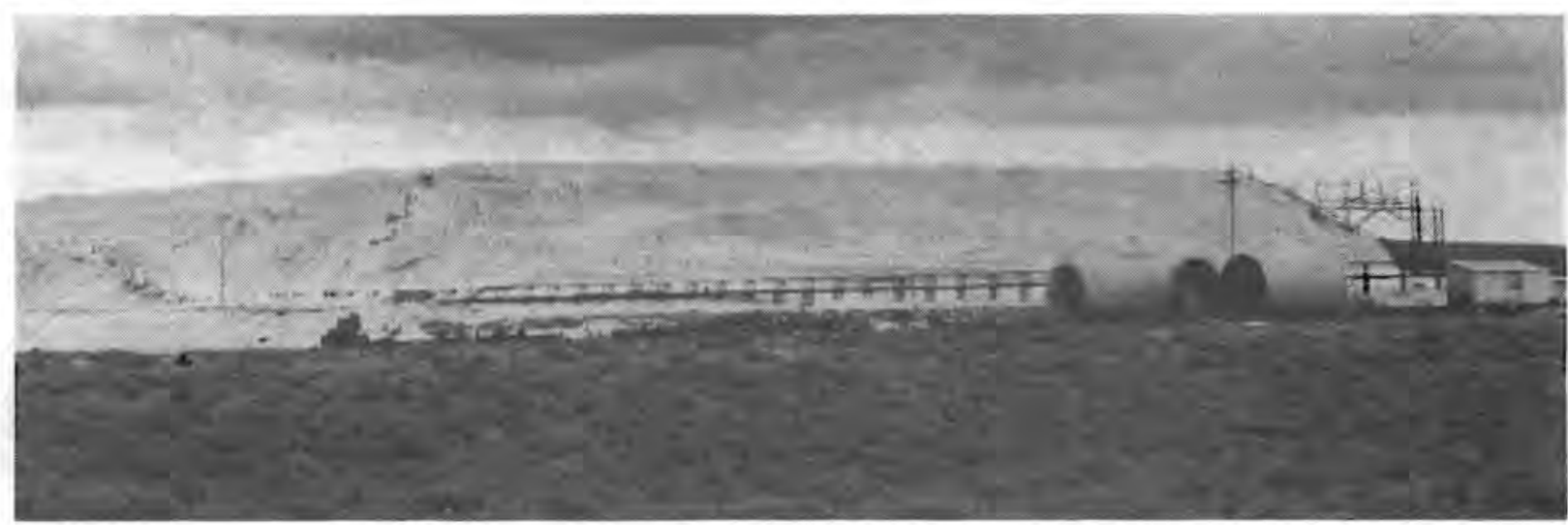

A mill tailings pile, resulting from the first processing of uranium ore. (Courtesy of U.S. Nuclear Regulatory Commission.)
The tailings contain elements such as thorium and radium, which are mainly byproducts of the decay of $238 \mathrm{U}$ as was shown in the table on p. 11. Some of these chemicals are not removed in the extraction of uranium. Generally, tailings leave the mill as a liquid sludge and are allowed to dry. They are collected in piles within enclosures. The photograph here shows a typical tailings pile. It is necessary to take precaution to prevent tailings from contaminating ground water or getting into the air as dust. For their radioactive content tailings are no more dangerous than the ore that was removed from the earth, but since the material has been brought to the surface and been converted to a new form, it can pose a hazard unless protective layers of earth are applied.

\section{Radioactivity in Tailings}

The tailings are classified as radioactive waste separately from the "low-level wastes" from power production and from isotope uses. The amount of radiation hazard to the general public in the surrounding region from tailings is relatively small, but in some instances the residue has been used in con- 
structing buildings and homes, and this can give a long-term radiation exposure to the occupants.

One of the isotopes of main concern is radon-222. As we saw on p. 11 , it is the daughter of radium-226, which has a halflife of 1600 yr. Radon is produced continuously by the decay of radium left with the ore residue. Radon-222 has a short half-life, 3.8 days, and decays in a chain with four shortlived products. The element radon is an inert gas of the same type as helium and neon. Thus, much of it can come out through the pores of the tallings and the soil into the atmosphere and be carried some distance by wind before it decays. The daughters of radon can deposit on surfaces as contamination or can deposit in lung tissue of animals and human beings.

Over the years, some 140 million tons of tailings have accumulated, and 10 to 15 million tons more are added each year. Earlier there was little concern about the potential hazard. Since almost all earth and rock contains uranium and thus radium, the tailings were treated essentially as just another form of ore residue. Regulations set by the states were not very rigorous and their enforcement was often lax.* It was not until 1966 that mill owners were encouraged to take better care of the tailings to stop erosion and prevent their use for construction.

The passage of the National Environmental Policy Act (NEPA) resulted in a new look at the situation and prompted the Nuclear Regulatory Commission to initiate a generic environmental impact statement (EIS) on mill tatlings. The EIS has some specific guidelines about ways to handle tailings. It recommends that tailings be located

\footnotetext{
"Vern Rogers, "Uranium Mill Tailings-Regulation and Legislation." In Proceedings of the Atomic Industrial Forum Workshop on the Management of Spent Fuel and Radioactive Wastes, September 16-19, 1979. Also see Luther Carter, "Uranium Mill Tallings: Congress Addresses a LongNeglected Problem." In Sclence. October 13, 1978, pp. $191 \mathrm{ff}$.
}

remote from population centers, preferably underground, with a cover 3 meters thick to keep the radon radioactivity that escapes below $2 \mathrm{pCi}$ per square meter per second. It also recommends that the bottom and walls of a tailings pit be covered with a thick layer of clay and that vegetation be grown above the pit to resist erosion.

\section{Other Sources of Radon}

Some studies show that the potential hazard to the public from mill tailings can be larger than that from other places in the nuclear fuel cycle, including reactors. The exact degree of hazard from radon and its daughters is difficult to specify, however, because there seems to be little or no correlation between lung cancer incidence and geographical areas having a high level of radon. Some conclusions in the literature are that other pollutants obscure the data and that the linear hypothesis of radiation damage may be too conservative and lead to overestimating the damage. The release of radon is not unique to uranium mining, since the mining of phosphates for fertilizers brings up radon in comparable amounts.

A sidelight on the subject of tailings is that naturally-occurring radon is also released by most building materials and also from the ground under homes. Efforts to conserve energy by eliminating air leaks have the effect of raising the radon concentration in homes and other buildings. There are technical answers, but their cost needs to be considered in relation to the hazard.

Additional information on the subject of mill tailings is found in a publication of the American Physical Soclety. $\dagger$

\footnotetext{
†"Report to the American Physical Society by the study group on nuclear fuel cycles and waste management," Reviews of Modern Phystcs. January 1978. pp. S77-S80.
} 


\section{LOW-LEVEL WASTES}

\section{How Low-Level Wastes Are Defined}

Radioactive wastes are classified officially as low-level if they are neither highlevel (fission products) or transuranics. Most contain a small amount of radioactive material in a rather large volume. Therefore, they usually do not require shielding or heatremoval equipment. Most low-level wastes may be disposed of by shallow-land burlal. They are mainly the by-products of the operation of nuclear reactors and the use of radioisotopes. Although there are some lowlevel wastes coming from defense operations, our chief interest is in commercial wastes. These wastes can be divided into two types-those from the nuclear fuel cycle and those from the "non-fuel" cycle. In the latter, we include the management of wastes from the decontamination or decommissioning of reactors.

\section{Low-Level Wastes from Nuclear Power Plants}

About half of the total low-level wastes generated today are from nuclear power plants. The radioactivity arises from two nuclear processes: activation and fission.

Activation results from the absorption by nuclei of neutrons in the nuclear reactor. Targets are the materials of construction of the core and vessel, the corrosion products in the cooling water or on surfaces, or the nuclei of other impurities in the water. Isotopes are transformed into new species that may be radioactive. An example is cobalt-60, half-life about 5.3yr, emitting gamma rays of $1.25 \mathrm{MeV}$ average. This isotope is formed mainly by slow-neutron reaction with cobalt59 , a stable component of stainless steel, as in the cooling system and pressure vessel. In addition, in the pressurized water reactors that use boron as a soluble control absorber for neutrons, there is produced a certain amount of tritium (hydrogen-3), half-life $12.3 \mathrm{yr}$. This isotope becomes an integral part of any effluent involving core cooling.

The second main source of low-level radioactivity is the collection of fission fragments, which comprise a large variety of radioisotopes with a range of half-lives. Although most of these are retained inside the fuel tubes, a few appear in the cooling water. Some result from neutron irradiation of small amounts of uranium left on the outside of fuel tubes during fabrication or as residual natural contamination. More result from pinhole corrosion leaks in the fuel tube walls that allow the release of small amounts of radioactive materials. Because it is impractical to shut the reactor down to remove these offending fuel assemblies, some leakage into the water is permitted.

To keep the activity of the coolant low, the water is treated by an ion exchanger; this extracts radioactive impurities of both the activation and fission types onto a resin bed that serves as a filter. The resins thus contain significant amounts of low-level radioactive wastes. The most important betagamma emitting isotopes are cesium-137, half-life around $30 \mathrm{yr}$, plus iodine-131, antimony-122, and cesium-134.

The wastes from nuclear reactors are in the form of gases, liquids, and solids. The problem of disposal of low-level wastes does not involve the gaseous materials or those very low-level liquid effluents that can readily be discharged with dilution to keep well below the limits on concentration set by the Nuclear Regulatory Commission. There are, however, certain liquids that contain too much activity to permit dilution and which must be disposed of or concentrated. Examples are wastes containing caustics, acids, or chemicals from regeneration of ion 
exchangers. Detergent wastes are those from laundry operations and from decontamination of personnel and equipment. Reactor cooling water collected from equipment leaks has a certain content of solid material. Coolant water from a PWR will also contain up to 2000 parts per million of boric acid.

One way of classifying low-level waste from reactors is by form:

- compacted trash (paper, rags, plastic, gloves, and clothing)

- bulk waste (dirt, wood, concrete, and steel)

- spent resins (from ion exchangers)

- solidified wet wastes (evaporator concentrates).

\section{Other Sources of Low-Level Wastes}

Institutional wastes comprise about a third of commercial wastes. They come from hospitals, medical schools, research laboratories, universities, and industrial organizations. These non-fuel cycle wastes include solid laboratory materials (glass, paper, etc.) and biological wastes (animal carcasses, tissue, etc.). A large fraction of the institutional wastes is in the form of scintillation detector fluids used as tracers for biomedical research. Millions of vials of these solutions, used for counting radioactive events, are disposed of each year. They typically contain the chemicals toluene or xylene, with a small proportion of tritium or carbon-14. The beta decay of these isotopes triggers the release of light that is detected by a sensor. The total annual activity in scintillation vials in the U.S. is low, only about $8 \mathrm{Ci}$ per year. Proper handling of the contents is required since the solvents used are flammable and chemically toxic. One way to handle these wastes is burning, with provision for dilution of the radioisotopes in large volumes of air.

The rest of the radioactive wastes come from industry. Among these industries are pharmaceutical companies, which use organic compounds containing tritium and carbon14, and nuclear fuel fabrication plants, which have very low-level wastes of slightly enriched uranium. Some low-level wastes

come from research and production at Department of Energy facilities, where they are stored.

Studies have been made of the main isotopes in the non-fuel-cycle wastes. The following table lists the radioactivities of these isotopes as dispatched to disposal sites. Most are of short half-life (much less than a year). Only tritium and radiocarbon are longlived.

Isotopes in Non-Fuel-Cycle Low-Level Waste Sent to Commercial Disposal Sites in the U.S. in One Year. (R. L. Anderson et al., Institutional Radioactive Wastes. NUREG/CR-0028, March 1978.)

\begin{tabular}{l} 
Isotope \\
\hline${ }^{3} \mathrm{H}$ tritium \\
${ }^{14} \mathrm{C}$ carbon \\
${ }^{35} \mathrm{P}$ phosphorus \\
${ }^{32} \mathrm{~S}$ sulfur \\
${ }^{51} \mathrm{Cr}$ chromium \\
${ }^{67} \mathrm{Ga}$ gallium \\
${ }^{99 m} \mathrm{Tc}$ technetium \\
${ }^{125} \mathrm{I}$ iodine \\
${ }^{131} \mathrm{I}$ iodine \\
Miscellaneous \\
Total
\end{tabular}

\begin{tabular}{cr} 
Half-Life & \multicolumn{2}{c}{ Activity, Ci } \\
\cline { 2 - 2 } $12.3 \mathrm{y}$ & 36,023 \\
$5730 \mathrm{y}$ & 10,709 \\
$14.3 \mathrm{~d}$ & 6,274 \\
$87.4 \mathrm{~d}$ & 2,440 \\
$27.7 \mathrm{~d}$ & 1,891 \\
$78.3 \mathrm{~h}$ & 132 \\
$6.0 \mathrm{~h}$ & 37,573 \\
$60.2 \mathrm{~d}$ & 12,737 \\
$8.04 \mathrm{~d}$ & 7,263 \\
& 15,490 \\
& Approx. 131,000
\end{tabular}

\section{Packaging and Disposal}

The most common containers by which low-level wastes are shipped are specially packed metal drums of 55- or 30-gallon size. Other wastes are shipped in a variety of crates, drums, boxes, and cans. Typically, the personnel at the disposal site dig trenches in the ground of dimensions $50 \mathrm{ft}$ wide and $30 \mathrm{ft}$ deep, dump containers into the trenches, and bulldoze the earth over the waste to fill the trench and create a mound several feet high to aid drainage. The sketch illustrates the typical method of burial of low-level waste drums.

There are some 20 repositories for lowlevel wastes in the United States. Of these, 14 are operated by the Department of Energy for programs supported by Federal funds, while six are commercial, operated by private industry, as shown on the map. However. 


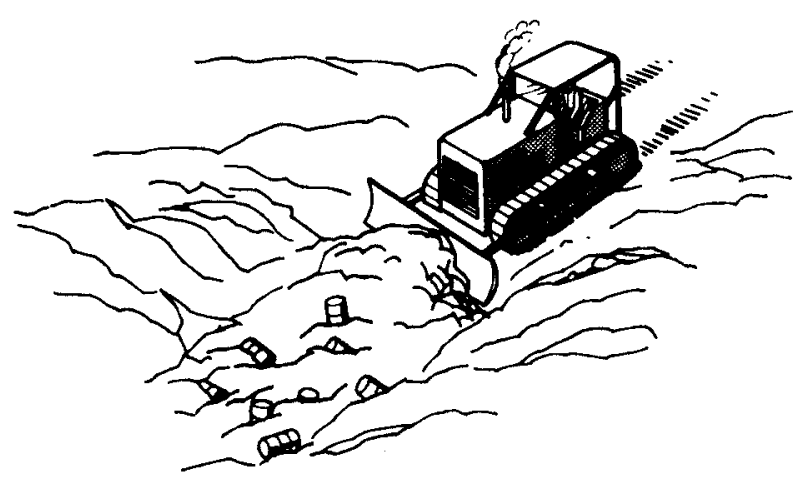

Burial of 55-gallon drums containing low-level wastes in a trench at a disposal site.

some of these-West Valley, New York; Sheffield, Illinois; and Maxey Flats, Kentuckyare closed and are currently not accepting new wastes. The volumes of low-level wastes at the commercial sites are shown in the following table.

The number of available commercial disposal sites continues to dwindle. Unless positive steps are taken soon, there is a real possibility that power plant operations will have to stop and medical and research uses of isotopes be curtailed. A number of states
Volumes of Low-Level Wastes at Commercial Burial Sites (Spent Fuel and Radioactive Waste Inventories and Projections as of December 31, 1980. DOE/NE-0017).
Site

Barnwell, South Carolina

Beatty, Nevada

Richland, Washington

Maxey Flats, Kentucky

Sheffield, llinois

West Valley, New York

Total
Volume, in millions of cubic feet

11.44

3.06

2.14

4.77

3.06

2.35

26.82 are thus examining the possibility of establishing low-level waste disposal sites either as individual states or through compacts with other states on a regional basis. The National Low-Level Radioactive Waste Policy Act passed by Congress in December 1980 says that each state is responsible for providing capacity for disposal of non-defense wastes and recommends regional management. Compacts among states are allowed with consent of Congress, and these may exclude wastes from other states after January $1,1986$.

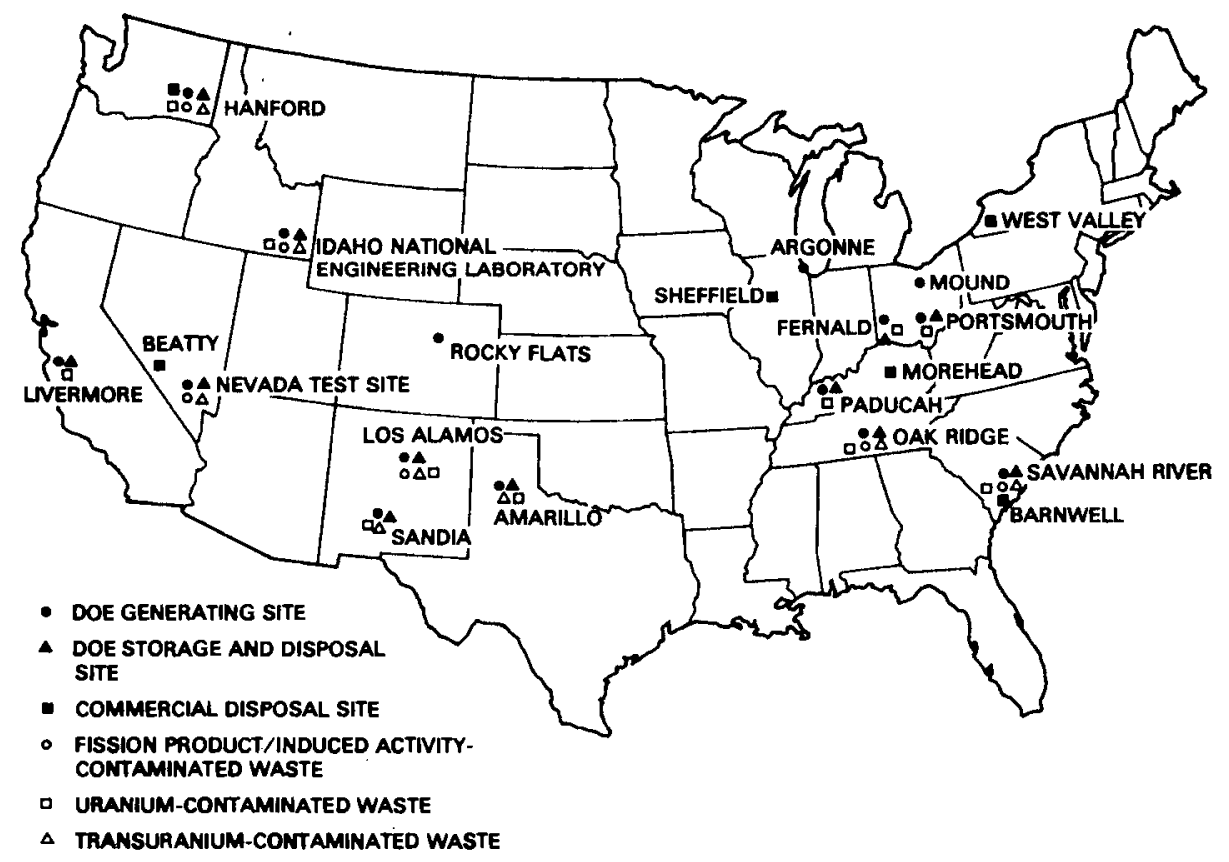

Generating, storage, and disposal sites for solid low-level radioactive waste. (From The Shallow Land Burial of Low-Level Radioactively Contaminated Solid Waste. National Academy of Sciences, 1979.) 
Although it is generally assumed that radioactivity should be avoided and controlled, there are amounts so low that they can safely be ignored. These are treated as exempt by the Nuclear Regulatory Commission, as described in the Code of Federal Regulations, 10CFR30 parts 30.14 to 30.19 . Examples are 1 microcurie $(\mu \mathrm{C} 1)$ of cobalt -60 and $5 \mu \mathrm{Ci}$ of cesium-137. The term de minimis is used to refer to trivial or ignorable amounts of radioactivity." Recent revisions in NRC regulations allow scintillation detector fluids and animal carcasses to be disposed of as ordinary chemical or biological wastes. The requirement is the activity of tritium or carbon-14 should be less than $0.05 \mu \mathrm{Ci} /$ gram, with limits on yearly disposal.

\section{Decontamination}

The operation over a period of time of any nuclear facility, be it fuel fabrication plant, reactor, or reprocessing plant, involves contamination by radioactive substances. Clean-up during operation is called decontamination, while steps taken after shutdown are called decommissioning.

Decontamination means the removal of radioactive material from surfaces such as building floors or walls, hand tools, and the insides of vessels, or from large volumes of water. The objective of decontamination is to reduce radiation exposure to persons working in the area. The result of decontamination is, of course, additional low-level wastes. The technique should be nondestructive and should be safe for the operator to apply; it would be illogical for workers to receive more person-rems than the reduction in dosage that the cleaning process provides.

Methods tend to be chosen according to the items to be decontaminated. Small tools and equipment are hand-scrubbed, with a

\footnotetext{
"From the Latin phrase de minimis non curat lex. "the law does not concern itself with trifles." See the paper by J. P. Corley and K. J. Schiager, "De Minimis Levels of Radioactivity in Waste Management," in the symposlum proceedings Waste Management '78, Tucson, Artzona, March 6-8, 1978.
}

cleaning agent and cloth or steel wool, by an operator wearing a respirator. Some use is made of ultrasonics, in which a water bath containing a solvent or wetting agent is vibrated at high frequency, about 25,000 cycles per second. For cleaning of removable reactor components, numerous methods are available-hand-scrubbing, ultrasonics, acid baths, electrical cleaning, sandblasting, strong chemicals, water jets, steam, and strippable coatings. When components are not removable, such as cooling pipes or heat exchangers, chemicals at high temperature are circulated through them. For decontaminating large amounts of water, filters and ionexchange devices are used, with the liquid passed through several times. The Three Mile Island reactor clean-up is providing a major test of decontamination techniques.

\section{Decommissioning}

Decommissioning means the removal of a nuclear power plant or other nuclear facility from service after its useful life and taking the necessary steps to protect the public from residual radiation hazard. The useful life of a reactor is the time between its startup and the point when repairs are excessively expensive or safety would be compromised by continued operation. An effort will probably be made to stretch the life of a plant from the expected 30 years to as much as 40 years if the system can continue to operate safely and productively. Several different ways of decommissioning are available: (a) "mothballing," which involves taking out fuel and radioactive waste and putting the rest of the system in a storage condition;( b) entombment, which consists of sealing the equipment permanently with a concrete blological shield; (c) prompt dismantling, which involves removal of all equipment giving rise to radiation above a pre-set level; (d) conversion, which is the replacement of the nuclear steam supply system by another heat source, but reusing the turbine-generator. Certain decontamination steps would always precede decom- 
missioning and would be an essential part of the process.

The radioactive wastes resulting from the decommissioning of a long-term reactor operation include a relatively small amount of activated corrosion products and fission products that have deposited on the Inside walls of piping and vessels. The main concern is with induced activity in metal, resulting from neutron bombardment. Most of this is in the core structural components. The following table gives data on the important isotopes.

Activation Products in Reactor Materials (From William J. Manion and DavidR. Perkins, Atomic Industrial Forum Workshop, September 16-19, 1979).

\begin{tabular}{|c|c|c|c|c|}
\hline Nuclide & $\begin{array}{c}\text { Percent } \\
\text { of } \\
\text { Activity }\end{array}$ & $\begin{array}{c}\text { Half-Life, } \\
\mathrm{y}\end{array}$ & Radiation & Comment \\
\hline Iron-55 & 49 & 2.7 & $\gamma, x$ & \\
\hline Cobalt -60 & 36 & 5.3 & $\gamma, \beta$ & $\begin{array}{l}\text { Main con- } \\
\text { tributor for } \\
\text { almost } 100 \mathrm{yr} \text {. }\end{array}$ \\
\hline Nickel-63 & 5 & 100 & $\beta$ & $\begin{array}{l}\text { High activity } \\
\text { but low dose. }\end{array}$ \\
\hline $\begin{array}{l}\text { Manganese-54 } \\
\text { and }\end{array}$ & 10 & 0.85 & $\gamma$ & \\
\hline Cobalt-58 & & 0.19 & $\beta^{+}, \gamma$ & \\
\hline $\begin{array}{l}\text { Nickel-59 } \\
\text { and } \\
\text { Niobium-94 }\end{array}$ & $\begin{array}{l}\text { Less } \\
\text { than } 1\end{array}$ & $\begin{array}{r}75.000 \\
20.300\end{array}$ & $\begin{array}{c}\mathrm{x} \\
\gamma, \beta, \mathrm{x}\end{array}$ & $\begin{array}{l}\text { Eventual domi- } \\
\text { nant Isotope. }\end{array}$ \\
\hline
\end{tabular}

Some of the larger pieces, such as a reactor vessel, can be cut up and burled as lowlevel waste. The highly radioactive materials would have to be treated separately. It is believed that permanent mothballing and entombment are not good cholces because of the long-lived residual radioactivity. This leaves the other two alternatives or some combination such as temporary mothballing for a period of 10-100 years, followed by disposal. Studies indicate that costs of decommissioning do not depend on the method used and are probably small compared with the cost of the facility. Estimated costs are around 50 million (1978) dollars, or around $5 \%$ of the cost of the nuclear power plant.

\section{Low-Level Radiation}

The average person does not receive any radiation exposure beyond that from natural background and occasional $x$-ray diagnosis. Individuals in certain areas or occupations may have received or continue to receive exposure. The long-term effect of such low-level radiation is the subject of investigation. One example is uranium miners, who receive extra dosage if they work in areas with insufficient ventilation to remove gaseous radon. Similarly, emissions of radioactive radon come from mill tallings as the residue of uranium mining. In certain communities where tallings were used for construction or foundations, the level of exposure was higher than background. Even the use of coal, which contains natural radioactive contamination, as a fuel for generating electricity gives off excess radiation to the atmosphere and to surfaces on which particles deposit. Residents of Utah, Arizona, and Nevada, where extensive above-ground nuclear weapons testing occurred in the two decades after World War II, received extra radiation as the result of fallout. It has been said that some military personnel received exposure as the result of being positioned near a nuclear bomb test. A small amount of fallout from tests by China, France, and India is still experienced in the Western Hemisphere. Workers in nuclear power plants are allowed to receive extra radiation exposure, within Federal guidelines and limIts. All these sources of low-level radiation are being studied under the supervision of the Environmental Protection Agency and Nuclear Regulatory Commission. ${ }^{*}$

\footnotetext{
*For example, see Assessment of Capabiltties and Research Needs in the Area of Health Effects of Low Level lonizing Radiation, NUREG-0602, EPA-600/8-79-019, August, 1979.
} 



\section{TRANSPORTATION}

Radioactive materials of many types are transported by public and private carriers all over the country. Many of the shipments are low-level medical isotopes, some are institutional wastes, and many are low-level wastes from reactor operations. On occasion, spent fuel from reactors is transferred.

\section{Concerns About Shipping}

People tend to be apprehensive about transportation of radioactive material through or near their communities. Well aware that accidents do happen, they react by making one of these statements: (a) no shipments should be made, (b) shipments should be made to avoid our town, (c) we should know the route to be taken and the schedule of shipments, (d) the vehicles should be clearly labeled "radioactive materials," (e) wastes should be shipped inconspicuously to avoid hijacking, or (f) a radiological rescue team should be avallable at all times.

Clearly, not all of these desires can be met. Radloactive materlals exist and must be transferred. When long-term repositories are built, it will be necessary to ship the highlevel defense wastes from present storage to the disposal site. Not all towns and cities can be avoided, but states have the opportunity to help set the routes and to receive notification of important shipments.

In the future, we can expect that more and more spent fuel will be transferred between reactor sites, central fuel storage sites, and reprocessing plants. Since some traffic accidents are inevitable, the public must be protected by containers designed to withstand impact, fire, and immersion.

\section{Facts About Transportation}

We can provide some statistics on transportation in general and nuclear materials in particular. Some five hundred billion packages of commodities of all kinds are transported in the U.S. each year. Motor carriers handle $57 \%$, rallroads $38 \%$, and waterways about $5 \%$. Less than $1 \%$ goes by air.

Hazardous materials shipments are a very small part ( 1 in 5000) of all goods and materials transported, and radioactive material shipments are a rather small part ( 1 in 50) of the hazardous materials. Therefore, one shipment in 250,000 contains radioactive material. The sketch graphically shows the percentage of shipments. The table lists current annual U.S. data on the shipments of radioactive materials.

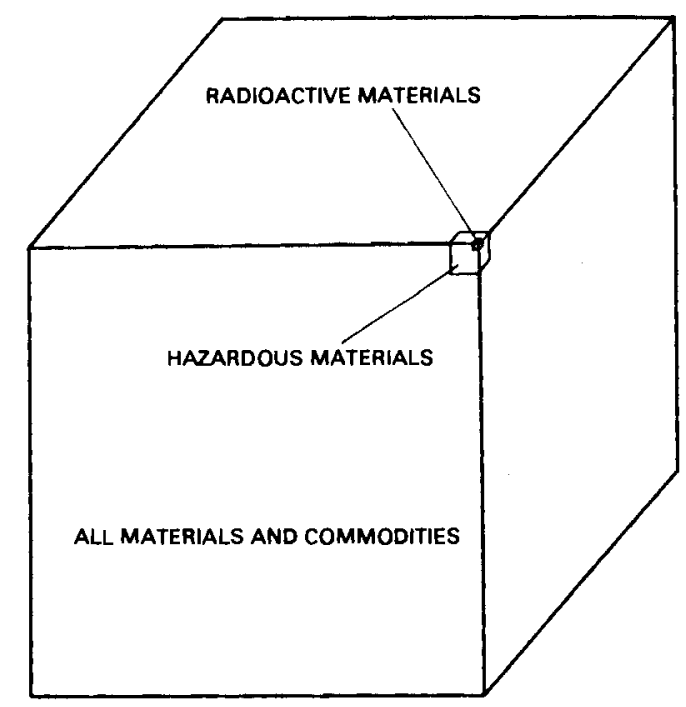

Shipments of goods in the U.S. Radioactive materials form $1 / 50$ of hazardous materials, which are $1 / 5000$ of all items shipped. 
Annual Shipments of Nuclear Materials in the U.S. (Data courtesy of Robert Jefferson, Transportation Technology Center, Sandia National Laboratories.)

Type of Material

Number of Ship-

Exempt amount or limited radioactive level materials, for example, smoke detectors, luminous signs or watches

Pharmaceutical and other medical sources, mainly radiolsotopes used for diagnosis or treatment ments per Year

Industrial radiation sources. including gages to measure thickness of paper, portable $\mathrm{x}$-ray devices

Nuclear materlals used in the front end of the nuclear fuel cycle, including uranium, fresh fuels from fabrication plants, and a small amount of interplant spent fuel

200,000

Wastes from all industrial and medical sources other than nuclear power plants

Nuclear power plant wastes

100.000

Total

50,000

$2,180,000$

The potential hazard to the public from transportation of radioactive waste depends on two factors: the frequency of accidents and the chances of leakage of radioactive material in case an accident happens. The following table shows figures (5-yr total) on

Five-year Total of Hazardous Materials Incident Reports in the U.S. by Classification (From Department of Transportation report DOT/RSPA/MTB-79/8.)

Classification

Flammable liquid

Corrosive materials

Poisons, class B

Flammable compressed gas

Oxidizing material

Nonflammable compressed gas

Miscellaneous and unknown

Flammable solid

Radioactive material

Explosives

Combustible Hquid

Poisons, class A

Total

\begin{tabular}{rrrr}
$\begin{array}{c}\text { Number of } \\
\text { Reports }\end{array}$ & $\begin{array}{c}\text { Percent of } \\
\text { Total }\end{array}$ \\
\cline { 1 - 1 } 16.406 & & 51.27 \\
10.672 & & 33.33 \\
2.026 & & 6.32 \\
718 & & 2.24 \\
644 & & 2.01 \\
535 & & 1.67 \\
472 & & 1.47 \\
183 & & 0.57 \\
144 & & 0.45 \\
122 & & 0.38 \\
69 & & 0.21 \\
27 & & 0.08 \\
& & 100
\end{tabular}

incidents involving the transport of hazardous materials of all types in the U.S. It should be emphasized that the figures refer only to accidents that are reported to the Department of Transportation. Some events of each type fail to be reported.

\section{Boxes, Cans, and Casks}

The philosophy of protecting the public against radiation in transportation has been that accidents are inevitable and that protection must be provided by the packaging of the radioactive materials. The degree of protection is selected on the basis of the level and type of radioactivity contained. Type A packages (see the diagram of a typical one) can contain a limited number of curies and are designed to withstand normal wear and tear of transport exclusive of accidents. Protections around the inner glass bottle are a metal can, a fiberboard insert, a lead container, absorbent material, and a fiberboard box. Type B packages (shown in two views)

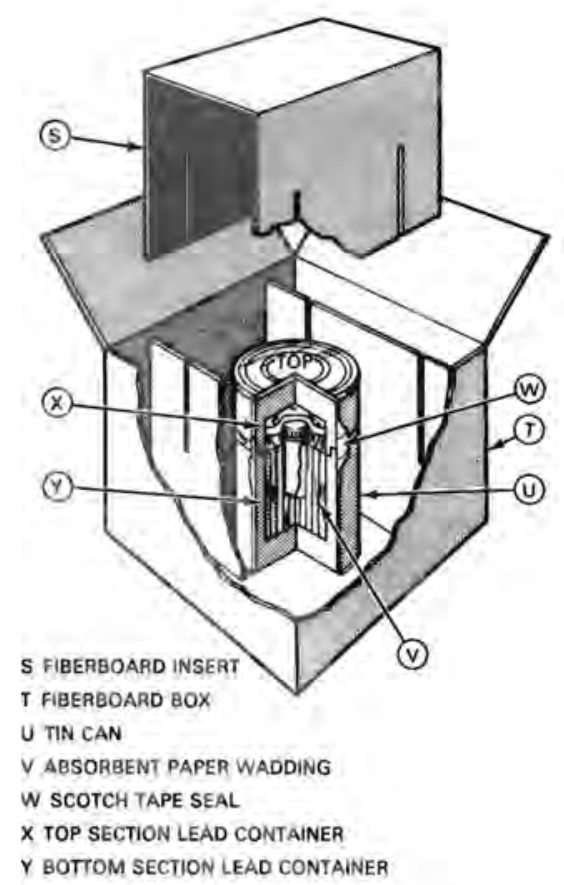

Diagram of a representative type A shipping container, which can vary markedly in size and material. (Courtesy of Department of Transportation.? 


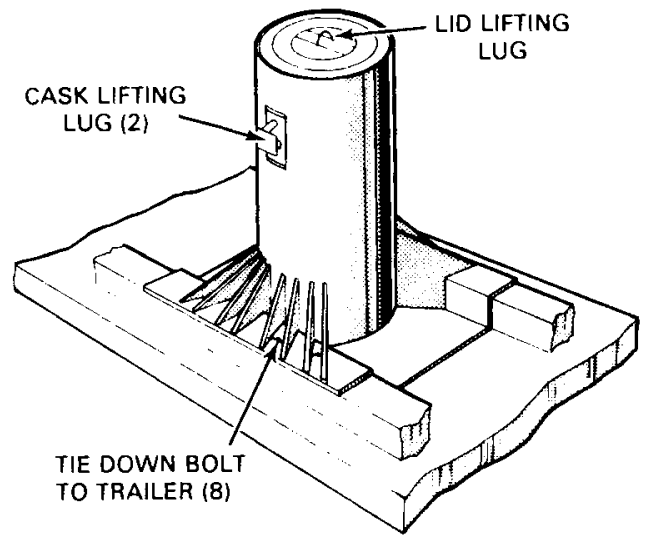

The two cutaway views show the design features of a spent fuel cask, $5 \mathrm{ft}$ in diameter and $16 \mathrm{ft}$ long. Developed by the General Electric Company for transporting spent fuel, it will hold 7 PWR or 18 BWR assemblies. It was designed to meet all the above protective requirements under ordinary conditions of temperature changes, wetting, vibrations, and shocks usually experienced in shipping.

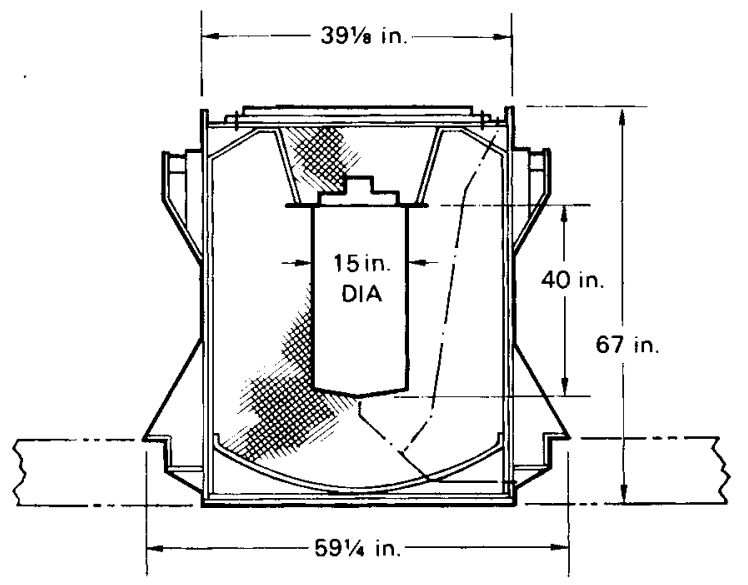

Type B transport cask used by Chem-Nuclear Systems, Inc. The capacity is $4 \mathrm{ft}^{3}$; lead shielding is over 10 in. thick; the cask lid weighs $1600 \mathrm{lb}$. (Adapted from a Department of Transportation report.)

are designed for a higher curie content and must withstand accidents without leaking. Important features are the holddown devices, heavy steel wall, fire protection, and internal suspension.

The shipping cask for spent nuclear fuel is a still more rugged and elaborate container. It provides four types of physical protection:

1. containment, to prevent material from being released into the environment

2. shielding, to prevent radiation exposure to employees or passersby

3. heat management, to take care of the energy released by decaying fission products

4. criticality prevention, to avoid accumulation of enough fissile material to be multiplying.

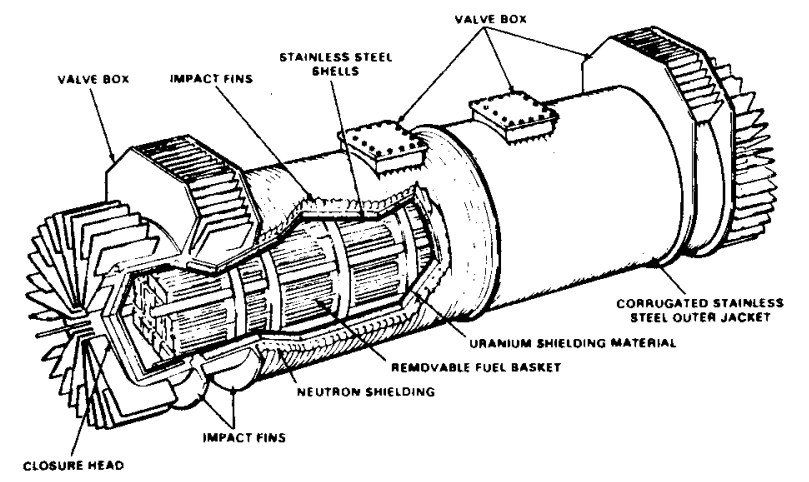

Cutaway view of a spent fuel shipping cask. PWR or BWR fuel assemblies are held in a fuel basket. Water and lead serve as shielding. Fins help remove heat to the air. (Courtesy of Pacific Northwest Laboratory.)

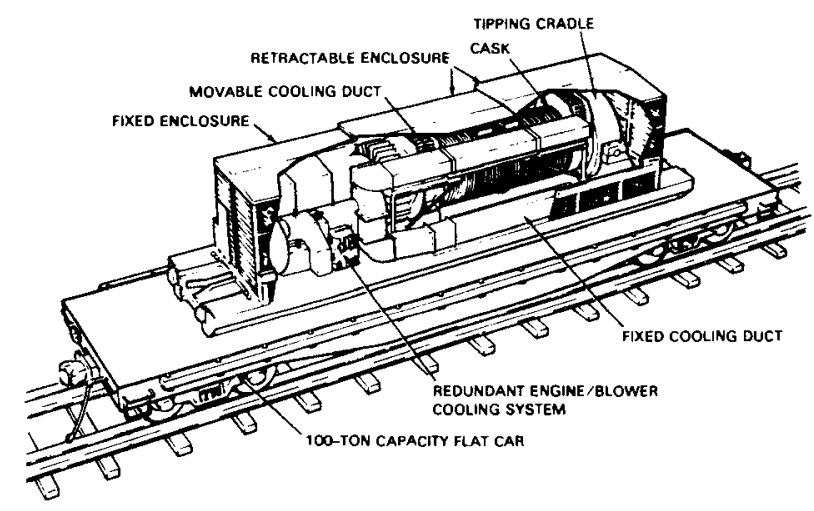

Spent fuel cask in normal arrangement for shipment by railroad. (Courtesy of General Electric Company.)

The shipping cask is also required by the Nuclear Regulatory Commission to withstand a series of conceivable events: a 30-ft fall on a flat, hard surface (as if the cask dropped from an overpass onto a concrete highway); a 40-in. fall onto a metal pin 6 in. in diameter (as if the cask hit a sharp corner 
of a bridge abutment); a 30-min exposure to a fire at a temperature of $1475^{\circ} \mathrm{F}$ (as if a tank of gasoline ruptured in an accident and a fire ensued); and complete immersion in water for $8 \mathrm{hr}$ (as if the cask rolled off into a creek along the highway). Road experiments were designed to further verify the integrity of the spent fuel cask as follows:

- A tractor-trailer rig carrying a cask was crashed into a concrete barrier at $60 \mathrm{mi} /$ $\mathrm{hr}$ and $84 \mathrm{mi} / \mathrm{hr}$ as shown in the photo.

- A locomotive going at $80 \mathrm{mi} / \mathrm{hr}$ ploughed into a cask on a truck, as at a crossing.

- A high-speed impact was followed by a fire.

None of the fuel casks was damaged enough to release radioactivity, and the damage that did occur confirmed the predictions from design analysis and scale-model tests.

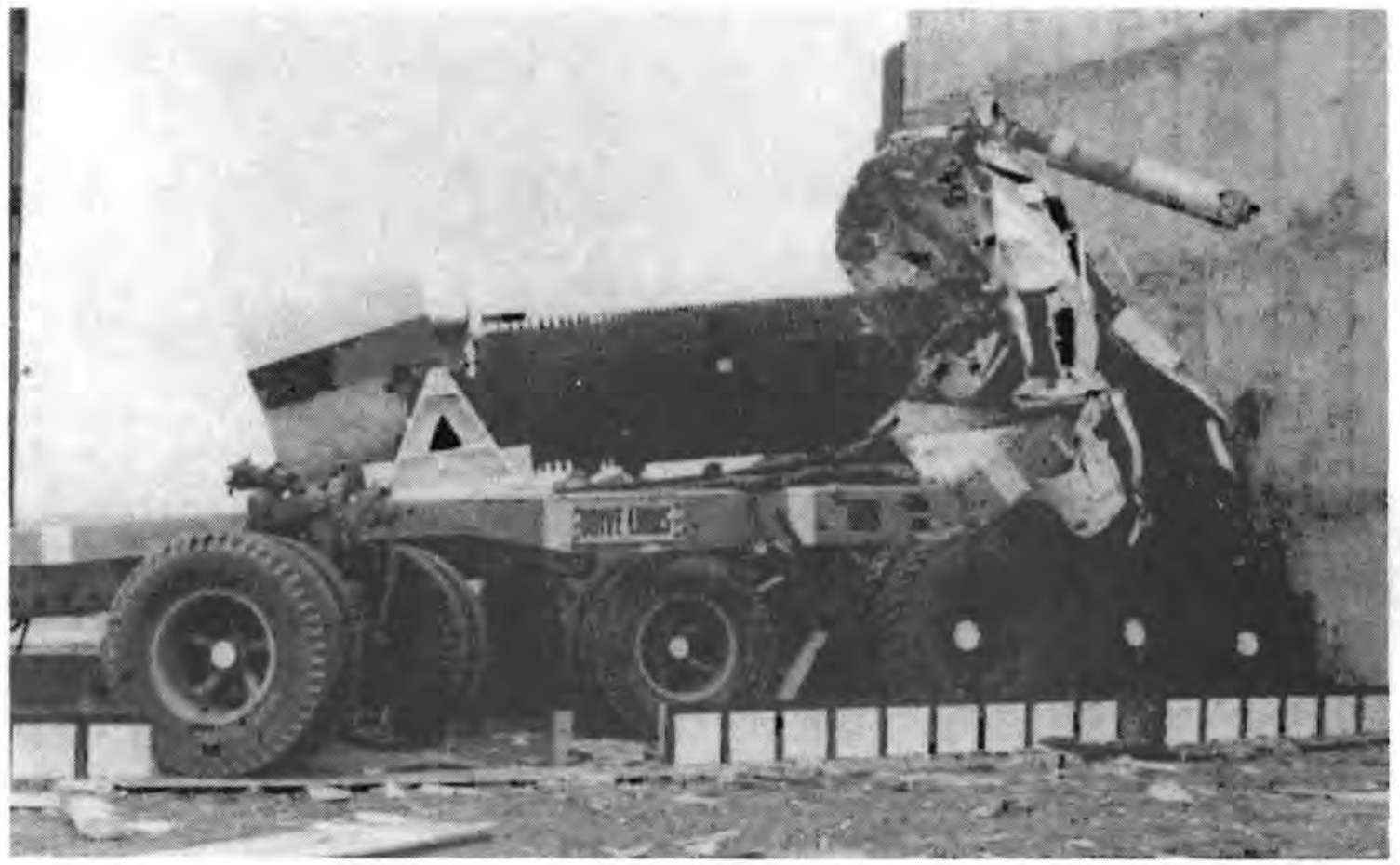

Photograph taken a fraction of a second after collision of a tractor-trailer with a concrete wall at more than $80 \mathrm{mi} / \mathrm{hr}$. (Courtesy of Sandia National Laboratories.) 


\section{METHODS OF HANDLING HIGH-LEVEL NUCLEAR WASTES}

\section{A Variety of Choices}

Numerous ways to dispose of nuclear wastes have been proposed over the years. Some are simple but not very reliable; others are complicated and safe but very expensive; some are temporary, others permanent; still others are exotic and impractical. We shall discuss some of the ideas, pointing out advantages and disadvantages.

There are several choices in general of what to do with wastes:

- hold for decay

- dilute and disperse

- concentrate and contain.

The first choice, to hold, is good if the radioactive material has a half-life of only a few days, as for example 8-day iodine-131 used for medical work. At the end of a reasonable time, such waste is harmless. The second choice, to dilute and disperse, is appropriate when the half-life of the substance is short and the waste form mixes well with air or water. The amount of radioactivity quickly becomes lower than allowable concentrations. An example is the controlled release of low-level liquids from normal reactor operation into a large stream. Another is the controlled release into the air of krypton- 85 gas from the chemical processing of spent fuel. The gas has practically no chemical or biological action and thus disperses throughout the great volume of the earth's atmosphere. The third choice, to concentrate and contain, can be used for substances with long half-life and significant potential hazard. Some ways to concentrate are: (a) to reduce the volume by evaporation of excess liquid, (b) to precipitate the wastes as a solid out of a larger volume of material, (c) to burn the material, retaining the ash and filtering the gases. "Contain" implies holding secure until the level of radioactivity is low.

We should distinguish between "storage" and "disposal." Storage is a temporary action in which waste awaits a more permanent handling. Disposal is a final action, with no intent to recover or transfer the material. The term "isolation" means placing the wastes where they can never cause harm to life forms. The wastes could be either stored or disposed of in such a location.

Opinions vary on the answer to the question "Should wastes be stored or disposed of?" In favor of storage is the idea that handling is safer after decay has taken place, that further research and development may lead to better ways to get rid of wastes, and that some new important use for the radioisotopes may be found. There are several arguments for disposal. One is that storage can result in accidental release of radioactivity, with accompanying hazard. Another is that disposal is final and requires no further action. Finally, some believe that public concern demands that the wastes be permanently eliminated.

A new word, "retrievability," refers to the ability to find and remove wastes if their container becomes damaged or is leaking. There are, of course, different degrees of retrievability. For example, it is easy to recover a coin dropped on the floor, but impossible to recover the contents of a bottle of perfume spilled on the sidewalk. An inbetween case is the piece of bread covered with peanut butter and jelly, dropped face down on a sandy beach.

As noted before, many ideas for handling wastes have come forth, and most of the concepts have been studied carefully. We 
shall now describe several techniques for the management of high-level wastes, mentioning advantages and disadvantages of each. The last method we will discuss, and the most highly favored, is geologic isolation.

\section{Underground Storage in Tanks}

We have already mentioned this method, used at Hanford to store defense wastes as a liquid or sludge. The original tanks were single-walled and in direct contact with the ground. Thus leaks resulted in contamination of the soil surrounding the tank. Modern tanks (see the diagram) are made of steel and sit inside metal-lined concrete boxes that have a monitored and filtered air flow through them. Cooling water passes through coils in the tank to prevent boiling; a condenser returns water evaporated from the waste. Measuring devices include liquid level gages, thermocouples for sensing temperature, and detectors for determining radioactivity in the air.

The main advantage of such a method is that with careful attention, a leak in a tank could be detected quickly and the contents transferred to a spare tank. Despite the double wall, detection instruments must be unusually reliable and continuous attention must be given over many years to be sure leaks do not occur to contaminate public water supplies. Such storage is very expensive. Finally, in the event of a strong enough earthquake, even double-walled tanks would rupture and leak. The method cannot be viewed as other than temporary.

\section{Surface Storage}

One would like to observe any changes in stored high-level wastes and to retrieve them if necessary. A retrievable surface storage facility (RSSF) was favored some years ago, and still has its supporters. Solidified wastes could be held for up to 100 yr awaiting developments or decisions about more permanent handling.

Several types of surface storage have been proposed.* First is the water basin,

\footnotetext{
*Interim Storage of Solidified High-Level Radioactive Wastes, National Academy of Sciences, 1975.
}

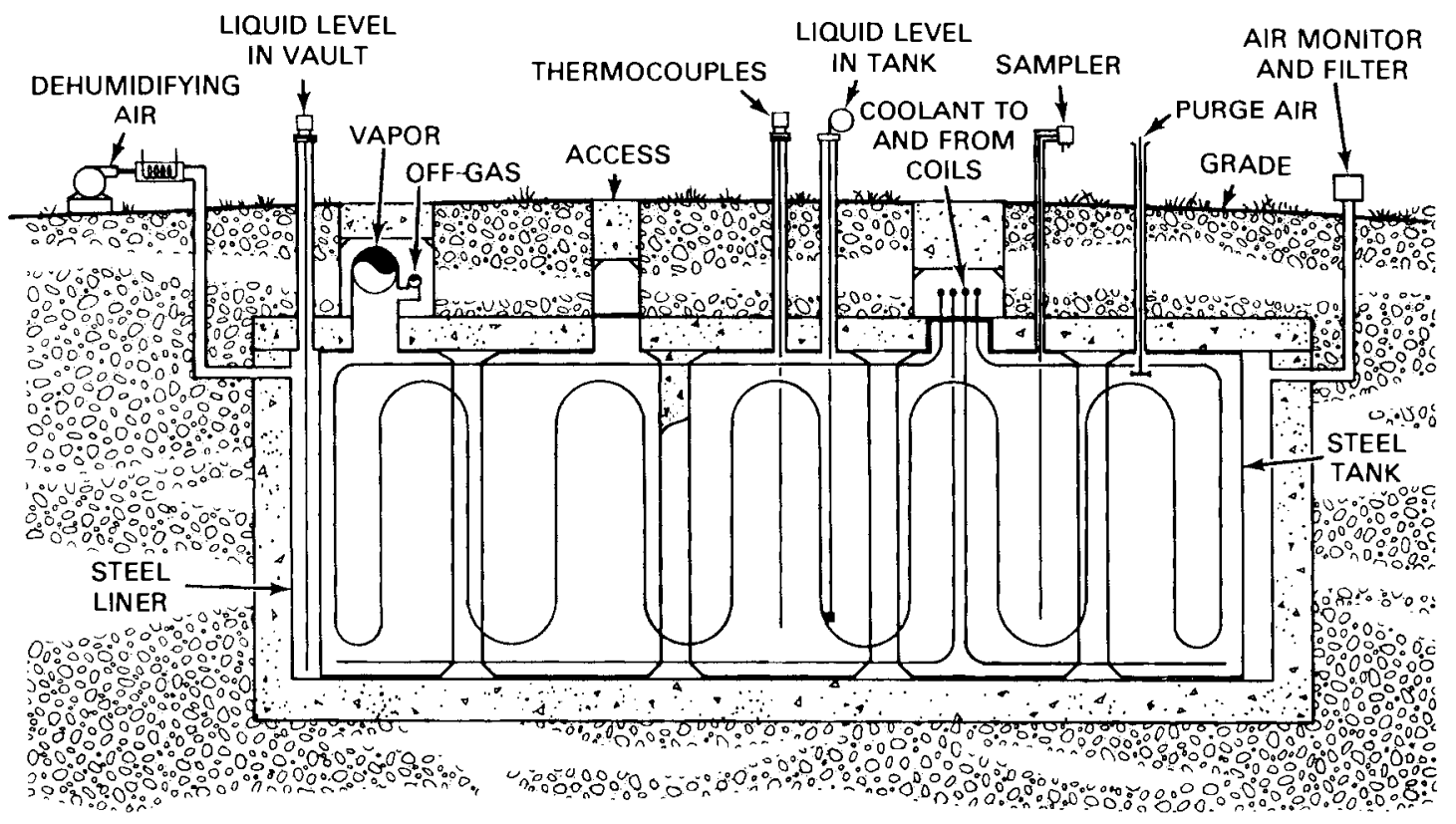

High-level waste storage tank. (From The Safety of Nuclear Reactors and Related Facilities, WASH-1250, U.S. Atomic Energy Commission, July 1973.) 
much like the pool used at a reactor site to hold spent fuel. This method is expensive because of the need for continuous monitoring and control of conditions in the pool such as temperature, water quality, and radioactivity level. The second type is an aircooled vault placed just below the ground level, as shown here. Air is forced through the spaces in the concrete and cools the containers of solidified waste. The third type is similar, but consists of an above-ground silo (pictured in a cutaway view), with air flowing by natural convection up through the space between container and concrete biological shield. Canada stores spent fuel in this manner.

\section{Seabed Disposal}

The dumping of low-level wastes in to the water of the ocean, either as a liquid or in the form of concrete containers, has been practiced from time to time over the years. Such disposal is possible because of the vast volume of water for dilution and the prior existence of radioactivity in seawater. However, the U.S. stopped ocean disposal in 1970.

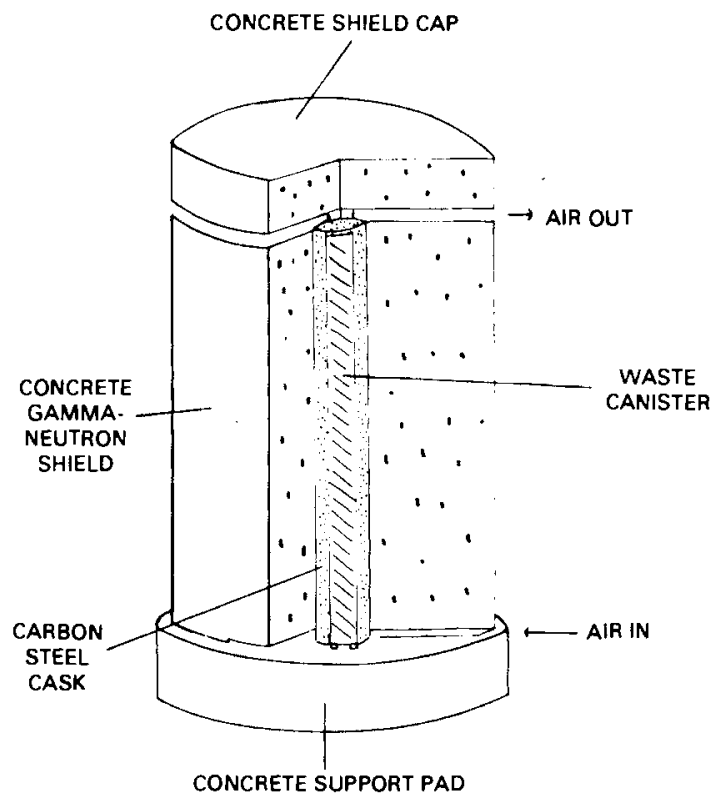

Cutaway view of an above-ground storage facility for solidified wastes. Canisters $10 \mathrm{ft}$ long are placed within the concrete shield. (Courtesy of the National Academy of Sciences.)

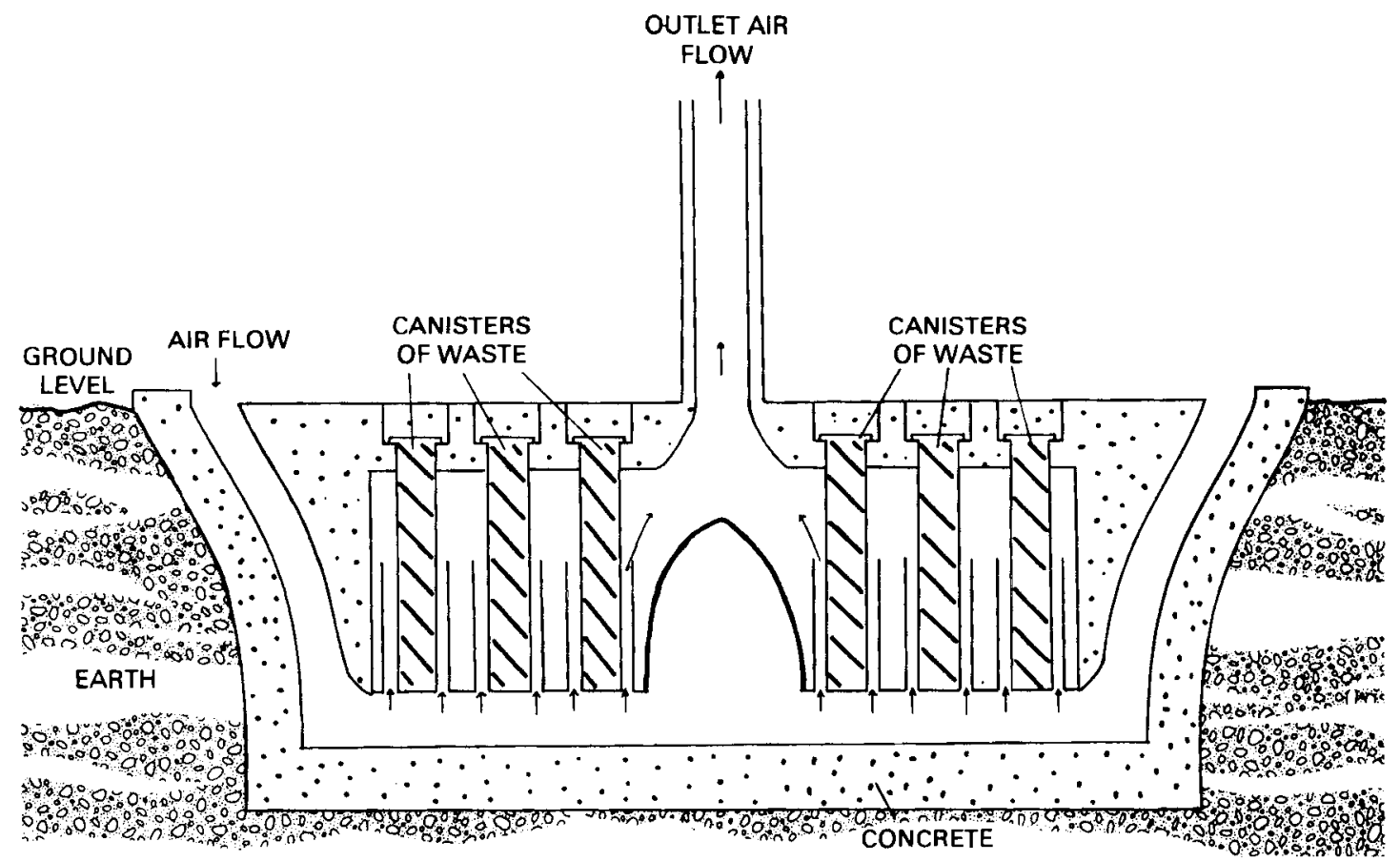

Air-cooled vault for the surface storage of solidified wastes. Chimney action draws air over the surface of waste containers. (Courtesy of the National Academy of Sciences.) 


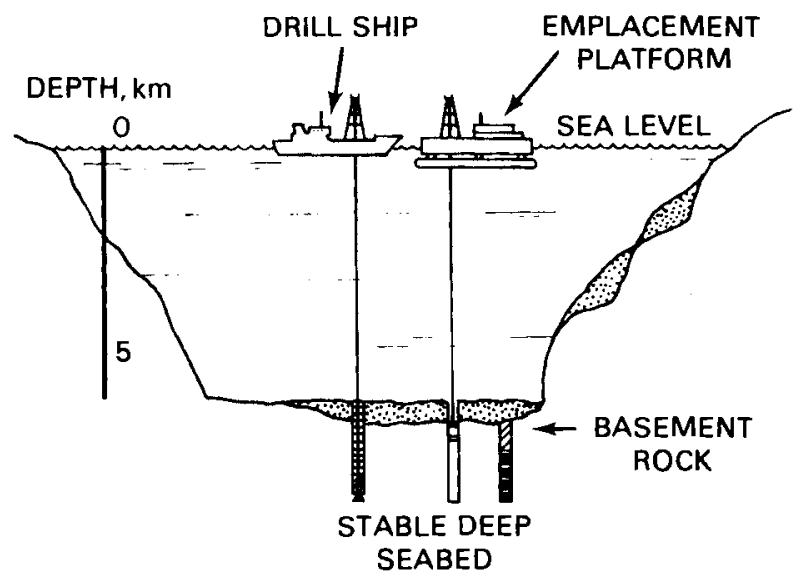

The seabed disposal technique. Holes are drilled in the ocean floor or pointed canisters are allowed to bury themselves deep in the sediment at the bottom. (Adapted from High-LevelRadioactive Waste Management Alternatives, WASH-1297, U.S Atomic Energy Commission, 1974.)

Other techniques involving the sea are shown in the simple sketch. An ocean-going vessel drills holes in the seabed and is followed by a machine that places canisters of wastes deep in the holes and inserts plugs of inert material. Sites would be chosen on the basis of their freedom from water currents and seismic disturbance. This method is similar in some ways to drilling for offshore oil. In a variation on this idea, canisters are allowed to drop with some speed into the sediment that covers the ocean floor to a great depth. Presumably the canisters would be fitted with sharp pointed ends and fins to guide them in vertical fall. Sediment would fall and settle into the hole thus produced, providing a thick protective layer. Any radioactivity escaping later would be held by the sediment and take many years to diffuse out. The disadvantage of the method is that the exact location of canisters cannot be known after their release and there is some uncertainty about the way radioactive materials would move through sediment.

Sea disposal by either method, however, is attractive. There is an enormous area of ocean floor that is far from civilization, is free from life forms, and does not contain minerals that explorers would seek. Even if containers deteriorated, there would be a vast volume of water to dilute the wastes that escaped. Seabed disposal is regarded as a backstop for more conventional disposal in the ground.

\section{Fractionation}

The term means "separating," and it refers to several ways to separate the materials in spent fuel-uranium, plutonium, and wastes of different types.

When spent fuel is reprocessed, most of the uranium and plutonium are removed for future use. These comprise the bulk of the spent fuel. The remainder is the fission products, with small amounts of other heavy elements present. For each metric ton (1000 $\mathrm{kg}$ ) of spent fuel the weights in the high-level waste residue are as listed below.

\begin{tabular}{lc} 
Residues from Reprocessing & Weight, kg \\
\cline { 1 - 1 } Fission products & 28.8 \\
Fuel & \\
Uranium & 4.8 \\
Plutonium & 0.04 \\
Transuranics & \\
$\quad$ Neptunium & 0.48 \\
Americium & 0.14 \\
Curium & 0.04 \\
Reprocessing chemicals & 68.5 \\
Total & 102.8
\end{tabular}

Thus the weight of reprocessed waste materials is one-tenth the weight of the spent fuel.

We recall that strontium-90 and cesium137 are the worst offending isotopes during the first few hundred years of waste storage. If these are extracted, the residual wastes contain only a thousandth as much activity. The volume of cesium-137 and strontium90 is now quite small, and although the wastes are highly radioactive, storage can be easily managed.

Another possible reason for separating the chemicals is to recover some scarce, valuable, and strategically-important elements. Studies* show that there is about $\$ 30,000$

\footnotetext{
-Allison M. Platt and Eugene A. Eschbach. 1981. "Rethinking the Management of High-Level Nuclear Waste: The Need for Fractlonation." Waste Management '81, Roy G. Post, ed., Vol. 1, p. 365.
} 
worth of ruthenium, rhodium, and palladium (precious metals now available only from South Africa and the USSR) in a metric ton of spent fuel. Since each reactor discharges 25 metric tons per year, the annual value would be $\$ 750,000$. Some of the isotopes of these elements are radioactive, but their half-lives are short.

Certain waste disposal methods, such as transmutation and space disposal (to be described shortly), require separation of the transuranics as a preliminary step. In this instance, the process is called "partitioning."

\section{Transmutation}

The word "transmute" means to convert one element into another by nuclear reaction. It reminds us of the goal of the alchemist of the middle ages-to turn base metal into gold. Such a process is now theoretically possible through neutron bombardment, but at a prohibitive cost.

As applied to nuclear wastes, transmutation would involve irradiation of wastes by neutrons as in a fission reactor or in some future fusion reactor. The neutrons are absorbed to produce new isotopes that may have a very short half-life or be stable. The process thus supplements natural radioactive decay as a way to eliminate the isotope, in effect, to shorten its half-life.

The rate at which radioisotopes can be transmuted depends mutually on the intensity of the neutron stream (the "neutron flux") and the receptiveness of the nucleus for neutron capture (the "cross section"). It is natural to think of strontium-90 and cesium137, whose half-lives are around $30 \mathrm{yr}$. Unfortunately, cross sections of these isotopes are too small for the fluxes avallable. A more likely choice is the group of transuranic elements such as plutonium, neptunium, americium, curium, and californium. These elements would be partitioned in a special expanded reprocessing system, fabricated along with ordinary reactor fuel, then irradiated in a light-water reactor or a fast breeder reactor. Because some of the nuclei are fissile, a small amount of power would be obtained. Disadvantages are the possibility of creating heavier radioisotopes that decay back down in an undesirable radioactive chain and the generation of considerable volume of process chemicals, some of which are insoluble. Furthermore, extra protection against radiation, including some neutrons, would have to be provided in the fuel fabrication operation. Other candidates for transmutation are the very long-lived fission products iodine-129 (15.7 million yr halflife) and technetium-99 (214,000 yr halflife). Only the latter, however, can be treated on a practical basis.

Although studies show that transmutation is feasible, it seems to be a more expensive choice than others. If fission reactors are used to produce neutrons to transmute wastes, new wastes are continually being generated. It might be better to use chargedparticle bombardment as in high-energy particle accelerators. Also fusion reactors, possibly available in the coming century, might supply enough neutrons to transmute waste. For the time being, the concept will be held in abeyance.

\section{Ice-Sheet Disposal}

Intuition tells us that the fartherwastes are removed from habitation, the safer people will be. One of the most remote sites on the earth is the polar ice cap in Antarctica. and several methods of disposing of waste there have been visualized, as shown in the sketch. The simplest would be to place waste-filled canisters in racks sitting on the ice. Another would fix the canisters in the ice, suspended on cables, with markers to show the waste location. In the most intriguing proposal, canisters would be allowed to melt their way down through the ice by means of their own decay heat, with melted ice freezing above them as they go. The containers would eventually sink to the solid rock base, a mile or so down.

These methods are very expensive because of the long distance the waste must be 


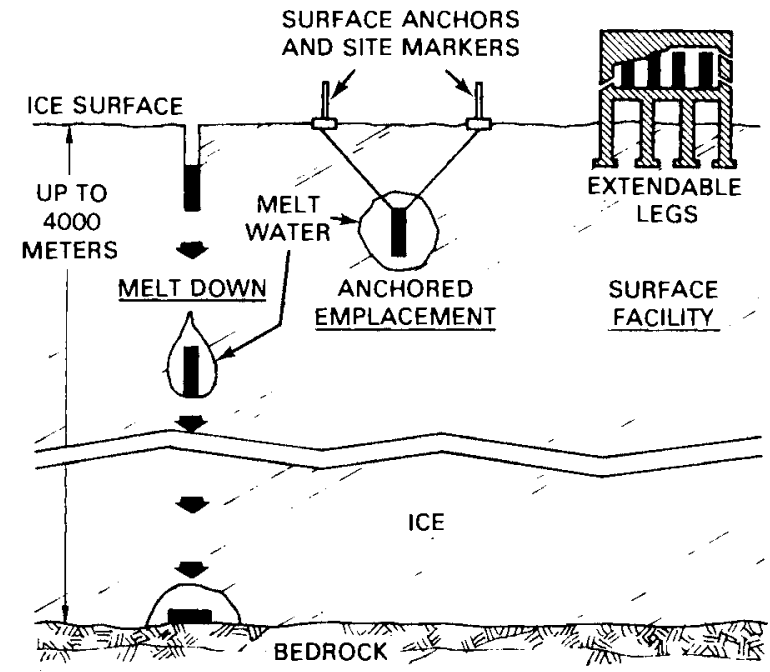

Ice-sheet disposal of solidified radioactive wastes. Containers are supported at the surface or allowed to melt their way down to bedrock. (From WASH-1297.)

transported and the very difficult weather conditions. Only a short time is avallable for entry to the region and placement of wastes. Also there are international problems since Antarctica is owned by many countries. One of the concerns is the water layer believed to separate the ice and bedrock. The layer is produced by the great weight of ice, like the film of water that allows the ice skater to glide over ice. Here, canisters would be exposed to water that is connected to the sea. Finally, there is the possibility that changes in climate over millennia would uncover the waste deposits. The ice disposal method appears to have no real advantages over other concepts.

\section{Disposal in Space}

The space program of the U.S. has been very successful. Achievements include the communication satellites, interplanetary voyages with measuring equipment, and manned trips to the moon. These accomplishments suggest the possibility of disposal of wastes outside the earth using rockets. Several ways, in order of increasing difficulty, are: placing containers of waste in orbit about our planet; putting them in orbit about the moon or depositing them on its surface; sending them into orbit about the sun as new "asteroids"; sending them into deep space; and shooting them into the sun. Rather than attempting to place all wastes in space, it may be desirable to partition the wastes and send only those of very long halflife. The fact that some of these are neutron emitters leads to a shielding problem.

Although space disposal seems attractive at first, there are some flaws. The first is the great cost per pound of waste disposed of. The waste is a small part of the total weight including vehicle and propellant. Second is the possibility of an aborted mission in which the rocket would burn up and the vaporized radioactive payload would fill the atmosphere. Or, the waste might plunge in to the earth's surface and not be detected. For any orbit about the earth, the vehicle might return prematurely, as did Skylab, with some vaporization in the atmosphere. The moon is not likely to be colonized, but future mining of its minerals and energy resources is conceivable. In any case, there are legal questions related to international access to the moon. Placing wastes in the sun, where they would be immediately consumed, would be ideal except for the tremendous expense. There is some reluctance about sending wastes to deep space-they might reach some extraterrestrial culture or some future human habitat. The space disposal concept will probably not be tested in the near future, but studies of the feasibility of isolating special radionuclides may continue.

The best choice, illustrated here, seems to be to use the shuttle Columbia to take wastes from the earth's surface to a low orbit around the earth, then transfer the cargo to an orbit about the sun halfway between the orbits of earth and Venus. There, they would circulate safely in orbit for the millions of years needed for decay.

\section{Several Kinds of Geologic Disposal}

The term "geologic disposal" simply means burial in the earth. There are many 


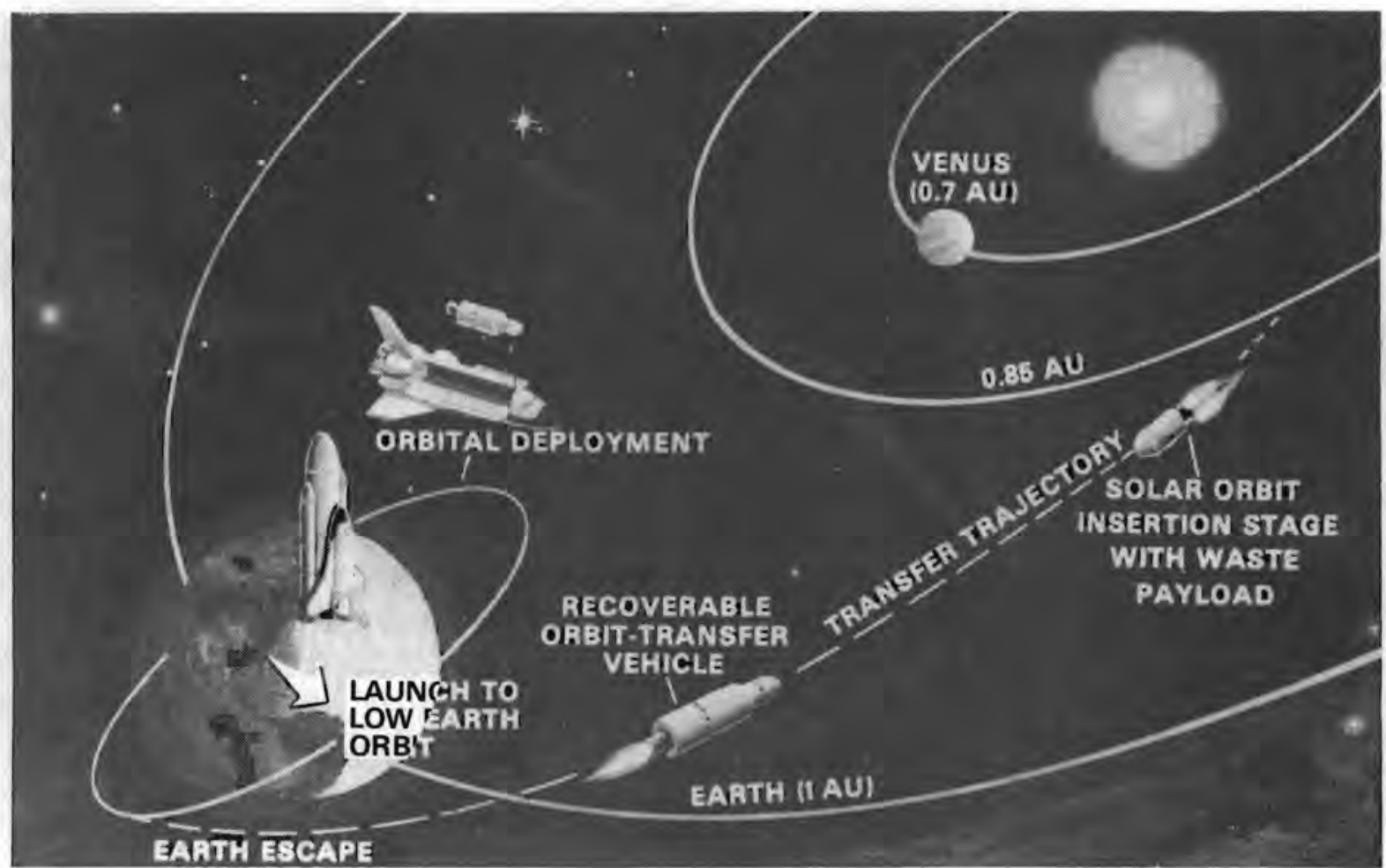

Extraterrestrial disposal of wastes by use of rockets. The Columbia shuttle takes wastes from earth to orbit around the earth; then they are put in orbit around the sun. (Courtesy of the Marshall Space Flight Center, NASA.)

types of such deposition. We shall review several of these, then in the next section, discuss at length the one that is favored.

First is the placement of solid wastes in a very deeply drilled hole. By "deep" we mean well below the level of circulating ground water. This may be as far as 6 to 10 miles beneath the earth's surface. The location must be geologically stable as well. Canisters of waste would be lowered into the hole and stacked in a column several miles high. Then the hole would be plugged. The advantage is remoteness from water and the biosphere. The method appears simple, but large holes have not been drilled to the depth contemplated, and it is difficult to learn the geologic features at such depths. The wastes would not be retrievable, but of course it might be unnecessary to retrieve them. Despite the uncertainties, the concept is very attractive and will continue to be studied as a back-up for the main method.

Second is the "rock-melting" technique sketched below. Here, solid or liquid wastes from a reprocessing plant are poured down a deep hole, say 3000 meters. The heat from radioactive decay melts the rock at the bottom, the waste mixes with the rock, and any

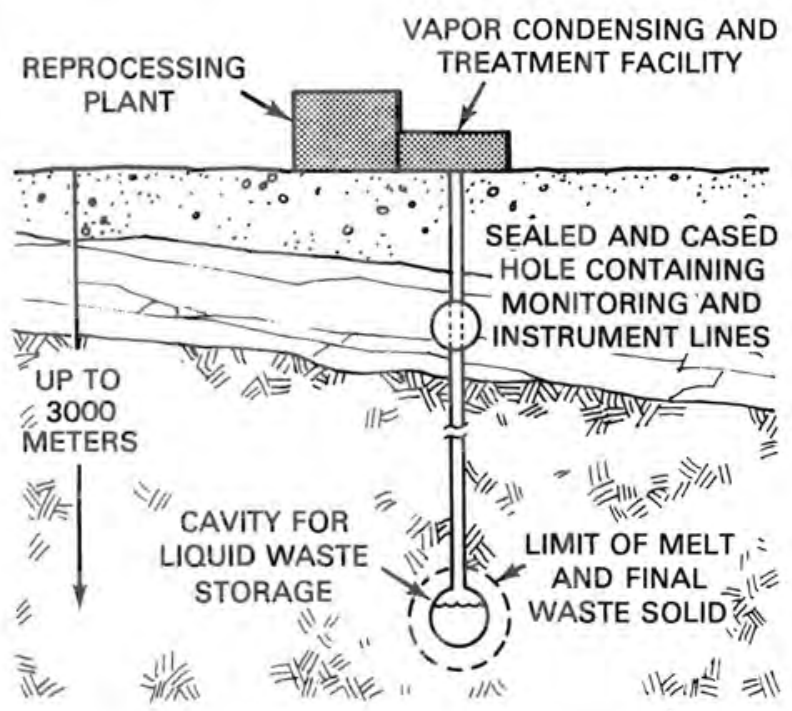

Rock-melting technique for waste disposai. Liquid or solid radioactive materials are poured down a hole to a cavity where decay heat melts waste and rock. (From WASH-1297.) 
liquid present boils away, and is caught and treated. The mixture is still in liquid form during the period when radioisotopes are most active, and there is some possibility of migration. The mass of rock-waste would eventually cool, after around a thousand years, and then the solid would be resistant to further change. The method is regarded as a possibility only for the distant future.

Third is liquid waste emplacement by pumping it into geologic structures. Water under high pressure is forced into rock such as shale, causing "hydrofracture," in which layers separate. Into the cavity liquid waste mixed with cement or clay would be pumped, to deposit in the crevices as large sheets. The method has been used both in the U.S. and the USSR. The method could not be used for all wastes, and the geology would need to be known very well. It is not regarded as a likely candidate for disposal of high-level waste.

Fourth is the use of specially-constructed double-wall tunnels in the side of a mountain. A series of main tunnels with branches would be filled with racks of waste by remotely-controlled conveyors. Similar devices would make repairs and do maintenance or remove leaking containers. The waste would be cooled by an air flow continuously monitored for radioactivity. There is some virtue in needing only to drill horizontal channels rather than vertical shafts as in other geologic methods. The method appears good for storage, but may not be adequate for permanent disposal.

Fifth is the island isolation method. Waste canisters are placed below the fresh water table on an uninhabited small island far from civilization. As a concept, this method lies between the seabed disposal and geologic disposal on land. It is not high on the priority list.

Sixth, and the most favored geologic method, is the placement of waste canisters in a mined cavity. We're merely mentioning the method here, but it is fully discussed in the next several chapters. As shown in the cutaway view, a shaft would extend from the earth's surface down to a series of horizontal tunnels in rock or other medium. Canisters would be placed in holes drilled in the tunnel floor, and the openings would be sealed. The advantage of the method is that conventional mining techniques can be applied. Minor disadvantages are the adverse effects of heat or radiation on the geologic material. This disposal concept is favored as the result of extensive study of a large variety of factors, including radiological and other effects, legal aspects, and the ability to correct or modify the repository if necessary.

In the next chapter, we discuss the early tests of the geologic disposal concept using rock salt as the medium.*

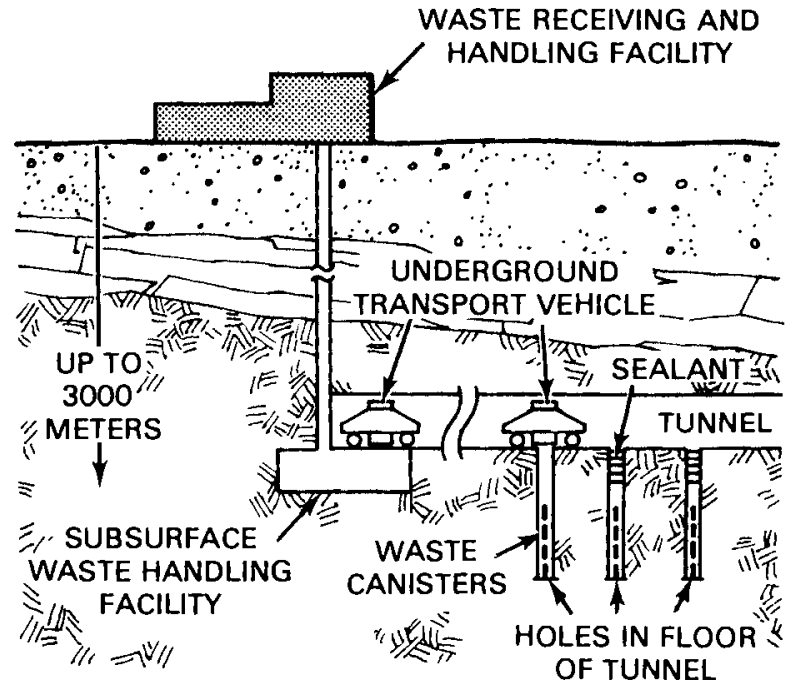

Emplacement of waste canisters in a mined cavity, a currently favored method. (From WASH-1297.)

*An attractive and readable textbook on geology is by Robert J. Foster, Physical Geology. 2nd ed., Charles E. Merrill Publishing Company, 1975. 


\section{PROJECT SALT VAULT}

What to do with radioactive wastes from the early nuclear reactors has been of concern for many years, and extensive studies have been made. "Project Salt Vault" is a story of both success and frustration.

\section{Disposal in Salt}

The U.S. Atomic Energy Commission in September 1955 requested the National Academy of Sciences and the National Research Councll to review the matter of high-level waste disposal. A committee of geologists and geophysicists was formed, the members met, visited, and discussed for a year and a half, coming up with a report in April 1957 with the title, The Disposal of Radioactive Waste on Land. The group said that it was "convinced that radioactive waste can be disposed of safely in a variety of ways and at a large number of sites in the United States." They said that waste storage in tanks was safe and economical for the present. Their second choice of method of permanent disposal was the use of silicate bricks in surface repositories or dry mines. Their main recommendation was that "disposal in salt is the most promising method for the near future." They noted the possible effects of heat on salt and that several years of research and testing would be needed before this system could be put in operation.

The salt that the committee recommended was natural sodium chloride in rock form, deposited long ago when oceans that covered the U.S. dried up. It appears in two arrangements: "bedded" or layered, and "domed," as a hill.

\section{Advantages of Rock Salt}

Salt is almost impermeable since it is plastic-cracks and crevices are sealed by pressure. It is abundant in the U.S., and locations are not in earthquake zones. The cost of excavating is relatively low. Its physical properties such as thermal conductivity and strength under compression are good. The most important idea, from the committee's viewpoint, however, was that deposited wastes would probably be free of contact with water in the future because the very existence of extensive salt deposits indicates that no water has been present for very long periods of time. This opinion formed the basis for proceeding to investigate seriously the disposal of wastes in salt.

Soon after the recommendation to dispose of wastes in salt was made by the National Academy of Sciences Committee, the Atomic Energy Commission (AEC) sponsored a 10-yr investigation of the method. The enterprise was given the name Project Salt Vault, and responsibility was given to Oak Ridge National Laboratory (ORNL). A brief review of what was learned will tell us the state of knowledge as of 1970 . The source of this information is a comprehensive ORNL report.*

\section{Laboratory Tests on Salt}

The study had several objectives. The first was to measure in the laboratory the physical properties of salt in order to calculate its behavior when subjected to influences such as heat, radiation, and pressure. Experimenters also wanted to discover the effects of the small amounts of water that are usually present in salt, especially when the temperature was raised. The second objec-

\footnotetext{
*R.L. Bradshaw and W.C. McClain. Editors. Project Salt Vault: A Demonstration of the Disposal of High-Activity Solidified Wastes in Underground Salt Mines, ORNL-4555, April 1971.
} 
tive was to find out whether it was possible to bring radioactive waste safely to the site of a salt mine, take it deep beneath the surface, and physically place it in cavities in the floor of a mine tunnel. The third aim was to measure the effects of heat, radiation, and pressure on salt structures in an actual mine over a long period of exposure to stresses of all kinds. Typical detectors used were thermocouples and strain gages. The fourth objective was to compare calculations with the measurements made in order to verify that good predictions could be made on an actual waste repository. The project involved the help and cooperation of state health personnel and geological experts. Some useful results of the early laboratory experiments were these:

1. Rock salt can withstand temperatures up to $250^{\circ} \mathrm{C}$ without deterioration. However, if brought to a temperature of $400^{\circ} \mathrm{C}$, it breaks up violently into small pieces. (One can visualize the water within the salt boiling and exerting internal pressure.)

2. Salt has good ability to shield against the nuclear radiation from radioactive waste, being comparable to light concrete in weight and composition. Favorable working conditions in the mine thus would be expected.

3. Radiation exposure causes some change in structural properties of salt, but the effect in the mine is expected to be small.

4. Radiation does not cause much dissociation of the compound sodium chloride. Little free chlorine gas is released.

\section{Field Studies in Kansas}

The site chosen for the field work was a mine near Lyons, Kansas, worked from 1890 to 1948 by the Carey Salt Company. Although the mine was still in fair condition, considerable clean-up and repair was required. A shaft hoist, a ventilating system, and an elaborate electric power and instrumentation system had to be installed. A selfpowered radioactive waste transporter with lead shield was obtained. It consisted of a truck that could carry waste containers and place them in the holes in the tunnel floor. The photograph shows a waste transport vehicle. Extensive preplanning was done to ensure safe operation.

Two maln experiments were performed at the site. The first involved embedding several heaters in a 20 -ft pillar of salt. Over many months, heat was supplied to simulate the effect of radioisotopes, and deformations in all directions were measured. The second experiment involved use of used fuel shipped to the site from the Engineering Test Reactor at Idaho Falls, Idaho. The radioactive spent fuel assemblies were placed in the floor of a tunnel. The sketch depicts waste placement operations. Then the shape of the cavity directly above the array of assemblies was carefully measured. The distortions of cavities were not severe, could be understood. and could be reproduced reasonably well by calculations. To keep a constant heat source and radiation dose, canisters were changed. Before the tests were made, it had been known that water in salt tends to migrate toward a source of heat, which containers of waste definitely generate. Measurements were made on the flow of such water and on its distribution in the cavity. Also it was found that ordinary steel merely rusted a little, but that stainless steel experienced stress corrosion as the result of attack by the chloride.

\section{Progress and Problems}

The overall conclusions of the Salt Vault test were that it is feasible and safe to handle radioactive materials deep underground and that most of the technical problems related to the use of salt can be resolved. As a result of these conclusions and an increasingly urgent need to show progress toward a waste disposal system, the Atomic Energy Commission in 1970 tentatively selected Lyons, Kansas, as the site of a demonstration waste repository.

An unforeseen series of events prevented the goal from being met. Although 


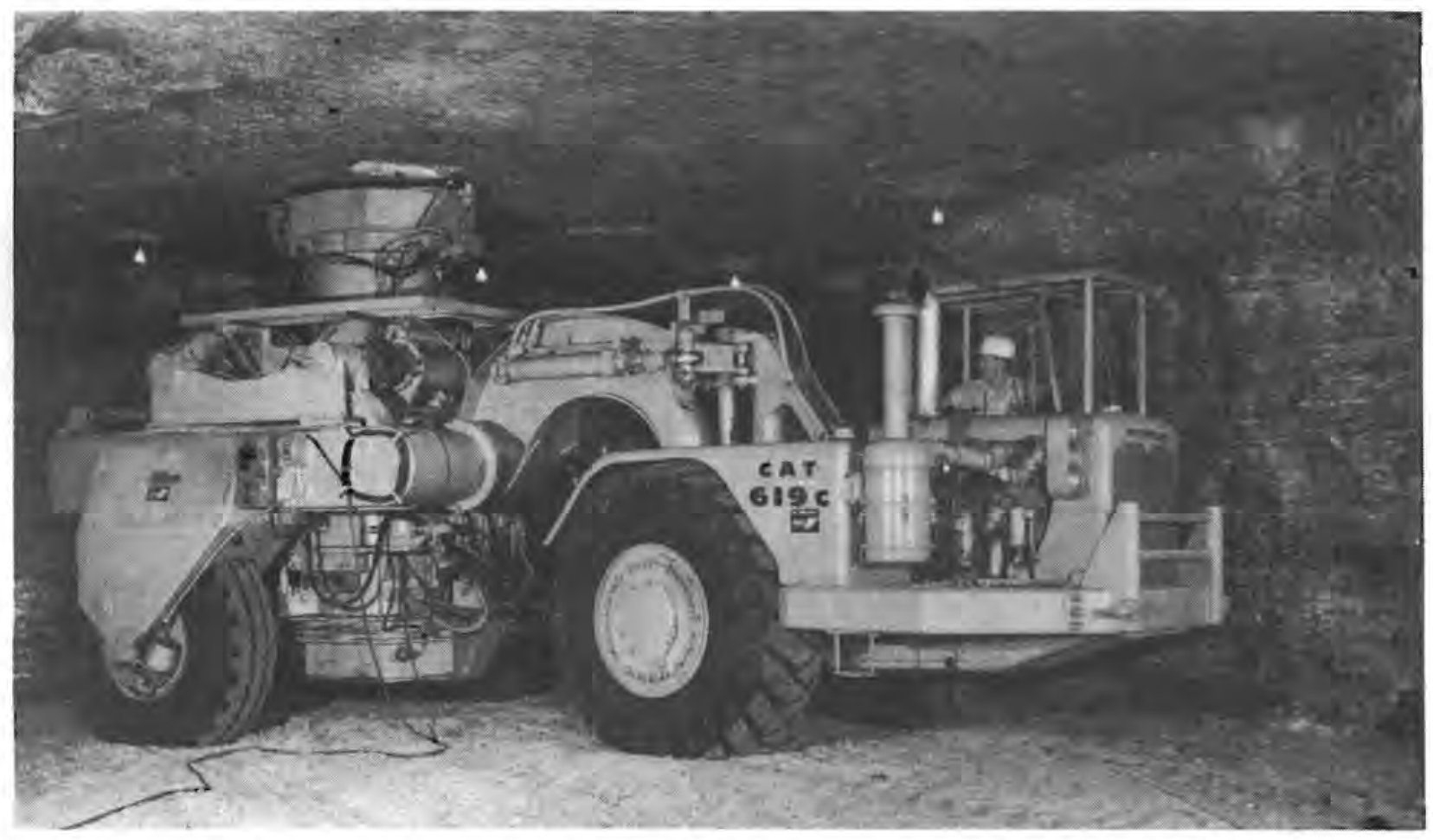

Underground transporter for waste containers. (Courtesy of Oak Ridge National Laboratory.)

some people in Kansas welcomed the Federal funding that would accompany a repository, others actively opposed its construction. There were communication problems among the main groups involved-the Atomic Energy Commission and its staff, the governor of Kansas and his advisers on geological matters, and Oak Ridge National Laboratory. It was eventually discovered that oil and gas drilling had been done in the area. Also it was learned that years earlier large amounts of water had been pumped into a nearby mine to dissolve and bring out the salt. This prior "solution mining" meant that there might still be water in the mine and certainly that there were openings for water to enter. These findings were a serious blow to the project, and the AEC was forced to cancel its plan.

More important perhaps than these technical difficulties was the need to communicate and gain fuller public participation. The Atomic Energy Commission management apparently was insensitive to the citizens' interests, alienated the people of Kansas, and gave the AEC a reputation for being secretive, arrogant, and incompetent. This view has colored the situation on Federal action on radioactive wastes ever since.

Despite the problems with the project, rock salt continues to be a promising host medium for wastes. Plans have been laid for the burial of transuranic (TRU) defense wastes in a salt deposit in Southeastern New Mexico. The project called Waste Isolation Pilot Plant (WIPP) involves drilling two deep shafts to verify that the geologic formation is suitable. If it is, the facility will be expanded with more shafts and a large underground mined area. TRU waste would then be shipped from Idaho, where it is being stored, to the Los Medanos area some 25 miles from the Carlsbad Caverns. The waste would first be placed in 55-gallon metal drums or large plywood boxes. These would be buried deep in the salt bed, but would be retrievable for a few years at least. The salt would serve as the main barrier to prevent radioisotopes from reaching the public. Calculated doses to the public are a small fraction of those from normal background radiation. 


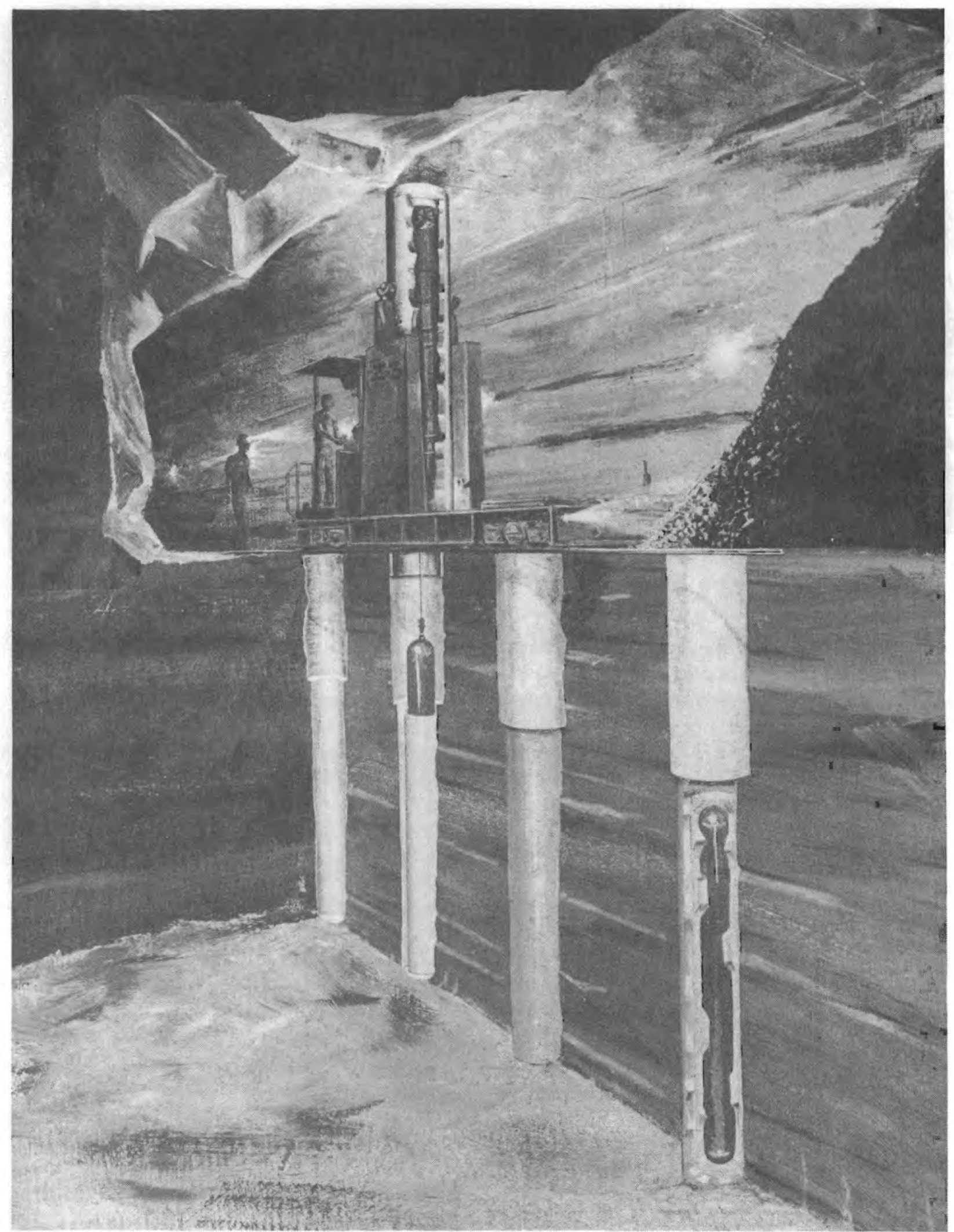

Artist's sketch of placement of canisters of waste in holes in the mine tunnel floor. (Courtesy of the Office of Nuclear Waste Isolation, Battelle Memorial Institute.) 


\section{MULTIPLE BARRIER APPROACH}

The goal of safe waste disposal is to ensure that practically no radioactive material ever reaches man. Thus in the handling of radionuclides, account must be taken of the pathways to man. The artist's sketch shows the relationship of the dispersal of radioactivity by air, water, and land to the food chain of plants and animals.

\section{Many Layers of Protection}

In the design and construction of a repository for radioactive nuclear wastes, a "system approach" has been proposed. This system results in many separate obstacles being placed between the waste and habitations. This concept was emphasized by the

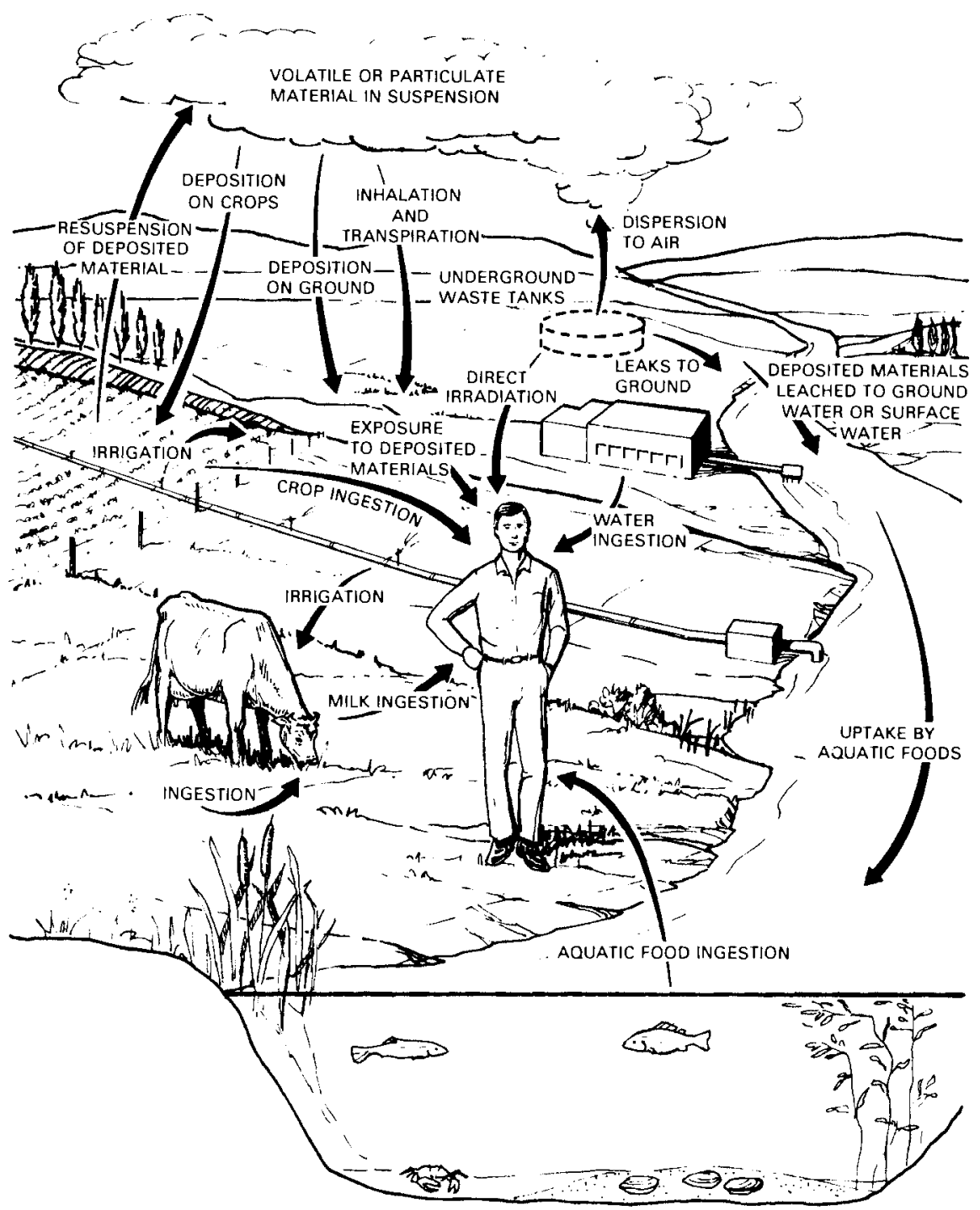

Major pathways by which environmentally dispersed radionuclides can affect living organisms. (Courtesy of Pacific Northwest Laboratory.) 
Interagency Review Group established by the Carter administration and was endorsed by both the Environmental Protection Agency and the Nuclear Regulatory Commission. A "defense in depth" or "multiple barrier" approach includes the materials with which the waste is mixed, the containers, and the packing around them, as well as the surrounding rock, which is the geologic medium.

We shall concentrate on the systems that have been studied most thoroughly and reserve discussion of research about new materials and methods until the next chapter. Using the diagram as a "roadmap," let us start from the inside of a repository for nuclear wastes and work our way outward, noting how the barriers stop, hinder, or delay the transfer of radioactive materials.

\section{Waste Form}

The first barrier is the waste form, that is, the combination of waste and solid. It is designed to achieve what is called "immobili- zation" of the radioactive materials. The mixture should be able to contain a reasonable amount of the waste as impurity and still remain strong and uniform in composition. It should not be damaged by heat or radiation from fission product decay nor be readily attacked chemically (leached) by water solutions that may be present underground.

Glass is the material mixed with waste that has been studied most, for these reasons:

1. It is easy to prepare, to mix with wastes, and cast into desired forms.

2. It forms a uniform mixture with many different types and amounts of wastes. The wastes become oxides and become part of the glass.

3. It conducts heat adequately.

4. It is durable and resistant to attack by chemicals so long as the temperature is reasonably low.

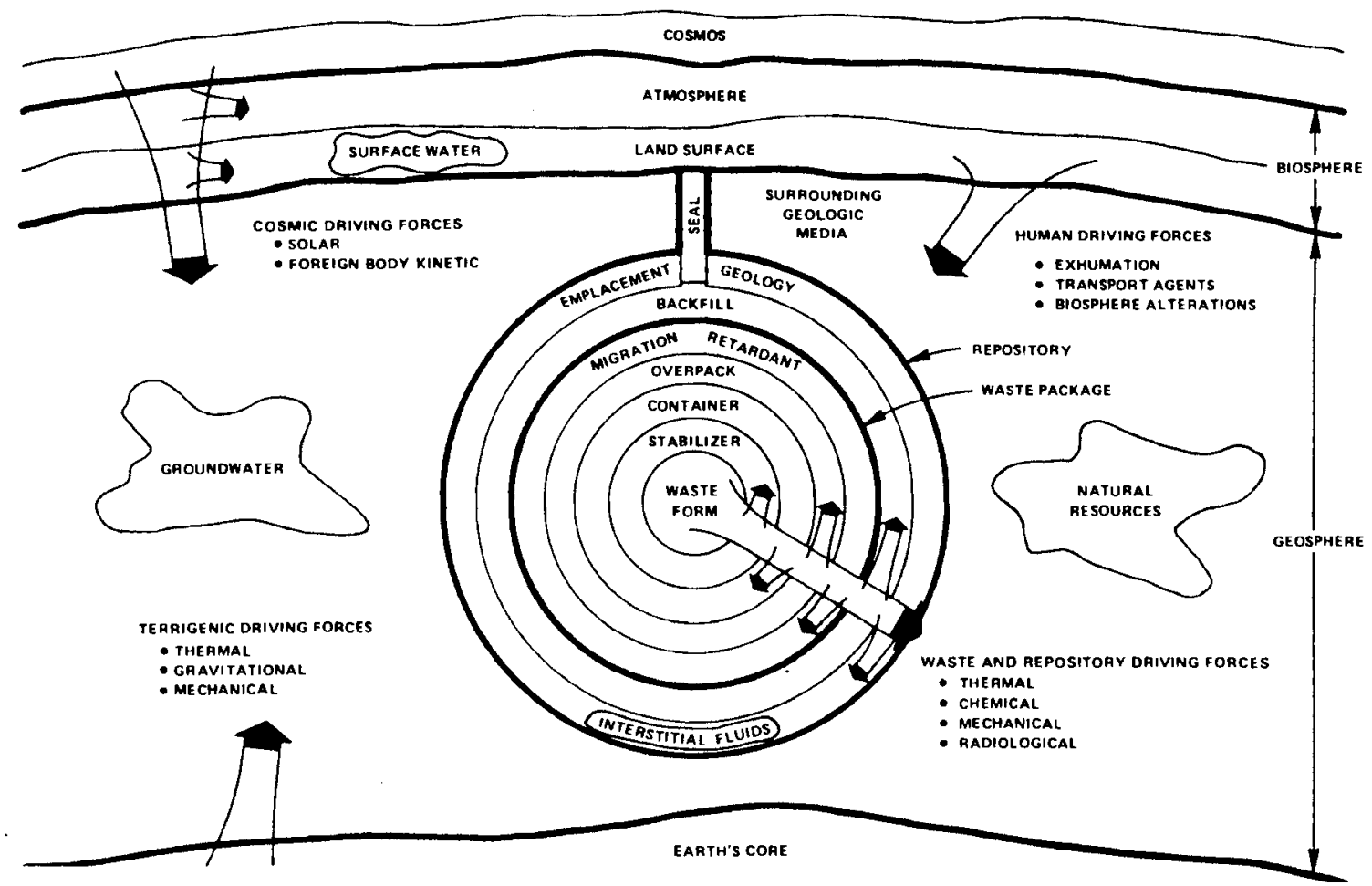

The use of multiple barriers to prevent the escape of radioactivity from a waste repository. The diagram shows the many layers of material and lists the forces that act. (Courtesy of Office of Nuclear Waste Isolation, Battelle Memorial Institute.) 
Some other facts about glass are not widely known. It is called amorphous because it has no definite crystalline form, in contrast to substances like ice, salt, and sugar. The use of the word "crystal" to describe a form of glass is a misnomer. Glass exists in what is called a vitreous condition (a supercooled liquid). As the temperature is raised. glass melts and flows as a liquid, making it easy to pour and cast into blocks. The solid or vitrified material is strong, but under the influence of heat, mechanical stress, and radiation it can shatter into small pieces. It is, however, devitrified glass that has been used in the laboratory experiments, and excessively high temperatures are not expected in the repository.

Glass is mainly the common element silicon, an ingredient of sand, but there are many other elements as well. Typical commercial glass as used for bottles or window panes has this composition:

\begin{tabular}{lrr} 
Compound & & Percent \\
\cline { 1 - 1 } Silica (silicon dioxide $\mathrm{SiO}_{2}$ ) & & 71.5 \\
Soda (sodium oxide $\mathrm{Na}_{2} \mathrm{O}$ ) & & 14.0 \\
Lime (calcium oxide $\mathrm{CaO}$ ) & & 13.0 \\
Alumina (aluminum oxide $\mathrm{Al}_{2} \mathrm{O}_{3}$ ) & & 1.5
\end{tabular}

The glass-waste mixture prepared by the French in a plant at Marcoule has a composition much like that of Pyrex glass, used for cooking because of its strength and resistance to temperature. The glass is the borosilicate type, in which boron oxide replaces lime. When fission products (FP) from reprocessed fuel are included, the French glass has this composition:

\begin{tabular}{lr} 
Compound & Percent \\
\cline { 1 - 1 } Silica & 42.5 \\
Soda & 14.0 \\
Boron oxide & 17.5 \\
Alumina & 8.5 \\
FP axides & 13.0 \\
Other & 4.5
\end{tabular}

The appearance of the latter glass resembles stained glass as in church windows.
The volume of glass needed to contain the wastes is rather small. If all electricity in the U.S. were produced by nuclear power and the high-level wastes were solidified, each person's yearly "share" of glass would be about the size of a 3/4-in.-diameter marble. Expressed otherwise, one 8-in.-diameter. 10 -ft-long canister would contain wasteglass for 35,000 people for a year.

The glass-waste procedures developed by the United States and France are similar. Each starts with a liquid waste that has been allowed to cool radioactively for a number of years. As shown in the cutaway drawing, it is sprayed into a furnace (kiln) which heats the material in air to form oxides into a fine dry powder that is called calcine. Small granules of glass (frit) are added to the dried wastes, and the mixture falls into a melting pot heated by electricity. The glass-waste mixture is drawn off into a stainless steel canister, the contents are allowed to cool thermally. and the container is sealed.

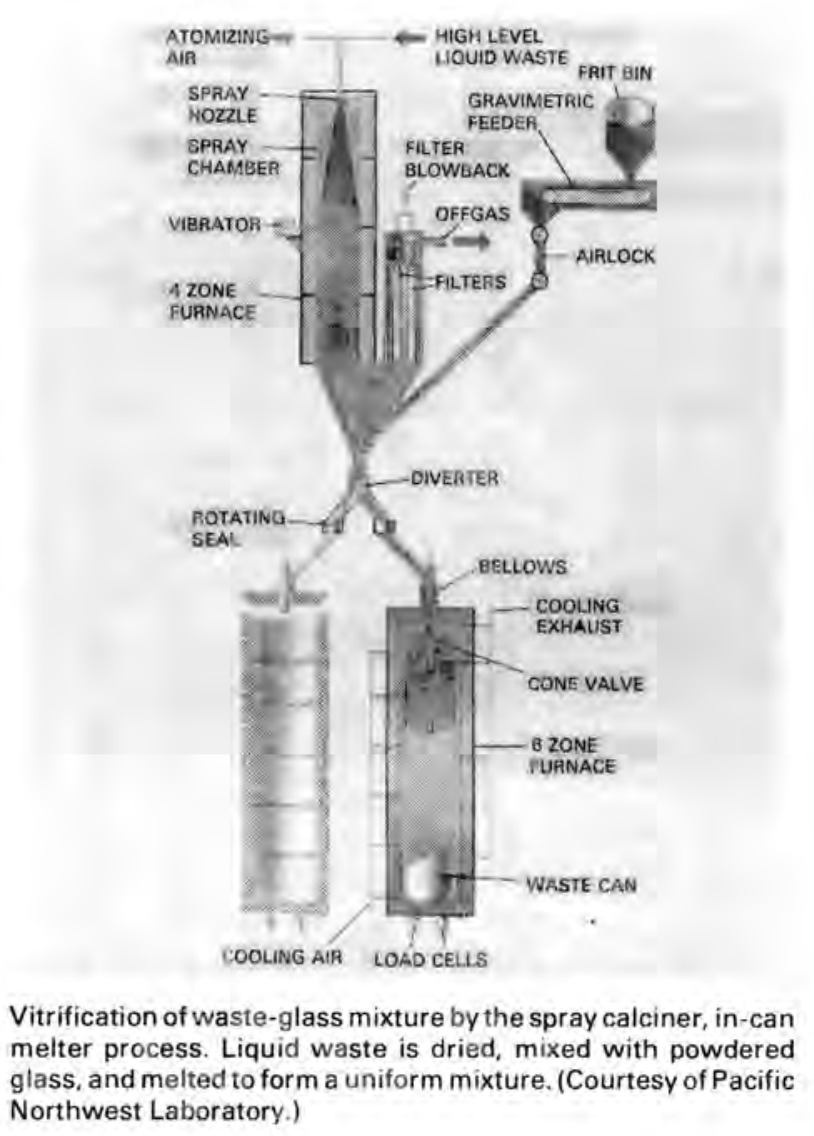


In the French method, canisters are then transferred to a temporary storage vault, consisting of an open cavity with a large number of racks into which canisters are placed. Air is circulated through the vault to remove waste heat, but the canisters would stay well below the temperature for devitrification of the glass, even if the air blower stopped and natural heat convection took over. The French plan to store canisters for a number of years, until the time comes to place them in a permanent disposal site.

\section{Containers}

This canister wall should also be resistant to leaching of water or water plus dissolved chemicals, since it provides temporary protection for the waste. The canister may be needed for strength if the waste is ever to be retrieved. The container materials most often considered are ordinary steel and, except for use in contact with salt, stainless steel. We will discuss other more resistant materials later.

\section{Packing}

Additional barriers may be inserted to prevent radioactivity from escaping. One such obstacle is the overpack, which is a layer of metal, ceramic, or cement that surrounds the container. Another is the buffer, a material such as bentonite, a clay that swells when it becomes wet. Such expansion and the natural filtering of clay prevents water and other chemicals from getting to the container. A third packing is the backfill, an absorptive or resistant substance that fills the hole from the repository to the surface of the earth.

\section{Geologic Medium}

The next barrier is the host medium, the geologic material that separates the repository from populated regions. The site should be far from faults in the earth's crust, from earthquake zones, and from known or potential volcanoes, and should not contain known valuable resources. There are many possibilities for this solid medium, including salt, basalt, granite, shale, and tuff, a compacted volcanic deposit.

Radiation from the waste will somewhat affect the medium in the immediate vicinity of the canisters. Heat from the waste will be conducted to greater distances, however, and the highest temperature will occur decades after the wastes are placed. The temperature dictates the size of the repository. For one with salt as the geologic medium, the maximum allowed areal heat is around 120 kilowatts $(\mathrm{kW})$ per acre. A higher temperature will damage the salt. For a typical PWR, 25 metric tons $(25,000 \mathrm{~kg})$ of spent fuel are taken out of the reactor each year. If the fuel is held for decay for several years, then reprocessed, and the high-level wastes are put into glass, the resulting volume of glass is about 2.25 cubic meters $\left(\mathrm{m}^{3}\right)$. Since the waste canisters ( $1 \mathrm{ft}$ diameter, $10 \mathrm{ft}$ long) have a capacity of $0.22 \mathrm{~m}^{3}$, it takes 10 canisters per year to accommodate one reactor.

Assuming each container yields $4 \mathrm{~kW}$, only about 30 canisters per acre of land can be put in place. Thus, it requires $1 / 3$ acre each year to take the high-level wastes from one reactor. For 72 reactors in operation, the yearly demand for land area is 24 acres. This is a minimum because there is a large back$\log$ of spent fuel needing treatment and there is an accumulation of transuranic wastes. Even so, it appears that the total land area for commercial reactor wastes for the rest of this century is a few square miles at most and that no more than two repositories would be needed.

\section{The Water Cycle of the Earth}

As it is important that the repository site be highly impermeable to water, let us

\footnotetext{
*Data on all aspects of waste isolation appear in many references, but a readable series of reports is Technical Support of Standards for High-Level Radioactive Waste Management, Volume A: Source Term Characterization; Volume B: Engineering Controls; Volume C: Migration Pathways. U.S. Environmental Protection Agency, 1977.
} 
briefly consider how the water cycle works. The "water cycle" of the earth is driven by energy from the sun. As we see in the sketch, water is evaporated from streams, lakes, and the ocean. It forms into clouds and falls as rain or snow on the land. Part of the water soaks into the ground, and part of it runs off, eventually reaching the streams that carry it to the sea. Water also leaves the earth by evaporation from the surface and by transpiration of vegetation.

A "water table" is formed at some distance under the ground surface. It can be thought of as the top of the body of water that settles in the ground. A water table varies somewhat in the course of a day or according to season. A well from which water is to be drawn must penetrate at least as deeply as the water table and preferably much deeper.

Water flows within the earth by means of aquifers, which are bodies of porous rock that readily conduct water. An example would be a layer of gravel. As shown in the drawing, underground water generally tends to flow toward depressions just as surface water does, but much more slowly. If there is a great deal of rainfall and there are good aquifers, the water table will be near the surface. If there is little rainfall and the rock is impervious to water, the water table may be thousands of feet down. There may be more than one aquifer, separated by impervious material. Fortunately, aquifers tend to lie parallel to the earth's surface so that water flow is not directly upward.

The "permeability" of a substance is a property that describes the ability of water to pass through. Materials with high permeability are gravel, limestone, and loose sand. Those with low permeability are salt, granite, clay, and tuff. One favorable feature of underground water flow is the filtering action the earth provides. Chemicals are trapped by the particles or walls of the crevices through which the water percolates. The amount of such purification depends on the chemical species, of course. The amount of certain long-lived radioactive chemicals that can be dissolved in water is less than that

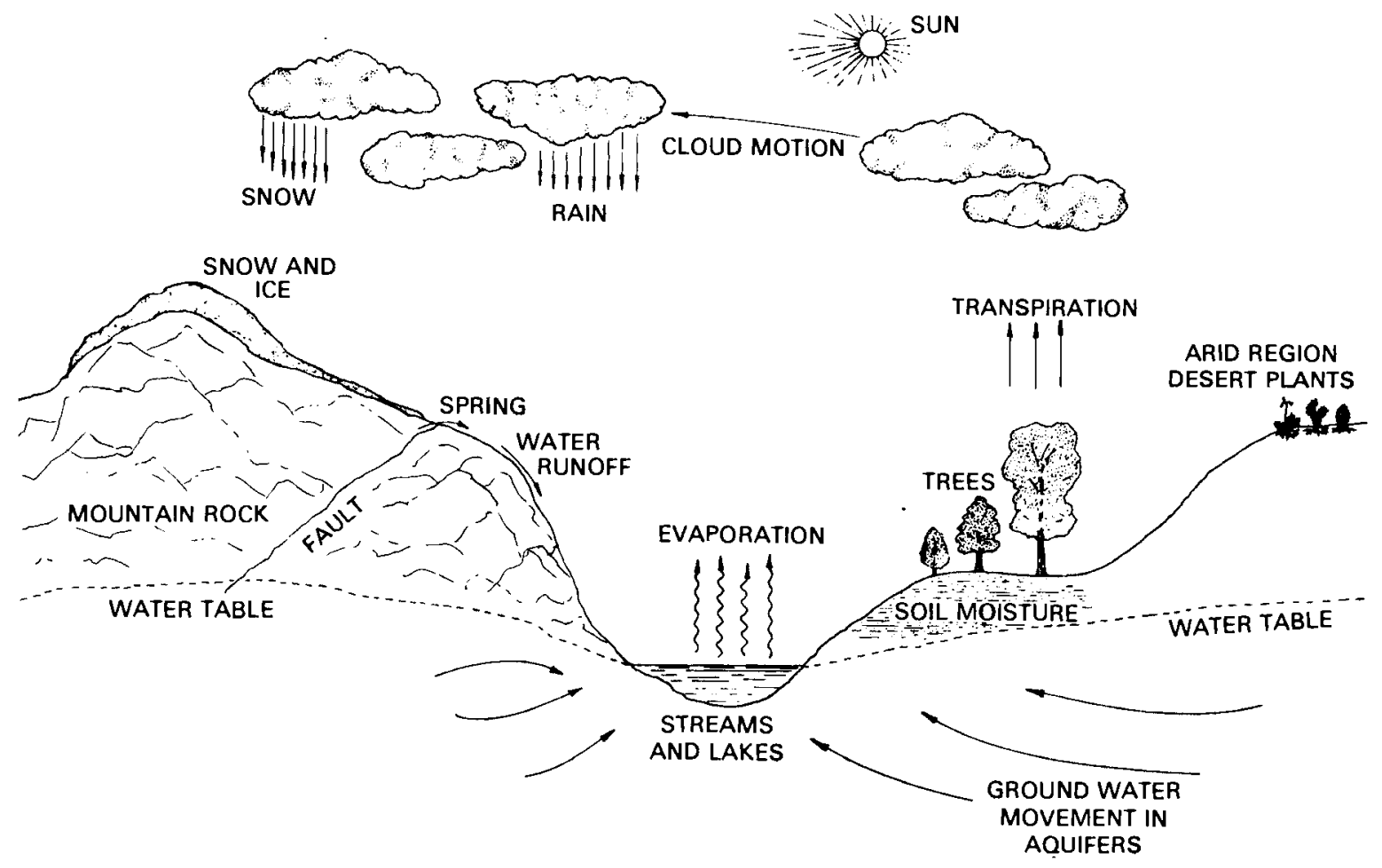

The water cycle. Precipitation falls on the earth, water flows within the ground, and evaporation completes the cycle. 
corresponding to the maximum permissible concentration. It is worth noting that we get from the ground in general a high-quality water, safe to drink despite the natural presence of minerals, including uranium.

\section{System Performance}

Calculations on the reliability of a wastedisposal repository as a system must take account of many factors. Two readily identified factors are the original amounts of each radioisotope and the date the waste is deposited. All half-lives and isotope chains are accurately known. An estimate is made of the length of time the canister holds up, for example, several hundred years; after this time, water could contact the waste form, probably glass. Using reasonable leach rates, the rate at which isotopes are released underground is obtained. Rates of flow, away from the site and through the geologic medium to a river at some distance, would be calculated for the individual isotopes, using data on typical subsoils and accounting for the tendency of chemicals to deposit along the paths within the earth.

In one study by the Pacific Northwest Laboratory, ${ }^{*}$ the dose was predicted for a person living near a river, drinking its water and eating aquatic food and irrigated crops. The affinity of chemicals for specific organs of the body was included in the calculation. The overall conclusions of this particular study were "potential incremental radiation

"H.C. Burkholder, M.O. Cloninger, D.A. Baker, and G. Jansen. "Incentives for Partitioning High-Level Waste." Nuclear Technology, November 1976. doses would be of the same order as or less than doses from natural sources" and "the methods developed can be applied to evaluating combinations of waste type and geologic medium...."

A rough measure of the time the repository must be secure can be developed. The graph shows the trend with time of potential ingestion toxicity of two types of material. One is the high-level wastes, assuming no reduction during migration from the repository. The other is the ore body that supplied the uranium used by the nuclear reactors that produced the wastes. The plots are seen to cross at around $600 \mathrm{yr}$. This figure would change, of course, if the method of calculating dosage were revised.

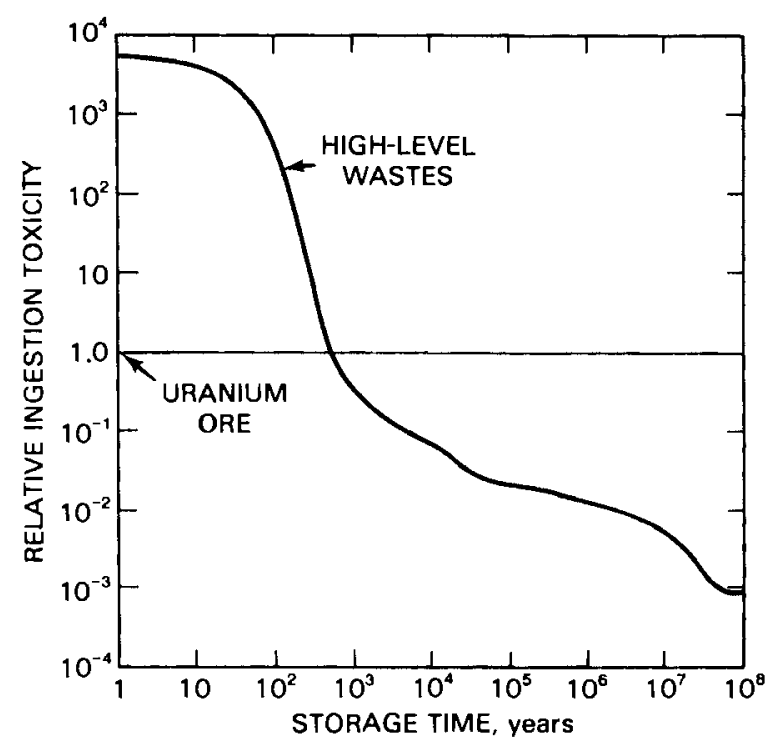

Comparison of toxicities. High-level waste toxicity exceeds that of the uranium ore from which it came until about 600 years out of the reactor. 


\section{RESEARCH ON WASTE ISOLATION}

The favored potential disposal method for high-level wastes for many years has been the placement of canned glass-waste mixtures in underground salt mines. The difficulties, however, following Project Salt Vault led to consideration of using a surfacestorage technique for the time required to consider and develop alternatives. More recently, questions were raised by some scientists about the integrity of glass as waste form in comparison with other potential materials. The choice of rock salt in preference to other host media such as granite and basalt was also questioned.

Research was begun at many laboratories to provide answers. These investigations are in the categories of waste form, container, host medium, and systems of these. Reports on progress in such research are now in the more readily accessible technical literature.* Data are also being assembled on geologic features that might be favorable to waste isolation. Improved methods have been developed for predicting the long-term behavior of buried waste. These "models" are blends of physical and chemical principles, mathematical theory, experimental data, and calculations using powerful computers.

\section{Research on Glass as Waste Form}

Studies of glass show that virtually all metal oxides are soluble in glass, which favors their retention. Other research reveals the conditions under which glass devitrifies, that is, cracks into pieces. The influence of mechanical stress, temperature, radiation,

\footnotetext{
"As, for example, in Gregory J. McCarthy, Editor, Scientific Basis for Nuclear Waste Management, Vol. 1, 1979, and Vol. 2, 1980. Plenum Press, Clyde J. M. Northrup, Jr., Editor.
}

and corrosion are examined. Of special interest is the effect of water, salt water, saltwater brine, and bitterns, which are brackish residues after salt has crystallized out of salt water. The amount of leaching has been found to vary with the elements. For example, the amounts removed per day (in micrograms per square centimeter) are cesium 1, strontium 0.1 , cerium 0.01 , and ruthenium 0.001 .

It turns out that glass, even when devitrified, has a better laboratory-measured resistance to corrosion than most other materials. Using a standard test procedure, measurements were made of the weights leached away by water for glass-waste and various minerals that have existed in nature for very long periods of time, as follows:

\begin{tabular}{|c|c|}
\hline Mineral & Percent \\
\hline Quartz & 0.41 \\
\hline Devitrified waste glass & 0.70 \\
\hline Granite & 1.10 \\
\hline Marble & 2.90 \\
\hline Slate & 4.10 \\
\hline Basalt & 6.10 \\
\hline
\end{tabular}

The length of time it takes for glass to devitrify depends on the temperature. Experiments suggest that the time is a million years at $300^{\circ} \mathrm{C}$ but only a thousand years at $400^{\circ} \mathrm{C}$. By suitable choice of dilution of waste and size of container, the temperature can be limited, say to $200^{\circ} \mathrm{C}$. Many researchers note that the processes in glass are quite complicated. Laboratory neutron bombardment of boron glass releases alpha particles that provide radiation effects in a very short time, thus accelerating the testing procedure greatly. The general conclusion is that glass is a reasonable material for waste form. Although there are other materials 
that will be more resistant to the effects of heat, water, and radiation, their processing may be more complex and they may not dissolve all the waste elements, as does glass.

\section{Natural Minerals to Hold Wastes}

Several alternative waste forms have been investigated. Among these is pollucite, a natural mineral that contains aluminum, silicon, and cesium. A waste form using pollucite would thus bond radioactive cesium very well. Much emphasis has been placed on "supercalcine." (To calcine a substance means to heat it to high temperature.) In the supercalcine process, waste materials in the form of natural minerals (pollucite, scheelite, fluorite, apatite, spinel, and corundum) are formed into a crystalline ceramic. Another form is "SYNROC" (for synthetic rock) as named by its inventor. It consists of a blend of a well-selected group of natural minerals (perovskite, zirconia, hollandite, barium felspar, leucite, kalsilite mica, sphene, fresnoite) which could contain key radioisotopes and can resist weathering and corrosion. Other investigations involve waste-glass spheres coated with a resistant material such as aluminum oxide or waste particles embedded in the element lead.

The next layer in the system of multiple barriers is the container material. Studies of the interaction of water and brine with stainless steel show that deterioration occurs quickly. Other materials being considered for canisters are mild steel, copper, titanium, and corundum (aluminum oxide). Investigations in Sweden have led to predictions that canisters made of these special materials can last thousands of years.

Special materials for holding wastes or for use in plugs and seals that prevent waste transfer through mine shafts are cement, concrete, asphalt, and mixtures of material such as bentonite and cement.

\section{Choices of Geologic Medium}

Several materials are candidates for the host geologic medium. Note on the three maps that in addition to rock salt in the Western and Gulf states, there are basalt and granite and argillaceous materials (clay and shale).

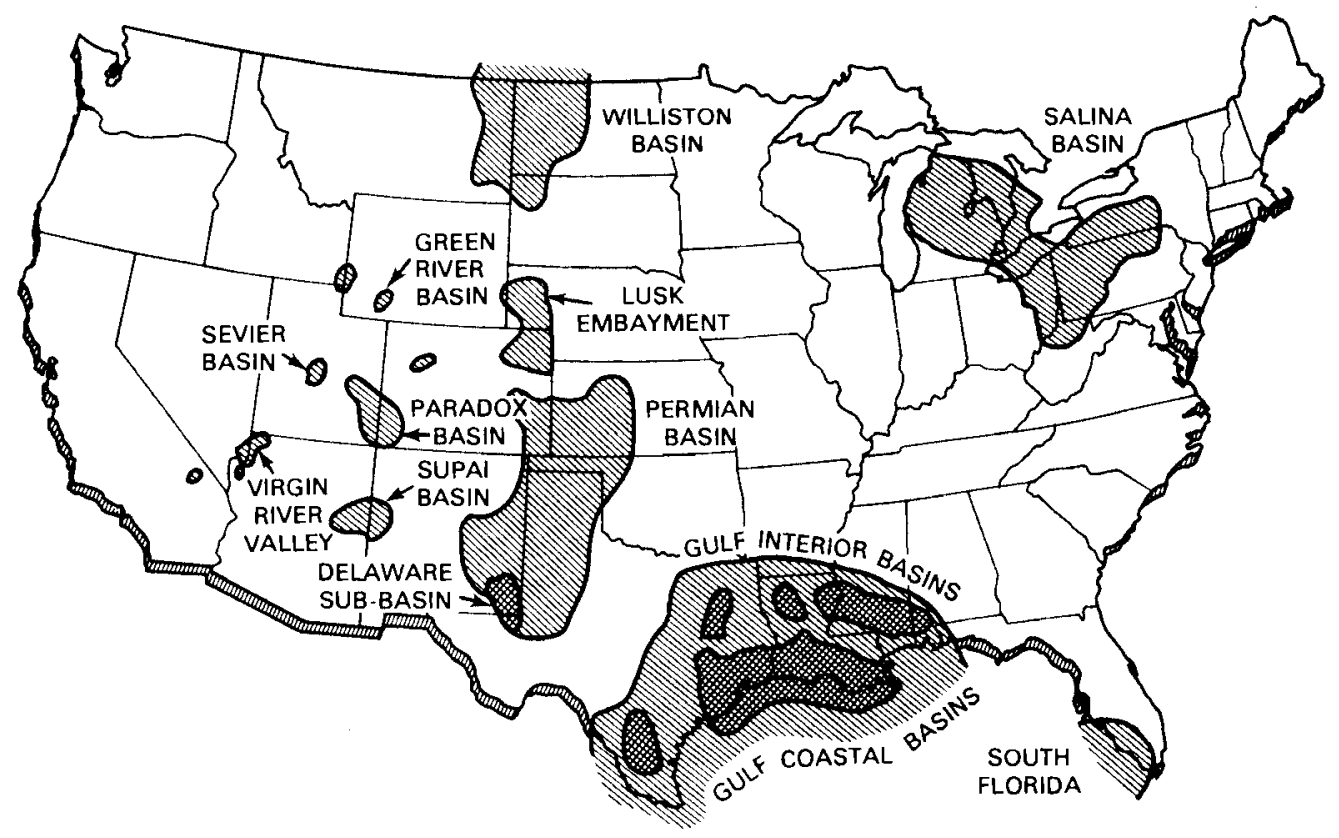

Rock salt deposits in the U.S. (From Reviews of Modern Physics, January 1978.) 


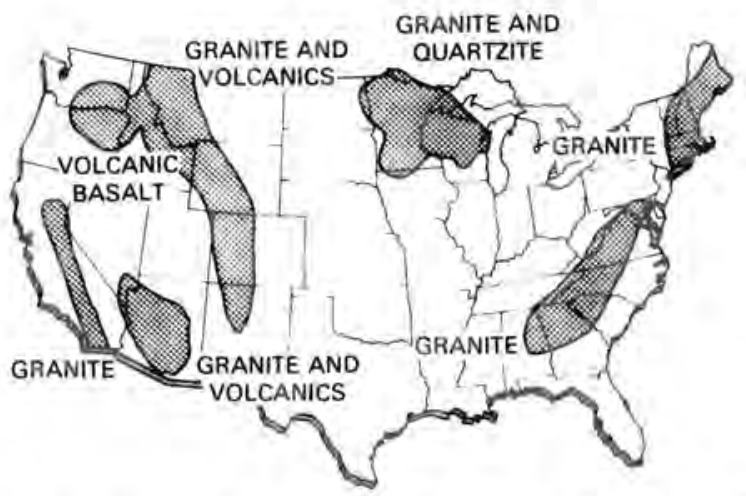

Deposits of crystalline rock (basalt, granite, tuff) in the U.S (From Reviews of Modern Physics, January 1978.)

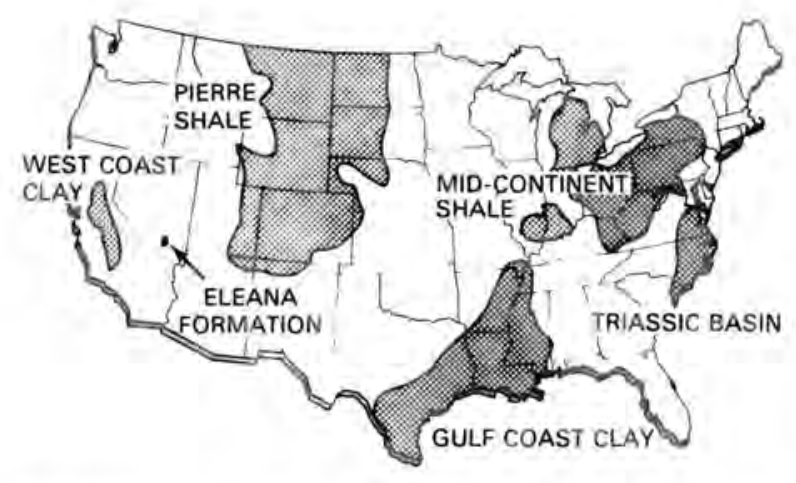

Deposits of argillaceous material (clay and shale) in the U.S. (From Reviews of Modern Physics, January 1978.)

Research on all these materials involves measurement of their porosity (the fraction that is space) and of their permeability, a number that describes the ease of water flow. There is a wide variation in the permeability among materials. Note its numerical value for the following substances, all of which have a porosity of about $1 / 2$, i.e., half solid and half space:

\begin{tabular}{lc} 
Material & Permeability \\
\cline { 1 - 1 } Clay & 0.000016 \\
Silt & 0.33 \\
Sand & 25.3 \\
Gravel & 1130
\end{tabular}

Roughly these numbers represent the rate of flow under a certain water pressure. Rates of flow of water through fissures (rather than through pores) in rock are also being measured. Other properties such as density, heat conductivity, and strength are measured so that the migration of radionuclides from the repository can be calculated.

\section{Models and Measurements}

The ultimate objective of a waste repository is to prevent significant amounts of radioactivity from reaching the public. It is generally understood that the required time for isolation is so long that actual tests of effectiveness cannot be made. The integrity of the repository, i.e., its satisfactory retention performance, must be assessed by the use of data and models. These lead to predictions of the rate at which radioactive materials might leak from the repository and what the exposure dosage might be under various circumstances.

The models used to predict waste repository performance have been partially checked, however, against the data on radioisotope migration at a "natural reactor" site. About two billion years ago, a nuclear chain reaction developed in uranium ore in Africa at Oklo, Gabon.* At that early date, the isotope $235 \mathrm{U}$ was more abundant relative to $238 \mathrm{U}$ than at present, and a natural chain reaction occurred. Neutron multiplication caused fission product isotopes to be produced, and a small migration of radioactivity in the ground occurred.

Suitable locations for repositories should have several special features. It is obviously preferable that they be far from human habitations. Generally, arid regions are better, and the repository should be located well above the water table or deep beneath aquifers. The rock should be uniform, free of pockets of water, streams, or defects such as breccia pipes (regions where the rock has caved in). The area should not have had prior intrusion by human activities such as mining or drilling for oil or water.

The techniques of measurement used by geologists and mining engineers can be used to explore a particular site. Samples of

\footnotetext{
"George A. Cowan, "A Natural Fission Reactor," Sclentific American, July 1976, p. 36.
} 
the rock can be taken, and properties such as porosity and permeability can be studied in the laboratory: but measurements in the field, at actual sites, often are more reliable. The slope of the water table (hydraulic gradient) can be found from water levels in wells, but in some cases the slope depends on prior water removal and is changing with time. If the slope is very small, one cannot be sure in which direction the water will flow.

Several physical methods are available to obtain data on the geologic medium. Seismic (sound) methods involve the reflection of waves from underground layers or unusual shapes. Radar (electromagnetic radiation) is useful for dry rocks, but not if a water layer is present. Electrical resistance measurements are useful near the surface. Drilling is more reliable than are some of the other methods, but it has the disadvantage of disturbing the potential site. To find defects, a large number of holes must be drilled. For example, in a site with an area of 3 square miles, it takes 300 holes to find a possible flaw of $600 \mathrm{ft}$ diameter.

Wide-ranging exploration is needed to find good locations for underground waste storage. Certain features are sought; others are avoided. In selecting a site, attention must be given to previous exploration for oil, to mineral boreholes (for example potash), and to solution mining. The locations of conventional mines are usually easy to find.

Repositories should be located in areas where earthquakes are unlikely. The chief concern would be for the safety of personnel involved in building, loading, and monitoring the facility. The effect of an earthquake deep in the earth is regarded as small. Every state in the United States but one (North Dakota) has experienced earthquakes of some intensity.* Areas with high frequency and intensity are located in Alaska, along the California coast, in western Nevada, and at

-Earthquake History of the United States, Publication 41-1 through 1970. U.S. Dept. of Commerce, 1973: Supplement 1971-76, U.S. Department of Commerce and Interior, 1979. The latter report includes a good description of each level of intensity on the Mercalli scale. the intersection of Missouri, Arkansas, Kentucky, and Tennessee. The midwestern states are relatively free of earthquakes. A rough seismic risk map of the lower 48 states is shown. Data on earthquake activity have been computerized for use in the nuclear waste program by Pacific Northwest Laboratory.

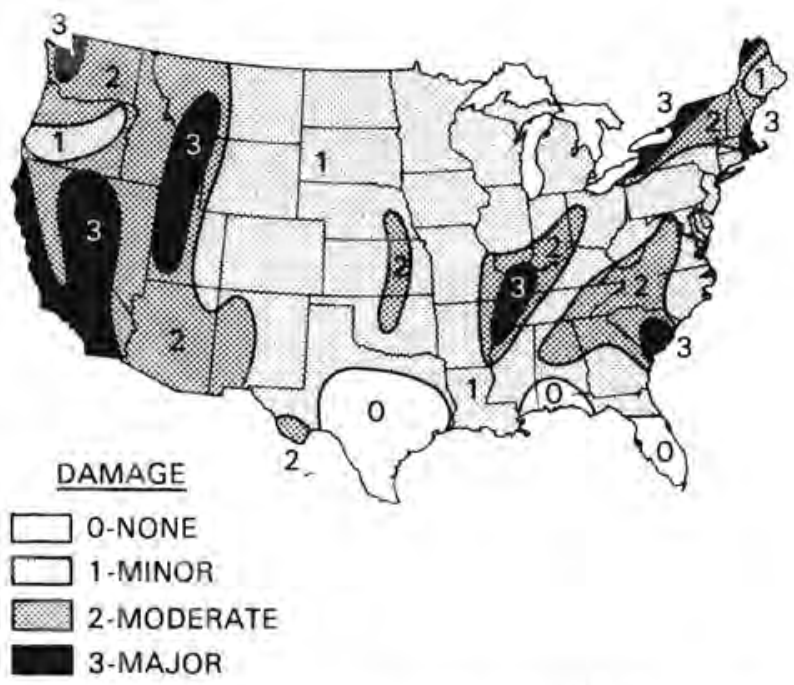

Seismic risk map for the "lower 48 " of the U.S, (From Earthquake History of the United States. U.S. Dept. of Commerce.)

The site should obviously not be near an active volcano. In the United States, the main volcanic areas are Hawaii, the coast of Alaska (especially along the Aleutian Islands) and the Cascade Mountains of the northwest. Included in the latter are Mt. Baker. Mt. Rainier, Mt. Shasta, Lassen Peak, and the now-familiar Mt. St. Helens, which erupted in 1980.

On the other hand, the products of ancient volcanoes are excellent candidates for host media. Hot ash and pumice deposited long ago by volcanoes have formed plateaus of solid rock called welded tuff. Lava in the form of basalt has formed a vast plateau in the Columbia River areas of Washington and Oregon. + Both tuff and basalt are nearly impervious and thus are promising

†Suggested reading is the brochure "Volcanoes of the United States," U.S. Dept. of the Interior Geological Survey. 
geologic media for waste disposal. DOE studies of basalt as a geologic medium are under way at the Hanford Site in Washington State. Electric heaters providing $5 \mathrm{~kW}$ to simulate canister power are embedded in the rock in three tunnels $700 \mathrm{ft}$ long. The measured temperatures, in the range of 200 to $300^{\circ} \mathrm{C}$, are well below the temperature for devitrification of glass.

The role of geology and of geological scientists is becoming more prominent in repository studies and design. Contributions to the selection of waste repository sites are being made regularly by the U.S. Geological Survey* and scientists of the universities.

The result of the studies of waste forms, container materials, packings, and geologic media will lead to a system in which each barrier will contribute to the holding of waste radioisotopes and the prevention of

\footnotetext{
*A recommended article is Geological Survey Circular 779, Geologic Disposal of High-Level Radioactive Wastes-Earth Science Perspecttves, by J.D. Bredehoeft, A.W. England, D.B. Stewart, N.J. Trask, and IJ. Winograd, 1978.
}

their reaching man. From one standpoint the system will be "overdesigned" in that there is a greater retention or delay of movement than is needed. From another view, there will be ample safety factors to protect against unexpected failures of components.

It is encouraging to consider the fact that rates of corrosion and migration of materials in the ground are rather small; otherwise the surface of the earth would not be as stable as it is. There is growing evidence that the geology is very favorable to the retention of wastes, which means that the waste form and container merely provide redundant protection.

Although research will continue on all components of the engineered and natural barriers to waste migration, it is generally believed that sufficient information is available to go ahead with actual test disposal. Future efforts are likely to be based on the engineer's policy in building any practical system: there eventually comes a time when a decision must be made to proceed, even though the perfect design is not available. 


\section{LEGAL REQUIREMENTS}

\section{Acts of Congress on Atomic Energy}

The handling of radioactive materials has been subject to laws and regulations for about 35 years. Governmental organizations and procedures have evolved since the Atomic Energy Act of 1946 was passed. It declared U.S. policy to be "... .that, subject at all times to the paramount objective of assuring the common defense and security, the development and utilization of atomic energy shall, so far as practicable, be directed toward improving the public welfare, increasing the standard of living, strengthening free competition in private enterprise, and promoting world peace." The Act (Public Law 585) established the Atomic Energy Commission (AEC) and directed it to, among other things, conduct research and development on the uses of fissionable and radioactive materials for medical, biological, health, industrial, and military purposes. Nuclear wastes were not specifically mentioned in the Act.

The Atomic Energy Act of 1954 was a considerably expanded version that encouraged both domestic and international development and utilization of atomic energy. This Act, with its amendments, has since served as a basic legal reference. Among its provisions was the congressional oversight of nuclear matters by the Joint Committee on Atomic Energy (JCAE). This body was required to hold hearings regularly and to conduct studies of the AEC's function. The Act provided for the regulation of the following: source materials (e.g., natural uranium), special nuclear materials (e.g., plutonium or enriched uranium), and by-product materials (other radioactive substances such as fission products and activation products).

The Federal Radiation Council, consisting of several cabinet members and the chairman of the AEC, was formed in 1959 to advise the President on radiation matters.

The National Environmental Policy Act of 1969 (NEPA) has had far reaching effects. Its purposes are "to prevent or eliminate damage to the environment and biosphere and stimulate the health and welfare of man." The Act also created the Council on Environmental Quality (CEQ), an advisory and coordinating group reporting to the President. The law requires every Federal action that might have a significant effect on the human environment to be accompanied by an Environmental Impact Statement (EIS), stating potential adverse effects and alternatives to the proposed action.

\section{Environmental Impact Statements}

Environmental Impact Statements play an important role in all decision-making processes. In the past, the Federal government was able to start new major programs after some studies of benefits and costs, but without reporting to or consulting the public. Under NEPA, an EIS must be prepared in great detail, taking into account these matters:

- Environmental effects, good and bad.

- Possible alternative actions to achieve the same objective.

- The relationship to resources and production.

The EIS that describes plans for disposal of commercial wastes is a report, ${ }^{*} 3-1 / 2$ in. thick, covering such matters as:

The proposed action-the use of mined geologic disposal.

\footnotetext{
*Final Environmental Impact Statement Management of Commercially Generated Radioactive Waste. DOE/0046F. U.S. Department of Energy, October 1980, Volumes 1, 2 and 3.
} 
A description of a repository.

Environmental impacts-radiological, resource needs, social and economic effects, land use, and effect on ecology.

Study of a total of nine different ways of handling waste and the selection of the better ones.

Back-up calculations, data, and literature references.

A collection of written public comments on a first draft EIS from individuals, industry, public interest groups, and State and Federal government. Responses to comments are given by DOE.

Report by a Hearing Board composed of nonDOE scientists, who conducted meetings to help achieve a satisfactory final EIS.

The requirement for an environmental impact statement means that the government plans are out in the open, giving the public a chance to advise, support or object.

Shortly after NEPA was passed, the Environmental Protection Agency (EPA) was established in the executive branch. It was charged with responsibility for air and water quality standards, limits on emissions of pollutants from manufacturing plants and from automobiles, and control of hazardous materials of all kinds, including radioactive wastes disposed of in waters. EPA took over authority from the AEC for setting environmental radiation protection standards and absorbed the duties of the Federal Radiation Council. The agency provides several mechanisms for public interaction-through hearings, public meetings, and advisory groups. For nuclear waste disposal EPA provides guidelines on all radiations affecting health, without reference to the method used or the repository site. Numerical values of radiation standards refer to each type of waste, such as high-level waste and discarded spent fuel. Its general environmental criteria were published in 1979.

\section{AEC, ERDA, NRC, DOE and Other Agencies}

The Energy Reorganization Act of 1974 divided the functions of the AEC-developmental and regulatory-between two new agencies, the Energy Research and Development Administration (ERDA) and the Nuclear Regulatory Commission (NRC). The Act consolidated all energy-related activities of the Federal government under one organization (ERDA).

The NRC, consisting of five members including the chairman, was set up to have licensing and regulatory authority over demonstration reactors, facilities for receipt and storage of high-level radioactive wastes, and "retrievable surface storage facilities" for long-term storage of radioactive waste. The Commission was authorized and directed to survey possible "nuclear energy center sites," which include facilities for enrichment, fabrication, irradiation, reprocessing, and waste storage. The NRC has the responsibility for licensing and regulating the possession, use, transportation, handling, and disposal of radioactive wastes. It is charged with ensuring public participation in hearings by admitting intervenors or accepting oral or written statements. The NRC is also required to develop working relationships with the States on regulation of nuclear material. Agreement States are those that have accepted authority for licensing and regulation of low-level waste operations, within NRL guidelines.

The present guidance by the NRC on nuclear waste management has been in effect for several years. In the Code of Federal Regulations Title 10 Energy we find a section on Waste Disposal. In 10CFR20 Sections 106 and 301 through 305, jurisdiction is defined and limits are set on release into air or water, or release to sanitary sewerage systems, on disposal by burial in soil, and on treatment or disposal by incineration. Regulations in Appendix F of 10CFR50 state, "A 
fuel reprocessing plant's inventory of highlevel liquid radioactive wastes will be limited to that produced in the prior 5 years...," and "High-level liquid radioactive wastes shall be converted to a dry solid . . . and placed in a sealed container prior to transfer to a Federal repository . . . All of these high-level radioactive wastes shall be transferred to a Federal repository no later than 10 years following separation of fission products from the irradiated fuel ...Disposal of high-level ... waste material will not be permitted on any land other than that owned and controlled by the Federal Government." There is no regulation on the subject of time limits on unreprocessed spent fuel.

The Energy Organization Act of 1977 replaced ERDA by the Department of Energy (DOE), whose Secretary is a part of the President's Cabinet. Absorbed were ERDA, the Federal Energy Agency (FEA), the Federal Radiation Council (FRC), and several other programs of different government departments. The Secretary of Energy has an Assistant Secretary for Nuclear Energy. DOE has the authority to conduct research and development on waste repositories and would also operate repositories once they are licensed. The main steps in the process are site studies, site selection, and facility design, test, and operation.

The Federal Emergency Management Agency (FEMA) has the duty to develop plans for response to emergencies involving radioactive material, for example, a nuclear reactor accident. FEMA works closely with State agencies and other Federal agencies.

The Department of Transportation (DOT) provides rules on the shipment of radioactive materials of all kinds. These regulations take precedence over local bans on transportation. A state can plan routes but not prohibit transfer.

Various Federal studies of waste have led to useful recommendations. Examples are those of NRC in 1977 and of the General Accounting Office (GAO) in 1980. Among the recommendations were (a) better classification of wastes, (b) improved tracking from origin to disposal, (c) better data on sources, (d) improved volume reduction, and (e) initiation of national planning.

The State Planning Council was formed in 1980 by Executive Order to advise on radioactive waste management. It is composed of several governors and other local elected officials, and representatives of the main concerned Federal agencies. The Council is designed to help make decisions as well.

A new Federal organization, the U.S. Radiation Policy Council, came into being February 21, 1980, by Executive Order. It is composed of assistant secretaries from most of the departments and agencies involved in nuclear affairs. Its general function is to formulate radiation protection policies, to monitor their implementation, to coordinate information, and to interact with the public. Topics on which the Council has prepared reports are the problem of radioactive radon gas in homes and other buildings, the situation on occupational radiation exposure standards, and the status of low-level radioactive waste. Other studies include the management of radiological emergencies, public information, and international radiation units.

Geologic disposal of high-level wastes under the direction of the Department of Energy will be governed by rules set by the Nuclear Regulatory Commission, complying with standards of the Environmental Protection Agency. The diagram shows the interaction of these three main organizations in the research, development, operation, and regulation of waste repositories.

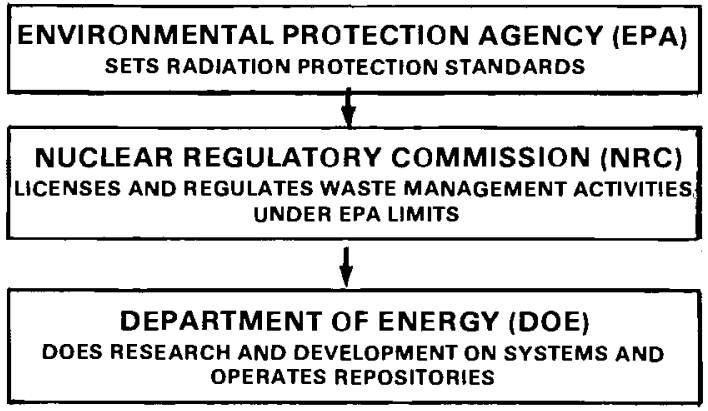

Relationship of three main governmental agencies in the commercial waste arena. 


\section{The Code of Federal Regulations}

Detailed regulations are provided by NRC in The Code of Federal Regulations. Some of the key features of draft regulation $10 C F R 60$ are noted here in very abbreviated form:

1. The lifetime of the repository is divided into natural phases-constructing the facility and placing wastes in it, the period of fission product decay, and the period of long-lived actinide decay.

2. A very thorough and comprehensive site study must be made. Many undesirable characteristics of a site will disqualify it, e.g., prior intrusion, presence of resources, possible flooding, etc. In contrast, favorable characteristics will enhance its licensing, e.g., great geologic stability, slow water movement, low population, little climate effect, etc.

3. The design of the waste package (waste form, container, overpack, etc.) shall take into account all nuclear, chemical, and physical properties and interactions.

4. The repository site should have a control zone around it, with prominent markers and records deposited around the world.

5. Wastes should be retrievable for 50 years after burial; no institutional control should be required after 100 years have elapsed; reasonable assurance of containment for 1000 years is expected. The annual percentage release thereafter should be less than a thousandth of a percent.

6. The assessment of the performance of the facility will be a combination of analyses using mathematical models, with conservative assumptions and calculations that take account of uncertainties, and utilizing expert opinion.

Increasing interest and concern about low-level radioactive wastes led to the enactment by Congress in late 1980 of the Low Level Waste Policy Act. It places the responsibility on the states to handle the waste problem with help from the Federal government, especially DOE. The Act also provides approval for states to form regional compacts. These are agreements to cooperate in storing and disposing of low-level wastes. Starting in 1986, a compact can exclude other states from using its burial site.

The Nuclear Regulatory Commission has prepared draft regulations (10CFR61) on disposal of low-level waste. The stated objectives briefly are:

- To achieve long-term confinement through multiple barriers without the need for maintenance.

- To provide regulations for all technical and administrative aspects of different types of disposal.

- To provide useful numbers and guidelines.

- To ensure that ground water is of drinking quality.

- To protect a person who reclaims a site.

The new regulation requires that wastes be treated according to the activity per gramthe higher the radioactivity, the greater the care to be taken.

Other organizations that contribute indirectly but significantly to the disposal of radioactive wastes are (a) the American National Standards Institute (ANSI), which develops written standards of quality, (b) the National Academy of Sciences, which sponsors special studies, (c) the American Nuclear Society, which publishes technical articles and books, (d) the National Governors' Association and the National Conference of State Legislatures, which maintain committees to advise on the waste situation.

Several public interest and environmental groups provide information and help develop public policy. Among them are the Sierra Club, the Union of Concerned Scientists, and the Natural Resources Defense Council.

The nuclear industry's views are represented by the Atomic Industrial Forum, Inc., which supplies information through its conferences and publications.

\footnotetext{
"Also see "General Criteria for Radioactive Waste Disposal" by Margaret N. Maxey, Laurence I. Moss, Burdon C. Musgrave, and Goldie B. Watkins in Scientffic Basis for Nuclear Waste Management, Vol. 2, Plenum Press, 1980.
} 
A comprehensive legal basis for the management of radioactive wastes is thus seen to be in place. It should be emphasized, however, that laws and organizations change with time-they are not carved in stone. Our representative system of government per- mits and encourages changes as needed. Thus new executive and congressional action on the handling and disposal of radioactive wastes can be expected, without volation of the basic concept of public participation. 



\section{THE NATIONAL RADIOACTIVE WASTE MANAGEMENT PROGRAM}

The details of any national program are inevitably determined by policies of the Federal administration then in office. This political fact has contributed to changes in direction in long-range waste management. There has been, however, a consistent policy to seek to protect workers and the public from hazard due to radiation. As soon as it was known that radioactive fission products existed, special precautions in handling them were taken. Research and design studies have been made over succeeding years on chemical processing, storage, and disposal.

In the Carter administration a formal plan of action was issued, based on recommendations of the Interagency Review Group, representing many different Federal government departments, agencies, and councils, as listed below:

Department of Energy

Department of State

Department of Interior

Department of Transportation

Department of Commerce

National Aeronautics and Space Administration

Arms Control and Disarmament Agency

Environmental Protection Agency

Office of Management and Budget

Council on Environmental Quality

Office of Science and Technology Policy

Office of Domestic Affairs and Policy

National Security Council

Nuclear Regulatory Commission.

Thereby input from all of the interested parties was acquired.

The Reagan administration continued many elements of the waste management plan but made several significant changes based on a new energy policy. We now list some of the highlights of the Reagan nuclear power and waste program.

\section{Nuclear Energy Policy}

The four main elements of the strategy "to achieve the full potential of fission energy's contribution to electrical energy supply" are stated as: converter reactor use, breeder reactor development and eventual use, spent fuel reprocessing, and the immobilization and disposal of high-level wastes. The premise is made that the reserves of natural uranium will be used up in a few decades, requiring the breeder to come into full deployment. Only through reprocessing of spent fuel can the breeder be supplied with its fissile fuel, plutonium. This leaves a high-level fission product residue to be disposed of.

\section{Protection of the Public}

Of primary importance in the national plan is the commitment to protect the public from harm from existing wastes and to demonstrate the technical feasibility of waste disposal in a timely way. The concept of geologic disposal in a mined cavity is emphasized, with the seabed and very deep hole methods as possible back-ups. The Office of Nuclear Waste Isolation at Battelle Memorial Institute, Columbus, Ohio, serves the Department of Energy as lead organization in planning and executing the program to isolate commercial high-level wastes.

\section{Public Participation in Decisions}

Suggestions and reactions by the public continue to be encouraged. Opportunity is given for both individuals and groups to have input to decisions, through the 
mechanisms of the environmental impact statement, as required by the National Environmental Policy Act. Among interested and concerned parties are state and local governmental officials, public interest groups, industrial representatives, technical experts, and individual citizens. The objectives of public participation are to distribute factual information, to improve decisions through open communication processes, and to achieve acceptance and cooperation in obtaining a safe program of waste management. Of special importance are agreement between the Federal government and the states in which waste is to be placed and acceptance by the people of the state. Other mechanisms for interaction include congressional hearings, public hearings sponsored by the Department of Energy and the State Planning Council, established in 1980.

\section{Storage of Existing Wastes}

Defense wastes will continue to be stored in a safe manner, and gradually converted into forms that are more convenient and secure.

\section{Management of Spent Fuel}

The Department of Energy plan does not provide Federal away-from-reactor spent fuel storage facilities. Instead, encouragement and assistance is given to electric utilities for expanding their storage space at reactor sites. Emphasis is placed on development of technology to increase storage capacity in a given volume.

\section{Construction of Terminal Storage Facility for Defense Wastes}

The Waste Isolation Pilot Plant (WIPP) near Carlsbad, New Mexico, is to be designed and constructed as directed by Congress, as a research and development facility. It is intended to demonstrate the safe disposal of wastes from defense activities, including both high-level wastes and transuranic wastes.

\section{Low-Level Wastes}

The national plan does not specifically cover these wastes. Technical assistance to the states, however, is provided to help them meet the obligations set by the Low Level Radioactive Waste Policy Act of December 1980. The lead organization is the National Low Level Waste Management Program. based in Idaho Falls, Idaho.

\section{Remedial Action Program}

Disposal of uranium mill tailings now located at 25 inactive sites will continue as required by law. This involves removing or stabilizing tailings piles. Tailings used in structures are to be removed to prevent radiation exposure to occupants in a few communities. Other remedial actions relate to radioactively contaminated sites that are no longer needed. Decontamination and decommissioning of previously used sites and Federally-owned surplus facilities are involved.

\section{Transportation Research and Development}

Safe, acceptable, and economical systems for the transportation of nuclear materials continue to be developed, supplementing those presently available or supplanting those that have become outmoded.

\section{Resolution of Institutional Issues}

Nontechnical issues that affect waste management are addressed through many processes-negotiation, legislation, regulations, referenda, and legal action. The roles of DOE and other Federal agencies will be better defined and extended as necessary. Examples are the Nuclear Regulatory Commission, the Environmental Protection Agency, the Department of Transportation, and the Department of the Interior.

\section{Commercial Waste Disposal Sites}

One of the main thrusts of the national program is to identify and qualify mined geo- 
logic sites for safe disposal of the high-level commercial nuclear wastes. Investigations continue on several different types of media. Basalt is being studied at the DOE Hanford Site in the State of Washington, while several materials-granite, tuff, and argilliteare considered in Nevada. There are several promising sites in the Gulf States and in Utah for the third type of medium, bedded salt or domed salt. These small-scale studies lead to a fuller scale test and evaluation program, which finally results in the formal establishment of a waste repository.

The final result of the combination of research, site surveys, testing, and construction would be one or more repositories of the type sketched here. Deep geologic disposal with the multibarrier approach is to be used. The facility would consist of a set of support buildings on the surface, one or two vertical shafts leading to the mine level thousands of feet below the surface, and an array of tunnels spreading out horizontally. Waste canisters would be placed in holes in the floors of these corridors, the holes would be filled, and the whole series of channels filled back to the surface.

\section{Key Milestones in the Waste Management Program}

Targets are:

(a) Finish design of a retrievable storage facility for high-level wastes in solidified form, in 1983.

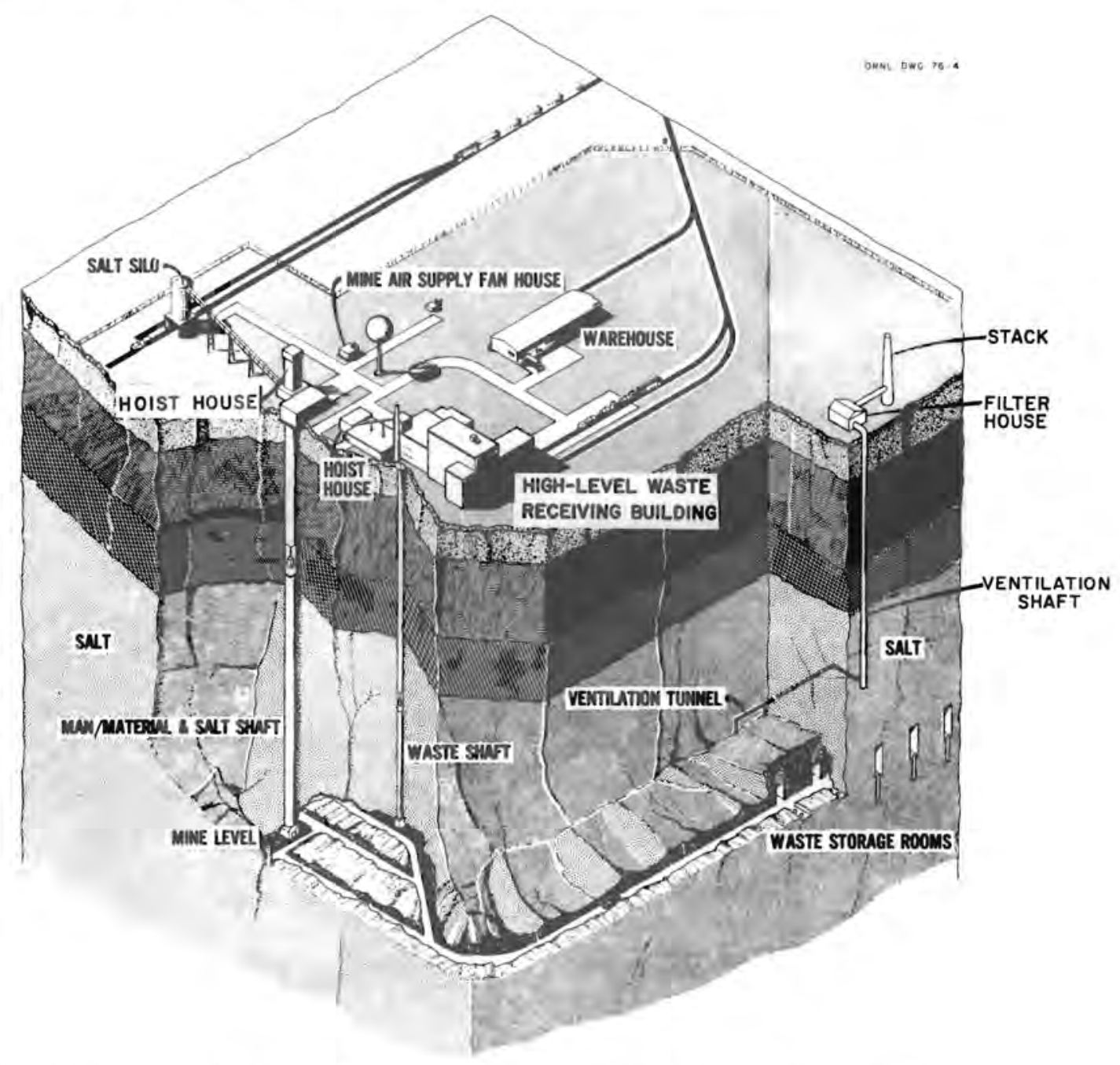

Artist's conception of a high-level radioactive waste repository. (Courtesy of Oak Ridge National Laboratory.) 
(b) Find three specific suitable sites in different geologic media, in 1983.

(c) Start drilling exploratory shafts at the above sites in 1983 and finish by 1985 . Perform complete examinations called "site characterizations" at each site.

(d) Pick one of the sites for a "test and evaluation" facility, in 1985.

(e) Submit license application to NRC for the first repository, in 1988.

(f) Place several hundred packages of radioactive waste in the test and evaluation facility, in 1989. The packages will have multiple barriers, will be moni- tored, and will be retrievable. Ways to keep worker exposure low will be studied.

The timetable for placement of wastes in a repository may appear to be rather slow, but two reasons for the pace may be given. First, the process of selection and qualification of sites should be deliberate and thorough to assure both safety and public confidence. Second, it is not urgent from a technical standpoint to dispose of wastes immediately, since additional decay reduces the amount of heat and radiation produced by the wastes. On the other hand, early decisions and action will ease people's minds about the reactor waste problem. 


\section{SOCIETAL ASPECTS OF RADIOACTIVE WASTES}

Nuclear waste management involves many technical subjects. From the physical sciences, we require such areas as physics, chemistry, mathematics, metallurgy, and geology. From the life sciences, we need biology, ecology, and medicine. Economics plays an important practical role. Since public vlews and attitudes determine what is acceptable and what is not, social subjects also have a bearing on waste management. Examples are sociology, psychology, politics, ethics, philosophy, and religion. We shall touch only briefly on the many themes or issues to which attention has been given. We take as a fact that there are great differences in personal philosophy and social values among people. Indeed, it often seems that there are as many opinions as people. In the interest of fairness, we present opposing points of view and encourage the reader to think about the merits of both sides of the controversy.

The application of a purely technical approach to the subject of wastes has been cited by some writers ${ }^{*}$ as one of the main defects of past waste management programs. The error is in assuming that social concerns are separate, or in treating them as an afterthought, whereas the technical and nontechnical are parts of the whole picture. The phrase "technological fix" means a solution that does not take account of all human factors. Too much faith in the technological fix may distort one's understanding of the real difficulties, which may be chiefly societal. Such faith is said to lead to an improper

\footnotetext{
*For example, Daniel S. Metlay in Essays on Issues Relevant to the Regulation of Radioactive Waste Management, NRC report, NUREG-0412, May 1978.
}

"decoupling" of the waste problem from nuclear power in general.

\section{Psychology}

Consider first the psychological aspects of the waste problem. It is clear that many people are fearful of nuclear reactors, radioactivity, radiation, and wastes. One basis for such reactions is the knowledge of the effects of the atom bomb. Most know that the nuclear fission process is common to weapons and reactors, and even though they tend to accept the statement that reactors are well-controlled, they still fear the chance of release of radioactivity. Surveys by the Battelle Human Affairs Research Centers have shown that the leakage of liquid wastes from storage tanks is a very important concern to the public, along with the possibility that water will enter a waste repository. Among industrial facilities, nuclear waste disposal sites and nuclear power plants are found to be of greatest concern to most people. There is clear evidence that the major effect of the Three Mile Island accident was on the emotional well-being of the people in the area rather than directly on their physical health.

\section{Economics}

One economic concern is related to the cost of radioactive waste disposal. It has been said that this expense has not been factored into the cost of electricity, but that if it is eventually, nuclear power will not be competitive with other energy sources. The industry, however, estimates that the cost of disposing of wastes is a fairly small fraction of the total power cost, so the issue is unimportant. 
Another economic matter, however, is that citizens oppose the location of any facility that may reduce land values. A typical reaction of any community, region, or state is that they do not want to be the "dumping ground for radioactive garbage." Even though they may recognize some benefits from the presence of a repository in the area or may accept the justice of shared responsibilities if there are shared benefits, they would like the waste to go elsewhere. There have been suggestions that the government might provide incentives in the form of some compensation for a community to accept a nearby repository.

\section{Politics}

Next let us examine some political aspects. The American people are typically suspicious of government and industry. The phrase "you can't fight city hall" expresses the belief that the bureaucracy pursues its goals without interest or concern for the real wishes of the citizens. Many people still believe that the energy crisis is a myth created by the oil companies. Many think that the desire for profit tends to outweigh safety, health, and benefit to people. Despite the fact that electrical utilities are regulated, many people regard them as insensitive to the public's welfare. The very popular movie "The China Syndrome" had more to say about management than about reactors. A vested interest in the success of the technology on the part of the regulatory body is said to lead to inadequate protection. Of course, the industry feels that it is actually overregulated. It is clear that government and industry must speak and act frankly, honestly, and consistently if they are to improve their credibility with the public.

Some theorists observe that the life of political institutions is short compared to the time required to isolate nuclear wastes from human beings. "Perpetual care" is assumed to be needed, but that is said to be impossible if the government is overthrown so violently that records are lost and control is suspended. One reaction to this view is that if there were a major governmental disruption the other hazards probably would far outweight those of buried wastes.* One might reasonably expect, too, that knowledge of the existence of a waste disposal site would be passed on by word of mouth regardless of the political structure. Another answer is that the need for long-term surveillance can be avoided if the integrity of the repository can be maintained for a long but finite time. Engineered and natural barriers may be able to keep the system safe until the waste radioactivity is harmless. It is always possible that unsuspecting future prospectors for valuable minerals or fuels will dig down into a repository and will accidentally be exposed to radiation. The use of radiation warning signs is suggested, but these might attract curious people. This hazard can be minimized by selection of a region relatively free of useful materials. It would seem that there is small chance of hazardous intrusion by a civilization that has a technology sophisticated enough for deep excavation but not equipped with simple radiation detectors.

Still another political aspect is noted. Those who are committed opponents of nuclear power, for whatever reason, find it useful strategically to object to any waste disposal concept on the assumption that continued failure to solve the waste problem will stop nuclear power. On the part of those who are committed advocates of nuclear power, it is equally desirable to show marked progress in solving the waste problem in order to remove one of the public doubts and concerns. One might imagine the possibility of bringing opponents and proponents into agreement and accord, but it is more realistic to expect action to be based on the usual debate and decision in our representative system of government.

\footnotetext{
"For example, according to Richard A. Watson, also in Essays on Issues Relevant to the Regulation of Radioactive Waste Management, NUREG-0412, p. 60.
} 
As discussed on p. 18, recommended limits on radiation exposure are based on the linear hypothesis, which implies that any amount of radiation is undesirable. A logical extension of that assumption is that the allowed excess should be exactly zero. It is then argued that if the achievement of such a level is impossible, the source of radiation, i.e., nuclear reactors, should be eliminated. Others feel that the expenditure of money, effort, and resources to reduce the radiation exposure should be consistent with needs to reduce other existing hazards throughout society, including toxic chemicals, fires, and accidents. The benefit/risk relation provides a basis for understanding how concerns about waste disposal appear to exceed those about other risks. The greater the perceived benefit, the greater is the acceptable risk. We badly need the automobile; hence we tolerate the hazard in using it. Some also believe that in light of the energy shortage, America needs nuclear power to keep economically strong.*

\section{Religion and Ethics}

The religious aspect enters in relation to the role of plutonium that is produced in the reactor fuel and is present to a certain extent in reprocessed wastes, and especially in spent fuel. Some view the element as evil because of the hazard it implies, while others view it as good because it ylelds needed power.

"See, for example, Ralph Kinney Bennett "Nuclear Power in Perspective, Reader's Digest, June 1981.
The ethical issues of waste management are those related to equity and justice. In principle, both people today and our descendants should enjoy a balance of benefits and risks. It has been said that "temporal equity" $\dagger$ is violated if we use nuclear power today and leave the wastes for future generations. Many believe that we should make every effort not to do things that will burden thoseliving in the future or might limit their choices. Continuing use of nuclear energy with waste production is viewed as a growing commitment that may not be desired by our descendants. An alternative opinion is that our main obligation is to the great number of people in the world today who are in serious need for energy to survive. Also it is pointed out that a legacy of a prosperous and productive civilization would be most appreciated by future generations. A requisite would be a well-developed energy resource such as nuclear, especially as fossil fuels became depleted. It is suggested by some that choices of actions to meet present responsibilities should not be limited by an unreasonable concern for the future.

Although many of these issues are real and important, it must be recognized by all that radioactive wastes exist and that something must be done with them. Thus there is a challenge to the government, industry, and the public to help find ways to dispose of wastes in a safe and timely manner.

†This issue is discussed fully in the report Public Pollcy Issues in Nuclear Waste Management, "by Stanley M. Nealey and Linda M. Radford. PNL-2743, Battelle Human Affairs Research Centers, October 1978. 


\section{PERSPECTIVES}

\section{A Summing Up}

We have sought to provide in the foregoing sections a brief but comprehensive picture of the past, present, and future of many aspects of radioactivity and radiation, nuclear power, radiation applications, and radioactive waste management. We have sought to be informative, factual, and fair.

It may be useful to the reader for us to now select some highlights, key ideas, and important conclusions from this discussion of nuclear wastes. The following list is not complete-the reader is encouraged to add items.

1. Radioactivity is both natural and manmade. The decay process gives radiations such as alpha particles, beta particles, and gamma rays. Natural background radiation comes mainly from cosmic rays and minerals in the ground.

2. Radiation can be harmful to the body and to genes, but the low-level radiation effect cannot be proved. Many methods of protection are available.

3. The fission process gives useful energy in the form of electricity from nuclear plants, but also produces wastes in the form of highly radioactive fission products.

4. There is a large volume of defense wastes stemming from World War II and subsequent weapons production. They are stored in underground tanks and trenches, awaiting final isolation. Their disposal deserves a high priority.

5. Radioisotopes and radiation are extensively used in research, medical diagnosis and treatment, industry, and space applications.

6. Continued attention is needed to the safe disposal of low-level radioactive wastes from nuclear reactors, industry, and health-related institutions. Also, the mill tailings as residue from uranium mining and refining must be handled properly.

7. People have been concerned about the disposal of nuclear wastes over many years, but other aspects of nuclear power development seemed more urgent and also more intriguing. Disposal was not seen as a difficult problem, which explains in part why the program has been plagued with many interruptions and changes of policy that have reduced the perceived credibility of government and industry.

8. The public has been concerned about the transportation of radioactive wastes. Isotopes, spent fuel, and various wastes are transported regularly in specially designed containers, able to withstand accidents.

9. Research on the waste disposal process will continue, but a well-conceived plan of action, consistently carried out, is necessary if the total waste problem is to be properly handled. Commitment, continuity, and flexibility are all needed features of a successful waste program.

10. The primary requirement of any waste isolation system is protection of the public and future generations from harm from radioactive materials. Goals are to limit the hazard to no greater than the original ore from which the fuel came, to keep the level of hazard as low as reasonably achievable, and to limit exposure to an insignificant increase over that due to normal background. The isolation of the waste need not be forever, but only until the radioactive materials have decayed sufficiently. 
11. Proper waste management involves science, technology, economics, and ethical/ social/political factors. Public participation in decisions is needed, and welldesigned organizational, administrative, and regulatory processes must be available. A legal structure exists to manage wastes, involving environmental protection standards, licensing and regulation, and research and development. $A$ series of national plans are being carried out on energy, nuclear energy, and radioactive waste isolation.

12. Several methods for disposing of highlevel wastes have been studied, with the conclusion that geologic disposal in mined cavities on land is preferable. Disposal in deep holes or in the seabed are back-up alternatives.

13. Much research and development work has been done on a disposal system involving glass as a waste form and rock salt as geologic medium. Land area requirements using this concept have been found not to be excessive. Others involve glass-waste in granite, basalt, and tuff.

14. There are many promising mineral forms, container materials, and host media that can be used in combination for waste isolation. Research is continuing on suitable waste forms. Detailed study of the specific geology, geography, and past history of a site is needed before placing a repository at that location.

15. Laboratory and field experiments and tests provide data that allow design calculations on long-term protection to be made, but they cannot prove that there will be no release of radioactivity. However, the technical community believes that the goal can be met of limiting the hazard to levels that are much less than variations in natural background. This would place the hazard far below that acceptable from other sources of risk in daily living.

16. Nuclear processes have become a significant part of our economy and culture through defense uses, applications of radioisotopes, and the generation of electrical power by nuclear fission. Longterm energy demands indicate that it will be necessary to utilize all sources, including nuclear. Wastes are an inevitable by-product and must be safely isolated or disposed of. It is a challenge to all of us to enhance the benefits and reduce the risks in all of the uses of the nucleus. 


\section{GLOSSARY}

Brief and simple definitions are given for words and phrases in this document and other literature on waste management. The four topics into which the glossary is divided are these:

Nuclear processes and radiation

Reactors and fuel

Waste characteristics

Geologic features.

\section{Nuclear Processes and Radiation}

Accelerator-an electric/magnetic device to give charged particles a high kinetic energy.

Activity-rate of disintegration (also see Curie).

Alpha particle-a type of radiation; the helium nucleus.

Beta particle-a type of radiation; the electron.

Biological half-life-time for half of a radioisotope to be eliminated from the body.

Curie-a unit of radioactivity equal to 37 billion disintegrations per second (d/s).

Daughter-a nucleus that results from radioactive decay.

Decay-the disintegration process of nuclei. Dose-quantity of radiation absorbed.

Electron-basic electrically-charged particle.

Electron volt $(\mathrm{eV})-\mathrm{a}$ unit of energy, $1.6 \mathrm{x}$ $10^{-19}$ watt-seconds.

Fission-splitting of nuclel by neutrons.

Fission products - the nuclei, usually radioactive, resulting from fission.

Gamma ray-a type of radiation; a highenergy photon or electromagnetic wave.

Genetic-an effect (as of radiation) on hereditary tissue.

Half-life-the length of time for half the atoms of a radioactive substance to decay.
Ionization-removal of electrons from an atom, for example, by means of radiation.

Isotope-atoms with the same atomic number but different mass number.

Joule-a unit of energy, the watt-second.

Linear hypothesis-the assumption that any radiation causes biological damage, according to a straight-line graph of health effect versus dose.

Neutron-a basic particle that is electrically neutral, weighing nearly the same as the hydrogen atom.

Periodic table-a chart of the chemical elements.

Person-rem (or man-rem)-the product of average dose by the number of people affected.

Rad-a unit of radiation energy absorption; $1 / 100$ joule per kilogram.

Radiation-particles or waves from atomic or nuclear processes (or from certain machines).

Radioactivity-spontaneous disintegration of an unstable nucleus.

Radioisotope-a radioactive isotope.

Radionuclide-a species of atom that is radioactive.

Rem-unit of radiation dosage equal to the rad for $x$-rays, gamma rays, and some beta particles; accounts for biological effect.

Somatic-a direct effect (as of radiation) on the health of tissue.

Tracer-an isotope used to follow a process.

X-rays-electromagnetic radiation of energy greater than that of visible light, usually produced by an $\mathrm{x}$-ray machine.

\section{Reactors and Fuel}

Assembly-bundle of fuel rods used in a reactor.

Barrier-metal sieve used in gaseous diffusion isotope separation. 
Boiling water reactor-a light-water cooled reactor in which some bolling occurs.

Breeder reactor - $\mathbf{a}$ reactor that produces more fissile material than it consumes (by a process called "breeding").

Cladding - the outer coating of nuclear fuel, for example, a tube.

Converter - a reactor in which some fertile material is made into fissile material.

Criticality - a condition in which a chain reaction involving neutrons and fuel is self-sustaining.

Decommissioning-removal from service at the end of useful life.

Decontamination-the removal of radioactive material.

Enrichment-a process to increase the percentage of a desired isotope such as uranium-235.

Fabrication (of fuel assemblies)-making uranium oxide fuel pellets and forming fuel rods and bundles of rods.

Fertile-a material that becomes fissile upon absorbing a neutron.

Fissile-able to be split by a low-energy neutron.

Fuel-fissionable material "burned" in a nuclear reactor, for example, uranium.

Fuel cycle-all steps in supplying, using, and processing fuel for nuclear reactors, including disposal of wastes.

Fusion-a nuclear process in which nuclei are combined to yield energy.

Implosion-a compression to detonate a nuclear weapon.

Licensing-giving a permit to build or operate a facility.

Light-water reactor ( $L W R$ ) - a nuclear reactor cooled and moderated by $\mathrm{H}_{2} \mathrm{O}$.

Moderator-a light element used to slow neutrons, as in a reactor.

Multiplication-neutron interaction with fissile material in a chain reaction.

Natural uranium-uranium as mined $10.7 \%$ 235U, 99.3\% 238U).

Pile-an early name for nuclear reactor.

Plutonium - the element formed by neutron absorption in uranium-238.
Pressurized water reactor (PWR) - a lightwater cooled reactor operated at high pressure without boiling.

Reactor-a device involving a chain reaction using neutrons.

Spent fuel-nuclear fuel that has been removed from a reactor after use to produce power.

Tonne-a metric ton, 1000 kilograms.

\section{Waste Characteristics}

Actinides-elements of the periodic table with atomic number 89 through 103.

Barrier - a component that slows the movement of radioisotopes.

Calcine-powder produced by heat treatment.

Canister-the primary container for solid waste.

Ceramic - insoluble solid oxide.

Disposal-removal from man's environment permanently.

Grout-a cement mixed with wastes.

High-level wastes-fission products plus some actinides.

Ion exchange-a process used to purify chemicals.

Isolation-preventing migration of wastes to the biosphere.

Leaching-dissolving in a liquid.

Low-level wastes-those not requiring shielding or heat removal; small transuranic content.

Mill tailings - see Tailings.

Once-through - a fuel cycle in which spent fuel is not reprocessed.

Partitioning-separation of certain radioisotopes from waste.

Regulation-maintenance of standards of performance through rules.

Repository-a location for waste to be held.

Reprocessing - the mechanical and chemical treatment of nuclear fuel to separate uranium, plutonium, and fission products.

Retrievable-able to reclaim if necessary.

Salt-sodium chloride, $\mathrm{NaCl}$, as a geologic medium.

Storage-holding temporarily. 
Tailings - the residue from extraction of uranium from its ore.

Transmutation-transformation of isotopes using nuclear reactions.

Transuranic-beyond uranium in the periodic table.

TRU-transuranic waste, with more than 10 nanocuries per gram.

\section{Geologic Features}

Anticline-see Fold.

Aquifer-underground layer of material through which water passes.

Bed-layered deposit of sediment in the form of rocks, products of weathering, organic materials, and precipitates. Also, bedded.

Biosphere-regions of the earth and atmosphere occupied by living beings.

Breccia-fragmented rock region (as in breccia pipe).

Diagenesis - the conversion of sediment into rock by compaction or chemical reaction.

Diapir-an anticline fold that has broken through the rocks above. Also, diapirism.

Dome- $a$ bed that arches up to form a rounded peak deposit. Also, domed.
Fault-a break in a rock formation usually involving diagonal movement. An example: the San Andreas fault in California.

Fold-a curved deformation of rock. The peaks are called anticlines, the valleys, synclines.

Glacier-large body of ice, often moving slowly.

Igneous rocks - formed by solidification of molten rock.

Lava-molten rock that issues from a volcano.

Magma-molten rock within the earth.

Metamorphic rocks - those changed by temperature and pressure.

Meteorite-a solid body from outer space that reaches the earth without vaporizing.

Salt bed-a deposit formed by the evaporation of sea water.

Sedimentary rocks-deposited in layers near the surface by water, wind, and ice.

Tectonic plate-geological concept of the movement of large segments of the earth's crust.

Volcano-a vent in the crust of the earth from which lava, gases, and ash erupt. 


\section{APPENDIX A}

\section{Scientific American Articles}

One of the most accessible and readable sources of information on nuclear topics, Including radioactive wastes, is the magazine Scientific American. Listed below in reverse chronological order are articles of possible interest for the period since 1970.

Wolfgang Sassin, "Energy," September 1980, p. 118.

Harold W. Lewis, "The Safety of Fission Reactors," March 1980, p. 53.

Kenneth S. Deffeyes and Ian D. MacGregor, "World Uranium Resources," January 1980, p. 66.

Harold P. Furth, "Progress toward a Tokamak Fusion Reactor," August 1979, p. 50.

Gerold Yonas, "Fusion Power with Particle Beams," November 1978, p. 50.

Donald R. Olander, "The Gas Centrifuge," August 1978, p. 37.

Bernard L. Cohen, "The Disposal of Radioactive Wastes from Fission Reactors," June 1977, p. 21.

Georges Vendryes, "Superphenix: A FullScale Breeder Reactor," March 1977, p. 26.

Richard N. Zare, "Laser Separation of Isotopes," February 1977, p. 86.

J. D. Macdougall, "Fission-Track Dating," December 1976, p. 114.

William Bebbington, "The Reprocessing of Nuclear Fuels," December 1976, p. 30.

George A. Cowan, "A Natural Fission Reactor," July 1976, p. 36.

H.A. Bethe, "The Necessity of Fission Power," January 1976, p. 21.
Hugh C. McIntyre, "Natural-Uranium HeavyWater Reactors," October 1975, p. 17.

John L. Emmett, John Nuckolls and Lowell Wood. "Fusion Power by Laser Implosion," June 1974, p. 24.

R. R. Wilson, "The Batavia Accelerator," February 1974, p. 72.

David N. Schramm, "The Age of Elements," January 1974, p. 69.

David J. Rose, "Energy Policy in the U.S.," January 1974, p. 20.

Bruno Coppi and Jan Rem, "The Tokamak Approach in Fusion Research," July 1972 , p. 65.

Colin Renfrew, "Carbon 14 and the Prehistory of Europe," October 1971, p. 63.

Chauncey Starr, "Energy and Power," September 1971, p. 36.

M. King Hubbert, "The Energy Resources of the Earth," September 1971, p. 60.

Milton Katz, "Decision-Making in the Production of Power," September 1971. p. 191.

Moshe J. Lubin and Arthur P. Fraas, "Fusion by Laser," June 1971, p. 21.

Riley D. Woodson, "Cooling Towers," May 1971, p. 70.

William C. Gough and Bernard J. Eastlund, "The Prospects of Fusion Power," February 1971, p. 50.

Bjorn Sigurbjornsson, "Induced Mutations in Plants," January 1971, p. 86.

Glenn T. Seaborg and Justin L. Bloom, "Fast Breeder Reactors," November 1970, p. 13. 


\section{APPENDIX B}

\section{Reference Material on Wastes}

Listed here are some of the additional books, reports, and articles on waste management that we consulted in the preparation of the document. Brief comments on the contents and usefulness are included. The sections to which they refer are noted. Most of the references are accessible through a library.

\section{GENERAL}

Arthur Fisher, "What Are We Going To Do About Nuclear Waste?" Popular Science, December 1978. An easily-read article on technical and political aspects of the waste problem. Descriptions are given of the alternative disposal methods.

Edmund Faltermayer, "Burying Nuclear Trash Where It Will Stay Put." Fortune, March 26, 1979. Discusses the relationship of spent fuel and wastes, the possible geologic media, and the political aspects of waste disposal.

John F. Hogerton, James G. Cline, Robert W. Kupp, and Charles B. Yulish. Nuclear Power Waste Management. Atomic Industrial Forum, Inc., March 1971. A booklet containing text, photographs, and diagrams for general public reading. Discusses briefly how radioactive materials are handled at plants, shipped, and stored.

“Nuclear Energy: Survival at Stake," Nation's Business, January 1980. Poses two questions, "Can the U.S. survive without nuclear energy?" and "Can the U.S. survive nuclear energy?" Discusses the general energy situation, the impact of Three Mile Island, the role of conservation, and the nuclear waste problem.

Marjorie Beane, A Nuclear Waste Primer. League of Women Voters Education Fund, Washington, D.C. Elementary survey of the topic of wastes.
Ernest E. Angino, "High-Level and LongLived Waste Disposal," Science, December 1977, p. 885. Recommends an international approach to the solution of the waste problem in view of the worldwide adoption of nuclear power. The paper has good information about the rock factors to be considered. the variety of disposal methods, thermal effects, and seismic matters. Many references are given.

Bernard L. Cohen, "High-Level Radioactive Waste from Light-Water Reactors," Reviews of Modern Physics, 49:1, 1977. Analyzes the production and containment of fission products and transuranic materials. Estimates the cancer risk as it depends on time after the placement of wastes. The total number of fatalities resulting from the use of nuclear power is found to be small.

"Report to the American Physical Society by the Study Group on Nuclear Fuel Cycles and Waste Management," Reviews of Modern Physics, S0, S1, 1978. A thorough technical assessment of the national issue of the utilization of nuclear fuels and the management of nuclear wastes. Considered are the principal economic, environmental, and health and safety implications. Conclusions and recommendations are provided.

Raymond L. Murray, Nuclear Energy. Second Edition, Pergamon Press, New York, 1980. A description of basic nuclear phenomena, devices, and processes, followed by a discussion of problems and opportunities. Designed for reading by first-year college students.

\section{CHAPTERS 3, 7, 10}

C. Michael Lederer and Virginia S. Shirley, Editors. Table of Isotopes. Seventh Edition, John Wiley, New York, 1978. A comprehensive compilation of properties of atoms and 
nuclei. Entries are arranged by mass number. Of particular interest are isotope abundances, half-lives, types of radiation emitted, and energies of radiation.

\section{CHAPTERS 4, 5, 6}

Bill Rados, "Primer on Radiation," FDA Consumer, July-August 1979. Discusses natural and manmade radiation, radiological health hazards, and the nature of biological effects. Easily read material.

\section{CHAPTERS 5, 6}

Bernard L. Cohen, "Impacts of the Nuclear Energy Industry on Human Health and Safety," American Scientist, SeptemberOctober 1976. Discusses the BEIR report, health effects of radiation, the linear hypothesis, routine releases from reactors, power plant accidents, transportation accidents, waste disposal, and plutonium theft. Risks from other sources are discussed and compared to nuclear risks.

Herbert Inhaber, "Risk with Energy from Conventional and Nonconventional Sources," Science, February 23, 1979. By taking account of all operations involved in producing energy, including mining, processing, and manufacture, the author finds the risks of various types of energy. Conventional sources are coal, oil, natural gas, nuclear, and hydro. Nonconventional are solar (three types), methanol, wind, and ocean. The startling (and controversial) conclusion was that solar energy caused more lost man-days of work than natural gas or nuclear. The reasons given are the large amounts of materials needed plus need for storage and back-up.

Ralph Lapp and George Russ, "Radiation Risks for Nuclear Workers," Atomic Industrial Forum, Inc., November 1979. A booklet designed for reading by plant personnel. Potential risks of occupational exposure to radiation are discussed and compared to those occurring in everyday life and in other occupations. Main sections are: introduction, sources and amounts of radiation, standards for occupational exposure, exposure record at nuclear plants, control of occupational exposures, monitoring employee radiation, occupational risks in perspective, appendix, sources of information, and selected references.

David J. Rose, Patrick W. Walsh and Larry L. Leskovjan, "Nuclear Power-Compared to What?" American Scientist, May-June 1976, p. 291. Discusses resources of oil, coal, uranium and other materials. Analyzes and lists health effects of the whole nuclear fuel cycle, including both radiation-related and not radiation-related fatalities. A similar examination of coal is made, but the opinion is given that much more information is needed on its hazards.

The Lauriston S. Taylor Lecture Series, sponsored by the National Council on Radiation Protection and Measurement, Washington, D.C.

Lecture 1: Sir Edward E. Pochin, "Why Be Quantitative About Radiation Risk Estimates?" 1978. Gives some numbers on the human health risk as it depends on personrem of radiation and warns against use of too precise figures. Provides comparisons with other familiar risks.

Lecture 3: Hymer L. Friedell, "Radiation Protection-Concepts and Trade Offs." 1979. Notes the distinction between older attention to immediate radiation effects and newer concern with long-term or late hazards. Emphasizes need for comparison of radiation risks with other hazards of life and the use of the hazard-benefit comparisons. The paper provides valuable discussion and data on radiation effects.

Richard Wilson, "Analyzing the Daily Risks of Life," Technology Review (MIT), February 1979, p. 41 . Semipopular treatment of the comparison of risks due to air pollution, smoking tobacco, drinking alcohol, driving an automobile, fire, accidents, and radiation. The author prepared a widely-mentioned table of risks that increase the chance of premature death by one in a million. 
Sources and Effects of Ionizing Radiation, United Nations Scientific Committee on the Effects of Atomic Radiation 1977 Report to the General Assembly, with annexes. United Nations, New York, 1977. The acronym UNSCEAR is used to describe the committee and its studies. The report consists of a brief summary and discussion of the effects of radiation, including carcinogenic, prenatal, and genetic. It then reviews sources of human radiation exposures, including natural, technologically enhanced, consumer products, fission reactors, nuclear explosions, and medical uses. The report has a voluminous appendix containing data, analysis, and references.

\section{CHAPTERS 5, 6, 20, 21}

D. J. Crawford and R. W. Leggett, "Assessing the Risk of Exposure to Radioactivity," American Scientist, September-October 1980 , p. 54. A nonmathematical but technical discussion of the steps required to find the effect of radioactivity. The example source of radioactivity is uranium mill tailings and the methods of transfer considered are air, water and food. Areas of uncertainty in relating dose to medical effect are noted. $A$ list of useful references is included.

\section{CHAPTER 9}

Radioactive Wastes at the Hanford Reservation, A Technical Review. National Academy of Sciences, Washington, D.C., 1978. A report by the Panel on Hanford Wastes of the Committee on Radioactive Waste Management. It was prompted by concerns by outside observers about leaks from tanks, countered by statements by the Energy Research and Development Administration (ERDA) that the matter was well in hand. The Panel did not find any radiation hazard to the public since dose limits were not exceeded. The main recommendation is that the wastes should be processed to solid form and buried, preferably at Hanford, to eliminate the need for surveillance. The group did not favor digging up plutonium- contaminated soil. A national program for research and development on waste disposal should be continued.

\section{CHAPTER 15}

David Dinsmore Comey, "The Legacy of Uranium Tailings," Bulletin of the Atomic Scientists, September 1975. Calls attention to the health effect of radon and its daughters from uranium mill tailings, citing a very large number of cancer deaths over the next 800 centuries. Notes that these effects are much greater than those claimed by various authors.

Bernard L. Cohen provides a rebuttal in the February 1976 issue of the magazine. He points out errors in Comey's cost calculations. The latter responds in the same issue. A letter to the editor is also included, with response.

\section{CHAPTER 17}

Environmental Survey of Transportation of Radioactive Materials to and from Nuclear Power Plants. USAEC, December 1972. Data on shipments that would result from operation of each reactor, estimated radiation doses resulting, and a description of the packages used for irradiated fuel. Appendices contain methods of calculation of exposure.

Everything You Always Wanted to Know About Shipping High-Level Nuclear Wastes. DOE/EV-0003, U.S. Department of Energy, January 1978. A set of 69 "most often asked" questions and detailed answers. Intended for lay audiences. Photographs and diagrams are included.

\section{CHAPTER 18}

An Evaluation of the Concept of Storing Radioactive Wastes in Bedrock Below the Savannah Rlver Plant Site. National Academy of Sciences, Washington, D.C., 1972. A report by the Committee on Radioactive Waste Management of the National Academy of Sciences-National Research 
Council. The group examined the geologic, hydrologic, chemical, geochemical, and ecological aspects of underground disposal at this particular site. The Committee recommended development of permanent storage facilities that would retain wastes at least a thousand years. In order to obtain necessary, precise information about the site, an exploratory shaft and tunnels are needed.

\section{CHAPTERS 18-21}

J. L. McElroy and R. E. Burns, Nuclear Waste Management Status and Recent Accomplishments, NP-1087 Electric Power Research Institute, 1979. The most significant accomplishments are (a) the successful operation of the waste vitrification plant at Marcoule, France, and (b) the publication of a repository system design study in Sweden (KBS). Note is made of the importance of data obtained on radionuclide migration from the site of the natural reactor in Oklo, Gabon. The trends give encouragement to the possibility of achieving safe waste disposal. Experiments are reported on glass "spiked" with alpha-emitting radioactive substances to provide accelerated radiation damage.

\section{CHAPTER 19}

The Disposal of Radioactive Waste on Land. Publication 519, National Academy of Sciences-National Research Council, Washington, D.C., September 1957. This classic report by the Committee on Waste Disposal of the Division of Earth Sciences provided the encouragement to the AEC to proceed with waste disposal studies in salt. Perusal of the report shows that the committee was concerned about the need for collecting a great deal of information before proceeding with waste disposal. As a second choice, the committee recommended stabilization of the waste in a ceramic material that could be stored in a dry place.

\section{CHAPTER 20}

Stanley N. David and Roger J. M. DeWiest, Hydrogeology, John Wiley, 1966. A textbook on the fluid-flow aspects of ground water, combining principles and practical applications. The description of the water cycle in words and diagrams is useful. Much emphasis is placed on how water flows, on exploration methods, and the behavior of water in different kinds of geologic formations.

\section{CHAPTERS 20, 21}

H. C. Burkholder, M. O.Cloninger, D. A. Baker and G. Jansen, "Incentives for Partitioning High-Level Waste," Nuclear Technology, $31: 202,1976$. An investigation is made of the need for removing certain chemicals from the waste prior to disposal. Examples are strontium-90, radium-226, (from uranium and plutonium), carbon-14, technetium-99, iodine-129 and neptunium-237. The general conclusion is that partitioning is not very effective but that further studies are needed. The paper is a useful reference because of its discussion of the method of investigation of repository performance.

H. C. Burkholder, Waste Isolation Performance Assessment-A Status Report. ONWI-60, Battelle Memorial Institute, November 1979. A descriptive report that explains what repository performance assessment is, how it is done, and the state of development, testing, and use of the methods. Contains a good review of all the phenomena that must be accounted for in analyzing the effectiveness of an isolation system.

G. de Marsily, E. Ledoux, A. Barbreau, and J. Margat, "Nuclear Waste Disposal: Can the Geologist Guarantee Isolation?" Science, August 5, 1977, p. 519. Four French scientists discuss the migration of radionuclides in geologic formations. They consider the nature of the waste, key long-lived isotopes $129 \mathrm{I}, 237 \mathrm{~Np}$, and $239 \mathrm{Pu}$, the behavior of glasswaste, and the geologic barrier. By means of a mathematical model they predict what are called "break-through" curves. Reference is made to the natural reactor at Oklo. They recommend main emphasis on preventing nuclides from getting into the geologic media. For the latter, ion exchange trapping of chemicals is important. 
The Disposal of Spent Nuclear Fuel, Topical Report. ONWI-59, Battelle Memorial Institute, December 1979. A general description of the disposal of spent fuel in mined geologic repositories. The main characteristics of spent fuel that distinguish it from wastes from reprocessing are listed. These are the fixed form, actinide content, fission gas, leaching effects, thermal energy, criticality, and resource value. Data, diagrams, and a comprehensive reference list are provided.

A Review of the Swedish KBS-II Plant for Disposal of Spent Nuclear Fuel. National Academy of Sciences, Washington, D.C., 1980. A report by the Committee on Radioactive Waste Management. Two parts of the Swedish plan are examined: (a) the thickwalled copper canister placed in bentonite clay and (b) the geologic disposal site. Both are deemed to be adequate for very long-term disposal. Water conditions, temperatures and criticality prevention are also judged to be satisfactory. Only the seals and backfill are questionable.

\section{CHAPTER 21}

J. D. Bredehoeft, A. W. England, D. B. Stewart, N. J. Trask and I. J. Winograd. Geologic Disposal of High-Level Radioactive WastesEarth-Science Perspectives. Circular 779, U.S. Geological Survey, 1978. A careful study of the problem of waste disposal. Amounts of wastes are noted; types of geologic media are identified; the interaction of the wastes with the media are considered; ground water transport and geologic prediction methods are discussed. The group emphasizes the need for continuing research on salt, other media, water flow, repository evaluation, and environmental effects.

Luther J. Carter, "Nuclear Wastes: The Science of Geologic Disposal Seen as Weak." Science, June 9, 1978, p. 1135. Discusses the new emphasis on needs for further study of geologic disposal of wastes.

Richard Kerr, "Nuclear Waste Disposal: Alternatives to Solidification in Glass Proposed." Science, April 1979, p. 289. The paper reports on several inclinations toward alternative waste forms such as ceramics. Work by G. J. McCarthy at Pennsylvania State University (supercalcine) and A. E. Ringwood in Australia (SYNROC) are discussed. Other techniques noted are coated pellets, metal-clad cermets, thick container walls (lead, copper, titanium).

A. E. Ringwood.Safe Disposal of High-Level Nuclear Reactor Wastes: A New Strategy. Australian National University Press, Canberra, 1978. A description of the use of natural rocks and minerals to retain the high-level radioactive wastes. Minerals are chosen for demonstrated stability for many millions of years. Described is a method of producing synthetic igneous rock systems, "SYNROC," which resists devitrification and leaching. The author thus states that the problem of isolating wastes from the biosphere can be solved.

\section{CHAPTER 22}

Mason Willrich and Richard K. Lester. Radioactive Waste, Management and Regulation. The Free Press, 1977. This book is a report on a study project sponsored by ERDA. It emphasizes the management and regulation of high-level and transuranic wastes. The chapter contents are these: 1 explains what radioactive waste is, 2 describes how wastes are and could be handled, 3 outlines existing legal matters, 4 gives alternatives, and 5 makes recommendations, the main one being the establishment of a national Radioactive Waste Authority.

\section{CHAPTER 23}

Environmental Impact Statement, Management of Commercially Generated Radioactive Waste. Volumes 1, 2 and 3, DOE/EIS-0046F, Department of Energy, October 1980. This is a generic environmental impact statement (GEIS) relating to the technical strategy of isolating wastes from nuclear power reactors of LWR type. All types of environmental effects are considered. The report describes alternative 
approaches to disposal and the research, development, site studies, and testing that are required to handle either spent fuel or canisters of waste from reprocessing. The second volume consists of technical appendices, and the third volume gives public comments and Hearing Board reports.

\section{CHAPTER 24}

Alan Jakimo, Irvin C. Bupp, "Nuclear Waste Disposal: Not in My Backyard." Technology Review (MIT), March-April 1978, p. 64. Discusses the public's perception of nuclear wastes, the history of fuel reprocessing, and the storage of spent fuel in water pools. Methods of disposal are outlined and the existence of a political problem is noted. Useful technical information and references.

Gene I. Rochlin, "Nuclear Waste Disposal: Two Social Criteria." Science, January 1977, p. 23. Two criteria are suggested and justified-(a) technical irreversibility, which means resistance to removal by either natural effects or the intrusion of man, (b) site multiplicity, including both a variety of locations and methods of disposal, e.g., outer space, seabed, transmutation, geologic, etc. The two criteria are related graphically. The author provides some ideas, but does not apply them specifically. The paper contains a great deal of relevant material, however.

Nuclear Phobia-Phobic Thinking about Nuclear Power. The Media Institute, Washington, D.C., March 1980. A monograph consisting of a discussion with Robert L. DuPont, M.D., a psychiatrist. He viewed many hours of video tapes of network TV news programs covering the Three Mile Island accident. He asserts that fears are accentuated by media presentations. An appendix of the pamphlet contains excerpts of a 1957 World Health Organization report, Mental Health Aspects of the Peaceful Uses of Atomic Energy. 
No. of

Copies

$\underline{\text { OFFS ITE }}$

A. A. Churm

DOE Chicago Patent Group

9880 South Cass Ave.

Argonne, IL 60439

27 DOE Technical Information Center P.0. Box 62

Oak Ridge, TN 37830

12 DOE Nuclear Waste Management Programs NE30, B-107, HQ

Washington, DC 20545

ATTN: W. W. Ballard, Jr.

C. R. Cooley

C. H. George

M. J. Lawrence

E. F. Mastal

G. K. Oertel

A. F. Perge

R. W. Ramsey, Jr.

K. Schmitz

R. S. Scott

V. G. Trice

E. J. Wahlquist

J. D. Threlkeld

DOE Office of Public Affairs

CP-20, Forrestal Bldg.

1000 Independence Ave. SW

Washington, DC 20585

3 DOE Office of Energy Research

$E R$, Forrestal Bldg.

1000 Independence Ave. SW

Washington, DC 20585

ATTN: L. K. Akers

D. D. Duggan

H. H. Young

J. B. Martin

NRC Division of Fuel Cycle and

Material Safety

Washington, DC 20555

J. Pomeroy

National Academy of Sciences

2105 Constitution Ave. NW

Washington, DC 20418

3 R. L. Murray

Nuclear Engineering Department North Carolina State University Raleigh, NC 27650
No. of

Copies

D. Jackson

DOE Office of Public Affairs

Albuquerque Operations Office

Albuquerque, NM 87115

D. F. Miller

DOE Office of Public Affairs

Nevada Operations off ice

Las Vegas, NV 89114

3 L. J. Smith

TRU Waste Systems Office

Rocky Flats Plant

Golden, CO 80401

9 Battelle Memorial Institute

Office of Nuclear Waste Isolation

505 King Ave.

Columbus, $\mathrm{OH} 43201$

ATTN: N. E. Carter

J. R. Finley

S. Goldsmith

M. Kehnemuyi

D. L. Keller

J. M. Mountain (2)

R. W. Peterson

B. A. Rawles

J. B. Gode 1

Brookhaven National Laboratory

Upton, NY 11973

M. N. Maxey

South Carolina Research Institute

670 First National Bank Bldg.

Columbia, SC 29201

F. K. Pittman

3508 Sagecrest Terrace

Ft. Worth, TX 76109

L. Carter

4522 Lowe 11 St. NW

Washington, DC 20016

D. W. Levy

3609 Woodbriar Circle

Tucker, GA 30084

B. Ledbetter

1755 Manzanita Dr. 0akland, CA 94611

E. L. Fankhauser

Columbia High School

930 Long Ave.

Richland, WA 99352 
No. of

Copies

M. R. Seitz

Columbia Basin College

2600 N. 20th

Pasco, WA 99301

\section{ONSITE}

5 DOE Richland Operations Office

R. B. Goranson

R. W. Newlin

H. E. Ransom

J. J. Schreiber

M. W. Shupe

Hanford Engineering Development Laboratory

W. W. Little, Jr.

6 Rockwell Hanford Operations

H. Babad

M. A. Fox

J. E. Kinzer

P. G. Lorenzini

BWIP Library

Rockwell Technical Information
No. of

Copies

37 Pacific Northwest Laboratory

J. B. Burnham

T. D. Chikalla

E. A. Eschbach

A. J. Haverfield

O. F. Hill

F. N. Hodges

H. H. Hollis

D. K. Kreid

M. R. Kreiter

L. T. Lakey

J. M. Latkovich

R. P. Marshall

J. Mendel

S. M. Nealey (HARC)

D. E. Olesen

T. Overcast (HARC)

A. M. Platt

J. A. Powe 11

L. L. Rader

J. Rasmussen (HARC)

J. V. Robinson (10)

K. J. Schneider

S. C. Slate

K. R. Smith

W. A. Watts

Technical Files (2)

Publishing Coordination 